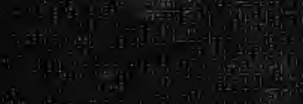




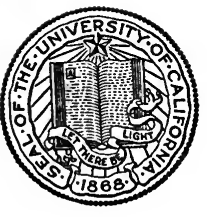

\title{
THE LIBRARY OF
}

THE UNIVERSITY OF CALIFORNIA LOS ANGELES

\author{
GIFT OF
}

Dr. Dinsmore Alter 
Recd "1/x

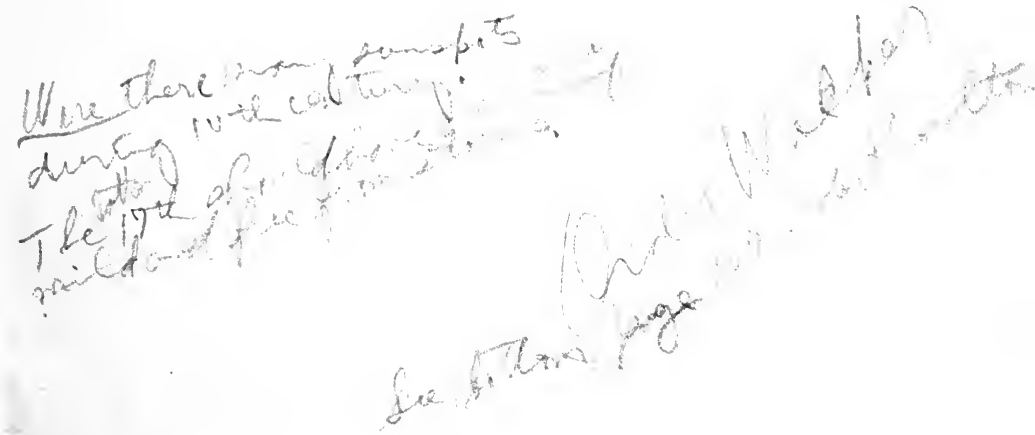







\section{CLIMATIC CHANGES}

THEIR NATURE AND CAUSES 

PUBLISHED ON THE FOUNDATION

ESTABLISHED IN MEMORY OF

THEODORE L. GLASGOW 


\section{OTHER BOOKS BY THE SAME AUTHORS}

\section{ELLSWORTH HUNTINGTON}

A. Four books showing the development of knowledge as to Historical Pulsations of Climate.

The Pulse of Asia. Boston, 1907.

Explorations in Turkestan. Expedition of 1903. Washington, 1905.

Palestine and Its Transformation. Boston, 1911.

The Climatic Factor, as Ilustrated in Arid America. Washington, 1914.

B. Two books illustrating the effect of climate on man.

Civilization and Climate. New Haven, 1915.

World Power and Evolution. New Haven, 1919.

C. Four books illustrating the general principles of Geography.

Asia: A Geography Reader. Chicago, 1912.

The Red Man's Continent. New Haven, 1919.

Principles of Human Geography (with S. W. Cushing). New York, 1920.

Business Geography (with F. E. Williams). New York, 1922.

D. A companion to the present volume.

Earth and Sun: An Hypothesis of Weather and Sunspots. New Haven. In press.

\section{STEPHEN SARGENT VISHER}

Geography, Geology and Biology of Southern Dakota. Vermilion, 1912. The Biology of Northwestern South Dakota. Vermilion, 1914.

The Geography of South Dakota. Vermilion, 1918.

Handbook of the Geology of Indiana (with others). Indianapolis, 1922.

Hurricanes of Australia and the South Pacific. Melbourne, 1922. 


\title{
CLIMATIC CHANGES
}

\section{THEIR NATURE AND CAUSES}

\author{
BY \\ ELLSWORTH HUNTINGTON \\ Research Associate in Geography in Yale University \\ AND \\ STEPHEN SARGENT VISHER \\ Associate Professor of Geology \\ in Indiana University
}

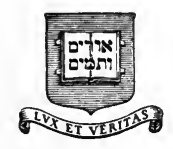

NEW HAVEN

YALE UNIVERSITY PRESS

LONDON : HUMPHREY MLFORD : OXFORD UNIVERSITY PRESS MDCCCCXXII 
COPYRIGHT 1922 BY

YALE UNIVERSITY PRESS

Published 1922. 


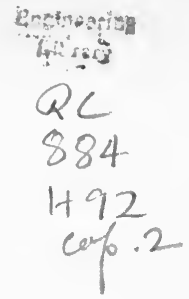

\section{THE THEODORE L. GLASGOW MEMORIAL} PUBLICATION FUND

The present volume is the fifth work published by the Yale University Press on the Theodore L. Glasgow Memorial Publication Fund. This foundation was established September 17, 1918, by an anonymous gift to Yale University in memory of Flight Sub-Lieutenant Theodore L. Glasgow, R.N. He was born in Montreal, Canada, and was educated at the University of Toronto Schools and at the Royal Military College, Kingston. In August, 1916, he entered the Royal Naval Air Service and in July, 1917, went to France with the Tenth Squadron attached to the Twentysecond Wing of the Royal Flying Corps. A month later, August 19, 1917, he was killed in action on the Ypres front. 

TO

THOMAS CHROWDER CHAMBERLIN

OF THE UNIVERSITY OF CHICAGO

WHOSE CLEAR AND MASTERLY DISCUSSION

OF THE GREAT PROBLEMS OF TERRESTRIAL EVOLUTION

HAS BEEN ONE OF THE MOST INSPIRING FACTORS

IN THE WRITING OF THIS BOOK 
There is a toy, which I have heard, and I would not have it given over, but waited upon a little. They say it is observed in the Low Countries (I know not in what part), that every five and thirty years the same kind and suit of years and weathers comes about again; as great frosts, great wet, great droughts, warm winters, summers with little heat, and the like, and they call it the prime; it is a thing I do the rather mention, because, computing backwards, I have found some concurrence.

FRANCIS BACON 


\section{PREFACE}

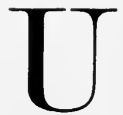

NITY is perhaps the keynote of modern science. This means unity in time, for the present is but the outgrowth of the past, and the future of the present. It means unity of process, for there seems to be no sharp dividing line between organic and inorganic, physical and mental, mental and spiritual. And the unity of modern science means also a growing tendency toward coöperation, so that by working together scientists discover much that would else have remained hid.

This book illustrates the modern trend toward unity in all of these ways. First, it is a companion volume to Earth and Sun. That volume is a discussion of the causes of weather, but a consideration of the weather of the present almost inevitably leads to a study of the climate of the past. Hence the two books were written originally as one, and were only separated from considerations of convenience. Second, the unity of nature is so great that when a subject such as climatic changes is considered, it is almost impossible to avoid other subjects, such as the movements of the earth's crust. Hence this book not only discusses climatic changes, but considers the causes of earthquakes and attempts to show how climatic changes may be related to great geological revolutions in the form, location, and altitude of the lands. Thus the book has a direct bearing on all the main physical factors which have molded the evolution of organic life, including man. 
In the third place, this volume illustrates the unity of modern science because it is preëminently a coöperative product. Not only have the two authors shared in its production, but several of the Yale Faculty have also coöperated. From the geological standpoint, Professor Charles Schuchert has read the entire manuscript in its final form as well as parts at various stages. He has helped not only by criticisms, suggestions, and facts, but by paragraphs ready for the printer. In the same way in the domain of physics, Professor Leigh Page has repeatedly taken time to assist, and either in writing or by word of mouth has contributed many pages. In astronomy, the same cordial coöperation has come with equal readiness from Professor Frank Schlesinger. Professors Schuchert, Schlesinger, and Page have contributed so materially that they are almost co-authors of the volume. In mathematics, Professor Ernest W. Brown has been similarly helpful, having read and criticised the entire book. In certain chemical problems, Professor Harry W. Foote has been our main reliance. The advice and suggestions of these men have frequently prevented errors, and have again and again started new and profitable lines of thought. If we have made mistakes, it has been because we have not profited sufficiently by their coöperation. If the main hypothesis of this book proves sound, it is largely because it has been built up in constant consultation with men who look at the problem from different points of vision. Our appreciation of their generous and unstinted coöperation is much deeper than would appear from this brief paragraph.

Outside the Yale Faculty we have received equally cordial assistance. Professor T. C. Chamberlin of the University of Chicago, to whom, with his permission, we take great pleasure in dedicating this volume, has read the 
entire proof and has made many helpful suggestions. We cannot speak too warmly of our appreciation not only of this, but of the way his work has served for years as an inspiration in the preliminary work of gathering data for this volume. Professor Harlow Shapley of Harvard University has contributed materially to the chapter on the sun and its journey through space; Professor Andrew E. Douglass of the University of Arizona has put at our disposal some of his unpublished results; Professors S. B. Woodworth and Reginald A. Daly, and Mr. Robert W. Sayles of Harvard, and Professor Henry F. Reid of Johns Hopkins have suggested new facts and sources of information; Professor E. R. Cumings of Indiana University has critically read the entire proof; conversations with Professor John P. Buwalda of the University of California while he was teaching at Yale make him another real contributor; and Mr. Wayland Williams has contributed the interesting quotation from Bacon on page $x$ of this book. Miss Edith S. Russell has taken great pains in preparing the manuscript and in suggesting many changes that make for clearness. Many others have also helped, but it is impossible to make due acknowledgment because such contributions have become so thoroughly a part of the mental background of the book that their source is no longer distinct in the minds of the authors.

The division of labor between the two authors has not followed any set rules. Both have had a hand in all parts of the book. The main draft of Chapters VII, VIII, IX, $\mathrm{XI}$, and XIII was written by the junior author; his contributions are also especially numerous in Chapters $\mathrm{X}$ and $\mathrm{XV}$; the rest of the book was written originally by the senior author. 



\section{CONTENTS}

I. The Uniformity of Climate . . . . . $\quad \begin{array}{r}\text { PAGE } \\ 1\end{array}$

II. The Variability of Climate . . . . 16

III. Hypotheses of Climatic Change . . . . 33

IV. The Solar Cyclonic Hypothesis . . . . 51

V. The Climate of History . . . . . . . . 64 -

VI. The Climatic Stress of the Fourteenth Century . . . . . . . . . . . . . 98

VII. Glaciation According to the Solar Cyclonic

Hypothesis . . . . . . . . . 110

VIII. Some Problems of Glacial Periods . . . 130

IX. The Origin of Loess . . . . . . . 155

X. Causes of Mild Geological Climates . . . 166

XI. Terrestrial Causes of Climatic Changes . . 188

XII. Post-Glacial Crustal Movements and Climatic Changes . . . . . . . . . 215

XIII. The Changing Composition of Oceans and

Atmosphere . . . . . . . . . 223

XIV. The Effect of Other Bodies on the Sun . . 242

XV. The Sun's Journey through Space . . . 264

XVI. The Earth's Crust and the Sun . . . . 285 


\section{LIST OF ILLUSTRATIONS}

Fig. 1. Climatic changes and mountain building PAGE

Fig. 2. Storminess at sunspot maxima vs. minima . . . . . . . . . 54

Fig. 3. Relative rainfall at times of increasing and decreasing sunspots . . . . 58,59

Fig. 4. Changes of climate in California and in western and central Asia . . . .

Fig. 5. Changes in California climate for 2000 years, as measured by growth of Sequoia trees . . . . . . . . 77

Fig. 6. Distribution of Pleistocene ice sheets . 123

Fig. 7. Permian geography and glaciation . . 145

Fig. 8. Effect of diminution of storms on movement of water . . . . . . . 175

Fig. 9. Cretaceous Paleogeography . . . . 201

Fig. 10. Climatic changes of 140,000 years as inferred from the stars . . . . . 279

Fig. 11. Sunspot curve showing cycles, 1750 to 1920 . . . . . . . . . . 283

Fig. 12. Seasonal distribution of earthquakes . $\quad 299$

Fig. 13. Wandering of the pole from 1890 to $1898 \quad 303$ 


\section{TABLES}

1. The Geological Time Table . . . . . $\quad 5$

2. Types of Climatic Sequence . . . . . . . 16

3. Correlation Coefficients between Rainfall and Growth of Sequoias in California . 80

4. Correlation Coefficients between Rainfall Records in California and Jerusalem . 84

5. Theoretical Probability of Stellar Approaches . . . . . . . . . . 260

6. Thirty-Eight Stars Having Largest Known Parallaxes . . . . . . . . . 276, 277

7. Destructive Earthquakes from 1800 to $\mathbf{1 8 9 9}$ Compared with Sunspots . . . . . 289

8. Seasonal March of Earthquakes . . . 295

9. Deflection of Path of Pole Compared with Earthquakes . . . . . . . . . 305

10. Earthquakes in 1903 to 1908 Compared with Departures of the Projected Curve of the Earth's Axis from the Eulerian Position 



\section{CHAPTER I}

\section{THE UNIFORMITY OF CLIMATE}

7 HE rôle of climate in the life of today suggests its importance in the past and in the future. No human being can escape from the fact that his food, clothing, shelter, recreation, occupation, health, and energy are all profoundly influenced by his climatic surroundings. A change of season brings in its train some alteration in practically every phase of human activity. Animals are influenced by climate even more than man, for they have not developed artificial means of protecting themselves. Even so hardy a creature as the dog becomes notably different with a change of climate. The thick-haired "husky" of the Eskimos has outwardly little in common with the small and almost hairless canines that grovel under foot in Mexico. Plants are even more sensitive than animals and men. Scarcely a single species can flourish permanently in regions which differ more than $20^{\circ} \mathrm{C}$. in average yearly temperature, and for most the limit of successful growth is $10^{\circ} .{ }^{1}$ So far as we yet know every living species of plant and animal, including man, thrives best under definite and limited conditions of temperature, humidity, and sunshine, and of the composition and movement of the atmosphere or water in which it lives. Any departure beyond the limits means lessened efficiency, and in the long run a lower rate of

1 W. A. Setchell: The Temperature Interval in the Geographical Distribution of Marine Algæ; Science, Vol. 52, 1920, p. 187. 
reproduction and a tendency toward changes in specific characteristics. Any great departure means suffering or death for the individual and destruction for the species.

Since climate has so profound an influence on life today, it has presumably been equally potent at other times. Therefore few scientific questions are more important than how and why the earth's climate has varied in the past, and what changes it is likely to undergo in the future. This book sets forth what appear to be the chief reasons for climatic variations during historic and geologic times. It assumes that causes which can now be observed in operation, as explained in a companion volume entitled Earth and Sun, and in such books as Humphreys' Physics of the Air, should be carefully studied before less obvious causes are appealed to. It also assumes that these same causes will continue to operate, and are the basis of all valid predictions as to the weather or climate of the future.

In our analysis of climatic variations, we may well begin by inquiring how the earth's climate has varied during geological history. Such an inquiry discloses three great tendencies, which to the superficial view seem contradictory. All, however, have a similar effect in providing conditions under which organic evolution is able to make progress. The first tendency is toward uniformity, a uniformity so pronounced and of such vast duration as to stagger the imagination. Superposed upon this there seems to be a tendency toward complexity. During the greater part of geological history the earth's climate appears to have been relatively monotonous, both from place to place and from season to season; but since the Miocene the rule has been diversity and complexity, a condition highly favorable to organic evolution. Finally, the uniformity of the vast eons of the past and the 
tendency toward complexity are broken by pulsatory changes, first in one direction and then in another. To our limited human vision some of the changes, such as glacial periods, seem to be waves of enormous proportions, but compared with the possibilities of the universe they are merely as the ripples made by a summer zephyr.

The uniformity of the earth's climate throughout the vast stretches of geological time can best be realized by comparing the range of temperature on the earth during that period with the possible range as shown in the entire solar system. As may be seen in Table 1, the geological record opens with the Archeozoic era, or "Age of Unicellular Life," as it is sometimes called, for the preceding cosmic time has left no record that can yet be read. Practically no geologists now believe that the beginning of the Archeozoic was less than one hundred million years ago; and since the discovery of the peculiar properties of radium many of the best students do not hesitate to say a billion or a billion and a half. ${ }^{2}$ Even in the Archeozoic the rocks testify to a climate seemingly not greatly different from that of the average of geologic time. The earth's surface was then apparently cool enough so that it was covered with oceans and warm enough so that the water teemed with microscopic life. The air must have been charged with water vapor and with carbon dioxide, for otherwise there seems to be no possible way of explaining the formation of mudstones and sandstones, limestones of vast thickness, carbonaceous shales, graphites, and iron ores. ${ }^{3}$ Although the Archeozoic has yielded no generally admitted fossils, yet what seem to be massive algæ and sponges have been

2 J. Barrell: Rhythms and the Measurements of Geologic Time; Bull. Geol. Soc. Am., Vol. 28, Dec., 1917, pp. 745-904.

3 Pirsson and Sehuchert: Textbook of Geology, 1915, pp. 538-550. 
found in Canada. On the other hand, abundant life is believed to have been present in the oceans, for by no other known means would it be possible to take from the air the vast quantities of carbon that now form carbonaceous shales and graphite.

In the next geologic era, the Proterozoic, the researches of Walcott have shown that besides the marine algæ there must have been many other kinds of life. The Proterozoic fossils thus far discovered include not only microscopic radiolarians such as still form the red ooze of the deepest ocean floors, but the much more significant tubes of annelids or worms. The presence of the annelids, which are relatively high in the scale of organization, is generally taken to mean that more lowly forms of animals such as cœlenterates and probably even the mollusca and primitive arthropods must already have been evolved. That there were many kinds of marine invertebrates living in the later Proterozoic is indicated by the highly varied life and more especially the trilobites found in the oldest Cambrian strata of the next succeeding period. In fact the Cambrian has sponges, primitive corals, a great variety of brachiopods, the beginnings of gastropods, a wonderful array of trilobites, and other lowly forms of arthropods. Since, under the postulate of evolution, the life of that time forms an unbroken sequence with that of the present, and since many of the early forms differ only in minor details from those of today, we infer that the climate then was not very different from that of today. The same line of reasoning leads to the conclusion that even in the middle of the Proterozoic, when multicellular marine animals must already have been common, the climate of the earth had already for an enormous period been such that all the lower types of oceanic invertebrates had already evolved. 


\section{TABLE 1 \\ THE GEOLOGICAL TIME TABLE ${ }^{4}$}

\section{COSMIC TIME}

Formative Era. Birth and growth of the earth. Beginnings of the atmosphere, hydrosphere, continental platforms, oceanic basins, and possibly of life. No known geological record.

\section{GEOLOGIC TIME}

Archeozolc Era. Origin of simplest life.

Proterozolc Era. Age of invertebrate origins. An early and a late ice age, with one or more additional ones indicated.

Paleozolc Era. Age of primitive vertebrate dominance.

Cambrian Period. First abundance of marine animals and dominance of trilobites.

Ordovician Period. First known fresh-water fishes.

Silurian Period. First known land plants.

Devonian Period. First known amphibians. "Table Mountain", ice age.

Mississippian Period. Rise of marine fishes (sharks).

Pennsylvanian Period. Rise of insects and first period of marked coal accumulation.

Permian Period. Rise of reptiles. Another great ice age.

Mesozolc Era. Age of reptile dominance.

Triassic Period. Rise of dinosaurs. The period closes with a cool climate.

Jurassio Period. Rise of birds and flying reptiles.

Comanchean Period. Rise of flowering plants and higher insects.

Cretaceous Period. Rise of archaic or primitive mammalia.

Cenozolc Era. Age of mammal dominance.

Early Cenozoic or Eocene and Oligocene time. Rise of higher mammals. Glaciers in early Eocene of the Laramide Mountains.

Late Cenozoic or Miocene and Pliocene time. Transformation of ape-like animals into man.

Glacial or Pleistocene time. Last great ice age.

\section{PRESENT TIME}

Psychozorc Era. Age of man or age of reason. Includes the present or " Recent time," estimated to be probably less than 30,000 years.

4 From Charles Schuchert in The Evolution of the Earth and Its Inhabitants: Edited by R. S. Lull, New Haven, 1918, but with revisions by Professor Schuchert. 
Moreover, they could live in most latitudes, for the indirect evidences of life in the Archeozoic and Proterozoic rocks are widely distributed. Thus it appears that at an almost incredibly early period, perhaps many hundred million years ago, the earth's climate differed only a little from that of the present.

The extreme limits of temperature beyond which the climate of geological times cannot have departed can be approximately determined. Today the warmest parts of the ocean have an average temperature of about $30^{\circ} \mathrm{C}$. on the surface. Only a few forms of life live where the average temperature is much higher than this. In deserts, to be sure, some highly organized plants and animals can for a short time endure a temperature as high as $75^{\circ} \mathrm{C}$. $\left(167^{\circ} \mathrm{F}.\right)$. In certain hot springs, some of the lowest unicellular plant forms exist in water which is only a little below the boiling point. More complex forms, however, such as sponges, worms, and all the higher plants and animals, seem to be unable to live either in water or air where the temperature averages above $45^{\circ} \mathrm{C}$. $\left(113^{\circ} \mathrm{F}\right.$.) for any great length of time and it is doubtful whether they can thrive permanently even at that temperature. The obvious unity of life for hundreds of millions of years and its presence at all times in middle latitudes so far as we can tell seem to indicate that since the beginning of marine life the temperature of the oceans cannot have averaged much above $50^{\circ} \mathrm{C}$. even in the warmest portions. This is putting the limit too high rather than too low, but even so the warmest parts of the earth can scarcely have averaged much more than $20^{\circ}$ warmer than at present.

Turning to the other extreme, we may inquire how much colder than now the earth's surface may have been since life first appeared. Proterozoic fossils have been 
found in places where the present average temperature approaches $0^{\circ} \mathrm{C}$. If those places should be colder than now by $30^{\circ} \mathrm{C}$., or more, the drop in temperature at the equator would almost certainly be still greater, and the seas everywhere would be permanently frozen. Thus life would be impossible. Since the contrasts between summer and winter, and between the poles and the equator seem generally to have been less in the past than at present, the range through which the mean temperature of the earth as a whole could vary without utterly destroying life was apparently less than would now be the case.

These considerations make it fairly certain that for at least several hundred million years the average temperature of the earth's surface has never varied more than perhaps $30^{\circ} \mathrm{C}$. above or below the present level. Even this range of $60^{\circ} \mathrm{C}$. $\left(108^{\circ} \mathrm{F}\right.$.) may be double or triple the range that has actually occurred. That the temperature has not passed beyond certain narrow limits, whatever their exact degree, is clear from the fact that if it had done so, all the higher forms of life would have been destroyed. Certain of the lowest unicellular forms might indeed have persisted, for when dormant they can stand great extremes of dry heat and of cold for a long time. Even so, evolution would have had to begin almost anew. The supposition that such a thing has happened is untenable, for there is no hint of any complete break in the record of life during geological times,-no sudden disappearance of the higher organisms followed by a long period with no signs of life other than indirect evidence such as occurs in the Archeozoic.

A change of $60^{\circ} \mathrm{C}$. or even of $20^{\circ}$ in the average temperature of the earth's surface may seem large when viewed from the limited standpoint of terrestrial ex- 
perience. Viewed, however, from the standpoint of cosmic evolution, or even of the solar system, it seems a mere trifle. Consider the possibilities. The temperature of empty space is the absolute zero, or $-273^{\circ} \mathrm{C}$. To this temperature all matter must fall, provided it exists long enough and is not appreciably heated by collisions or by radiation. At the other extreme lies the temperature of the stars. As stars go, our sun is only moderately hot, but the temperature of its surface is calculated to be nearly $7000^{\circ} \mathrm{C}$., while thousands of miles in the interior it may rise to $20,000^{\circ}$ or $100,000^{\circ}$ or some other equally unknowable and incomprehensible figure. Between the limits of the absolute zero on the one hand, and the interior of a sun or star on the other, there is almost every conceivable possibility of temperature. Today the earth's surface averages not far from $14^{\circ} \mathrm{C}$., or $287^{\circ}$ above the absolute zero. Toward the interior, the temperature in mines and deep wells rises about $1^{\circ} \mathrm{C}$. for every 100 meters. At this rate it would be over $500^{\circ} \mathrm{C}$. at a depth of ten miles, and over $5000^{\circ}$ at 100 miles.

Let us confine ourselves to surface temperatures, which are all that concern us in discussing climate. It has been calculated by Poynting ${ }^{5}$ that if a small sphere absorbed and re-radiated all the heat that fell upon it, its temperature at the distance of Mercury from the sun would average about $210^{\circ} \mathrm{C}$; at the distance of Venus, $85^{\circ}$; the earth $27^{\circ}$; Mars $-30^{\circ}$; Neptune $-219^{\circ}$. A planet much nearer the sun than is Mercury might be heated to a temperature of a thousand, or even several thousand, degrees, while one beyond Neptune would remain almost at absolute zero. It is well within the range of possibility that the temperature of a planet's surface should be

5 J. H. Poynting: Radiation in the Solar System; Phil. Trans. A, 1903, 202 , p. 525 . 
anywhere from near $-273^{\circ} \mathrm{C}$. up to perhaps $5000^{\circ} \mathrm{C}$. or more, although the probability of low temperature is much greater than of high. Thus throughout the whole vast range of possibilities extending to perhaps $10,000^{\circ}$, the earth claims only $60^{\circ}$ at most, or less than 1 per cent. This may be remarkable, but what is far more remarkable is that the earth's range of $60^{\circ}$ includes what seem to be the two most critical of all possible temperatures, namely, the freezing point of water, $0^{\circ} \mathrm{C}$., and the temperature where water can dissolve an amount of carbon dioxide equal to its own volume. The most remarkable fact of all is that the earth has preserved its temperature within these narrow limits for a hundred million years, or perchance a thousand million.

To appreciate the extraordinary significance of this last fact, it is necessary to realize how extremely critical are the temperatures from about $0^{\circ}$ to $40^{\circ} \mathrm{C}$, , and how difficult it is to find any good reason for a relatively uniform temperature through hundreds of millions of years. Since the dawn of geological time the earth's temperature has apparently always included the range from about the freezing point of water up to about the point where protoplasm begins to disintegrate. Henderson, in The Fitness of the Environment, rightly says that water is "the most familiar and the most important of all things." In many respects water and carbon dioxide form the most unique pair of substances in the whole realm of chemistry. Water has a greater tendency than any other known substance to remain within certain narrowly defined limits of temperature. Not only does it have a high specific heat, so that much heat is needed to raise its temperature, but on freezing it gives up more heat than any substance except ammonia, while none of the common liquids approach it in the amount of addi- 
tional heat required for conversion into vapor after the temperature of vaporization has been reached. Again, water substance, as the physicists call all forms of $\mathrm{H}_{2} \mathrm{O}$, is unique in that it not only contracts on melting, but continues to contract until a temperature several degrees above its melting point is reached. That fact has a vast importance in helping to keep the earth's surface at a uniform temperature. If water were like most liquids, the bottoms of all the oceans and even the entire body of water in most cases would be permanently frozen.

Again, as a solvent there is literally nothing to compare with water. As Henderson puts it: "Nearly the whole science of chemistry has been built up around water and aqueous solution." One of the most significant evidences of this is the variety of elements whose presence can be detected in sea water. According to Henderson they include hydrogen, oxygen, nitrogen, carbon, chlorine, sodium, magnesium, sulphur, phosphorus, which are easily detected; and also arsenic, cæsium, gold, lithium, rubidium, barium, lead, boron, fluorine, iron, iodine, bromine, potassium, cobalt, copper, manganese, nickel, silver, silicon, zinc, aluminium, calcium, and strontium. Yet in spite of its marvelous power of solution, water is chemically rather inert and relatively stable. It dissolves all these elements and thousands of their compounds, but still remains water and can easily be separated and purified. Another unique property of water is its power of ionizing dissolved substances, a property which makes it possible to produce electric currents in batteries. This leads to an almost infinite array of electro-chemical reactions which play an almost dominant rôle in the processes of life. Finally, no common liquid except mercury equals water in its power

${ }^{6}$ L. J. Henderson: The Fitness of the Environment, 1913. 
of capillarity. This fact is of enormous moment in biology, most obviously in respect to the soil.

Although carbon dioxide is far less familiar than water, it is almost as important. "These two simple substances," says Henderson, "are the common source of every one of the complicated substances which are produced by living beings, and they are the common end products of the wearing away of all the constituents of protoplasm, and of the destruction of those materials which yield energy to the body." One of the remarkable physical properties of carbon dioxide is its degree of solubility in water. This quality varies enormously in different substances. For example, at ordinary pressures and temperatures, water can absorb only about 5 per cent of its own volume of oxygen, while it can take up about 1300 times its own volume of ammonia. Now for carbon dioxide, unlike most gases, the volume that can be absorbed by water is nearly the same as the volume of the water. The volumes vary, however, according to temperature, being absolutely the same at a temperature of about $15^{\circ} \mathrm{C}$. or $59^{\circ} \mathrm{F}$., which is close to the ideal temperature for man's physical health and practically the same as the mean temperature of the earth's surface when all seasons are averaged together. "Hence, when water is in contact with air, and equilibrium has been established, the amount of free carbonic acid in a given volume of water is almost exactly equal to the amount in the adjacent air. Unlike oxygen, hydrogen, and nitrogen, carbonic acid enters water freely; unlike sulphurous oxide and ammonia, it escapes freely from water. Thus the waters can never wash carbonic acid completely out of the air, nor can the air keep it from the waters. It is the one substance which thus, in considerable quantities relative to its total amount, everywhere accompanies 
water. In earth, air, fire, and water alike these two substances are always associated.

"Accordingly, if water be the first primary constituent of the environment, carbonic acid is inevitably the second,-because of its solubility possessing an equal mobility with water, because of the reservoir of the atmosphere never to be depleted by chemical action in the oceans, lakes, and streams. In truth, so close is the association between these two substances that it is scarcely correct logically to separate them at all; together they make up the real environment and they never part company.",

The complementary qualities of carbon dioxide and water are of supreme importance because these two are the only known substances which are able to form a vast series of complex compounds with highly varying chemical formulæ. No other known compounds can give off or take on atoms without being resolved back into their elements. No others can thus change their form freely without losing their identity. This power of change without destruction is the fundamental chemical characteristic of life, for life demands complexity, change, and growth.

In order that water and carbon dioxide may combine to form the compounds on which life is based, the water must be in the liquid form, it must be able to dissolve carbon dioxide freely, and the temperature must not be high enough to break up the highly complex and delicate compounds as soon as they are formed. In other words, the temperature must be above freezing, while it must not rise higher than some rather indefinite point between $50^{\circ} \mathrm{C}$. and the boiling point, where all water finally turns into vapor. In the whole range of temperature, so far as

7 Henderson: loc. cit., p. 138. 
we know, there is no other interval where any such complex reactions take place. The temperature of the earth for hundreds of millions of years has remained firmly fixed within these limits.

The astonishing quality of the earth's uniformity of temperature becomes still more apparent when we consider the origin of the sun's heat. What that origin is still remains a question of dispute. The old ideas of a burning sun, or of one that is simply losing an original supply of heat derived from some accident, such as collision with another body, were long ago abandoned. The impact of a constant supply of meteors affords an almost equally unsatisfactory explanation. Moulton ${ }^{8}$ states that if the sun were struck by enough meteorites to keep up its heat, the earth would almost certainly be struck by enough so that it would receive about half of 1 per cent as much heat from them as from the sun. This is millions of times more heat than is now received from meteors. If the sun owes its heat to the impact of larger bodies at longer intervals, the geological record should show a series of interruptions far more drastic than is actually the case.

It has also been supposed that the sun owes its heat to contraction. If a gaseous body contracts it becomes warmer. Finally, however, it must become so dense that its rate of contraction diminishes and the process ceases. Under the sun's present condition of size and density a radial contraction of 120 feet per year would be enough to supply all the energy now radiated by that body. This seems like a hopeful source of energy, but Kelvin calculated that twenty million years ago it was ineffective and ten million years hence it will be equally so. Moreover, if this is the source of heat, the amount of radia-

8 F. R. Moulton: Introduction to Astronomy, 1916. 
tion from the sun would have to vary enormously. Twenty million years ago the sun would have extended nearly to the earth's orbit and would have been so tenuous that it would have emitted no more heat than some of the nebulæ in space. Some millions of years later, when the sun's radius was twice as great as at present, that body would have emitted only one-fourth as much heat as now, which would mean that on the earth's surface the theoretical temperature would have been $200^{\circ}$ below the present level. This is utterly out of accord with the uniformity of climate shown by the geological record. In the future, if the sun's contraction is the only source of heat, the sun can supply the present amount for only ten million years, which would mean a change utterly unlike anything of which the geological record holds even the faintest hint. ${ }^{\circ}$

Altogether the problem of how the sun can have remained so uniform and how the earth's atmosphere and other conditions can also have remained so uniform throughout hundreds of millions of years is one of the most puzzling in the whole realm of nature. If appeal is taken to radioactivity and the breaking up of uranium into radium and helium, conditions can be postulated which will give the required amount of energy. Such is also the case if it be supposed that there is some unknown process which may induce an atomic change like radioactivity in bodies which are now supposed to be stable elements. In either case, however, there is as yet no satisfactory explanation of the uniformity of the earth's climate. A hundred million or a thousand million years ago the temperature of the earth's surface was very much the same as now. The earth had then presumably ceased to emit any great amount of heat, if we may judge

9 Moulton: loc. cit. 
from the fact that its surface was cool enough so that great ice sheets could accumulate on low lands within $40^{\circ}$ of the equator. The atmosphere was apparently almost like that of today, and was almost certainly not different enough to make up for any great divergence of the sun from its present condition. We cannot escape the stupendous fact that in those remote times the sun must have been essentially the same as now, or else that some utterly unknown factor is at work. 


\section{THE VARIABILITY OF CLIMATE}

HE variability of the earth's climate is almost as extraordinary as its uniformity. This variability is made up partly of a long, slow tendency in one direction and partly of innumerable cycles of every conceivable duration from days, or even hours, up to millions of years. Perhaps the easiest way to grasp the full complexity of the matter is to put the chief types of climatic sequence in the form of a table.

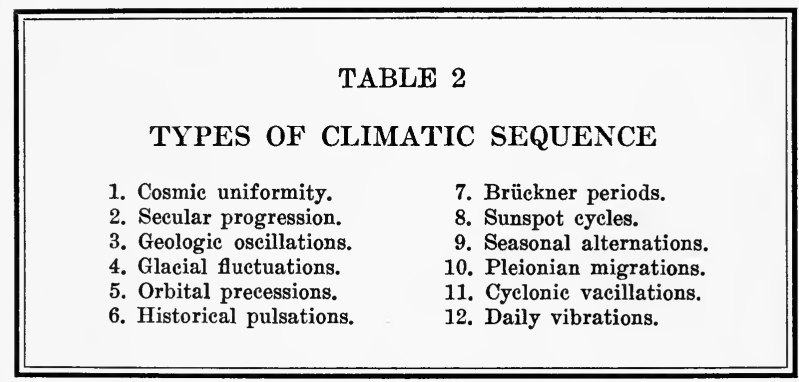

In assigning names to the various types an attempt has been made to indicate something of the nature of the sequence so far as duration, periodicity, and general tendencies are concerned. Not even the rich English language of the twentieth century, however, furnishes words with enough shades of meaning to express all that 
is desired. Moreover, except in degree, there is no sharp distinction between some of the related types, such as glacial fluctuations and historic pulsations. Yet, taken as a whole, the table brings out the great contrast between two absolutely diverse extremes. At the one end lies wellnigh eternal uniformity, or an extremely slow progress in one direction throughout countless ages; at the other, rapid and regular vibrations from day to day, or else irregular and seemingly unsystematic vacillations due to cyclonic storms, both of which types are repeated millions of times during even a single glacial fluctuation.

The meaning of cosmic uniformity has been explained in the preceding chapter. Its relation to the other types of climatic sequences seems to be that it sets sharply defined limits beyond which no changes of any kind have ever gone since life, as we know it, first began. Secular progression, on the other hand, means that in spite of all manner of variations, now this way and then the other, the normal climate of the earth, if there is such a thing, has on the whole probably changed a little, perhaps becoming more complex. After each period of continental uplift and glaciation-for such are preëminently the times of complexity-it is doubtful whether the earth has ever returned to quite its former degree of monotony. Today the earth has swung away from the great diversity of the glacial period. Yet we still have contrasts of what seem to us great magnitude. In low depressions, such as Turfan in the central deserts of Eurasia, the thermometer sometimes ranges from $0^{\circ} \mathrm{F}$. in the morning to $60^{\circ}$ in the shade at noon. On a cloudy day in the Amazon forest close to the seashore, on the contrary, the temperature for months may rise to $85^{\circ}$ by day and sink no lower than $75^{\circ}$ at night.

The reasons for the secular progression of the earth's 
climate appear to be intimately connected with those which have caused the next, and, in many respects, more important type of climatic sequence, which consists of geological oscillations. Both the progression and the oscillations seem to depend largely on three purely terrestrial factors: first, the condition of the earth's interior, including both internal heat and contraction; second, the salinity and movement of the ocean; and third, the composition and amount of the atmosphere. To begin with the earth's interior-its loss of heat appears to be an almost negligible factor in explaining either secular progression or geologic oscillation. According to both the nebular and the planetesimal hypotheses, the earth's crust appears to be colder now than it was hundreds or thousands of millions of years ago. The emission of internal heat, however, had probably ceased to be of much climatic significance near the beginning of the geological record, for in southern Canada glaciation occurred very early in the Proterozoic era. On the other hand, the contraction of the earth has produced remarkable effects throughout the whole of geological time. It has lessened the earth's circumference by a thousand miles or more, as appears from the way in which the rocks have been folded and thrust bodily over one another. According to the laws of dynamics this must have increased the speed of the earth's rotation, thus shortening the day, and also having the more important effect of increasing the bulge at the equator. On the other hand, recent investigations indicate that tidal retardation has probably diminished the earth's rate of rotation more than seemed probable a few years ago, thus lengthening the day and diminishing the bulge at the equator. Thus two opposing forces have been at work, one causing acceleration and one retardation. Their combined 
effect may have been a factor in causing secular progression of climate. It almost certainly was of much importance in causing pronounced oscillations first one way and then the other. This matter, together with most of those touched in these first chapters, will be expanded in later parts of the book. On the whole the tendency appears to have been to create climatic diversity in place of uniformity.

The increasing salinity of the oceans may have been another factor in producing secular progression, although of slight importance in respect to oscillations. While the oceans were still growing in volume, it is generally assumed that they must have been almost fresh for a vast period, although Chamberlin thinks that the change in salinity has been much less than is usually supposed. So far as the early oceans were fresher than those of today, their deep-sea circulation must have been less hampered than now by the heavy saline water which is produced by evaporation in warm regions. Although this saline water is warm, its weight causes it to descend, instead of moving poleward in a surface current; this descent slows up the rise of the cold water which has moved along in the depths of the ocean from high latitudes, and thus checks the general oceanic circulation. If the ancient oceans were fresher and hence had a freer circulation than now, a more rapid interchange of polar and equatorial water presumably tended to equalize the climate of all latitudes.

Again, although the earth's atmosphere has probably changed far less during geological times than was formerly supposed, its composition has doubtless varied. The total volume of nitrogen has probably increased, for that gas is so inert that when it once becomes a part of the air it is almost sure to stay there. On the other hand, 
the proportions of oxygen, carbon dioxide, and water vapor must have fluctuated. Oxygen is taken out constantly by animals and by all the processes of rock weathering, but on the other hand the supply is increased when plants break up new carbon dioxide derived from volcanoes. As for the carbon dioxide, it appears probable that in spite of the increased supply furnished by volcanoes the great amounts of carbon which have gradually been locked up in coal and limestone have appreciably depleted the atmosphere. Water vapor also may be less abundant now than in the past, for the presence of carbon dioxide raises the temperature a little and thereby enables the air to hold more moisture. When the area of the oceans has diminished, and this has recurred very often, this likewise would tend to reduce the water vapor. Moreover, even a very slight diminution in the amount of heat given off by the earth, or a decrease in evaporation because of higher salinity in the oceans, would tend in the same direction. Now carbon dioxide and water vapor both have a strong blanketing effect whereby heat is prevented from leaving the earth. Therefore, the probable reduction in the carbon dioxide and water vapor of the earth's atmosphere has apparently tended to reduce the climatic monotony and create diversity and complexity. Hence, in spite of many reversals, the general tendency of changes, not only in the earth's interior and in the oceans, but also in the atmosphere, appears to be a secular progression from a relatively monotonous climate in which the evolution of higher organic forms would scarcely be rapid to an extremely diverse and complex climate highly favorable to progressive evolution. The importance of these purely terrestrial agencies must not be lost sight of when we come to discuss other agencies outside the earth. 
In Table 2 the next type of climatic sequence is geologic oscillation. This means slow swings that last millions of years. At one extreme of such an oscillation the climate all over the world is relatively monotonous; it returns, as it were, toward the primeval conditions at the beginning of the secular progression. At such times magnolias, sequoias, figs, tree ferns, and many other types of subtropical plants grew far north in places like Greenland, as is well known from their fossil remains of middle Cenozoic time, for example. At these same times, and also at many others before such high types of plants had evolved, reef-making corals throve in great abundance in seas which covered what is now Wisconsin, Michigan, Ontario, and other equally cool regions. Today these regions have an average temperature of only about $70^{\circ} \mathrm{F}$. in the warmest month, and average well below freezing in winter. No reef-making corals can now live where the temperature averages below $68^{\circ} \mathrm{F}$. The resemblance of the ancient corals to those of today makes it highly probable that they were equally sensitive to low temperature. Thus, in the mild portions of a geologic oscillation the climate seems to have been so equable and uniform that many plants and animals could live 1500 and at other times even 4000 miles farther from the equator than now.

At such times the lands in middle and high latitudes were low and small, and the oceans extended widely over the continental platforms. Thus unhampered ocean currents had an opportunity to carry the heat of low latitudes far toward the poles. Under such conditions, especially if the conception of the great subequatorial continent of Gondwana land is correct, the trade winds and the westerlies must have been stronger and steadier than now. This would not only enable the westerlies, 
which are really southwesterlies, to carry more heat than now to high latitudes, but would still further strengthen the ocean currents. At the same time, the air presumably contained an abundance of water vapor derived from the broad oceans, and an abundance of atmospheric carbon dioxide inherited from a preceding time when volcanoes contributed much carbon dioxide to the air. These two constituents of the atmosphere may have exercised a pronounced blanketing effect whereby the heat of the earth with its long wave lengths was kept in, although the energy of the sun with its shorter wave lengths was not markedly kept out. Thus everything may have combined to produce mild conditions in high latitudes, and to diminish the contrast between equator and pole, and between summer and winter.

Such conditions perhaps carry in themselves the seeds of decay. At any rate while the lands lie quiet during a period of mild climate great strains must accumulate in the crust because of the earth's contraction and tidal retardation. At the same time the great abundance of plants upon the lowlying plains with their mild climates, and the marine creatures upon the broad continental platforms, deplete the atmospheric carbon dioxide. Part of this is locked up as coal and part as limestone derived from marine plants as well as animals. Then something happens so that the strains and stresses of the crust are released. The sea floors sink; the continents become relatively high and large; mountain ranges are formed; and the former plains and emergent portions of the continental platforms are eroded into hills and valleys. The large size of the continents tends to create deserts and other types of climatic diversity; the presence of mountain ranges checks the free flow of winds and also creates diversity; the ocean currents are likewise 
checked, altered, and diverted so that the flow of heat from low to high latitudes is diminished. At the same time evaporation from the ocean diminishes so that a decrease in water vapor combines with the previous depletion of carbon dioxide to reduce the blanketing effect of the atmosphere. Thus upon periods of mild monotony there supervene periods of complexity, diversity, and severity. Turn to Table 1 and see how a glacial climate again and again succeeds a time when relative mildness! prevailed almost everywhere. Or examine Fig. 1 and notice how the lines representing temperatures go up and down. In the figure Schuchert makes it clear that when the lands have been large and mountain-making has been important, as shown by the high parts of the lower shaded area, the climate has been severe, as shown by the descent of the snow line, the upper shaded area. In the diagram the climatic oscillations appear short, but this is merely because they have been crowded together, especially in the left hand or early part. There an inch in length may represent a hundred million years. Even at the righthand end an inch is equivalent to several million years.

The severe part of a climatic oscillation, as well as the mild part, will be shown in later chapters to bear in itself certain probable seeds of decay. While the lands are being uplifted, volcanic activity is likely to be vigorous and to add carbon dioxide to the air. Later, as the mountains are worn down by the many agencies of water, wind, ice, and chemical decay, although much carbon dioxide is locked up by the carbonation of the rocks, the carbon locked up in the coal is set free and increases the carbon dioxide of the air. At the same time the continents settle slowly downward, for the earth's crust though rigid as steel is nevertheless slightly viscous and will flow if subjected to sufficiently great and enduring pres- 
sure. The area from which evaporation can take place is thereby increased because of the spread of the oceans over the continents, and water vapor joins with the carbon dioxide to blanket the earth and thus tends to keep it uniformly warm. Moreover, the diminution of the lands frees the ocean currents from restraint and permits them to flow more freely from low latitudes to high. Thus in the course of millions of years there is a return toward monotony. Ultimately, however, new stresses accumulate in the earth's crust, and the way is prepared for another great oscillation. Perhaps the setting free of the stresses takes place simply because the strain at last becomes irresistible. It is also possible, as we shall see, that an external agency sometimes adds to the strain and thereby determines the time at which a new oscillation shall begin.

In Table 2 the types of climatic sequences which follow "geologic oscillations" are "glacial fluctuations," "orbital precessions" and "historical pulsations." Glacial fluctuations and historical pulsations appear to be of the same type, except as to severity and duration, and hence may be considered together. They will be treated briefly here because the theories as to their causes are outlined in the next two chapters. Oddly enough, although the historic pulsations lie much closer to us than do the glacial fluctuations, they were not discovered until two or three generations later, and are still much less known. The most important feature of both sequences is the swing from a glacial to an interglacial epoch or from the arsis or accentuated part of an historical pulsation to the thesis or unaccented part. In a glacial epoch or in the arsis of an historic pulsation, storms are usually abundant and severe, the mean temperature is lower than usual, snow accumulates in high 


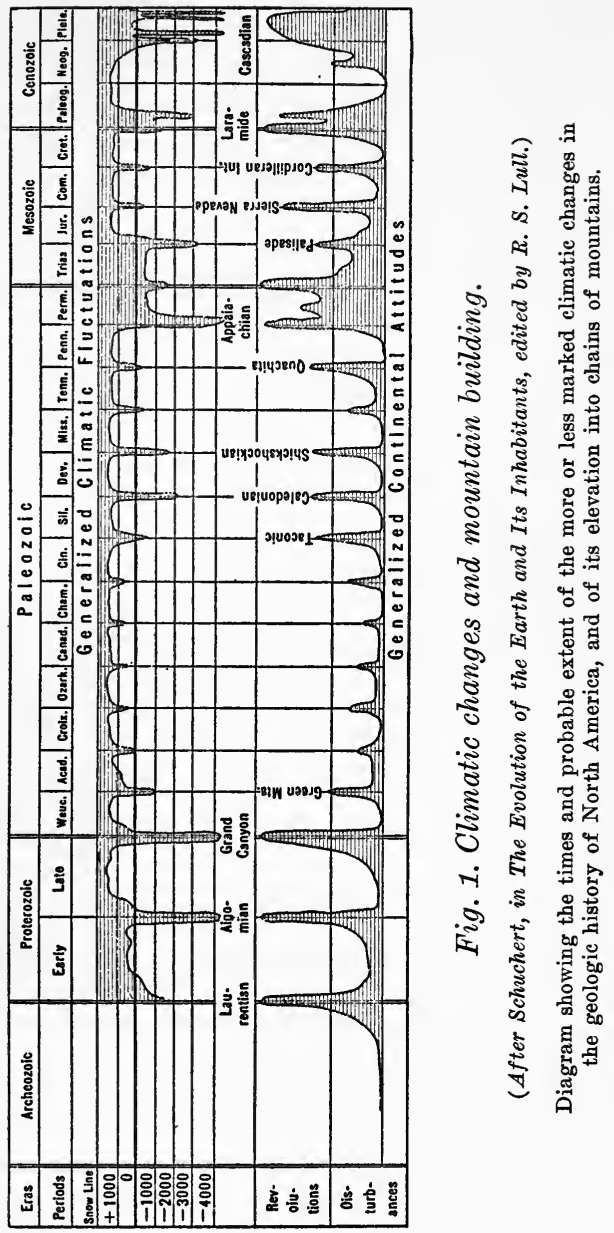


latitudes or upon lofty mountains. For example, in the last such period during the fourteenth century, great floods and droughts occurred alternately around the North Sea; it was several times possible to cross the Baltic Sea from Germany to Sweden on the ice, and the ice of Greenland advanced so much that shore ice caused the Norsemen to change their sailing route between Iceland and the Norse colonies in southern Greenland. At the same time in low latitudes and in parts of the continental interior there is a tendency toward diminished rainfall and even toward aridity and the formation of deserts. In Yucatan, for example, a diminution in tropical rainfall in the fourteenth century seems to have given the Mayas a last opportunity for a revival of their decaying civilization.

Among the climatic sequences, glacial fluctuations are perhaps of the most vital import from the standpoint of organic evolution; from the standpoint of human history the same is true of climatic pulsations. Glacial epochs have repeatedly wiped out thousands upon thousands of species and played a part in the origin of entirely new types of plants and animals. This is best seen when the life of the Pennsylvanian is contrasted with that of the Permian. An historic pulsation may wipe out an entire civilization and permit a new one to grow up with a radically different character. Hence it is not strange that the causes of such climatic phenomena have been discussed with extraordinary vigor. In few realms of science has there been a more imposing or more interesting array of theories. In this book we shall consider the more important of these theories. A new solar or cyclonic hypothesis and the hypothesis of changes in the form and altitude of the land will receive the most attention, but the other 
chief hypotheses are outlined in the next chapter, and are frequently referred to throughout the volume.

Between glacial fluctuations and historical pulsations in duration, but probably less severe than either, come orbital precessions. These stand in a group by themselves and are more akin to seasonal alternations than to any other type of climatic sequence. They must have occurred with absolute regularity ever since the earth began to revolve around the sun in its present elliptical orbit. Since the orbit is elliptical and since the sun is in one of the two foci of the ellipse, the earth's distance from the sun varies. At present the earth is nearest the sun in the northern winter. Hence the rigor of winter in the northern hemisphere is mitigated, while that of the southern hemisphere is increased. In about ten thousand years this condition will be reversed, and in another ten thousand the present conditions will return once more. Such climatic precessions, as we may here call them, must have occurred unnumbered times in the past, but they do not appear to have been large enough to leave in the fossils of the rocks any traces that can be distinguished from those of other climatic sequences.

We come now to Brückner periods and sunspot cycles. The Brückner periods have a length of about thirty-three years. Their existence was suggested at least as long ago as the days of Sir Francis Bacon, whose statement about them is quoted on the flyleaf of this book. They have since been detected by a careful study of the records of the time of harvest, vintage, the opening of rivers to navigation, and the rise or fall of lakes like the Caspian Sea. In his book on Klimaschwankungen seit 1700, Brückner has collected an uncommonly interesting assortment of facts as to the climate of Europe for more than two centuries. More recently, by a study of the rate of 
growth of trees, Douglass, in his book on Climatic Cycles and Tree Growth, has carried the subject still further. In general the nature of the 33-year periods seems to be identical with that of the 11- or 12- year sunspot cycle, on the one hand, and of historic pulsations on the other. For a century observers have noted that the variations in the weather which everyone notices from year to year seem to have some relation to sunspots. For generations, however, the relationship was discussed without leading to any definite conclusion. The trouble was that the same change was supposed to take place in all parts of the world. Hence, when every sort of change was found somewhere at any given sunspot stage, it seemed as though there could not be a relationship. Of late years, however, the matter has become fairly clear. The chief conclusions are, first, that when sunspots are numerous the average temperature of the earth's surface is lower than normal. This does not mean that all parts are cooler, for while certain large areas grow cool, others of less extent become warm at times of many sunspots. Second, at times of many sunspots storms are more abundant than usual, but are also confined somewhat closely to certain limited tracks so that elsewhere a diminution of storminess may be noted. This whole question is discussed so fully in Earth and Sun that it need not detain us further in this preliminary view of the whole problem of climate. Suffice it to say that a study of the sunspot cycle leads to the conclusion that it furnishes a clue to many of the unsolved problems of the climate of the past, as well as a key to prediction of the future.

Passing by the seasonal alternations which are fully explained as the result of the revolution of the earth around the sun, we may merely point out that, like the daily vibrations which bring Table 2 to a close, they 
emphasize the outstanding fact that the main control of terrestrial climate is the amount of energy received from the sun. This same principle is illustrated by pleionian migrations. The term "pleion" comes from a Greek word meaning "more." It was taken by Arctowski to designate areas or periods where there is an excess of some climatic element, such as atmospheric pressure, rainfall, or temperature. Even if the effect of the seasons is eliminated, it appears that the course of these various elements does not run smoothly. As everyone knows, a period like the autumn of 1920 in the eastern United States may be unusually warm, while a succeeding period may be unseasonably cool. These departures from the normal show a certain rough periodicity. For example, there is evidence of a period of about twenty-seven days, corresponding to the sun's rotation and formerly supposed to be due to the moon's revolution which occupies almost the same length of time. Still other periods appear to have an average duration of about three months and of between two and three years. Two remarkable discoveries have recently been made in respect to such pleions. One is that a given type of change usually occurs simultaneously in a number of well-defined but widely separated centers, while a change of an opposite character arises in another equally well-defined, but quite different, set of centers. In general, areas of high pressure have one type of change and areas of low pressure the other type. So systematic are these relationships and so completely do they harmonize in widely separated parts of the earth, that it seems certain that they must be due to some outside cause, which in all probability can be only the sun. The second discovery is that pleions, when once formed, travel irregularly along the earth's surface. Their paths have not yet been worked out in detail, but a general 
migration seems well established. Because of this, it is probable that if unusually warm weather prevails in one part of a continent at a given time, the "thermo-pleion," or excess of heat, will not vanish but will gradually move away in some particular direction. If we knew the path that it would follow we might predict the general temperature along its course for some months in advance. The paths are often irregular, and the pleions frequently show a tendency to break up or suddenly revive. Probably this tendency is due to variations in the sun. When the sun is highly variable, the pleions are numerous and strong, and extremes of weather are frequent. Taken as a whole the pleions offer one of the most interesting and hopeful fields not only for the student of the causes of climatic variations, but for the man who is interested in the practical question of long-range weather forecasts. Like many other climatic phenomena they seem to represent the combined effect of conditions in the sun and upon the earth itself.

The last of the climatic sequences which require explanation is the cyclonic vacillations. These are familiar to everyone, for they are the changes of weather which occur at intervals of a few days, or a week or two, at all seasons, in large parts of the United States, Europe, Japan, and some of the other progressive parts of the earth. They do not, however, occur with great frequency in equatorial regions, deserts, and many other regions. Up to the end of the last century, it was generally supposed that cyclonic storms were purely terrestrial in origin. Without any adequate investigation it was assumed that all irregularities in the planetary circulation of the winds arise from an irregular distribution of heat due to conditions within or upon the earth itself. These irregularities were supposed to produce cyclonic storms 
in certain limited belts, but not in most parts of the world. Today this view is being rapidly modified. Undoubtedly, the irregularities due to purely terrestrial conditions are one of the chief contributory causes of storms, but it begins to appear that solar variations also play a part. It has been found, for example, that not only the mean temperature of the earth's surface varies in harmony with the sunspot cycle, but that the frequency and severity of storms vary in the same way. Moreover, it has been demonstrated that the sun's radiation is not constant, but is subject to innumerable variations. This does not mean that the sun's general temperature varies, but merely that at some times heated gases are ejected rapidly to high levels so that a sudden wave of energyt strikes the earth. Thus, the present tendency is to believe that the cyclonic variations, the changes of weather which come and go in such a haphazard, irresponsible way, are partly due to causes pertaining to the earth itself and partly to the sun.

From this rapid survey of the types of climatic sequences, it is evident that they may be divided into four great groups. First comes cosmic uniformity, one of the most marvelous and incomprehensible of all known facts. We simply have no explanation which is in any respect adequate. Next come secular progression and geologic oscillations, two types of change which seem to be due mainly to purely terrestrial causes, that is, to changes in the lands, the oceans, and the air. The general tendency of these changes is toward complexity and diversity, thus producing progression, but they are subject to frequent reversals which give rise to oscillations lasting millions of years. The processes by which the oscillations take place are fully discussed in this book. Nevertheless, because they are fairly well understood, they are deferred 
until after the third group of sequences has been discussed. This group includes glacial fluctuations, historic pulsations, Brückner periods, sunspot cycles, pleionian migrations, and cyclonic vacillations. The outstanding fact in regard to all of these is that while they are greatly modified by purely terrestrial conditions, they seem to owe their origin to variations in the sun. They form the chief subject of Earth and Sun and in their larger phases are the most important topic of this book also. The last group of sequences includes orbital precessions, seasonal alternations, and daily variations. These may be regarded as purely solar in origin. Yet their influence, like that of each of the other groups, is much modified by the earth's own conditions. Our main problem is to separate and explain the two great elements in climatic changes, - the effects of the sun, on the one hand, and of the earth on the other. 


\section{CHAPTER III}

\section{HYPOTHESES OF CLIMATIC CHANGE}

TE next step in our study of climate is to review the main hypotheses as to the causes of glaciation. These hypotheses apply also to other types of climatic changes. We shall concentrate on glacial periods, however, not only because they are the most dramatic and well-known types of change, but because they have been more discussed than any other and have also had great influence on evolution. Moreover, they stand near the middle of the types of climatic sequenees, and an understanding of them does much to explain the others. In reviewing the various theories we shall not attempt to cover all the ground, but/shall merely state the main ideas of the few theories which have had an important influence upon scientific thought.

The conditions which any satisfactory climatic hypothesis must satisfy are briefly as follows:

(1) Due weight must be given to the fact that changes of climate are almost certainly due to the combined effect of a variety of causes, both terrestrial and solar or cosmic.

(2) Attention must also be paid to both sides in the long controversy as to whether glaciation is due primarily to a diminution in the earth's supply of heat or to a redistribution of the heat through changes in atmospheric and oceanic circulation. At present the great 
majority of authorities are on the side of a diminution of heat, but the other view also deserves study.

(3) A satisfactory hypothesis must explain the frequent synchronism between two great types of phenomena; first, movements of the earth's crust whereby continents are uplifted and mountains upheaved; and, second, great changes of climate which are usually marked by relatively rapid oscillations from one extreme to another.

(4) No hypothesis can find acceptance unless it satisfies the somewhat exacting requirements of the geological record, with its frequent but irregular repetition of long, mild periods, relatively cool or intermediate periods like the present, and glacial periods of more or less severity and perhaps accompanying the more or less widespread uplifting of continents. At least during the later glacial periods the hypothesis must explain numerous climatic epochs and stages superposed upon a single general period of continental upheaval. Moreover, although historical geology demands cycles of varied duration and magnitude, it does not furnish evidence of any rigid periodicity causing the cycles to be uniform in length or intensity.

(5) Most important of all, a satisfactory explanation of climatic changes and crustal deformation must take account of all the agencies which are now causing similar phenomena. Whether any other agencies should be considered is open to question, although the relative importance of existing agencies may have varied.

I. Croll's Eccentricity Theory. One of the most ingenious and most carefully elaborated scientific hypotheses is Croll's ${ }^{1}$ precessional hypothesis as to the effect of the earth's own motions. So well was this worked

1 James Croll: Climate and Time, 1876. 
out that it was widely accepted for a time and still finds a place in popular but unscientific books, such as Wells' Outline of History, and even in scientific works like Wright's Quaternary Ice Age. The gist of the hypothesis has already been given in connection with the type of climatic sequence known as orbital precessions. The earth is 93 million miles away from the sun in January and 97 million in July. The earth's axis " precesses," however, just as does that of a spinning top. Hence arises what is known as the precession of the equinoxes, that is, a steady change in the season at which the earth is in perihelion, or nearest to the sun. In the course of 21,000 years the time of perihelion varies from early in January through the entire twelve months and back to January. Moreover, the earth's orbit is slightly more elliptical at certain periods than at others, for the planets sometimes become bunched so that they all pull the earth in one direction. Hence, once in about one hundred thousand years the effect of the elliptical shape of the earth's orbit is at a maximum.

Croll argued that these astronomical changes must alter the earth's climate, especially by their effect on winds and ocean currents. His elaborate argument contains a vast amount of valuable material. Later investigation, however, seems to have proven the inadequacy of his hypothesis. In the first place, the supposed cause does not seem nearly sufficient to produce the observed results. Second, Croll's hypothesis demands that glaciation in the northern and southern hemisphere take place alternately. A constantly growing collection of facts, however, indicates that glaciation does not occur in the two hemispheres alternately, but at the same time. Third, the hypothesis calls for the constant and frequent repetition of glaciation at absolutely regular intervals. The geo- 
logical record shows no such regularity, for sometimes several glacial epochs follow in relatively close succession at irregular intervals of perhaps fifty to two hundred thousand years, and thus form a glacial period; and then for millions of years there are none. Fourth, the eccentricity hypothesis provides no adequate explanation for the glacial stages or subepochs, the historic pulsations, and the other smaller climatic variations which are superposed upon glacial epochs and upon one another in bewildering confusion. In spite of these objections, there can be little question that the eccentricity of the earth's orbit and the precession of the equinoxes with the resulting change in the season of perihelion must have some climatic effect. Hence Croll's theory deserves a permanent though minor place in any full discussion of the causes of climatic changes.

II. The Carbon Dioxide Theory. At about the time that the eccentricity theory was being relegated to a minor niche, a new theory was being developed which soon exerted a profound influence upon geological thought. Chamberlin, ${ }^{2}$ adopting an idea suggested by

2 T. C. Chamberlin: An attempt to frame a working hypothesis of the cause of glacial periods on an atmospheric basis; Jour. Geol., Vol. VII, 1899, pp. 545-584, 667-685, 757-787.

T. C. Chamberlin and R. D. Salisbury: Geology, Vol. II, 1906, pp. 93106, 655-677, and Vol. IIr, pp. 432-446.

S. Arrhenius (Kosmische Physik, Vol. II, 1903, p. 503) carried out some investigations on carbon dioxide which have had a pronounced effect on later conclusions.

F. Frech adopted Arrhenius' idea and developed it in a paper entitled Ueber die Klima-Aenderungen der Geologischen Vergangenheit. Compte Rendu, Tenth (Mexico) Congr. Geol. Intern., 1907 (=1908), pp. 299-325.

The exact origin of the carbon dioxide theory has been stated so variously that it seems worth while to give the exact facts. Prompted by the suggestion of Tyndall that glaciation might be due to depletion of atmospheric carbon dioxide, Chamberlin worked up the essentials of his early views before he saw any publication from Arrhenius, to whom the idea has often been attributed. In 1895 or earlier Chamberlin began to give the carbon dioxide hypothesis to his students and to discuss it before local scientific 
Tyndall, fired the imagination of geologists by his skillful exposition of the part played by carbon dioxide in causing climatic changes. Today this theory is probably? more widely accepted than any other. We have already seen that the amount of carbon dioxide gas in the atmosphere has a decided climatic importance. Moreover, there can be little doubt that the amount of that gas in the atmosphere varies from age to age in response to the extent to which it is set free by volcanoes, consumed by plants, combined with rocks in the process of weathering, dissolved in the ocean or locked up in the form of coal and limestone. The main question is whether such variations can produce changes so rapid as glacial epochs and historical pulsations.

Abundant evidence seems to show that the degree to which the air can be warmed by carbon dioxide is sharply limited. Humphreys, in his excellent book on the Physics of the Air, calculates that a layer of carbon dioxide forty centimeters thick has practically as much blanketing effect as a layer indefinitely thicker. In other words, forty centimeters of carbon dioxide, while having no appreci-

bodies. In 1897 he prepared a paper on "A Group of Hypotheses Bearing on Climatic Changes,' Jour. Geol., Vol. V (1897), to be read at the meeting of the British Association at Toronto, basing his conclusions on Tyndall's determination of the competency of carbon dioxide as an absorber of heat radiated from the earth. He had essentially completed this when a paper by Arrhenius "On the influence of carbonic acid in the air upon the temperature of the ground," Phil. Mag., 1896, pp. 237-276, first came to his attention. Chamberlin then changed his conservative, tentative statement of the functions of carbon dioxide to a more sweeping one based on Arrhenius' very definite quantitative deductions from Langley's experiments. Both Langley and Arrhenius were then in the ascendancy of their reputations and seemingly higher authorities could scarcely have been chosen, nor a finer combination than experiment and physico-mathematical development. Arrhenius' deductions were later proved to have been overstrained, while Langley's interpretation and even his observations were challenged. Chamberlin's latest views are more like his earlier and more conservative statement. 
able effect on sunlight coming toward the earth, would filter out and thus retain in the atmosphere all the outgoing terrestrial heat that carbon dioxide is capable of absorbing. Adding more would be like adding another filter when the one in operation has already done all that that particular kind of filter is capable of doing. According to Humphreys' calculations, a doubling of the carbon dioxide in the air would in itself raise the average temperature about $1.3^{\circ} \mathrm{C}$. and further carbon dioxide would have practically no effect. Reducing the present supply by half would reduce the temperature by essentially the same amount.

The effect must be greater, however, than would appear from the figures given above, for any change in temperature has an effect on the amount of water vapor, which in turn causes further changes of temperature. Moreover, as Chamberlin points out, it is not clear whether Humphreys allows for the fact that when the 40 centimeters of $\mathrm{CO}_{2}$ nearest the earth has been heated by terrestrial radiation, it in turn radiates half its heat outward and half inward. The outward half is all absorbed in the next layer of carbon dioxide, and so on. The process is much more complex than this, but the end result is that even the last increment of $\mathrm{CO}_{2}$, that is, the outermost portions in the upper atmosphere, must apparently absorb an infinitesimally small amount of heat. This fact, plus the effect of water vapor, would seem to indicate that a doubling or halving of the amount of $\mathrm{CO}_{2}$ would have an effect of more than $1.3^{\circ} \mathrm{C}$. A change of even $2^{\circ} \mathrm{C}$. above or below the present level of the earth's mean temperature would be of very appreciable climatic significance, for it is commonly believed that during the height of the glacial period the mean temperature was only $5^{\circ}$ to $8^{\circ} \mathrm{C}$. lower than now. 
Nevertheless, variations in atmospheric carbon dioxide do not necessarily seem competent to produce the relatively rapid climatic fluctuations of glacial epochs and historic pulsations as distinguished from the longer swings of glacial periods and geological eras. In Chamberlin's view, as in ours, the elevation of the land, the modification of the currents of the air and of the ocean, and all that goes with elevation as a topographic agency constitute a primary cause of climatic changes. A special effect of this is the removal of carbon dioxide from the air by the enhanced processes of weathering. This, as he carefully states, is a very slow process, and cannot of itself lead to anything so sudden as the oncoming of glaciation. But here comes Chamberlin's most distinctive contribution to the subject, namely, the hypothesis that changes in atmospheric temperature arising from variations in atmospheric carbon dioxide are able to cause a reversal of the deep-sea oceanic circulation.

According to Chamberlin's view, the ordinary oceanic circulation of the greater part of geological time was the reverse of the present circulation. Warm water descended to the ocean depths in low latitudes, kept its heat while creeping slowly poleward, and rose in high latitudes producing the warm climate which enabled corals, for example, to grow in high latitudes. Chamberlin holds this opinion largely because there seems to him to be no other reasonable way to account for the enormously long warm periods when heat-loving forms of life lived in what are now polar regions of ice and snow. He explains this reversed circulation by supposing that an abundance of atmospheric carbon dioxide, together with a broad distribution of the oceans, made the atmosphere so warm that the evaporation in low latitudes was far more rapid than now. Hence the surface water of the ocean became 
a relatively concentrated brine. Such a brine is heavy and tends to sink, thereby setting up an oceanic circulation the reverse of that which now prevails. At present the polar waters sink because they are cold and hence contract. Moreover, when they freeze a certain amount of salt leaves the ice and thereby increases the salinity of the surrounding water. Thus the polar water sinks to the depths of the ocean, its place is taken by warmer and lighter water from low latitudes which moves poleward along the surface, and at the same time the cold water of the ocean depths is forced equatorward below the surface. But if the equatorial waters were so concentrated that a steady supply of highly saline water kept descending to low levels, the direction of the circulation would have to be reversed. The time when this would occur would depend upon the delicate balance between the downward tendencies of the cold polar water and of the warm saline equatorial water.

Suppose that while such a reversed circulation prevailed, the atmospheric $\mathrm{CO}_{2}$ should be depleted, and the air cooled so much that the concentration of the equatorial waters by evaporation was no longer sufficient to cause them to sink. A reversal would take place, the present type of circulation would be inaugurated, and the whole earth would suffer a chill because the surface of the ocean would become cool. The cool surfacewater would absorb carbon dioxide faster than the previous warm water had done, for heat drives off gases from water. This would hasten the cooling of the atmosphere still more, not only directly but by diminishing the supply of atmospheric moisture. The result would be glaciation. But ultimately the cold waters of the higher latitudes would absorb all the carbon dioxide they could hold, the slow equatorward creep would at length permit 
the cold water to rise to the surface in low latitudes. There the warmth of the equatorial sun and the depleted supply of carbon dioxide in the air would combine to cause the water to give up its carbon dioxide once more. If the atmosphere had been sufficiently depleted by that time, the rising waters in low latitudes might give up more carbon dioxide than the cold polar waters absorbed. Thus the atmospheric supply would increase, the air would again grow warm, and a tendency toward deglaciation, or toward an inter-glacial condition would arise. At such times the oceanic circulation is not supposed to have been reversed, but merely to have been checked and made slower by the increasing warmth. Thus inter-glacial conditions like those of today, or even considerably warmer, are supposed to have been produced with the present type of circulation.

The emission of carbon dioxide in low latitudes could not permanently exceed the absorption in high latitudes. After the present type of circulation was finally established, which might take tens of thousands of years, the two would gradually become equal. Then the conditions which originally caused the oceanic circulation to be reversed would again destroy the balance; the atmospheric carbon dioxide would be depleted; the air would grow cooler; and the cycle of glaciation would be repeated. Each cycle would be shorter than the last, for not only would the swings diminish like those of a pendulum, but the agencies that were causing the main depletion of the atmospheric carbon dioxide would diminish in intensity. Finally as the lands became lower through erosion and submergence, and as the processes of weathering became correspondingly slow, the air would gradually be able to accumulate carbon dioxide; the temperature would increase; and at length the oceanic circulation would be 
reversed again. When the warm saline waters of low latitudes finally began to sink and to set up a flow of warm water poleward in the depths of the ocean, a glacial period would definitely come to an end.

This hypothesis has been so skillfully elaborated, and contains so many important elements that one can scarcely study it without profound admiration. We believe that it is of the utmost value as a step toward the truth, and especially because it emphasizes the great function of oceanic circulation. Nevertheless, we are unable to accept it in full for several reasons, which may here be stated very briefly. Most of them will be discussed fully in later pages.

(1) While a reversal of the deep-sea circulation would undoubtedly be of great climatic importance and would produce a warm climate in high latitudes, we see no direct evidence of such a reversal. It is equally true that there is no conclusive evidence against it, and the possibility of a reversal must not be overlooked. There seem, however, to be other modifications of atmospheric and oceanic circulation which are able to produce the observed results.

(2) There is much, and we believe conclusive, evidence that a mere lowering of temperature would not produce glaciation. What seems to be needed is changes in atmospheric circulation and in precipitation. The carbon dioxide hypothesis has not been nearly so fully developed on the meteorological side as in other respects.

(3) The carbon dioxide hypothesis seems to demand that the oceans should have been almost as saline as now in the Proterozoic era at the time of the first known glaciation. Chamberlin holds that such was the case, but the constant supply of saline material brought to the ocean by rivers and the relatively small deposition of 
such material on the sea floor seem to indicate that the early oceans must have been much fresher than those of today.

(4) The carbon dioxide hypothesis does not attempt to explain minor climatic fluctuations such as post-glacial stages and historic pulsations, but these appear to be of the same nature as glacial epochs, differing only in degree.

(5) Another reason for hesitation in accepting the carbon dioxide hypothesis as a full explanation of glacial fluctuations is the highly complex and non-observational character of the explanation of the alternation of glacial and inter-glacial epochs and of their constantly decreasing length.

(6) Most important of all, a study of the variations of weather and of climate as they are disclosed by present records and by the historic past suggests that there are now in action certain other causes which are competent to explain glaciation without recourse to a process whose action is beyond the realm of observation.

These considerations lead to the conclusion that the carbon dioxide hypothesis and the reversal of the oceanic circulation should be regarded as a tentative rather than a final explanation of glaciation. Nevertheless, the action of carbon dioxide seems to be an important factor in producing the longer oscillations of climate from one geological era to another. It probably plays a considerable part in preparing the way for glacial periods and in making it possible for other factors to produce the more rapid changes which have so deeply influenced organic evolution.

III. The Form of the Land. Another great cause of climatic change consists of a group of connected phenomena dependent upon movements of the earth's crust. 
As to the climatic potency of changes in the lands there is practical agreement among students of climatology and glaciation. That the height and extent of the continents, the location, size, and orientation of mountain ranges, and the opening and closing of oceanic gateways at places like Panama, and the consequent diversion of oceanic currents, exert a profound effect upon climate can scarcely be questioned. Such changes may be introduced rapidly, but their disappearance is usually slow compared with the rapid pulsations to which climate has been subject during historic times and during stages of glacial retreat and advance, or even in comparison with the epochs into which the Pleistocene, Permian, and perhaps earlier glacial periods have been divided. Hence, while crustal movements appear to be more important than the eccentricity of the earth's orbit or the amount of carbon dioxide in the air, they do not satisfactorily explain glacial fluctuations, historic pulsations, and especially the present little cycles of climatic change. All these changes involve a relatively rapid swing from one extreme to another, while an upheaval of a continent, which is at best a slow geologic process, apparently cannot be undone for a long, long time. Hence such an upheaval, if acting alone, would lead to a relatively longlived climate of a somewhat extreme type. It would help to explain the long swings, or geologic oscillations between a mild and uniform climate at one extreme, and a complex and varied climate at the other, but it would not explain the rapid climatic pulsations which are closely associated with great movements of the earth's crust. It might prepare the way for them, but could not cause them. That this conclusion is true is borne out by the fact that vast mountain ranges, like those at the close of the Jurassic and Cretaceous, are upheaved without bringing 
on glacial climates. Moreover, the marked Permian ice age follows long after the birth of the Hercynian Mountians and before the rise of others of later Permian origin.

IV. The Volcanic Hypothesis. In the search for some cause of climatic change which is highly efficient and yet able to vary rapidly and independently, Abbot, Fowle, Humphreys, and others, ${ }^{3}$ have concluded that volcanic eruptions are the missing agency. In Physics of the Air, Humphreys gives a careful study of the effect of volcanic dust upon terrestrial temperature. He begins with a mathematical investigation of the size of dust particles, and their quantity after certain eruptions. He demonstrates that the power of such particles to deflect light of short wave-lengths coming from the sun is perhaps thirty times more than their power to retain the heat radiated in long waves from the earth. Hence it is estimated that if a Krakatoa were to belch forth dust every year or two, the dust veil might cause a reduction of about $6^{\circ} \mathrm{C}$. in the earth's surface temperature. As in every such complicated problem, some of the author's assumptions are open to question, but this touches their quantitative and not their qualitative value. It seems certain that if volcanic explosions were frequent enough and violent enough, the temperature of the earth's surface would be considerably lowered.

Actual observation supports this theoretical conclusion. Humphreys gathers together and amplifies all that he and Abbot and Fowle have previously said as to observations of the sun's thermal radiation by means of the

3 C. G. Abbot and F. E. Fowle: Volcanoes and Climate; Smiths. Misc. Coll., Vol. 60, 1913, 24 pp.

W. J. Humphreys: Volcanic dust and other factors in the production of climatic and their possible relation to ice ages; Bull. Mount Weather Observatory, Vol. 6, Part 1, 1913, 26 pp. Also, Physics of the Air, 1920. 
pyrheliometer. This summing up of the relations between the heat received from the sun, and the occurrence of explosive volcanic eruptions leaves little room for doubt that at frequent intervals during the last century and a half a slight lowering of terrestrial temperature has actually occurred after great eruptions. Nevertheless, it does not justify Humphreys' final conclusion that "phenomena within the earth itself suffice to modify its own climate, . . . that these and these alone have actually caused great changes time and again in the geologic past." Humphreys sees so clearly the importance of the purely terrestrial point of view that he unconsciously slights the cosmic standpoint and ignores the important solar facts which he himself adduces elsewhere at considerable length.

In addition to this the degree to which the temperature of the earth as a whole is influenced by volcanic eruptions is by no means so clear as is the fact that there is some influence. Arctowski, ${ }^{4}$ for example, has prepared numerous curves showing the march of temperature month after month for many years. During the period from 1909 to 1913, which includes the great eruption of Katmai in Alaska, low temperature is found to have prevailed at the time of the eruption, but, as Arctowski puts it, on the basis of the curves for 150 stations in all parts of the world: "The supposition that these abnormally low temperatures were due to the veil of volcanic dust produced by the Katmai eruption of June 6, 1912, is completely out of the question. If that had been the case, temperature would have decreased from that date on, whereas it was decreasing for more than a year before that date."

4H. Arctowski: The Pleionian Cycle of Climatic Fluctuations; Am. Jour. Sci., Vol. 42, 1916, pp. 27-33. See also Annals of the New York Academy of Sciences, Vol. 24, 1914. 
Köppen, ${ }^{5}$ in his comprehensive study of temperature for a hundred years, also presents a strong argument against the idea that volcanic eruptions have an important place in determining the present temperature of the earth. A volcanic eruption is a sudden occurrence. Whatever effect is produced by dust thrown into the air must occur within a few months, or as soon as the dust has had an opportunity to be wafted to the region in question. When the dust arrives, there will be a rapid drop through the few degrees of temperature which the dust is supposed to be able to account for, and thereafter a slow rise of temperature. If volcanic eruptions actually caused a frequent lowering of terrestrial temperature in the hundred years studied by Köppen, there should be more cases where the annual temperature is decidedly below the normal than where it shows a large departure in the opposite direction. The contrary is actually the case.

A still more important argument is the fact that the earth is now in an intermediate condition of climate. Throughout most of geologic time, as we shall see again and again, the climate of the earth has been milder than now. Regions like Greenland have not been the seat of glaciers, but have been the home of types of plants which now thrive in relatively low latitudes. In other words, the earth is today only part way from a glacial epoch to what may be called the normal, mild climate of the earth-a climate in which the contrast from zone to zone was much less than now, and the lower air averaged warmer. Hence it seems impossible to avoid the conclusion that the cause of glaciation is still operating with considerable

5 W. Köppen: Über mehrjährige Perioden der Witterung ins besondere üzer die II-jährige Periode der Temperatur. Also, Lufttemperaturen Sonnenflecke und Vulcanausbrüche; Meteorologische Zeitschrift, Vol. 7, 1914, pp. 305-328. 
although diminished efficiency. But volcanic dust is obviously not operating to any appreciable extent at present, for the upper air is almost free from dust a large part of the time.

Again, as Chamberlin suggests, let it be supposed that a Krakatoan eruption every two years would produce a glacial period. Unless the most experienced field workers on the glacial formations are quite in error, the various glacial epochs of the Pleistocene glacial period had a joint duration of at least 150,000 years and perhaps twice as much. That would require 75,000 Krakatoan eruptions. But where are the pits and cones of such eruptions? There has not been time to erode them away since the Pleistocene glaciation. Their beds of volcanic ash would presumably be as voluminous as the glacial beds, but there do not seem to be accumulations of any such size. Even though the same volcano suffered repeated explosions, it seems impossible to find sufficient fresh volcanic debris. Moreover, the volcanic hypothesis has not yet offered any.mechanism for systematic glacial variations. Hence, while the hypothesis is important, we must search further for the full explanation of glacial fluctuations, historic pulsations, and the earth's present quasi-glacial climate.

V. The Hypothesis of Polar Wandering. Another hypothesis, which has some adherents, especially among geologists, holds that the position of the earth's axis has shifted repeatedly during geological times, thus causing glaciation in regions which are not now polar. Astrophysicists, however, are quite sure that no agency could radically change the relation between the earth and its axis without likewise altering the orbits of the planets to a degree that would be easily recognized. Moreover, the distribution of the centers of glaciation both in the Per- 
mian and Pleistocene periods does not seem to conform to this hypothesis.

VI. The Thermal Solar Hypothesis. The only other explanations of the climatic changes of glacial and historic times which now seem to have much standing are two distinct and almost antagonistic solar hypotheses. One is the idea that changes in the earth's climate are due to variations in the heat emitted by the sun and hence in the temperature of the earth. The other is the entirely different idea that climatic changes arise from solar conditions which cause a redistribution of the earth's atmospheric pressure and hence produce changes in winds, ocean currents, and especially storms. This second, or "cyclonic," hypothesis is the subject of a book entitled Earth and Sun, which is to be published as a companion to the present volume. It will be outlined in the next chapter. The other, or thermal, hypothesis may be dismissed briefly. Unquestionably a permanent change in the amount of heat emitted by the sun would permanently alter the earth's climate. There is absolutely no evidence, however, of any such change during geologic time. The evidence as to the earth's cosmic uniformity and as to secular progression is all against it. Suppose that for thirty or forty thousand years the sun cooled off enough so that the earth was as cool as during a glacial epoch. As glaciation is soon succeeded by a mild climate, some agency would then be needed to raise the sun's temperature. The impact of a shower of meteorites might accomplish this, but that would mean a very sudden heating, such as there is no evidence of in geological history. In fact, there is far more evidence of sudden cooling than of sudden heating. Moreover, it is far beyond the bounds of probability that such an impact should be repeated again and again with just such force as to bring the cli- 
mate back almost to where it started and yet to allow for the slight changes which cause secular progression. Another and equally cogent objection to the thermal form of solar hypothesis is stated by Humphreys as follows: "A change of the solar constant obviously alters all surface temperatures by a roughly constant percentage. Hence a decrease of the heat from the sun would in general cause a decrease of the interzonal temperature gradients; and this in turn a less vigorous atmospheric circulation, and a less copious rain or snowfall-exactly the reverse of the condition, namely, abundant precipitation, most favorable to extensive glaciation."

This brings us to the end of the main hypotheses as to climatic changes, aside from the solar cyclonic hypothesis which will be discussed in the next chapter. It appears that variations in the position of the earth at perihelion have a real though slight influence in causing cycles with a length of about 2600 years. Changes in the carbon dioxide of the air probably have a more important but extremely slow influence upon geologic oscillations. Variations in the size, shape, and height of the continents are constantly causing all manner of climatic complications, but do not cause rapid fluctuations and pulsations. The eruption of volcanic dust appears occasionally to lower the temperature, but its potency to explain the complex climatic changes recorded in the rocks has probably been exaggerated. Finally, although minor changes in the amount of heat given out by the sun occur constantly and have been demonstrated to have a climatic effect, there is no evidence that such changes are the main cause of the climatic phenomena which we are trying to explain. Nevertheless, in connection with other solar changes they may be of high importance. 


\section{CHAPTER IV}

\section{THE SOLAR CYCLONIC HYPOTHESIS}

$\prod$ HE progress of science is made up of a vast succession of hypotheses. The majority die in early infancy. A few live and are for a time widely accepted. Then some new hypothesis either destroys them completely or shows that, while they contain elements of truth, they are not the whole truth. In the previous chapter we have discussed a group of hypotheses of this kind, and have tried to point out fairly their degree of truth so far as it can yet be determined. In this chapter we shall outline still another hypothesis, the relation of which to present climatic conditions has been fully developed in Earth and Sun; while its relation to the past will be explained in the present volume. This hypothesis is not supposed to supersede the others, for so far as they are true they cannot be superseded. It merely seems to explain some of the many conditions which the other hypotheses apparently fail to explain. To suppose that it will suffer a fate more glorious than its predecessors would be presumptuous. The best that can be hoped is that after it has been pruned, enriched, and modified, it may take its place among the steps which finally lead to the goal of truth.

In this chapter the new hypothesis will be sketched in broad outline in order that in the rest of this book the reader may appreciate the bearing of all that is said. Details of proof and methods of work will be omitted, 
since they are given in Earth and Sun. For the sake of brevity and clearness the main conclusions will be stated without the qualifications and exceptions which are fully explained in that volume. Here it will be necessary to pass quickly over points which depart radically from accepted ideas, and which therefore must arouse serious question in the minds of thoughtful readers. That, however, is a necessary consequence of the attempt which this book makes to put the problem of climate in such form that the argument can be followed by thoughtful students in any branch of knowledge and not merely by specialists. Therefore, the specialist can merely be asked to withhold judgment until he has read all the evidence as given in Earth and Sun, and then to condemn only those parts that are wrong and not the whole argument.

Without further explanation let us turn to our main problem. In the realm of climatology the most important discovery of the last generation is that variations in the weather depend on variations in the activity of the sun's atmosphere. The work of the great astronomer, Newcomb, and that of the great climatologist, Köppen, have shown beyond question that the temperature of the earth's surface varies in harmony with variations in the number and area of sunspots. ${ }^{1}$ The work of Abbot has shown that the amount of heat radiated from the sun also varies, and that in general the variations correspond with those of the sunspots, although there are exceptions, especially when the spots are fewest. Here, however, there at once arises a puzzling paradox. The earth cer-

1 The so-ealled sunspot numbers to which reference is made again and again in this book are based on a system devised by Wolf and revised by A. Wolfer. The number and size of the spots are both taken into account. The numbers from 1749 to 1900 may be found in the Monthly Weather Review for April, 1902, and from 1901 to 1918 in the same journal for 1920. 
tainly owes its warmth to the sun. Yet when the sun emits the most energy, that is, when sunspots are most numerous, the earth's surface is coolest. Doubtless the earth receives more heat than usual at such times, and the upper air may be warmer than usual. Here we refer only to the air at the earth's surface.

Another large group of investigators have shown that atmospheric pressure also varies in harmony with the number of sunspots. Some parts of the earth's surface have one kind of variation at times of many sunspots and other parts the reverse. These differences are systematic and depend largely on whether the region in question happens to have high atmospheric pressure or low. The net result is that when sunspots are numerous the earth's storminess increases, and the atmosphere is thrown into commotion. This interferes with the stable planetary winds, such as the trades of low latitudes and the prevailing westerlies of higher latitudes. Instead of these regular winds and the fair weather which they bring, there is a tendency toward frequent tropical hurricanes in the lower latitudes and toward more frequent and severe storms of the ordinary type in the latitudes where the world's most progressive nations now live. With the change in storminess there naturally goes a change in rainfall. Not all parts of the world, however, have increased storminess and more abundant rainfall when sunspots are numerous. Some parts change in the opposite way. Thus when the sun's atmosphere is particularly disturbed, the contrasts between different parts of the earth's surface are increased. For example, the northern United States and southern Canada become more stormy and rainy, as appears in Fig. 2, and the same is true of the Southwest and along the south Atlantic coast. In a crescent-shaped central area, however, 
extending from Wyoming through Missouri to Nova Scotia, the number of storms and the amount of rainfall decrease.

The two controlling factors of any climate are the temperature and the atmospheric pressure, for they determine the winds, the storms, and thus the rainfall. A study of the temperature seems to show that the peculiar paradox of a hot sun and a cool earth is due largely to the increased storminess during times of many sunspots. The earth's surface is heated by the rays of the sun, but

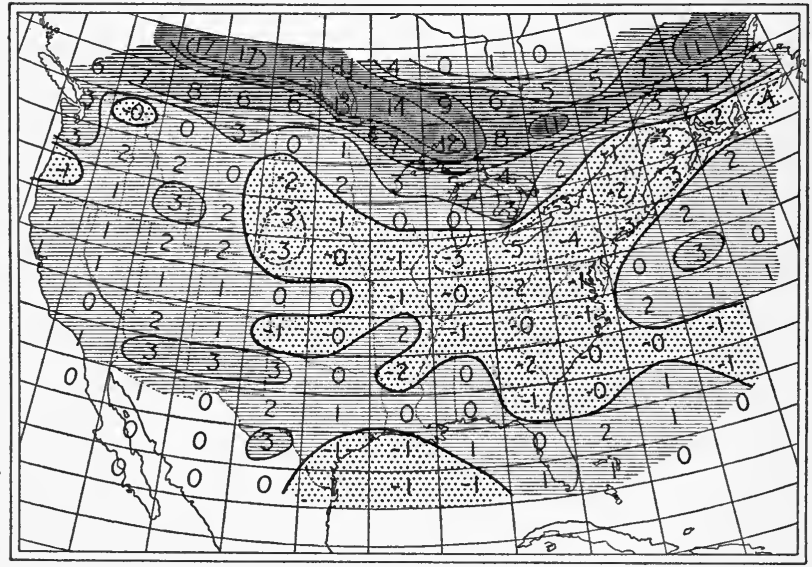

Fig. 2. Storminess at sunspot maxima vs. minima.

(After Kullmer.)

Based on nine years' nearest sunspot minima and nine years' nearest sunspot maxima in the three sunspot cycles from 1888 to 1918 . Heavy shading indicates excess of storminess when sunspots are numerous. Figures indicate average yearly number of storms by which years of maximum sunspots exceed those of minimum sunspots. 
most of the rays do not in themselves heat the air as they pass through it. The air gets its heat largely from the heat absorbed by the water vapor which is intimately mingled with its lower portions, or from the long heat waves sent out by the earth after it has been warmed by the sun. The faster the air moves along the earth's surface the less it becomes heated, and the more heat it takes away. This sounds like a contradiction, but not to anyone who has tried to heat a stove in the open air. If the air is still, the stove rapidly becomes warm and so does the air around it. If the wind is blowing, the cool air delays the heating of the stove and prevents the surface from ever becoming as hot as it would otherwise. That seems to be what happens on a large scale when sunspots are numerous. The sun actually sends to the earth more energy than usual, but the air moves with such unusual rapidity that it actually cools the earth's surface a trifle by carrying the extra heat to high levels where it is lost into space.

There has been much discussion as to why storms are numerous when the sun's atmosphere is disturbed. Many investigators have supposed it was due entirely and directly to the heating of the earth's surface by the sun. This, however, needs modification for several reasons. In the first place, recent investigations show that in a great many cases changes in barometric pressure precede changes in temperature and apparently cause them by altering the winds and producing storms. This is the opposite of what would happen if the effect of solar heat upon the earth's surface were the only agency. In the second place, if storms were due exclusively to variations in the ordinary solar radiation which comes to the earth as light and is converted into heat, the solar effect ought 
to be most pronounced when the center of the sun's visible disk is most disturbed. As a matter of fact the storminess is notably greatest when the edges of the solar disk are most disturbed. These facts and others lead to the conclusion that some agency other than heat must also play some part in producing storminess.

The search for this auxiliary agency raises many difficult questions which cannot yet be answered. On the whole the weight of evidence suggests that electrical phenomena of some kind are involved, although variations in the amount of ultra-violet light may also be important. Many investigators have shown that the sun emits electrons. Hale has proved that the sun, like the earth, is magnetized. Sunspots also have magnetic fields the strength of which is often fifty times as great as that of the sun as a whole. If electrons are sent to the earth, they must move in curved paths, for they are deflected by the sun's magnetic field and again by the earth's magnetic field. The solar deflection may cause their effects to be greatest when the spots are near the sun's margin; the terrestrial deflection may cause concentration in bands roughly concentric with the magnetic poles of the earth. These conditions correspond with the known facts.

Farther than this we cannot yet go. The calculations of Humphreys seem to indicate that the direct electrical effect of the sun's electrons upon atmospheric pressure is too small to be of appreciable significance in intensifying storms. On the other hand the peculiar way in which activity upon the margins of the sun appears to be correlated not only with atmospheric electricity, but with barometric pressure, seems to be equally strong evidence in the other direction. Possibly the sun's electrons and its electrical waves produce indirect effects by being 
converted into heat, or by causing the formation of ozone and the condensation of water vapor in the upper air. Any one of these processes would raise the temperature of the upper air, for the ozone and the water vapor would be formed there and would tend to act as a blanket to hold in the earth's heat. But any such change in the temperature of the upper air would influence the lower air through changes in barometric pressure. These considerations are given here because the thoughtful reader is likely to inquire how solar activity can influence storminess. Moreover, at the end of this book we shall take up certain speculative questions in which an electrical hypothesis will be employed. For the main portions of this book it makes no difference how the sun's variations influence the earth's atmosphere. The only essential point is that when the solar atmosphere is active the storminess of the earth increases, and that is a matter of direct observation.

Let us now inquire into the relation between the small cyclonic vacillations of the weather and the types of climatic changes known as historic pulsations and glacial fluctuations. One of the most interesting results of recent investigations is the evidence that sunspot cycles on a small scale present almost the same phenomena as do historic pulsations and glacial fluctuations. For instance, when sunspots are numerous, storminess increases markedly in a belt near the northern border of the area of greatest storminess, that is, in southern Canada and thence across the Atlantic to the North Sea and Scandinavia. (See Figs. 2 and 3.) Corresponding with this is the fact that the evidence as to climatic pulsations in historic times indicates that regions along this path, for instance Greenland, the North Sea region, and southern Scandi- 


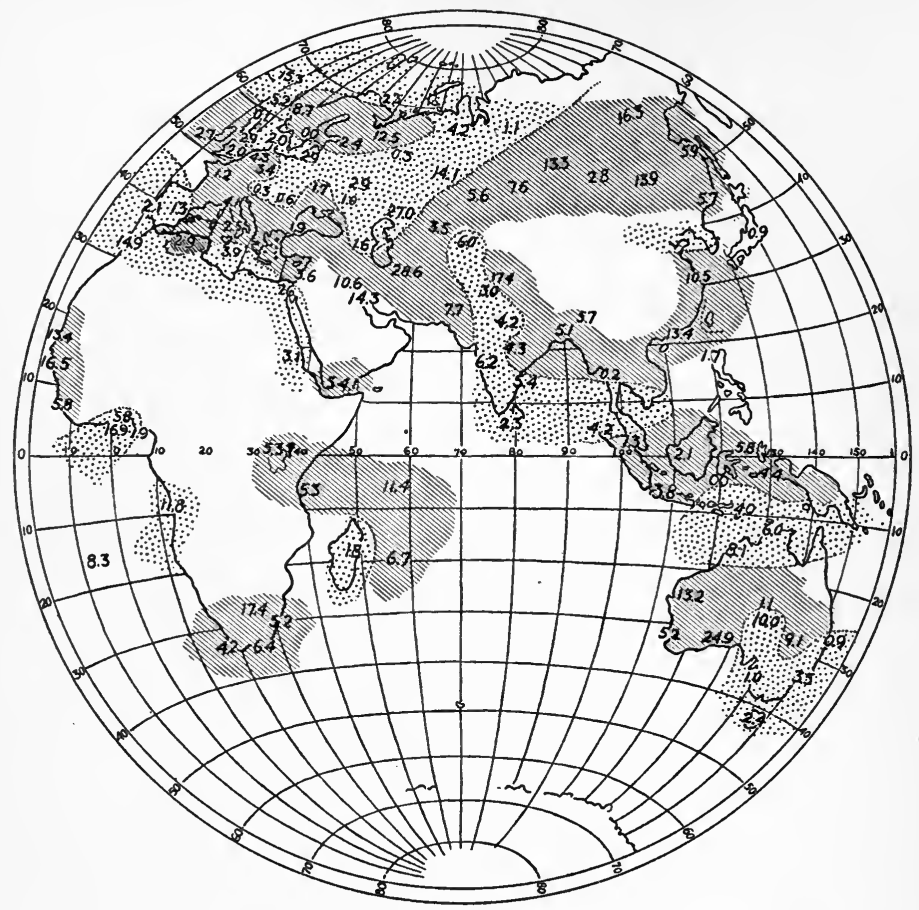

Fig. 3. Relative rainfall at times of increasing and decreasing sunspots.

Heavy shading, more rain with increasing spots. Light shading, more rain with decreasing spots. No data for unshaded areas.

Figures indicate percentages of the average rainfall by which the rainfall during periods of increasing spots exceeds or falls short of rainfall during periods of decreasing spots. The excess or deficiency is stated in percentages of the average. Rainfall data from Walker: Sunspots and Rainfall. 


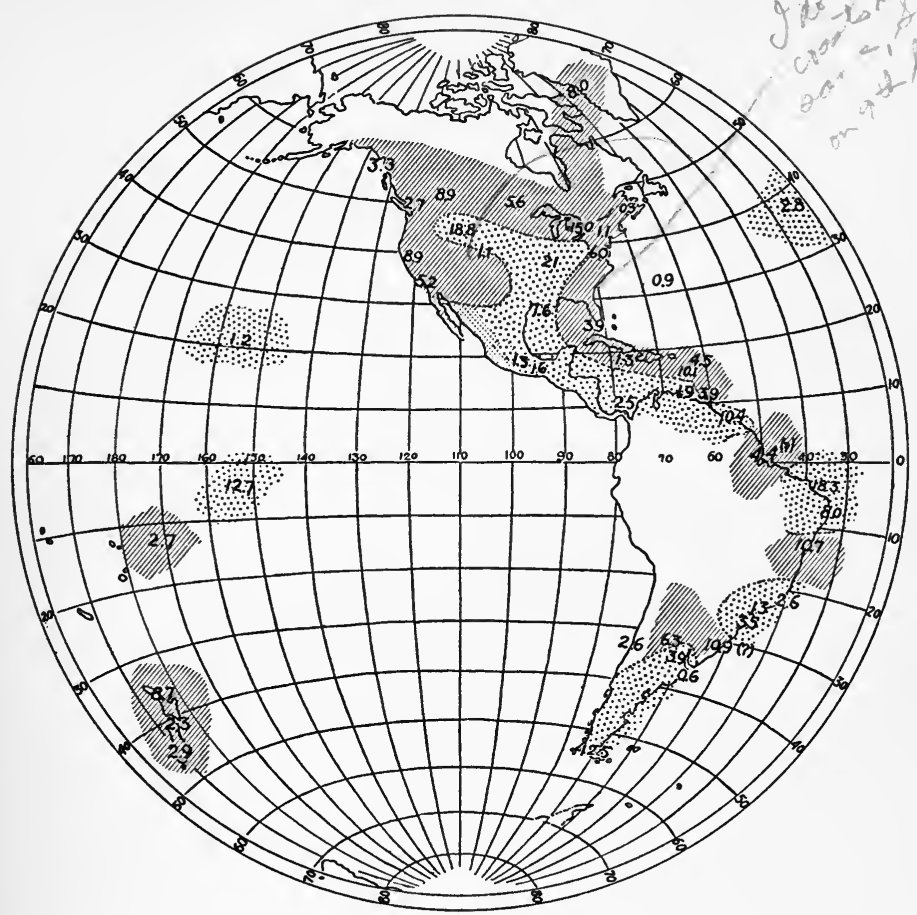

Fig. 3. Relative rainfall at times of increasing and decreasing sunspots.

Heavy shading, more rain with increasing spots. Light shading, more rain with decreasing spots. No data for unshaded areas.

Figures indicate percentages of the average rainfall by which the rainfall during periods of increasing spots exceeds or falls short of rainfall during periods of decreasing spots. The excess or deficiency is stated in percentages of the average. Rainfall data from Walker: Sunspots and Rainfall. 
navia, were visited by especially frequent and severe storms at the climax of each pulsation. Moreover, the greatest accumulations of ice in the glacial period were on the poleward border of the general regions where now the storms appear to increase most at times of solar activity.

Even more clear is the evidence from other regions where storms increase at times of many sunspots. One such region includes the southwestern United States, while another is the Mediterranean region and the semiarid or desert parts of Asia farther east. In these regions innumerable ruins and other lines of evidence show that at the climax of each climatic pulsation there was more storminess and rainfall than at present, just as there now is when the sun is most active. In still earlier times, while ice was accumulating farther north, the basins of these semi-arid regions were filled with lakes whose strands still remain to tell the tale of much-increased rainfall and presumable storminess. If we go back still further in geological times to the Permian glaciation, the areas where ice accumulated most abundantly appear to be the regions where tropical hurricanes produce the greatest rainfall and the greatest lowering of temperature at times of many sunspots. From these and many other lines of evidence it seems probable that historic pulsations and glacial fluctuations are nothing more than sunspot cycles on a large scale. It is one of the fundamental rules of science to reason from the known to the unknown, from the near to the far, from the present to the past. Hence it seems advisable to investigate whether any of the climatic phenomena of the past may have arisen from an intensification of the solar conditions which now appear to give rise to similar phenomena on a small scale. 
The rest of this chapter will be devoted to a résumé of certain tentative conclusions which have no bearing on the main part of this book, but which apply to the closing chapters. There we shall inquire into the periodicity of the climatic phenomena of geological times, and shall ask whether there is any reason to suppose that the sun's activity has exhibited similar periodicity. This leads to an investigation of the possible causes of disturbances in the sun's atmosphere. It is generally assumed that sunspots, solar prominences, the bright clouds known as faculæ, and other phenomena denoting a perturbed state of the solar atmosphere, are due to some cause within the sun. Yet the limitation of these phenomena, especially the sunspots, to restricted latitudes, as has been shown in Earth and Sun, does not seem to be in harmony with an internal solar origin, even though a banded arrangement may be normal for a rotating globe. The fairly regular periodicity of the sunspots seems equally out of harmony with an internal origin. Again, the solar atmosphere has two kinds of circulation, one the so-called "rice grains," and the other the spots and their attendant phenomena. Now the rice grains present the appearance that would be expected in an atmospheric circulation arising from the loss of heat by the outer part of a gaseous body like the sun. For these reasons and others, numerous good thinkers from Wolf to Schuster have held that sunspots owe their periodicity to causes outside the sun. The only possible cause seems to be the planets, acting either through gravitation, through forces of an electrical origin, or through some other agency. Various new investigations which are described in Earth and Sun support this conclusion. The chief difficulty in accepting it hitherto has been that although Jupiter, because of its size, would be 
expected to dominate the sunspot cycle, its period of 11.86 years has not been detected. The sunspot cycle has appeared to average 11.2 years in length, and has been called the 11-year cycle. Nevertheless, a new analysis of the sunspot data shows that when attention is concentrated upon the major maxima, which are least subject to retardation or acceleration by other causes, a periodicity closely approaching that of Jupiter is evident. Moreover, when the effects of Jupiter, Saturn, and the other planets are combined, they produce a highly variable curve which has an extraordinary resemblance to the sunspot curve. The method by which the planets influence the sun's atmosphere is still open to question. It may be through tides, through the direct effect of gravitation, through electro-magnetic forces, or in some other way. Whichever it may be, the result may perhaps be slight differences of atmospheric pressure upon the sun. Such differences may set in motion slight whirling movements analogous to terrestrial storms, and these presumably gather momentum from the sun's own energy. Since the planetary influences vary in strength because of the continuous change in the relative distances and positions of the planets, the sun's atmosphere appears to be swayed by cyclonic disturbances of varying degrees of severity. The cyclonic disturbances known as sunspots have been proved by Hale to become more highly electrified as they increase in intensity. At the same time hot gases presumably well up from the lower parts of the solar atmosphere and thereby cause the sun to emit more heat. Thus by one means or another, the earth's atmosphere appears to be set in commotion and cycles of climate are inaugurated.

If the preceding reasoning is correct, any disturbance of the solar atmosphere must have an effect upon the 
earth's climate. If the disturbance were great enough and of the right nature it might produce a glacial epoch. The planets are by no means the only bodies which act upon the sun, for that body sustains a constantly changing relation to millions of other celestial bodies of all sizes up to vast universes, and at all sorts of distances. If the sun and another star should approach near enough to one another, it is certain that the solar atmosphere would be disturbed much more than at present.

Here we must leave the cyclonic hypothesis of climate and must refer the reader once more to Earth and Sun for fuller details. In the rest of this book we shall discuss the nature of the climatic changes of past times and shall inquire into their relation to the various climatic hypotheses mentioned in the last two chapters. Then we shall inquire into the possibility that the solar system has ever been near enough to any of the stars to cause appreciable disturbances of the solar atmosphere. We shall complete our study by investigating the vexed question of why movements of the earth's crust, such as the uplifting of continents and mountain chains, have generally occurred at the same time as great climatic fluctuations. This would not be so surprising were it not that the climatic phenomena appear to have consisted of highly complex cycles while the uplift has been a relatively steady movement in one direction. We shall find some evidence that the solar disturbances which seem to cause climatic changes also have a relation to movements of the crust. 


\section{CHAPTER V}

\section{THE CLIMATE OF HISTORY ${ }^{1}$}

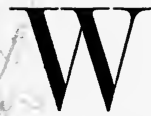

$\mathrm{E}$ are now prepared to consider the climate of the past. The first period to claim attention is the few thousand years covered by written history. Strangely enough, the conditions during this time are known with less accuracy than are those of geological periods hundreds of times more remote. Yet if pronounced changes have occurred since the days of the ancient Babylonians and since the last of the postglacial stages, they are of great importance not only because of their possible historic effects, but because they bridge the gap between the little variations of climate which are observable during a single lifetime and the great changes known as glacial epochs. Only by bridging the gap can we determine whether there is any genetic relation between the great changes and the small. A full discussion of the climate of historic times is not here advisable, for it has been considered in detail in numerous other publications. ${ }^{2}$ Our most profitable course would seem to be to consider first the general trend of opinion and then to take up the chief objections to each of the main hypotheses.

In the hot debate over this problem during recent

1 Much of this chapter is taken from The Solar Hypothesis of Climatic Changes; Bull. Geol. Soc. Am., Vol. 25, 1914.

2 Ellsworth Huntington: Explorations in Turkestan, 1905; The Pulse of Asia, 1907; Palestine and Its Transformation, 1911; The Climatic Factor, 1915 ; World Power and Evolution, 1919. 
decades the ideas of geographers seem to have gone through much the same metamorphosis as have those of geologists in regard to the climate of far earlier times.

As every geologist well knows, at the dawn of geology people believed in climatic uniformity-that is, it was supposed that since the completion of an original creative act there had been no important changes. This view quickly disappeared and was superseded by the hypothesis of progressive cooling and drying, an hypothesis which had much to do with the development of the nebular hypothesis, and which has in turn been greatly strengthened by that hypothesis. The discovery of evidence of widespread continental glaciation, however, necessitated a modification of this view, and succeeding years have brought to light a constantly increasing number of glacial, or at least cool, periods distributed throughout almost the whole of geological time. Moreover, each year, almost, brings new evidence of the great complexity of glacial periods, epochs, and stages. Thus, for many decades, geologists have more and more been led to believe that in spite of surprising uniformity, when viewed in comparison with the cosmic possibilities, the climate of the past has been highly unstable from the viewpoint of organic evolution, and its changes have been of all degrees of intensity.

Geographers have lately been debating the reality of historic changes of climate in the same way in which geologists debated the reality of glacial epochs and stages. Several hypotheses present themselves but these may all be grouped under three headings; namely, the hypotheses of (1) progressive desiccation, (2) climatic uniformity, and (3) pulsations. The hypothesis of progressive desiccation has been widely advocated. In many of the drier portions of the world, especially between $30^{\circ}$ 
and $40^{\circ}$ from the equator, and preëminently in western and central Asia and in the southwestern United States, almost innumerable facts seem to indicate that two or three thousand years ago the climate was distinctly moister than at present. The evidence includes old lake strands, the traces of desiccated springs, roads in places now too dry for caravans, other roads which make detours around dry lake beds where no lakes now exist, and fragments of dead forests extending over hundreds of square miles where trees cannot now grow for lack of water. Still stronger evidence is furnished by ancient ruins, hundreds of which are located in places which are now so dry that only the merest fraction of the former inhabitants could find water. The ruins of Palmyra, in the Syrian Desert, show that it must once have been a city like modern Damascus, with one or two hundred thousand inhabitants, but its water supply now suffices for only one or two thousand. All attempts to increase the water supply have had only a slight effect and the water is notoriously sulphurous, whereas in the former days, when it was abundant, it was renowned for its excellence. Hundreds of pages might be devoted to describing similar ruins. Some of them are even more remarkable for their dryness than is Niya, a site in the Tarim Desert of Chinese Turkestan. Yet there the evidence of desiccation within 2000 years is so strong that even so careful and conservative a man as Hann, ${ }^{3}$ pronounces it "überzeugend.",

A single quotation from scores that might be used will illustrate the conclusions of some of the most careful archæologists. ${ }^{4}$

3 J. Hann: Klimatologie, Vol. 1, 1908, p. 352.

4 H. C. Butler: Desert Syria, the Land of a Lost Civilization; Geographical Review, Feb., 1920, pp. 77-108. 
Among the regions which were once populous and highly civilized, but which are now desert and deserted, there are few which were more closely connected with the beginnings of our own civilization than the desert parts of Syria and northern Arabia. It is only of recent years that the vast extent and great importance of this lost civilization has been fully recognized and that attempts have been made to reduce the extent of the unexplored area and to discover how much of the territory which has long been known as desert was formerly habitable and inhabited. The results of the explorations of the last twenty years have been most astonishing in this regard. It has been found that practically all of the wide area lying between the coast range of the eastern Mediterranean and the Euphrates, appearing upon the maps as the Syrian Desert, an area embracing somewhat more than 20,000 square miles, was more thickly populated than any area of similar dimensions in England or in the United States is today if one excludes the immediate vicinity of the large modern cities. It has also been discovered that an enormous desert tract lying to the east of Palestine, stretching eastward and southward into the country which we know as Arabia, was also a densely populated country. How far these settled regions extended in antiquity is still unknown, but the most distant explorations in these directions have failed to reach the end of ruins and other signs of former occupation.

The traveler who has crossed the settled, and more or less populous, coast range of northern Syria and descended into the narrow fertile valley of the Orontes, encounters in any farther journey toward the east an irregular range of limestone hills lying north and south and stretching to the northeast almost halfway to the Euphrates. These hills are about 2,500 feet high, rising in occasional peaks from 3,000 to 3,500 feet above sea level. They are gray and unrelieved by any visible vegetation. On ascending into the hills the traveler is astonished to find at every turn remnants of the work of men's hands, paved roads, walls which divided fields, terrace walls of massive structure. Presently he comes upon a small deserted and partly ruined town 
composed of buildings large and small constructed of beautifully wrought blocks of limestone, all rising out of the barren rock which forms the ribs of the hills. If he mounts an eminence in the vicinity, he will be still further astonished to behold similar ruins lying in all directions. He may count ten or fifteen or twenty, according to the commanding position of his lookout. From a distance it is often difficult to believe that these are not inhabited places; but closer inspection reveals that the gentle hand of time or the rude touch of earthquake has been laid upon every building. Some of the towns are better preserved than others; some buildings are quite perfect but for their wooden roofs which time has removed, others stand in picturesque ruins, while others still are level with the ground. On a far-off hilltop stands the ruin of a pagan temple, and crowning some lofty ridge lie the ruins of a great Christian monastery. Mile after mile of this barren gray country may be traversed without encountering a single human being. Day after day may be spent in traveling from one ruined town to another without seeing any green thing save a terebinth tree or two standing among the ruins, which have sent their roots down into earth still preserved in the foundations of some ancient building. No soil is visible anywhere except in a few pockets in the rock from which it could not be washed by the torrential rains of the wet season; yet every ruin is surrounded with the remains of presses for the making of oil and wine. Only one oasis has been discovered in these high plateaus.

Passing eastward from this range of hills, one descends into a gently rolling country that stretches miles away toward the Euphrates. At the eastern foot of the hills one finds oneself in a totally different country, at first quite fertile and dotted with frequent villages of flat-roofed houses. Here practically all the remains of ancient times have been destroyed through ages of building and rebuilding. Beyond this narrow fertile strip the soil grows drier and more barren, until presently another kind of desert is reached, an undulating waste of dead soil. Few walls or towers or arches rise to break the monotony of the unbroken 
landscape; but the careful explorer will find on closer examination that this region was more thickly populated in antiquity even than the hill country to the west. Every unevenness of the surface marks the site of a town, some of them cities of considerable extent.

We may draw certain very definite conclusions as to the former conditions of the country itself. There was soil upon the northern hills where none now exists, for the buildings now show unfinished foundation courses which were not intended to be seen; the soil in depressions without outlets is deeper than it formerly was; there are hundreds of olive and wine presses in localities where no tree or vine could now find footing; and there are hillsides with ruined terrace walls rising one above the other with no sign of earth near them. There was also a large natural water supply. In the north as well as in the south we find the dry beds of rivers, streams, and brooks with sand and pebbles and well-worn rocks but no water in them from one year's end to the other. We find bridges over these dry streams and crudely made washing boards along their banks directly below deserted towns. Many of the bridges span the beds of streams that seldom or never have water in them and give clear evidence of the great climatic changes that have taken place. There are well heads and well houses, and inscriptions referring to springs; but neither wells nor springs exist today except in the rarest instances. Many of the houses had their rock-hewn cisterns, never large enough to have supplied water for more than a brief period, and corresponding to the cisterns which most of our recent forefathers had which were for convenience rather than for dependence. Some of the towns in southern Syria were provided with large public reservoirs, but these are not large enough to have supplied water to their original populations. The high plateaus were of course without irrigation; but there are no signs, even in the lower flatter country, that irrigation was ever practiced; and canals for this purpose could not have completely disappeared. There were forests in the immediate vicinity, forests producing timbers of great length and thickness; for in the north and northeast prac- 
tically all the buildings had wooden roofs, wooden intermediate floors, and other features of wood. Costly buildings, such as temples and churches, employed large wooden beams; but wood was used in much larger quantities in private dwellings, shops, stables, and barns. If wood had not been plentiful and cheapwhich means grown near by-the builders would have adopted the building methods of their neighbors in the south, who used very little wood and developed the most perfect type of lithic architecture the world has ever seen. And here there exists a strange anomaly: Northern Syria, where so much wood was employed in antiquity, is absolutely treeless now; while in the mountains of southern Syria, where wood must have been scarce in antiquity to have forced upon the inhabitants an almost exclusive use of stone, there are still groves of scrub oak and pine, and travelers of half a century ago reported large forests of chestnut trees. ${ }^{5}$ It is perfectly apparent that large parts of Syria once had soil and forests and springs and rivers, while it has none of these now, and that it had a much larger and better distributed rainfall in ancient times than it has now.

Professor Butler's careful work is especially interesting because of its contrast to the loose statements of those who believe in climatic uniformity. So far as I am aware, no opponent of the hypothesis of climatic changes has ever even attempted to show by careful statistical analysis that the ancient water supply of such ruins was no greater than that of the present. The most that has been done is to suggest that there may have been sources of water which are now unknown. Of course, this might be true in a single instance, but it could scarcely be the case in many hundreds or thousands of ruins.

\footnotetext{
5 This is due to the fact that where these forests occur, in Gilead for example, the mountains to the west break down, so that the west winds with water from the Mediterranean are able to reach the inner range without having lost all their water. It is one of the misfortunes of Syria that its mountains generally rise so close to the sea that they shut off rainfall from the interior and cause the rain to fall on slopes too steep for easy cultivation.
} 
Although the arguments in favor of a change of climate during the last two thousand years seem too strong to be ignored, their very strength seems to have been a source of error. A large number of people have jumped to the conclusion that the change which appears to have occurred in certain regions occurred everywhere, and that it consisted of a gradual desiccation.

Many observers, quite as careful as those who believe in progressive desiccation, point to evidences of aridity in past times in the very regions where the others find proof of moisture. Lakes such as the Caspian Sea fell to such a low level that parts of their present floors were exposed and were used as sites for buildings whose ruins are still extant. Elsewhere, for instance in the Tian-Shan Mountains, irrigation ditches are found in places where irrigation never seems to be necessary at present. In Syria and North Africa during the early centuries of the Christian era the Romans showed unparalleled activity in building great aqueducts and in watering land which then apparently needed water almost as much as it does today. Evidence of this sort is abundant and is as convincing as is the evidence of moister conditions in the past. It is admirably set forth, for example, in the comprehensive and ably written monograph of Leiter on the climate of North Africa. ${ }^{6}$ The evidence cited there and elsewhere has led many authors strongly to advocate the hypothesis of climatic uniformity. They have done exactly as have the advocates of progressive change, and have extended their conclusions over the whole world and over the whole of historic times.

The hypotheses of climatic uniformity and of progres-

6 H. Leiter: Die Frage der Klimaanderung waherend geschichtlicher Zeit in Nordafrika. Abhandl. K. K. Geographischen Gesellschaft, Wien, 1909, p. 143 . 
sive change both seem to be based on reliable evidence. They may seem to be diametrically opposed to one another, but this is only when there is a failure to group the various lines of evidence according to their dates, and according to the types of climate in which they happen to be located. When the facts are properly grouped in both time and space, it appears that evidence of moist conditions in the historic Mediterranean lands is found during certain periods ; for instance, four or five hundred years before Christ, at the time of Christ, and 1000 A. D. The other kind of evidence, on the contrary, culminates at other epochs, such as about $1200 \mathrm{~B}$. C. and in the seventh and thirteenth centuries after Christ. It is also found during the interval from the culmination of a moist epoch to the culmination of a dry one, for at such times the climate was growing drier and the people were under stress. This was seemingly the case during the period from the second to the fourth centuries of our era. North Africa and Syria must then have been distinctly better watered than at present, as appears from Butler's vivid description; but they were gradually becoming drier, and the natural effect on a vigorous, competent people like the Romans was to cause them to construct numerous engineering works to provide the necessary water.

The considerations which have just been set forth have led to a third hypothesis, that of pulsatory climatic changes. According to this, the earth's climate is not stable, nor does it change uniformly in one direction. It appears to fluctuate back and forth not only in the little waves which we see from year to year or decade to decade, but in much larger waves, which take hundreds of years or even a thousand. These in turn seem to merge into and be imposed on the greater waves which form glacial stages, glacial epochs, and glacial periods. At the 
present time there seems to be no way of determining whether the general tendency is toward aridity or toward glaciation. The seventh century of our era was apparently the driest time during the historic period-distinctly drier than the present-but the thirteenth century was almost equally dry, and the twelfth or thirteenth before Christ may have been very dry.

The best test of an hypothesis is actual measurements. In the case of the pulsatory hypothesis we are fortunately able to apply this test by means of trees. The growth of vegetation depends on many factors-soil, exposure, wind, sun, temperature, rain, and so forth. In a dry region the most critical factor in determining how a tree's growth shall vary from year to year is the supply of moisture during the few months of most rapid growth. ${ }^{7}$ The work of Douglass ${ }^{8}$ and others has shown that in Arizona and California the thickness of the annual rings affords a reliable indication of the amount of moisture available during the period of growth. This is especially true when the growth of several years is taken as the unit and is compared with the growth of a similar number of years before or after. Where a long series of years is used, it is necessary to make corrections to eliminate the effects of age, but this can be done by mathematical methods of considerable accuracy. It is difficult to determine whether the climate at the beginning

7 A most careful and convincing study of this problem is embodied in an article by J. W. Smith: The Effects of Weather upon the Yield of Corn; Monthly Weather Review, Vol. 42, 1914, pp. 78-92. On the basis of the yield of corn in Ohio for 60 years and in other states for shorter periods, he shows that the rainfall of July has almost as much influence on the crop as has the rainfall of all other months combined. See his Agricultural Meteorology, New York, 1920.

8 See chapter by A. E. Douglass in The Climatic Factor; and his book on Climatic Cycles and Tree-Growth; Carnegie Inst., 1919. Also article by M. N. Stewart: The Relation of Precipitation to Tree Growth, in the Monthly Weather Review, Vol. 41, 1913. 
and end of a tree's life was the same, but it is easily possible to determine whether there have been pulsations while the tree was making its growth. If a large number of trees from various parts of a given district all formed thick rings at a certain period and then formed thin ones for a hundred years, after which the rings again become thick, we seem to be safe in concluding that the trees have lived through a long, dry period. The full reasons for this belief and details as to the methods of estimating climate from tree growth are given in The Climatic Factor.

The results set forth in that volume may be summarized as follows: During the years 1911 and 1912, under the auspices of the Carnegie Institution of Washington, measurements were made of the thickness of the rings of growth on the stumps of about 450 sequoia trees in California. These trees varied in age from 250 to nearly 3250 years. The great majority were over 1000 years of age, seventy-nine were over 2000 years, and three over 3000. Even where only a few trees are available the record is surprisingly reliable, except where occasional accidents occur. Where the number approximates 100, accidental variations are largely eliminated and we may accept the record with considerable confidence. Accordingly, we may say that in California we have a fairly accurate record of the climate for 2000 years and an approximate record for 1000 years more. The final results of the measurements of the California trees are shown in Fig. 4, where the climatic variations for 3000 years in California are indicated by the solid line. The high parts of the line indicate rainy conditions, the low parts, dry. An examination of this curve shows that during 3000 years there have apparently been climatic variations more important than any which have taken place during the past century. In order to bring out the 

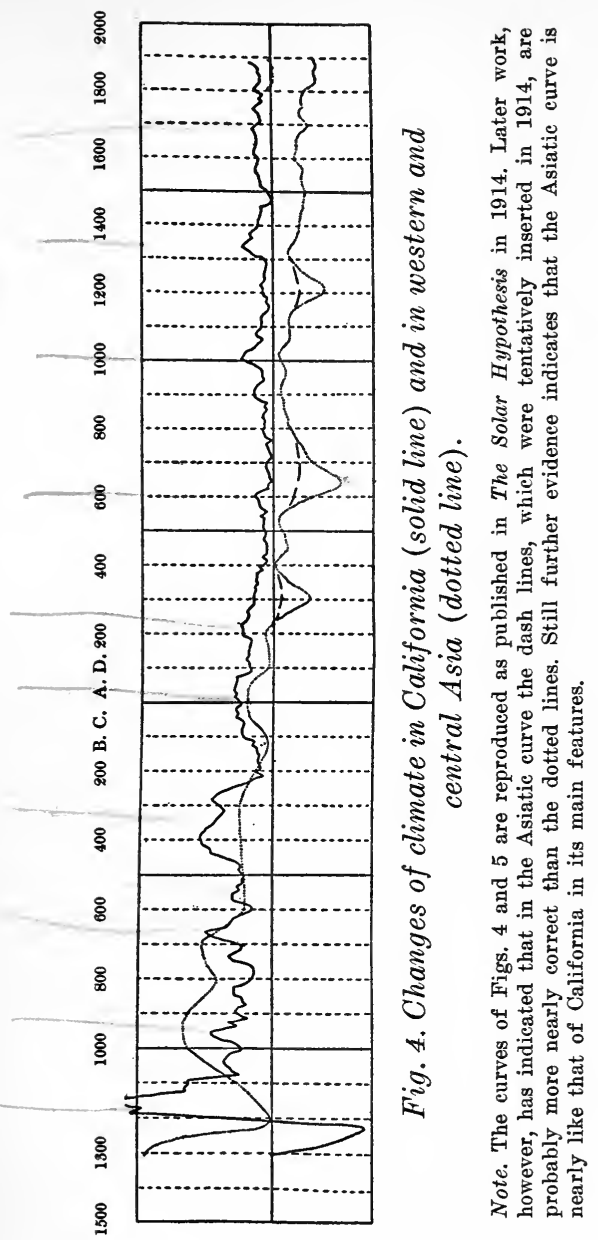
details more clearly, the more reliable part of the California curve, from $100 \mathrm{~B}$. C. to the present time, has been reproduced in Fig. 5. This is identical with the corresponding part of Fig. 4, except that the vertical scale is three times as great.

The curve of tree growth in California seems to be a true representation of the general features of climatic pulsations in the Mediterranean region. This conclusion was originally based on the resemblance between the solid line of Fig. 4, representing tree growth, and the dotted line representing changes of climate in the eastern Mediterranean region as inferred from the study of ruins and of history before any work on this subject had been done in America. ${ }^{9}$ The dotted line is here reproduced for its historical significance as a stage in the study of climatic changes. If it were to be redrawn today on the basis of the knowledge acquired in the last twelve years, it would be much more like the tree curve. For example, the period of aridity suggested by the dip of the dotted line about 300 A. D. was based largely on Professor Butler's data as to the paucity of inscriptions and ruins dating from that period in Syria. In the recent article, from which a long quotation has been given, he shows that later work proves that there is no such paucity. On the other hand, it has accentuated the marked and sudden decay in civilization and population which occurred shortly after $600 \mathrm{~A}$. D. He reached the same conclusion to which the present authors had come on wholly different grounds, namely, that the dip in the dotted line about 300 A. D. is not warranted, whereas the dip about $630 \mathrm{~A}$. D. is extremely important. In similar fashion the work of

9 The dotted line is taken from Palestine and Its Transformation, $\mathrm{pp.}$ 327 and 403. 


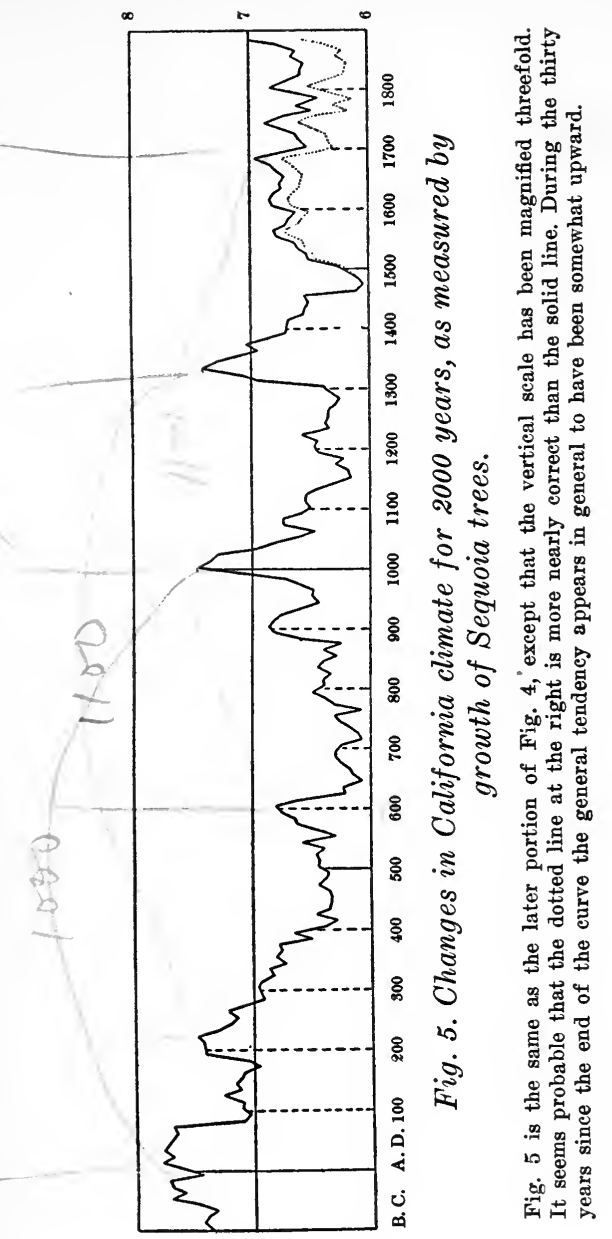


Stein $^{10}$ in central Asia makes it clear that the contrast between the water supply about 200 B. C. and in the preceding and following centuries was greater than was supposed on the basis of the scanty evidence available when the dotted line of Fig. 4 was drawn in 1910.

Since the curve of the California trees is the only continuous and detailed record yet available for the climate of the last three thousand years, it deserves most careful study. It is especially necessary to determine the degree of accuracy with which the growth of the trees represents (1) the local rainfall and (2) the rainfall of remote regions such as Palestine. Perhaps the best way to determine these matters is the standard mathematical method of correlation coefficients. If two phenomena vary in perfect unison, as in the case of the turning of the wheels and the progress of an automobile when the brakes are not applied, the correlation coefficient is 1.00 , being positive when the automobile goes forward and negative when it goes backward. If there is no relation between two phenomena, as in the case of the number of miles run by a given automobile each year and the number of chickens hatched in the same period, the coefficient is zero. A partial relationship where other factors enter into the matter is represented by a coefficient between zero and one, as in the case of the movement of the automobile and the consumption of gasoline. In this case the relation is very obvious, but is modified by other factors, including the roughness and grade of the road, the amount of traffic, the number of stops, the skill of the driver, the condition and load of the automobile, and the state of the weather. Such partial relationships are the kind for which correlation coefficients are most useful, for the size of the coefficients shows the relative im-

10 M. A. Stein: Ruins of Desert Cathay, London, 1912. 
portance of the various factors. A correlation coefficient four times the probable error, which can always be determined by a formula well known to mathematicians, is generally considered to afford evidence of some kind of relation between two phenomena. When the ratio between coefficient and error rises to six, the relationship is regarded as strong.

Few people would question that there is a connection between tree growth and rainfall, especially in a climate with a long summer dry season like that of California. But the growth of the trees also depends on their position, the amount of shading, the temperature, insect pests, blights, the wind with its tendency to break the branches, and a number of other factors. Moreover, while rain commonly favors growth, great extremes are relatively less helpful than more moderate amounts. Again, the roots of a tree may tap such deep sources of water that neither drought nor excessive rain produces much effect for several years. Hence in comparing the growth of the huge sequoias with the rainfall we should expect a correlation coefficient high enough to be convincing, but decidedly below 1.00. Unfortunately there is no record of the rainfall where the sequoias grow, the nearest long record being that of Sacramento, nearly 200 miles to the northwest and close to sea level instead of at an altitude of about 6000 feet.

Applying the method of correlation coefficients to the annual rainfall of Sacramento and the growth of the sequoias from 1863 to 1910 , we obtain the results shown in Table 3. The trees of Section A of the table grew in moderately dry locations although the soil was fairly deep, a condition which seems to be essential to sequoias. In this case, as in all the others, the rainfall is reckoned from July to June, which practically means from October 
TABLE 3

CORRELATION COEFFICIENTS BETWEEN RAINFALL AND GROWTH OF SEQUOIAS IN CALIFORNIA ${ }^{11}$

A. Sacramento Rainfall and Growth of 18 Sequoias in Dry Locations, 1861-1910

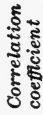

$(r)$

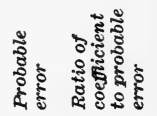

(e) $\left(\frac{r}{e}\right)$

$\pm 0.096 \quad 0.6$

$\pm 0.090 \quad 3.2$

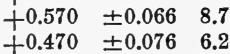

4 years of rainfall $\ldots \ldots \ldots \ldots \ldots \ldots \ldots+0.470 \pm 0.076 \quad 6.2$

B. Sacramento Rainfall and Growth of 112 Sequoias Mostly in MoIst Locations, 1861-1910

3 years of rainfall $\ldots \ldots \ldots \ldots \ldots \ldots \ldots+0.340 \pm 0.0873 .9$

4 years of rainfall $\ldots \ldots \ldots \ldots \ldots \ldots \ldots \ldots+0.371 \pm 0.084 \quad 4.5$

5 years of rainfall $\ldots \ldots \ldots \ldots \ldots \ldots \ldots \ldots+0.398 \pm 0.0824 .9$

6 years of rainfall $\ldots \ldots \ldots \ldots \ldots \ldots \ldots \ldots+0.418 \pm 0.079 \quad 5.3$

7 years of rainfall $\ldots \ldots \ldots \ldots \ldots \ldots \ldots \ldots+0.471 \pm 0.076 \quad 6.2$

8 years of rainfall $\ldots \ldots \ldots \ldots \ldots \ldots \ldots(+0.520) \pm 0.0717 .3$

9 years of rainfall $\ldots \ldots \ldots \ldots \ldots \ldots \ldots \ldots+0.575 \pm 0.0658 .8$

10 years of rainfall $\ldots \ldots \ldots \ldots \ldots \ldots \ldots+0.577 \pm 0.0658 .8$

C. Sacramento Rainfall and Growth of 80 Sequoias in Moist Locations, 1861-1910

10 years of rainfall $\ldots \ldots \ldots \ldots \ldots \ldots \ldots+0.605 \pm 0.0629 .8$

D. Annual Sequoia Growth and Rainfall of Preceding 5 Years at Stations on Southern Pacific Railroad

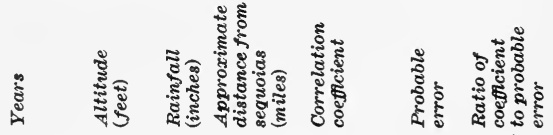

$\begin{array}{lrrrrccc} & & & & (r) & (e) & \left(\frac{r}{e}\right) \\ \text { Sacramento, } & 1861-1910 & 70 & 19.40 & 200 & +0.398 & \pm 0.081 & 4.9 \\ \text { Colfax, } & 1871-1909 & 2400 & 48.94 & 200 & +0.122 & \pm 0.113 & 1.1 \\ \text { Summit, } & 1871-1909 & 7000 & 48.07 & 200 & +0.148 & \pm 0.113 & 1.3 \\ \text { Truckee, } & 1871-1909 & 5800 & 27.12 & 200 & +0.300 & \pm 0.105 & 2.9 \\ \text { Boca, } & 1871-1909 & 5500 & 20.34 & 200 & +0.604 & \pm 0.076 & 8.0 \\ \text { Winnemucca, } & 1871-1909 & 4300 & 8.65 & 300 & +0.492 & \pm 0.089 & 5.5\end{array}$

11 In the preparation and interpretation of this table the help of $\mathrm{Mr}$. G. B. Cressey is gratefully acknowledged. 
to May, since there is almost no summer rain. Thus the tree growth in 1861 is compared with the rainfall of the preceding rainy season, $1860-1861$, or of several preceding rainy seasons as the table indicates.

In the first line of Section A a correlation coefficient of only -0.056 , which is scarcely six-tenths of the probable error, means that there is no appreciable relation between the rainfall of a given season and the growth during the following spring and summer. The roots of the sequoias probably penetrate so deeply that the rain and melted snow of the spring months do not sink down rapidly enough to influence the trees before the growing season comes to an end. The precipitation of two preceding seasons, however, has some effect on the trees, as appears in the second line of Section A, where the correlation coefficient is +0.288 , or 3.2 times the probable error. When the rainfall of three seasons is taken into account the coefficient rises to +0.570 , or 8.7 times the probable error, while with four years of rainfall the coefficient begins to fall off. Thus the growth of these eighteen sequoias on relatively dry slopes appears to have depended chiefly on the rainfall of the second and third preceding rainy seasons. The growth in 1900, for example, depended largely on the rainfall in the rainy seasons of 1897-1898 and 1898-1899.

Section B of the table shows that with 112 trees, growing chiefly in moist depressions where the water supply is at a maximum, the correlation between growth and rainfall, +0.577 for ten years' rainfall, is even higher than with the dry trees. The seepage of the underground water is so slow that not until four years' rainfall is taken into account is the correlation coefficient more than four times the probable error. When only the trees growing in moist locations are employed, the coefficient be- 
tween tree growth and the rainfall for ten years rises to the high figure of +0.605 , or 9.8 times the probable error, as appears in Section C. These figures, as well as many others not here published, make it clear that the curve of sequoia growth from 1861 to 1910 affords a fairly close indication of the rainfall at Sacramento, provided allowance be made for a delay of three to ten years due to the fact that the moisture in the soil gradually seeps down the mountain-sides and only reaches the sequoias after a considerable interval.

If a rainfall record were available for the place where the trees actually grow, the relationship would probably be still closer.

The record at Fresno, for example, bears out this conclusion so far as it goes. But as Fresno lies at a low altitude and its rainfall is of essentially the Sacramento type, its short record is of less value than that of Sacramento. The only rainfall records among the Sierras at high levels, where the rainfall and temperature are approximately like those of the sequoia region, are found along the main line of the Southern Pacific railroad. This runs from Oakland northeastward seventy miles across the open plain to Sacramento, then another seventy miles, as the crow flies, through Colfax and over a high pass in the Sierras at Summit, next twenty miles or so down through Truckee to Boca, on the edge of the inland basin of Nevada, and on northeastward another 160 miles to Winnemucca, where it turns east toward Ogden and Salt Lake City. Section D of Table 3 shows the correlation coefficients between the rainfall along the railroad and the growth of the sequoias. At Sacramento, which lies fairly open to winds from the Pacific and thus represents the general climate of central California, the coefficient is nearly five times the probable error, thus indicating a 
real relation to sequoia growth. Then among the foothills of the Sierras at Colfax, the coefficient drops till it is scarcely larger than the probable error. It rises rapidly, however, as one advances among the mountains, until at Boca it attains the high figure of +0.604 or eight times the probable error, and continues high in the dry area farther east. In other words the growth of the sequoias is a good indication of the rainfall where the trees grow and in the dry region farther east.

In order to determine the degree to which the sequoia record represents the rainfall of other regions, let us select Jerusalem for comparison. The reasons for this selection are that Jerusalem furnishes the only available record that satisfies the following necessary conditions: (1) its record is long enough to be important; (2) it is located fairly near the latitude of the sequoias, $32^{\circ} \mathrm{N}$ versus $37^{\circ} \mathrm{N}$; (3) it is located in a similar type of climate with winter rains and a long dry summer; (4) it lies well above sea level (2500 feet) and somewhat back from the seacoast, thus approximating although by no means duplicating the condition of the sequoias; and (5) it lies in a region where the evidence of climatic changes during historic times is strongest. The ideal place for comparison would be the valley in which grow the cedars of Lebanon. Those trees resemble the sequoias to an extraordinary degree, not only in their location, but in their great age. Some day it will be most interesting to compare the growth of these two famous groups of old trees.

The correlation coefficients for the sequoia growth and the rainfall at Jerusalem are given in Section A, Table 4. They are so high and so consistent that they scarcely leave room for doubt that where a hundred or more sequoias are employed, as in Fig. 5, their curve of growth affords a good indication of the fluctuations of 
TABLE 4

CORRELATION COEFFICIENTS BETWEEN RAINFALL RECORDS IN CALIFORNIA AND JERUSALEM

A. Jerusalem Rainfall for 3 Years and Various Groups of SEQUOIAS 12

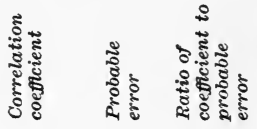

11 trees measured by Douglass ......

80 trees, moist locations, Groups IA, IIA, IIIA, VA $\ldots \ldots \ldots \ldots \ldots+0.500 \pm 0.0736 .8$

101 trees, 69 in moist locations, 32 in

dry, I, II, III $\ldots \ldots \ldots \ldots \ldots \ldots+0.616 \pm 0.06110 .1$

112 trees, 80 in moist locations, 32 in

dry, I, II, III, V $\ldots \ldots \ldots \ldots++^{0.675} \pm 0.05312 .7$

B. Rainfall at Jerusalem and at Stations in California and Nevada

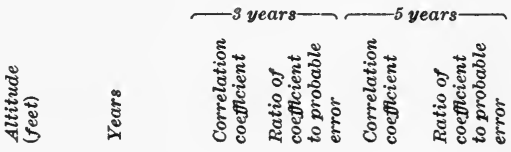

$\begin{array}{lrrcccc} & & & (r) & (\bar{e}) & (r) & (\bar{e}) \\ \text { Sacramento, } & 70 & 1861-1910 & +0.386 & 4.7 & +0.352 & 4.2 \\ \text { Colfax, } & 2400 & 1871-1909 & +0.311 & 3.1 & +0.308 & 3.0 \\ \text { Summit, } & 7000 & 1871-1909 & +0.099 & 0.9 & +0.248 & 2.3 \\ \text { Truckee, } & 5800 & 1871-1909 & +0.229 & 2.2 & +0.337 & 3.3 \\ \text { *Boca, } & 5500 & 1871-1909 & +0.482 & 6.4 & +0.617 & 8.6 \\ \text { Winnemucca, } & 4300 & 1871-1909 & +0.235 & 2.2 & +0.260 & 2.4 \\ \text { San Bernardino, } & 1050 & 1871-1909 & +0.275 & 2.7 & +0.177 & 1.8\end{array}$

C. Rainfall for 3 Years at California and Nevada Stations, 1871-1909

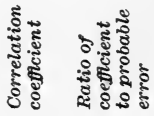

$(r)$

Sacramento and San Bernardino .......... + 0.66310 .7

San Bernardino and Winnemueca .......... +0.291 2.8

12 For the tree data used in these comparisons, see The Climatic Factor, p. 328, and A. E. Douglass: Climatic Cycles and Tree Growth, p. 123.

* One year interpolated. 
climate in western Asia. The high coefficient for the eleven trees measured by Douglass suggests that where the number of trees falls as low as ten, as in the part of Fig. 4 from 710 to 840 B. C., the relation between tree growth and rainfall is still close even when only one year's growth is considered. Where the unit is ten years of growth, as in Figs. 4 and 5, the accuracy of the tree curve as a measure of rainfall is much greater than when a single year is used as in Table 4 . When the unit is raised to thirty years, as in the smoothed part of Fig. 4 previous to 240 B. C., even four trees, as from 960 to 1070 , probably give a fair approximation to the general changes in rainfall, while a single tree prior to $1110 \mathrm{~B}$. C. gives a rough indication.

Table 4 shows a peculiar feature in the fact that the correlations of Section A between tree growth and the rainfall of Jerusalem are decidedly higher than those between the rainfall in the two regions. Only at Sacramento and Boca are the rainfall coefficients high enough to be conclusive. This, however, is not surprising, for even between Sacramento and San Bernardino, only 400 miles apart, the correlation coefficient for the rainfall by three-year periods is only 10.7 times the probable error, as appears in Section C of Table 4, while between San Bernardino and Winnemucca 500 miles away, the corresponding figure drops to 2.8. It must be remembered that in some respects the growth of the sequoias is a much better record of rainfall than are the records kept by man. The human. record is based on the amount of water caught by a little gauge a few inches in diameter. Every gust of wind detracts from the accuracy of the record; a mile away the rainfall may be double what it is at the gauge. Each sequoia, on the other hand, draws its moisture from an area thousands of times as large as 
a rain gauge. Moreover, the trees on which Figs. 4 and 5 are based were scattered over an area fifty miles long and several hundred square miles in extent. Hence they represent the summation of the rainfall over an area millions of times as large as that of a rain gauge. This fact and the large correlation coefficients between sequoia growth and Jerusalem rainfall should be considered in connection with the fact that all the coefficients between the rainfall of California and Nevada and that of Jerusalem are positive. If full records of the complete rainfall of California and Nevada on the one hand and of the eastern Mediterranean region on the other were available for a long period, they would probably agree closely.

Just how widely the sequoias can be used as a measure of the climate of the past is not yet certain. In some regions, as will shortly be explained, the climatic changes seem to have been of an opposite character from those of California. In others the Californian or eastern Mediterranean type of change seems sometimes to prevail but is not always evident. For example, at Malta the rainfall today shows a distinct relation to that of Jerusalem and to the growth of the sequoias. But the correlation coefficient between the rainfall of eight-year periods at Naples, a little farther north, and the growth of the sequoias at the end of the periods is -0.132 , or only 1.4 times the probable error and much too small to be significant. This is in harmony with the fact that although Naples has summer droughts, they are not so pronounced as in California and Palestine, and the prevalence of storms is much greater. Jerusalem receives only 8 per cent of its rain in the seven months from April to October, and Sacramento 13, while Malta receives 31 per cent and Naples 43. Nevertheless, there is some evidence that in the past the climatic fluctuations of southern Italy fol- 
lowed nearly the same course as those of California and Palestine. This apparent discrepancy seems to be explained by our previous conclusion that changes of climate are due largely to a shifting of storm tracks. When sunspots are numerous the storms which now prevail in northern Italy seem to be shifted southward and traverse the Mediterranean to Palestine just as similar storms are shifted southward in the United States. This perhaps accounts for the agreement between the sequoia curve and the agricultural and social history of Rome from about 400 B. C. to 100 A. D., as explained in World Power and Evolution. For our present purposes, however, the main point is that since rainfall records have been kept the fluctuations of climate indicated by the growth of the sequoias have agreed closely with fluctuations in the rainfall of the eastern Mediterranean region. Presumably the same was true in the past. In that case, the sequoia curve not only is a good indication of climatic changes or pulsations in regions of similar climate, but may serve as a guide to coincident but different changes in regions of other types.

An enormous body of other evidence points to the same conclusion. It indicates that while the average climate of the present is drier than that of the past in regions having the Mediterranean type of winter rains and summer droughts, there have been pronounced pulsations during historic times so that at certain times there has actually been greater aridity than at present. This conclusion is so important that it seems advisable to examine the only important arguments that have been raised against it, especially against the idea that the general rainfall of the eastern Mediterranean was greater in the historic past than at present. The first objection is the unquestionable fact that droughts and famines have 
occurred at periods which seem on other evidence to have been moister than the present. This argument has been much used, but it seems to have little force. If the rainfall of a given region averages thirty inches and varies from fifteen to forty-five, a famine will ensue if the rainfall drops for a few years to the lower limit and does not rise much above twenty for a few years. If the climate of the place changes during the course of centuries, so that the rainfall averages only twenty inches, and ranges from seven to thirty-five, famine will again ensue if the rainfall remains near ten inches for a few years. The ravages of the first famine might be as bad as those of the second. They might even be worse, because when the rainfall is larger the population is likely to be greater and the distress due to scarcity of food would affect a larger number of people. Hence historic records of famines and droughts do not indicate that the climate was either drier or moister than at present. They merely show that at the time in question the climate was drier than the normal for that particular period.

The second objection is that deserts existed in the past much as at present. This is not a real objection, however, for, as we shall see more fully, some parts of the world suffer one kind of change and others quite the opposite. Moreover, deserts have always existed, and when we talk of a change in their climate we merely mean that their boundaries have shifted. A concrete example of the mistaken use of ancient dryness as proof of climatic uniformity is illustrated by the march of Alexander from India to Mesopotamia. Hedin gives an excellent presentation of the case in the second volume of his Overland to India. He shows conclusively that Alexander's army suffered terribly from lack of water and provisions. This certainly proves that the climate was dry, but it by no 
means indicates that there has been no change from the past to the present. We do not know whether Alexander's march took place during an especially dry or an especially wet year. In a desert region like Makran, in southern Persia and Beluchistan, where the chief difficulties occurred, the rainfall varies greatly from year to year. We have no records from Makran, but the conditions there are closely similar to those of southern Arizona and New Mexico. In 1885 and 1905 the rainfall for five stations in that region was as follows:

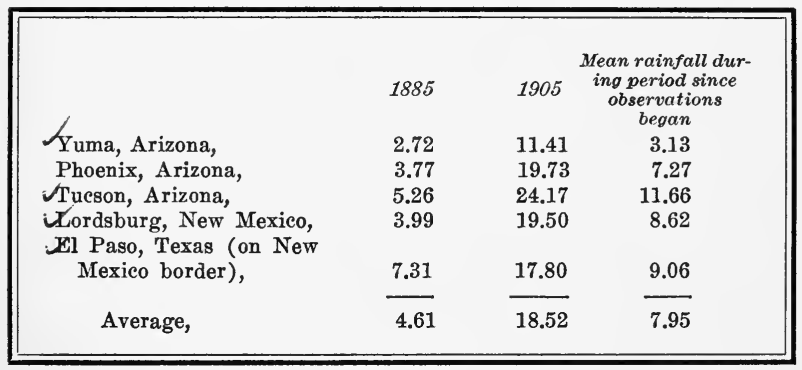

These stations are distributed over an area nearly 500 miles east and west. Manifestly a traveler who spent the year 1885 in that region would have had much more difficulty in finding water and forage than one who traveled in the same places in 1905 . During 1885 the rainfall was 42 per cent less than the average, and during 1905 it was 134 per cent more than the average. Let us suppose, for the sake of argument, that the average rainfall of southeastern Persia is six inches today and was ten inches in the days of Alexander. If the rainfall from year to year varied as much in the past in Persia as it does now in New Mexico and Arizona, the rainfall during an ancient 
dry year, corresponding in character to 1885 , would have been about 5.75 inches. On the other hand, if we suppose that the rainfall then averaged less than at present,-let us say four inches,-a wet year corresponding to 1905 in the American deserts might have had a rainfall of about ten inches. This being the case, it is clear that our estimate of what Alexander's march shows as to climate must depend largely on whether $325 \mathrm{~B}$. C. was a wet year or a dry year. Inasmuch as we know nothing about this, we must fall back on the fact that a large army accomplished a journey in a place where today even a small caravan usually finds great difficulty in procuring forage and water. Moreover, elephants were taken 180 miles across what is now an almost waterless desert, and yet the old historians make no comment on such a feat which today would be practically impossible. These things seem more in harmony with a change of climate than with uniformity. Nevertheless, it is not safe to place much reliance on them except when they are taken in conjunction with other evidence, such as the numerous ruins, which show that Makran was once far more densely populated than now seems possible. Taken by itself, such incidents as Alexander's march cannot safely be used either as an argument for or against changes of climate.

The third and strongest objection to any hypothesis of climatic changes during historic times is based on vegetation. The whole question is admirably set forth by J. W. Gregory, ${ }^{13}$ who gives not only his own results, but. those of the ablest scholars who have preceded him. His conclusions are important because they represent one of the few cases where a definite statistical attempt has been made to prove the exact condition of the climate of the

13 J. W. Gregory: Is the Earth Drying Up? Geog. Jour., Vol. 43, 1914, pp. 148-172 and 293-318. 
past. After stating various less important reasons for believing that the climate of Palestine has not changed, he discusses vegetation. The following quotation indicates his line of thought. A sentence near the beginning is italicized in order to call attention to the importance which Gregory and others lay on this particular kind of evidence :

Some more certain test is necessary than the general conclusions which can be based upon the historical and geographical evidence of the Bible. In the absence of rain gauge and thermometric records, the most precise test of climate is given by the vegetation; and fortunately the palm affords a very delicate test of the past climate of Palestine and the eastern Mediterranean. . . . The date palm has three limits of growth which are determined by temperature; thus it does not reach full maturity or produce ripe fruit of good quality below the mean annual temperature of $69^{\circ} \mathrm{F}$. The isothermal of $69^{\circ}$ crosses southern Algeria near Biskra; it touches the northern coasts of Cyrenaica near Derna and passes Egypt near the mouth of the Nile, and then bends northward along the coast lands of Palestine.

To the north of this line the date palm grows and produces fruit, which only ripens occasionally, and its quality deteriorates as the temperature falls below $69^{\circ}$. Between the isotherms of $68^{\circ}$ and $64^{\circ}$, limits which include northern Algeria, most of Sicily, Malta, the southern parts of Greece and northern Syria, the dates produced are so unripe that they are not edible. In the next cooler zone, north of the isotherm of $62^{\circ}$, which enters Europe in southwestern Portugal, passes through Sardinia, enters Italy near Naples, crosses northern Greece and Asia Minor to the east of Smyrna, the date palm is grown only for its foliage, since it does not fruit.

Hence at Benghazi, on the north African coast, the date palm is fertile, but produces fruit of poor quality. In Sicily and at Algiers the fruit ripens occasionally and at Rome and Nice the palm is grown only as an ornamental tree. 
The date palm therefore affords a test of variations in mean annual temperature of three grades between $62^{\circ}$ and $69^{\circ}$.

This test shows that the mean annual temperature of Palestine has not altered since Old Testament times. The palm tree now grows dates on the coast of Palestine and in the deep depression around the Dead Sea, but it does not produce fruit on the highlands of Judea. Its distribution in ancient times, as far as we can judge from the Bible, was exactly the same. It grew at "Jericho, the city of palm trees" (Deut. xxxiv : 3 and 2 Chron. xxviii : 15), and at Engedi, on the western shore of the Dead Sea (2 Chron. xx:2; Sirach xxiv:14); and though the palm does not still live at Jericho-the last apparently died in 1838its disappearance must be due to neglect, for the only climatic change that would explain it would be an increase in cold or moisture. In olden times the date palm certainly grew on the highlands of Palestine; but apparently it never produced fruit there, for the Bible references to the palm are to its beauty and erect growth: "The righteous shall flourish like the palm" (Ps. xcii: 12); "They are upright as the palm tree" (Jer. $\mathrm{x}: 5$ ); "Thy stature is like to a palm tree" (Cant. vii : 7). It is used as a symbol of victory (Rev. vii : 9), but never praised as a source of food.

Dates are not once referred to in the text of the Bible, but according to the marginal notes the word translated "honey" in 2 Chron. xxxi : 5 may mean dates. . . .

It appears, therefore, that the date palm had essentially the same distribution in Palestine in Old Testament times as it has now; and hence we may infer that the mean temperature was then the same as now. If the climate had been moister and cooler, the date could not have flourished at Jericho. If it had been warmer, the palms would have grown freely at higher levels and Jericho would not have held its distinction as the city of palm trees. ${ }^{14}$

In the main Gregory's conclusions seem to be well grounded, although even according to his data a change 14 Geog. Jour., Vol. 43, pp. 159-161. 
of $2^{\circ}$ or $3^{\circ}$ in mean temperature would be perfectly feasible. It will be noticed, however, that they apply to temperature and not to rainfall. They merely prove that two thousand years ago the mean temperature of Palestine and the neighboring regions was not appreciably different from what it is today. This, however, is in no sense out of harmony with the hypothesis of climatic pulsations. Students of glaciation believe that during the last glacial epoch the mean temperature of the earth as a whole was only $5^{\circ}$ or $6^{\circ} \mathrm{C}$. lower than at present. If the difference between the climate of today and of the time of Christ is a tenth as great as the difference between the climate of today and that which prevailed at the culmination of the last glacial epoch, the change in two thousand years has been of large dimensions. Yet this would require a rise of only half a degree Centigrade in the mean temperature of Palestine. Manifestly, so slight a change would scarcely be detectable in the vegetation.

The slightness of changes in mean temperature as compared with changes in rainfall may be judged from a comparison of wet and dry years in various regions. For example, at Berlin between 1866 and 1905 the ten most rainy years had an average precipitation of $670 \mathrm{~mm}$. and a mean temperature of $9.15^{\circ} \mathrm{C}$. On the other hand, the ten years of least rainfall had an average of $483 \mathrm{~mm}$. and a mean temperature of $9.35^{\circ}$. In other words, a difference of $137 \mathrm{~mm}$., or 39 per cent, in rainfall was accompanied by a difference of only $0.2^{\circ} \mathrm{C}$. in temperature. Such contrasts between the variability of mean rainfall and mean temperature are observable not only when individual years are selected, but when much longer periods are taken. For instance, in the western Gulf region of the United States the two inland stations of Vicksburg, Mississippi, and Shreveport, Louisiana, and the two mari- 
time stations of New Orleans, Louisiana, and Galveston, Texas, lie at the margins of an area about 400 miles long. During the ten years from 1875 to 1884 their rainfall averaged 59.4 inches, ${ }^{15}$ while during the ten years from 1890 to 1899 it averaged only 42.4 inches. Even in a region so well watered as the Gulf States, such a change -40 per cent more in the first decade than in the second -is important, and in drier regions it would have a great effect on habitability. Yet in spite of the magnitude of the change the mean temperature was not appreciably different, the average for the four stations being $67.36^{\circ} \mathrm{F}$. during the more rainy decade and $66.94^{\circ} \mathrm{F}$. during the less rainy decade-a difference of only $0.42^{\circ} \mathrm{F}$. It is worth noticing that in this case the wetter period was also the warmer, whereas in Berlin it was the cooler. This is probably because a large part of the moisture of the Gulf States is brought by winds having a southerly component. Similar relationships are apparent in other places. We select Jerusalem because we have been discussing Palestine. At the time of writing, the data available in the Quarterly Journal of the Palestine Exploration Fund cover the years from 1882-1899 and 1903-1909. Among these twenty-five years the thirteen which had most rain had an average of 34.1 inches and a temperature of $62.04^{\circ} \mathrm{F}$. The twelve with least rain had 24.4 inches and a temperature of $62.44^{\circ}$. A difference of 40 per cent in rainfall was accompanied by a difference of only $0.4^{\circ} \mathrm{F}$. in temperature.

The facts set forth in the preceding paragraphs seem to show that extensive changes in precipitation and storminess can take place without appreciable changes of mean temperature. If such changed conditions can per-

15 See A. J. Henry: Secular Variation of Precipitation in the United States; Bull. Am. Geog. Soc., Vol. 46, 1914, pp. 192-201. 
sist for ten years, as in one of our examples, there is no logical reason why they cannot persist for a hundred or a thousand. The evidence of changes in climate during the historic period seems to suggest changes in precipitation much more than in temperature. Hence the strongest of all the arguments against historic changes of climate seems to be of relatively little weight, and the pulsatory hypothesis seems to be in accord with all the known facts.

Before the true nature of climatic changes, whether historic or geologic, can be rightly understood, another point needs emphasis. When the pulsatory hypothesis was first framed, it fell into the same error as the hypotheses of uniformity and of progressive change-that is, the assumption was made that the whole world is either growing drier or moister with each pulsation. A study of the ruins of Yucatan, in 1912, and of Guatemala, in 1913, as is explained in The Climatic Factor, has led to the conclusion that the climate of those regions has changed in the opposite way from the changes which appear to have taken place in the desert regions farther south. These Maya ruins in Central America are in many cases located in regions of such heavy rainfall, such dense forests, and such malignant fevers that habitation is now practically impossible. The land cannot be cultivated except in especially favorable places. The people are terribly weakened by disease and are among the lowest in Central America. Only a hundred miles from the unhealthful forests we find healthful areas, such as the coasts of Yucatan and the plateau of Guatemala. Here the vast majority of the population is gathered, the large towns are located, and the only progressive people are found. Nevertheless, in the past the region of the forests was the home of by far the most progressive people who are ever known to have lived in America previous to the 
days of Columbus. They alone brought to high perfection the art of sculpture; they were the only American people who invented the art of writing. It seems scarcely credible that such a people would have lived in the worst possible habitat when far more favored regions were close at hand. Therefore it seems as if the climate of eastern Guatemala and Yucatan must have been relatively dry at some past time. The Maya chronology and traditions indicate that this was probably at the same time when moister conditions apparently prevailed in the subarid or desert portions of the United States and Asia. Fig. 3 shows that today at times of many sunspots there is a similar opposition between a tendency toward storminess and rain in subtropical regions and toward aridity in low latitudes near the heat equator.

Thus our final conclusion is that during historic times there have been pulsatory changes of climate. These changes have been of the same type in regions having similar kinds of climate, but of different and sometimes opposite types in places having diverse climates. As to the cause of the pulsations, they cannot have been due to the precession of the equinoxes nor apparently to any allied astronomical cause, for the time intervals are too short and too irregular. They cannot have been due to changes in the percentage of carbon dioxide in the atmosphere, for not even the strongest believers in the climatic efficacy of that gas hold that its amount could fluctuate in any such violent way as would be necessary to explain the pulsations shown in the California curve of tree growth. Volcanic activity seems more probable as at least a partial cause, and it would be worth while to investigate the matter more fully. Nevertheless, it can apparently be only a minor cause. In the first place, the main effect of a cloud of dust is to alter the temperature, but 
Gregory's summary of the palm and the vine shows that variations in temperature are apparently of very slight importance during historic times. Again, ruins on the bottoms of enclosed salt lakes, old beaches now under the water, and signs of irrigation ditches where none are now needed indicate a climate drier than the present. Volcanic dust, however, cannot account for such a condition, for at present the air seems to be practically free from such dust for long periods. Thus we now experience the greatest extreme which the volcanic hypothesis permits in one direction, but there have been greater extremes in the same direction. The thermal solar hypothesis is likewise unable to explain the observed phenomena, for neither it nor the volcanic hypothesis offers any explanation of why the climate varies in one way in Mediterranean climates and in an opposite way in regions near the heat equator.

This leaves the cyclonic hypothesis. It seems to fit the facts, for variations in cyclonic storms cause some regions to be moister and others drier than usual. At the same time the variations in temperature are slight, and are apparently different in different regions, some places growing warm when others grow cool. In the next chapter we shall study this matter more fully, for it can best be appreciated by examining the course of events in a specific century. 


\section{CHAPTER VI}

\section{THE CLIMATIC STRESS OF THE FOURTEENTH CENTURY}

$\mathrm{I}$

$\mathrm{N}$ order to give concreteness to our picture of the climatic pulsations of historic times let us take a specific period and see how its changes of climate were distributed over the globe and how they are related to the little changes which now take place in the sunspot cycle. We will take the fourteenth century of the Christian era, especially the first half. This period is chosen because it is the last and hence the best known of the times when the climate of the earth seems to have taken a considerable swing toward the conditions which now prevail when the sun is most active, and which, if intensified, would apparently lead to glaciation. It has already been discussed in World Power and Evolution, but its importance and the fact that new evidence is constantly coming to light warrant a fuller discussion.

To begin with Europe; according to the careful account of Pettersson ${ }^{1}$ the fourteenth century shows

a record of extreme climatic variations. In the cold winters the rivers Rhine, Danube, Thames, and Po were frozen for weeks and months. On these cold winters there followed violent floods, so that the rivers mentioned inundated their valleys. Such floods are recorded in 55 summers in the 14th century. There is, of

10 . Pettersson: The connection between hydrographical and meteorologieal phenomena; Quarterly Journal of the Royal Meteorological Society, Vol. 38 , pp. 174-175. 
course, nothing astonishing in the fact that the inundations of the great rivers of Europe were more devastating 600 to 700 years ago than in our days, when the flow of the rivers has been regulated by canals, locks, etc.; but still the inundations in the 13th and 14th centuries must have surpassed everything of that kind which has occurred since then. In 1342 the waters of the Rhine rose so high that they inundated the city of Mayence and the Cathedral "usque ad cingulum hominis." The walls of Cologne were flooded so that they could be passed by boats in July. This occurred also in $\mathbf{1 3 7 4}$ in the midst of the month of February, which is of course an unusual season for disasters of the kind. Again in other years the drought was so intense that the same rivers, the Danube, Rhine, and others, nearly dried up, and the Rhine could be forded at Cologne. This happened at least twice in the same century. There is one exceptional summer of such evil record that centuries afterwards it was spoken of as "the old hot summer of 1357."

Pettersson goes on to speak of two oceanic phenomena on which the old chronicles lay greater stress than on all others :

The first [is] the great storm-floods on the coast of the North Sea and the Baltic, which occurred so frequently that not less than nineteen floods of a destructiveness unparalleled in later times are recorded from the 14th century. The coastline of the North Sea was completely altered by these floods. Thus on January 16, 1300, half of the island Heligoland and many other islands were engulfed by the sea. The same fate overtook the island of Borkum, torn into several islands by the storm-flood of January 16, which remoulded the Frisian Islands into their present shape, when also Wendingstadt, on the island of Sylt, and Thiryu parishes were engulfed. This flood is known under the name of "the great man-drowning." The coasts of the Baltic also were exposed to storm-floods of unparalleled violence. On November 1, 1304, the island of Ruden was torn asunder from Rugen by the force of the waves. Time does not allow me to dwell upon individual disasters of this kind, but it will be well 
to note that of the nineteen great floods on record eighteen occurred in the cold season between the autumnal and vernal equinoxes.

The second remarkable phenomenon mentioned by the chronicles is the freezing of the entire Baltic, which occurred many times during the cold winters of these centuries. On such occasions it was possible to travel with carriages over the ice from Sweden to Bornholm and from Denmark to the German coast (Lubeck), and in some cases even from Gotland to the coast of Estland.

Norlind ${ }^{2}$ says that "the only authentic accounts" of the complete freezing of the Baltic in the neighborhood of the Kattegat are in the years 1296, 1306, 1323, and 1408. Of these 1296 is "much the most uncertain," while 1323 was the coldest year ever recorded, as appears from the fact that horses and sleighs crossed regularly from Sweden to Germany on the ice.

Not only central Europe and the shores of the North Sea were marked by climatic stress during the fourteenth century, but Scandinavia also suffered. As Pettersson puts it:

On examining the historic (data) from the last centuries of the Middle Ages, Dr. Bull of Christiania has come to the conclusion that the decay of the Norwegian kingdom was not so much a consequence of the political conditions at that time, as of the frequent failures of the harvest so that corn [wheat] for bread had to be imported from Lübeck, Rostock, Wismar and so forth. The Hansa Union undertook the importation and obtained political power by its economic influence. The Norwegian land-owners were forced to lower their rents. The population decreased and became impoverished. The revenue sank 60 to 70 per cent. Even the income from Church property decreased.

2 A. Norlind: Einige Bemerkungen über das Klima der historischen Zeit nebst einem Verzeichnis mittelaltlicher Witterungs erscheinungen; Lunds Univ. Arsskrift, N. F., Vol. 10, 1914, 53 pp. 
In 1367 corn was imported from Lübeck to a value of onehalf million kroner. The trade balance inclined to the disadvantage of Norway whose sole article of export at that time was dried fish. (The production of fish increased enormously in the Baltic regions off south Sweden because of the same changes which were influencing the lands, but this did not benefit Norway.) Dr. Bull draws a comparison with the conditions described in the Sagas when Nordland [at the Arctic Circle] produced enough corn to feed the inhabitants of the country. At the time of Asbjörn Selsbane the chieftains in Trondhenäs [still farther north in latitude $69^{\circ}$ ] grew so much corn that they did not need to go southward to buy corn unless three successive years of dearth had occurred. The province of Trondheim exported wheat to Iceland and so forth. Probably the turbulent political state of Scandinavia at the end of the Middle Ages was in a great measure due to unfavorable climatic conditions, which lowered the standard of life, and not entirely to misgovernment and political strife as has hitherto been taken for granted.

During this same unfortunate first half of the fourteenth century England also suffered from conditions which, if sufficiently intensified, might be those of a glacial period. According to Thorwald Rogers ${ }^{3}$ the severest famine ever experienced in England was that of 13151316, and the next worst was in 1321. In fact, from 1308 to 1322 great scarcity of food prevailed most of the time. Other famines of less severity occurred in 1351 and 1369. "The same cause was at work in all these cases," says Rogers, "incessant rain, and cold, stormy summers. It is said that the inclemency of the seasons affected the cattle, and that numbers perished from disease and want." After the bad harvest of 1315 the price of wheat, which was already high, rose rapidly, and in May, 1316, was about five times the average. For a year or more thereafter it remained at three or four times the ordinary

3 Thorwald Rogers: A History of Agriculture and Prices in England. 
level. The severity of the famine may be judged from the fact that previous to the Great War the most notable scarcity of wheat in modern England and the highest relative price was in December, 1800. At that time wheat cost nearly three times the usual amount, instead of five as in 1316. During the famine of the early fourteenth century "it is said that people were reduced to subsist upon roots, upon horses and dogs, and stories are told of even more terrible acts by reason of the extreme famine." The number of deaths was so great that the price of labor suffered a permanent rise of at least 10 per cent. There simply were not people enough left among the peasants to do the work demanded by the more prosperous class who had not suffered so much.

After the famine came drought. The year 1325 appears to have been peculiarly dry, and 1331, 1344, 1362, 1374, and 1377 were also dry. In general these conditions do little harm in England. They are of interest chiefly as showing how excessive rain and drought are apt to succeed one another.

These facts regarding northern and central Europe during the fourteenth century are particularly significant when compared with the conclusions which we have drawn in Earth and Sun from the growth of trees in Germany and from the distribution of storms. A careful study of all the facts shows that we are dealing with two distinct types of phenomena. In the first place, the climate of central Europe seems to have been peculiarly continental during the fourteenth century. The winters were so cold that the rivers froze, and the summers were so wet that there were floods every other year or oftener. This seems to be merely an intensification of the conditions which prevail at the present time during periods of many sunspots, as indicated by the growth of trees at 
Eberswalde in Germany and by the number of storms in winter as compared with summer. The prevalence of droughts, especially in the spring, is also not inconsistent with the existence of floods at other seasons, for one of the chief characteristics of a continental climate is that the variations from one season to another are more marked than in oceanic climates. Even the summer droughts are typically continental, for when continental conditions prevail, the difference between the same season in different years is extreme, as is well illustrated in Kansas. It must always be remembered that what causes famine is not so much absolute dryness as a temporary diminution of the rainfall.

The second type of phenomena is peculiarly oceanic in character. It consists of two parts, both of which are precisely what would be expected if a highly continental climate prevailed over the land. In the first place, at certain times the cold area of high pressure, which is the predominating characteristic of a continent during the winter, apparently spread out over the neighboring oceans. Under such conditions an inland sea, such as the Baltic, would be frozen, so that horses could cross the ice even in the Far West. In the second place, because of the unusually high pressure over the continent, the barometric gradients apparently became intensified. Hence at the margin of the continental high-pressure area the winds were unusually strong and the storms of corresponding severity. Some of these storms may have passed entirely along oceanic tracks, while others invaded the borders of the land, and gave rise to the floods and to the wearing away of the coast described by Pettersson.

Turning now to the east of Europe, Brückner's ${ }^{4}$ study

4 E. Brückner: Klimaschwankungen seit 1700, Vienna, 1891. 
of the Caspian Sea shows that that region as well as western Europe was subject to great climatic vicissitudes in the first half of the fourteenth century. In 1306-1307 the Caspian Sea, after rising rapidly for several years, stood thirty-seven feet above the present level and it probably rose still higher during the succeeding decades. At least it remained at a high level, for Hamdulla, the Persian, tells us that in 1325 a place called Aboskun was under water. ${ }^{5}$

Still further east the inland lake of Lop Nor also rose at about this time. According to a Chinese account the Dragon Town on the shore of Lop Nor was destroyed by a flood. From Himley's translation it appears that the level of the lake rose so as to overwhelm the city completely. This would necessitate the expansion of the lake to a point eighty miles east of Lulan, and fully fifty from the present eastern end of the Kara Koshun marsh. The water would have to rise nearly, or quite, to a strand which is now clearly visible at a height of twelve feet above the modern lake or marsh.

In India the fourteenth century was characterized by what appears to have been the most disastrous drought in all history. Apparently the decrease in rainfall here was as striking as the increase in other parts of the world. No statistics are available but we are told that in the great famine which began in 1344 even the Mogul emperor was unable to obtain the necessaries of life for his household. No rain worth mentioning fell for years. In some places the famine lasted three or four years, and in some twelve, and entire cities were left without an inhabitant. In a later famine, 1769-1770, which occurred in Bengal shortly after the foundation of British rule in

5 For a full discussion of the changes in the Caspian Sea see The Pulse of Asia, pp. 329-358. 
India, but while the native officials were still in power, a third of the population, or ten out of thirty millions, perished. The famine in the first half of the fourteenth century seems to have been far worse. These Indian famines were apparently due to weak summer monsoons caused presumably by the failure of central Asia to warm up as much as usual. The heavier snowfall, and the greater cloudiness of the summer there, which probably accompanied increased storminess, may have been the reason.

The New World as well as the Old appears to have been in a state of climatic stress during the first half of the fourteenth century. According to Pettersson, Greenland furnishes an example of this. At first the inhabitants of that northland were fairly prosperous and were able to approach from Iceland without much hindrance from the ice. Today the North Atlantic Ocean northeast of Iceland is full of drift ice much of the time. The border of the ice varies from season to season, but in general it extends westward from Iceland not far from the Arctic circle and then follows the coast of Greenland southward to Cape Farewell at the southern tip and around to the western side for fifty miles or more. Except under exceptional circumstances a ship cannot approach the coast until well northward on the comparatively ice-free west coast. In the old Sagas, however, nothing is said of ice in this region. The route from Iceland to Greenland is carefully described. In the earliest times it went from Iceland a trifle north of west so as to approach the coast of Greenland after as short an ocean passage as possible. Then it went down the coast in a region where approach is now practically impossible because of the ice. At that time this coast was icy close to the shore, but there is no sign that navigation was rendered difficult as is now the 
case. Today no navigator would think of keeping close inland. The old route also went north of the island on which Cape Farewell is located, although the narrow channel between the island and the mainland is now so blocked with ice that no modern vessel has ever penetrated it. By the thirteenth century, however, there appears to have been a change. In the Kungaspegel or Kings' Mirror, written at that time, navigators are warned not to make the east coast too soon on account of ice, but no new route is recommended in the neighborhood of Cape Farewell or elsewhere. Finally, however, at the end of the fourteenth century, nearly 150 years after the Kungaspegel, the old sailing route was abandoned, and ships from Iceland sailed directly southwest to avoid the ice. As Pettersson says:

. . At the end of the thirteenth and the beginning of the fourteenth century the European civilization in Greenland was wiped out by an invasion of the aboriginal population. The colonists in the Vesterbygd were driven from their homes and probably migrated to America leaving behind their cattle in the fields. So they were found by Ivar Bardsson, steward to the Bishop of Gardar, in his official journey thither in 1342.

The Eskimo invasion must not be regarded as a common raid. It was the transmigration of a people, and like other big movements of this kind [was] impelled by altered conditions of nature, in this case the alterations of climate caused by [or which caused?] the advance of the ice. For their hunting and fishing the Eskimos require an at least partially open arctic sea. The seal, their principal prey, cannot live where the surface of the sea is entirely frozen over. The cause of the favorable conditions in the Viking-age was, according to my hypothesis, that the ice then melted at a higher latitude in the arctic seas.

The Eskimos then lived further north in Greenland and North America. When the climate deteriorated and the sea which gave them their living was closed by ice the Eskimos had to find 
a more suitable neighborhood. This they found in the land colonized by the Norsemen whom they attacked and finally annihilated.

Finally, far to the south in Yucatan the ancient Maya civilization made its last flickering effort at about this time. Not much is known of this but in earlier periods the history of the Mayas seems to have agreed quite closely with the fluctuations in climate. ${ }^{6}$ Among the Mayas, as we have seen, relatively dry periods were the times of greatest progress.

Let us turn now to Fig. 3 once more and compare the climatic conditions of the fourteenth century with those of periods of increasing rainfall. Southern England, Ireland, and Scandinavia, where the crops were ruined by extensive rain and storms in summer, are places where storminess and rainfall now increase when sunspots are numerous. Central Europe and the coasts of the North Sea, where flood and drought alternated, are regions which now have relatively less rain when sunspots increase than when they diminish. However, as appears from the trees measured by Douglass, the winters become more continental and hence cooler, thus corresponding to the cold winters of the fourteenth century when people walked on the ice from Scandinavia to Denmark. When such high pressure prevails in the winter, the total rainfall is diminished, but nevertheless the storms are more severe than usual, especially in the spring. In southeastern Europe, the part of the area whence the Caspian derives its water, appears to have less rainfall during times of increasing sunspots than when sunspots are few, but in an equally large area to the south, where the moun-

6 S. Q. Morley: The Inscriptions at Copán; Carnegie Inst. of Wash., No. $219,1920$.

Ellsworth Huntington: The Red Man's Continent, 1919. 
tains are higher and the run-off of the rain is more rapid, the reverse is the case. This seems to mean that a slight diminution in the water poured in by the Volga would be more than compensated by the water derived from Persia and from the Oxus and Jaxartes rivers, which in the fourteenth century appear to have filled the Sea of Aral and overflowed in a large stream to the Caspian. Still farther east in central Asia, so far as the records go, most of the country receives more rain when sunspots are many than when they are few, which would agree with what happened when the Dragon Town was inundated. In India, on the contrary, there is a large area where the rainfall diminishes at times of many sunspots, thus agreeing with the terrible famine from which the Moguls suffered so severely. In the western hemisphere, Greenland, Arizona, and California are all parts of the area where the rain increases with many sunspots, while Yucatan seems to lie in an area of the opposite type. Thus all the evidence seems to show that at times of climatic stress, such as the fourteenth century, the conditions are essentially the same as those which now prevail at times of increasing sunspots.

As to the number of sunspots, there is little evidence previous to about 1750 . Yet that little is both interesting and important. Although sunspots have been observed with care in Europe only a little more than three centuries, the Chinese have records which go back nearly to the beginning of the Christian era. Of course the records are far from perfect, for the work was done by individuals and not by any great organization which continued the same methods from generation to generation. The mere fact that a good observer happened to use his smoked glass to advantage may cause a particular period to appear to have an unusual number of spots. On the 
other hand, the fact that such an observer finds spots at some times and not at others tends to give a valuable check on his results, as does the comparison of one observer's work with that of another. Hence, in spite of many and obvious defects, most students of the problem agree that the Chinese record possesses much value, and that for a thousand years or more it gives a fairly true idea of the general aspect of the sun. In the Chinese records the years with many spots fall in groups, as would be expected, and are sometimes separated by long intervals. Certain centuries appear to have been marked by unusual spottedness. The most conspieuous of these is the fourteenth, when the years,1370 to 1385 were particularly noteworthy, for spots large enough to be visible to the naked eye covered the sun much of the time. Hence Wolf, ${ }^{7}$ who has made an exhaustive study of the matter, concludes that there was an absolute maximum of spots about 1372 . While this date is avowedly open to question, the great abundance of sunspots at that time makes it probable that it cannot be far wrong. If this is so, it seems that the great climatic disturbances of which we have seen evidence in the fourteenth century occurred at a time when sunspots were increasing, or at least when solar activity was under some profoundly disturbing influence. Thus the evidence seems to show not merely that the climate of historic times has been subject to important pulsations, but that those pulsations were magnifications of the little climatic changes which now take place in sunspot cycles. The past and the present are apparently a unit except as to the intensity of the changes.

7 See summary of Wolf's work with additional information by H. Fritz; Zürich Vierteljahrschrift, Vol. 38, 1893, pp. 77-107. 


\section{GLACIATION ACCORDING TO THE SOLAR- CYCLONIC HYPOTHESIS ${ }^{1}$}

DE remarkable phenomena of glacial periods afford perhaps the best available test to which any climatic hypothesis can be subjected. In this chapter and the two that follow, we shall apply this test. Since much more is known about the recent Great Ice Age, or Pleistocene glaciation, than about the more ancient glaciations, the problems of the Pleistocene will receive especial attention. In the present chapter the oncoming of glaciation and the subsequent disappearance of the ice will be outlined in the light of what would be expected according to the solar-cyclonic hypothesis. Then in the next chapter several problems of especial climatic significance will be considered, such as the localization of ice sheets, the succession of severe glacial and mild inter-glacial epochs, the sudden commencement of glaciation and the peculiar variations in the height of the snow line. Other topics to be considered are the occurrence of pluvial or rainy climates in non-glaciated regions, and glaciation near sea level in subtropical latitudes during the Permian and Proterozoic. Then in Chapter IX we shall consider the development and distribution of the remarkable deposits of wind-blown material known as loess.

Facts not considered at the time of framing an hypothe-

1 This chapter is an amplification and revision of the sketch of the glacial period contained in The Solar Hypothesis of Climatic Changes; Bull. Geol. Soc. Am., Vol. 25, 1914. 
sis are especially significant in testing it. In this particular case, the cyclonic hypothesis was framed to explain the historic changes of climate revealed by a study of ruins, tree rings, and the terraces of streams and lakes, without special thought of glaciation or other geologic changes. Indeed, the hypothesis had reached nearly its present form before much attention was given to geological phases of the problem. Nevertheless, it appears to meet even this severe test.

According to the solar-cyclonic hypothesis, the Pleistocene glacial period was inaugurated at a time when certain terrestrial conditions tended to make the earth especially favorable for glaciation. How these conditions arose will be considered later. Here it is enough to state what they were. Chief among them was the fact that the continents stood unusually high and were unusually large. This, however, was not the primary cause of glaciation, for many of the areas which were soon to be glaciated were little above sea level. For example, it seems clear that New England stood less than a thousand feet higher than now. Indeed, Salisbury ${ }^{2}$ estimates that eastern North America in general stood not more than a few hundred feet higher than now, and W. B. Wright ${ }^{3}$ reaches the same conclusion in respect to the British Isles. Nevertheless, 'widespread lands, even if they are not all high, lead to climatic conditions which favor glaciation.. For example, enlarged continents cause low temperature in high latitudes because they interfere with the ocean currents that carry heat polewards. Such continents also cause relatively cold winters, for lands cool much sooner than does the ocean. Another result is a

2 R. D. Salisbury: Physical Geography of the Pleistocene, in Outlines of Geologic History, by Willis, Salisbury, and others, 1910, p. 265.

3 The Quaternary Ice Age, 1914, p. 364. 
diminution of water vapor, not only because cold air cannot hold much vapor, but also because the oceanic area from which evaporation takes place is reduced by the emergence of the continents. Again, when the continents are extensive the amount of carbonic acid gas in the atmosphere probably decreases, for the augmented erosion due to uplift exposes much igneous rock to the air, and weathering consumes the atmospheric carbon dioxide. When the supply of water vapor and of atmospheric carbon dioxide is small, an extreme type of climate usually prevails. The combined result of all these conditions is that continental emergence causes the climate to be somewhat cool and to be marked by relatively great contrasts from season to season and from latitude to latitude.

When the terrestrial conditions thus permitted glaciation, unusual solar activity is supposed to have greatly increased the number and severity of storms and to have altered their location, just as now happens at times of many sunspots. If such a change in storminess had occurred when terrestrial conditions were unfavorable for glaciation, as, for example, when the lands were low and there were widespread epicontinental seas in middle and high latitudes, glaciation might not have resulted. In the Pleistocene, however, terrestrial conditions permitted glaciation, and therefore the supposed increase in storminess caused great ice sheets.

The conditions which prevail at times of increased storminess have been discussed in detail in Earth and Sun. Those which apparently brought on glaciation seem to have acted as follows: In the first place the storminess lowered the temperature of the earth's surface in several ways. The most important of these was the rapid upward convection in the centers of cyclonic storms whereby 
abundant heat was carried to high levels where most of it was radiated away into space. The marked increase in the number of tropical cyclones which accompanies increased solar activity was probably important in this respect. Such cyclones carry vast quantities of heat and moisture out of the tropics. The moisture, to be sure, liberates heat upon condensing, but as condensation occurs above the earth's surface, much of the heat escapes into space. Another reason for low temperature was that under the influence of the supposedly numerous storms of Pleistocene times evaporation over the oceans must have increased. This is largely because the velocity of the winds is relatively great when storms are strong and such winds are powerful agents of evaporation. But evaporation requires heat, and hence the strong winds lower the temperature. ${ }^{3 a}$

The second great condition which enabled increased storminess to bring on glaciation was the location of the storm tracks. Kullmer's maps, as illustrated in Fig. 2, suggest that a great increase in solar activity, such as is postulated in the Pleistocene, might shift the main storm track poleward even more than it is shifted by the milder solar changes during the twelve-year sunspot cycle. If this is so, the main track would tend to cross North America through the middle of Canada instead of near the southern border. Thus there would be an increase in precipitation in about the latitude of the Keewatin and Labradorean centers of glaciation. From what is known of storm tracks in Europe, the main increase in the intensity of storms would probably center in Scandinavia. Fig. 3 in Chapter $\mathrm{V}$ bears this out. That figure, it will be recalled, shows what happens to precipitation when solar

3a For fuller discussion of climatic controls see S. S. Visher: Seventy Laws of Climate, Annals Assoc. Am. Geographers, 1922. 
activity is increasing. A high rate of precipitation is especially marked in the boreal storm track, that is, in the northern United States, southern Canada, and northwestern Europe.

Another important condition in bringing on glaciation would be the fact that when storms are numerous the total precipitation appears to increase in spite of the slightly lower temperature. This is largely because of the greater evaporation. The excessive evaporation arises partly from the rapidity of the winds, as already stated, and partly from the fact that in areas where the air is clear the sun would presumably be able to act more effectively than now. It would do so because at times of abundant sunspots the sun in our own day has a higher solar constant than at times of milder activity. Our whole hypothesis is based on the supposition that what now happens at times of many sunspots was intensified in glacial periods.

A fourth condition which would cause glaciation to result from great solar activity would be the fact that the portion of the yearly precipitation falling as snow would increase, while the proportion of rain would diminish in the main storm track. This would arise partly because the storms would be located farther north than now, and partly because of the diminution in temperature due to the increased convection. The snow in itself would still further lower the temperature, for snow is an excellent reflector of sunlight. The increased cloudiness which would accompany the more abundant storms would also cause an unusually great reflection of the sunlight and still further lower the temperature. Thus at times of many sunspots a strong tendency toward the accumulation of snow would arise from the rapid convection and consequent low temperature, from the northern location 
of storms, from the increased evaporation and precipitation, from the larger percentage of snowy rather than rainy precipitation, and from the great loss of heat due to reflection from clouds and snow.

If events at the beginning of the last glacial period took place in accordance with the cyclonic hypothesis, as outlined above, one of the inevitable results would be the production of snowfields. The places where snow would accumulate in special quantities would be central Canada, the Labrador plateau, and Scandinavia, as well as certain mountain regions. As soon as a snowfield became somewhat extensive, it would begin to produce striking climatic alterations in addition to those to which it owed its origin. ${ }^{4}$ For example, within a snowfield the summers remain relatively cold. Hence such a field is likely to be an area of high pressure at all seasons. The fact that the snowfield is always a place of relatively high pressure results in outblowing surface winds except when these are temporarily overcome by the passage of strong cyclonic storms. The storms, however, tend to be concentrated near the margins of the ice throughout the year instead of following different paths in each of the four seasons. This is partly because cyclonic lows always avoid places of high pressure and are thus pushed out of the areas where permanent snow has accumulated. On the other hand, at times of many sunspots, as Kullmer has shown, the main storm track tends to be drawn

\footnotetext{
4 Many of these alterations are implied or discussed in the following papers:

1. F. W. Harmer: Influence of Winds upon the Climate of the Pleistocene; Quart. Jour. Geol. Soc., Vol. 57, 1901, p. 405.

2. C. E. P. Brooks: Meteorological Conditions of an Ice Sheet; Quart. Jour. Royal Meteorol. Soc., Vol. 40, 1914, pp. 53-70, and The Evolution of Climate in Northwest Europe; op. cit., Vol. 47, 1921, pp. 173-194.

3. W. H. Hobbs: The Rôle of the Glacial Anticyelone in the Air Circulation of the Globe; Proc. Am. Phil. Soc., Vol. 54, 1915, pp. 185-225.
} 
poleward, perhaps by electrical conditions. Hence when a snowfield is present in the north, the lows, instead of migrating much farther north in summer than in winter, as they now do, would merely crowd on to the snowfield a little farther in summer than in winter. Thus the heavy precipitation which is usual in humid climates near the centers of lows would take place near the advancing margin of the snowfield and cause the field to expand still farther southward.

The tendency toward the accumulation of snow on the margins of the snowfields would be intensified not only by the actual storms themselves, but by other conditions. For example, the coldness of the snow would tend to cause prompt condensation of the moisture brought by the winds that blow toward the storm centers from low latitudes. Again, in spite of the general dryness of the air over a snowfield, the lower air contains some moisture due to evaporation from the snow by day during the clear sunny weather of anti-cyclones or highs. Where this is sufficient, the cold surface of the snowfields tends to produce a frozen fog whenever the snowfield is cooled by radiation, as happens at night and during the passage of highs. Such a frozen fog is an effective reflector of solar radiation. Moreover, because ice has only half the specific heat of water, and is much more transparent to heat, such a "radiation fog" composed of ice crystals is a much less effective retainer of heat than clouds or fog made of unfrozen water particles. Shallow fogs of this type are described by several polar expeditions. They clearly retard the melting of the snow and thus help the icefield to grow.

For all these reasons, so long as storminess remained great, the Pleistocene snowfields, according to the solar hypothesis, must have deepened and expanded. In due 
time some of the snow was converted into glacial ice. When that occurred, the growth of the snowfield as well as of the ice cap must have been accelerated by glacial movement. Under such circumstances, as the ice crowded southward toward the source of the moisture by which it grew, the area of high pressure produced by its low temperature would expand. This would force the storm track southward in spite of the contrary tendency due to the sun. When the ice sheet had become very extensive, the track would be crowded relatively near to the northern margin of the trade-wind belt. Indeed, the Pleistocene ice sheets, at the time of their maximum extension, reached almost as far south as the latitude now marking the northern limit of the trade-wind belt in summer. As the storm track with its frequent low pressure and the subtropical belt with its high pressure were forced nearer and nearer together, the barometric gradient between the two presumably became greater, winds became stronger, and the storms more intense.

This zonal crowding would be of special importance in summer, at which time it would also be most pronounced. In the first place, the storms would be crowded far upon the ice cap which would then be protected from the sun by a cover of fog and cloud more fully than at any other season. Furthermore, the close approach of the tradewind belt to the storm belt would result in a great increase in the amount of moisture drawn from the belt of evaporation which the trade winds dominate. In the trade-wind belt, clear skies and high temperature make evaporation especially rapid. Indeed, in spite of the vast deserts it is probable that more than three-fourths of the total evaporation now taking place on the earth occurs in the belt of trades, an area which includes about onehalf of the earth's surface. 
The agency which could produce this increased drawing northward of moisture from the trade-wind belt would be the winds blowing into the lows. According to the cyclonic hypothesis, many of these lows would be so strong that they would temporarily break down the subtropical belt of high pressure which now usually prevails between the trades and the zone of westerly winds. This belt is even now often broken by tropical cyclones. If the storms of more northerly regions temporarily destroyed the subtropical high-pressure belt, even though they still remained on its northern side, they would divert part of the trade winds. Hence the air which now is carried obliquely equatorward by those winds would be carried spirally northward into the cyclonic lows. Precipitation in the storm track on the margin of the relatively cold ice sheet would thus be much increased, for most winds from low latitudes carry abundant moisture. Such a diversion of moisture from low latitudes probably explains the deficiency of precipitation along the heat equator at times of solar activity, as shown in Fig. 3. Taken as a whole, the summer conditions, according to the cyclonic hypothesis, would be such that increased evaporation in low latitudes would coöperate with increased storminess, cloudiness, and fog in higher latitudes to preserve and increase the accumulation of ice upon the borders of the ice sheet. The greater the storminess, the more this would be true and the more the ice sheet would be able to hold its own against melting in summer. Such a combination of precipitation and of protection from the sun is especially important if an ice sheet is to grow.

The meteorologist needs no geologic evidence that the storm track was shoved equatorward by the growth of the ice sheet, for he observes a similar shifting whenever a winter's snow cap occupies part of the normal storm 
tract. The geologist, however, may welcome geologic evidence that such an extreme shift of the storm track actually occurred during the Pleistocene. Harmer, in 1901, first pointed out the evidence which was repeated with approval by Wright of the Ireland Geological Survey in 1914. ${ }^{5}$ According to these authorities, numerous boulders of a distinctive chalk were deposited by Pleistocene icebergs along the coast of Ireland. Their distribution shows that at the time of maximum glaciation the strong winds along the south coast of Ireland were from the northeast while today they are from the southwest. Such a reversal could apparently be produced only by a southward shift of the center of the main storm track from its present position in northern Ireland, Scotland, and Norway to a position across northern France, central Germany, and middle Russia. This would mean that while now the centers of the lows commonly move northeastward a short distance north of southern Ireland, they formerly moved eastward a short distance south of Ireland. It will be recalled that in the northern hemisphere the winds spiral into a low counter-clockwise and that they are strongest near the center. When the centers pass not far north of a given point, the strong winds therefore blow from the west or southwest, while when the centers pass just south of that point, the strong winds come from the east or northeast.

In addition to the consequences of the crowding of the storm track toward the trade-wind belt, several other conditions presumably operated to favor the growth of the ice sheet. For example, the lowering of the sea level by the removal of water to form the snowfields and glaciers interfered with warm currents. It also increased the rate of erosion, for it was equivalent to an uplift of 5 W. B. Wright: The Quaternary Ice Age, 1914, p. 100. 
all the land. One consequence of erosion and weathering was presumably a diminution of the carbon dioxide in the atmosphere, for although the ice covered perhaps a tenth of the lands and interfered with carbonation to that extent, the removal of large quantities of soil by accelerated erosion on the other nine-tenths perhaps more than counterbalanced the protective effect of the ice. At the same time, the general lowering of the temperature of the ocean as well as the lands increased the ocean's capacity for carbon dioxide and thus facilitated absorption. At a temperature of $50^{\circ} \mathrm{F}$. water absorbs 32 per cent more carbon dioxide than at $68^{\circ}$. The high waves produced by the severe storms must have had a similar effect on a small scale. Thus the percentage of carbon dioxide in the atmosphere was presumably diminished. Of less significance than these changes in the lands and the air, but perhaps not negligible, was the increased salinity of the ocean which accompanied the removal of water to form snow, and the increase of the dissolved mineral load of the rejuvenated streams. Increased salinity slows up the deep-sea circulation, as we shall see in a later chapter. This increases the contrasts from zone to zone.

At times of great solar activity the agencies mentioned above would apparently coöperate to cause an advance of ice sheets into lower latitudes. The degree of solar activity would have much to do with the final extent of the ice sheets. Nevertheless, certain terrestrial conditions would tend to set limits beyond which the ice would not greatly advance unless the storminess were extraordinarily severe. The most obvious of these conditions is the location of oceans and of deserts or semi-arid regions. The southwestward advance of the European ice sheet and the southeastward advance of the Labradorean sheet in America were stopped by the Atlantic. The semi-aridity 
of the Great Plains, produced by their position in the lee of the Rocky Mountains, stopped the advance of the Keewatin ice sheet toward the southwest. The advance of the European ice sheet southeast seems to have been stopped for similar reasons. The cessation of the advance would be brought about in such an area not alone by the light precipitation and abundant sunshine, but by the dryness of the air, and also by the power of dust to absorb the sun's heat. Much dust would presumably be drawn in from the dry regions by passing cyclonic storms and would be scattered over the ice.

The advance of the ice is also slowed up by a rugged topography, as among the Appalachians in northern Pennsylvania. Such a topography besides opposing a physical obstruction to the movement of the ice provides bare south-facing slopes which the sun warms effectively. Such warm slopes are unfavorable to glacial advance. The rugged topography was perhaps quite as effective as the altitude of the Appalachians in causing the conspicuous northward dent in the glacial margin in Pennsylvania. Where glaciers lie in mountain valleys the advance beyond a certain point is often interfered with by the deployment of the ice at the mouths of gorges. Evaporation and melting are more rapid where a glacier is broad and thin than where it is narrow and thick, as in a gorge. Again, where the topography or the location of oceans or dry areas causes the glacial lobes to be long and narrow, the elongation of the lobe is apparently checked in several ways. Toward the end of the lobe, melting and evaporation increase rapidly because the planetary westerly winds are more likely to overcome the glacial winds and sweep across a long, narrow lobe than across a broad one. As they cross the lobe, they accelerate evaporation, and probably lessen cloudiness, with a con- 
sequent augmentation of melting. Moreover, although lows rarely cross a broad ice sheet, they do cross a narrow lobe. For example, Nansen records that strong lows occasionally cross the narrow southern part of the Greenland ice sheet. The longer the lobe, the more likely it is that lows will cross it, instead of following its margin. Lows which cross a lobe do not yield so much snow to the tip as do those which follow the margin. Hence elongation is retarded and finally stopped even without a change in the earth's general climate.

Because of these various reasons the advances of the ice during the several epochs of a glacial period might be approximately equal, even if the durations of the periods of storminess and low temperature were different. Indeed, they might be sub-equal, even if the periods differed in intensity as well as length. Differences in the periods would apparently be manifested less in the extent of the ice than in the depth of glacial erosion and in the thickness of the terminal moraines, outwash plains, and other glacial or glacio-fluvial formations.

Having completed the consideration of the conditions leading to the advance of the ice, let us now consider the condition of North America at the time of maximum glaciation. ${ }^{6}$ Over an area of nearly four million square miles, occupying practically all the northern half of the continent and part of the southern half, as appears in Fig. 6, the surface was a monotonous and almost level plain of ice covered with snow. When viewed from a high altitude, all parts except the margins must have presented a uniformly white and sparkling appearance. Along the margins, however, except to the north, the

- The description of the distribution of the ice sheet is based on T. C. Chamberlin's wall map of North America at the maximum of glaciation, 1913. 


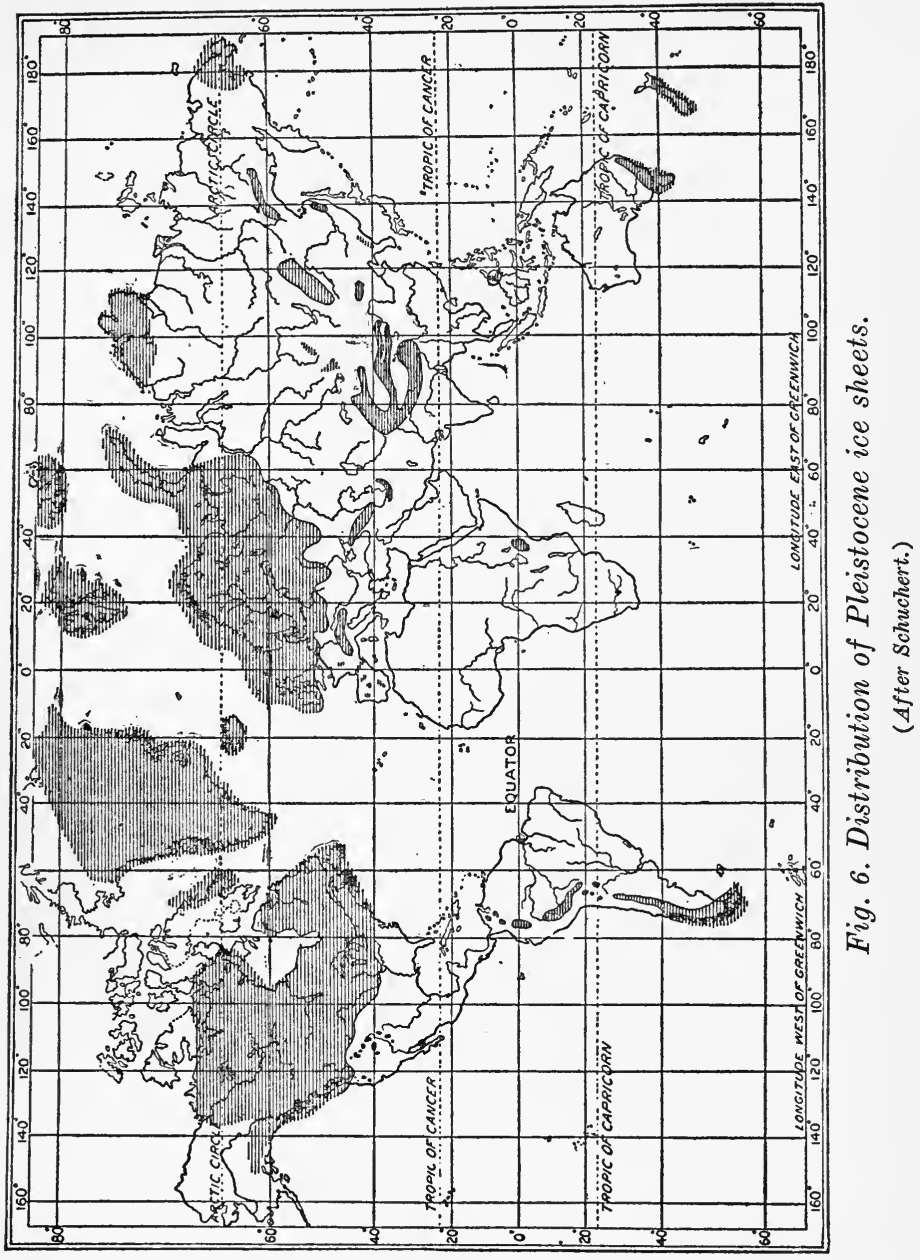


whiteness was irregular, for the view must have included not only fresh snow, but moving clouds and dirty snow or ice. Along the borders where melting was in progress there was presumably more or less spottedness due to morainal material or glacial débris brought to the surface by ice shearage and wastage. Along the dry southwestern border it is also possible that there were numerous dark spots due to dust blown onto the ice by the wind.

The great white sheet with its ragged border was roughly circular in form, with its center in central Canada. Yet there were many departures from a perfectly circular form. Some were due to the oceans, for, except in northern Alaska, the ice extended into the ocean all the way from New Jersey around by the north to Washington. On the south, topographic conditions made the margin depart from a simple arc. From New Jersey to Ohio it swung northward. In the Mississippi Valley it reached far south; indeed most of the broad wedge between the Ohio and the Missouri rivers was occupied by ice. From latitude $37^{\circ}$ near the junction of the Missouri and the Mississippi, however, the ice margin extended almost due north along the Missouri to central North Dakota. It then stretched westward to the Rockies. Farther west lowland glaciation was abundant as far south as western Washington. In the Rockies, the Cascades, and the Sierra Nevadas glaciation was common as far south as Colorado and southern California, respectively, and snowfields were doubtless extensive enough to make these ranges ribbons of white. Between these lofty ranges lay a great unglaciated region, but even in the Great Basin itself, in spite of its present aridity, certain ranges carried glaciers, while great lakes expanded widely. 
In this vast field of snow the glacial ice slowly crept outward, possibly at an average speed of half a foot a day, but varying from almost nothing in winter at the north, to several feet a day in summer at the south. ${ }^{7}$ The force which caused the movement was the presence of the ice piled up not far from the margins. Almost certainly, however, there was no great dome from the center in Canada outward, as some early writers assumed. Such a dome would require that the ice be many thousands of feet thick near its center. This is impossible because of the fact that ice is more voluminous than water (about 9 per cent near the freezing point). Hence when subjected to sufficient pressure it changes to the liquid form. As friction and internal heat tend to keep the bottom of a glacier warm, even in cold regions, the probabilities are that only under very special conditions was a continental ice sheet much thicker than about 2500 feet. In Antarctica, where the temperature is much lower than was probably attained in the United States, the ice sheet is nearly level, several expeditions having traveled hundreds of miles with practically no change in altitude. In Shackleton's trip almost to the South Pole, he encountered a general rise of 3000 feet in 1200 miles. Mountains, however, projected through the ice even near the pole and the geologists conclude that the ice is not very thick even at the world's coldest point, the South Pole.

Along the margin of the ice there were two sorts of movement, much more rapid than the slow creep of the ice. One was produced by the outward drift of snow carried by the outblowing dry winds and the other and more important was due to the passage of cyclonic storms. Along the border of the ice sheet, except at the

\footnotetext{
${ }^{7}$ Chamberlin and Salisbury: Geology, 1906, Vol. 3, and W. H. Hobbs: Characteristies of Existing Glaciers, 1911.
} 
north, storm presumably closely followed storm. Their movement, we judge, was relatively slow until near the southern end of the Mississippi lobe, but when this point was passed they moved much more rapidly, for then they could go toward instead of away from the far northern path which the sun prescribes when solar activity is great. The storms brought much snow to the icefield, perhaps sometimes in favored places as much as the hundred feet a year which is recorded for some winters in the Sierras at present. Even the unglaciated intermontane Great Basin presumably received considerable precipitation, perhaps twice as much as its present scanty supply. The rainfall was enough to support many lakes, one of which was ten times as large as Great Salt Lake; and grass was doubtless abundant upon many slopes which are now dry and barren. The relatively heavy precipitation in the Great Basin was probably due primarily to the increased number of storms, but may also have been much influenced by their slow eastward movement. The lows presumably moved slowly in that general region not only because they were retarded and turned from their normal path by the cold ice to the east, but because during the summer the area between the Sierra snowfields on the west and the Rocky Mountain and Mississippi Valley snowfields on the east was relatively warm. Hence it was normally a place of low pressure and therefore of inblowing winds. Slow-moving lows are much more effective than fast-moving ones in drawing moisture northwestward from the Gulf of Mexico, for they give the moisture more time to move spirally first northeast, under the influence of the normal southwesterly winds, then northwest and finally southwest as it approaches the storm center. In the case of the present lows, before much moisture-laden air can describe such 
a circuit, first eastward and then westward, the storm center has nearly always moved eastward across the Rockies and even across the Great Plains. A result of this is the regular decrease in precipitation northward, northwestward, and westward from the Gulf of Mexico.

Along the part of the glacial margins where for more than 3000 miles the North American ice entered the Atlantic and the Pacific oceans, myriads of great blocks broke off and floated away as stately icebergs, to scatter boulders far over the ocean floor and to melt in warmer climes. Where the margin lay upon the lands numerous streams issued from beneath the ice, milk-white with rock flour, and built up great outwash plains and valley trains of gravel and sand. Here and there, just beyond the ice, marginal lakes of strange shapes occupied valleys which had been dammed by the advancing ice. In many of them the water level rose until it reached some low point in the divide and then overflowed, forming rapids and waterfalls. Indeed, many of the waterfalls of the eastern United States and Canada were formed in just this way and not a few streams now occupy courses through ridges instead of parallel to them, as in preglacial times.

In the zone to the south of the continental ice sheet, the plant and animal life of boreal, cool temperate, and warm temperate regions commingled curiously. Heather and Arctic willow crowded out elm and oak; musk ox, hairy mammoth, and marmot contested with deer, chipmunk, and skunk for a chance to live. Near the ice on slopes exposed to the cold glacial gales, the immigrant boreal species were dominant, but not far away in more protected areas the species that had formerly lived there held their own. In Europe during the last two advances of the great ice sheet the caveman also struggled with 
fierce animals and a fiercer climate to maintain life in an area whose habitability had long been decreasing.

The next step in our history of glaciation is to outline the disappearance of the ice sheets. When a decrease in solar activity produced a corresponding decrease in storminess, several influences presumably combined to cause the disappearance of the ice. Most of their results are the reverse of those which brought on glaciation. A few special aspects, however, some of which have been discussed in Earth and Sun, ought to be brought to mind. A diminution in storminess lessens upward convection, wind velocity, and evaporation, and these changes, if they occurred, must have united to raise the temperature of the lower air by reducing the escape of heat. Again a decrease in the number and intensity of tropical cyclones presumably lessened the amount of moisture carried into mid-latitudes, and thus diminished the precipitation. The diminution of snowfall on the ice sheets when storminess diminished was probably highly important. The amount of precipitation on the sheets was presumably lessened still further by changes in the storminess of middle latitudes. When storminess diminishes, the lows follow a less definite path, as Kullmer's maps show, and on the average a more southerly path. Thus, instead of all the lows contributing snow to the ice sheet, a large fraction of the relatively few remaining lows would bring rain to areas south of the ice sheet. As storminess decreased, the trades and westerlies probably became steadier, and thus carried to high latitudes more warm water than when often interrupted by storms. Steadier southwesterly winds must have produced a greater movement of atmospheric as well as oceanic heat to high latitudes. The warming due to these two causes was probably the chief reason for the disappearance of the European ice sheet 
and of those on the Pacific coast of North America. The two greater American ice sheets, however, and the glaciers elsewhere in the lee of high mountain ranges, probably disappeared chiefly because of lessened precipitation. If there were no cyclonic storms to draw moisture northward from the Gulf of Mexico, most of North America east of the Rocky Mountain barrier would be arid. Therefore a diminution of storminess would be particularly effective in causing the disappearance of ice sheets in these regions.

That evaporation was an especially important factor in causing the ice from the Keewatin center to disappear, is suggested by the relatively small amount of watersorted material in its drift. In South Dakota, for example, less than 10 per cent of the drift is stratified. ${ }^{8}$ On the other hand, Salisbury estimates that perhaps a third of the Labradorean drift in eastern Wisconsin is crudely stratified, about half of that in New Jersey, and more than half of the drift in western Europe.

When the sun's activity began to diminish, all these conditions, as well as several others, would coöperate to cause the ice sheets to disappear. Step by step with their disappearance, the amelioration of the climate would progress so long as the period of solar inactivity continued and storms were rare. If the inactivity continued long enough, it would result in a fairly mild climate in high latitudes, though so long as the continents were emergent this mildness would not be of the extreme type. The inauguration of another cycle of increased disturbance of the sun, with a marked increase in storminess, would inaugurate another glacial epoch. Thus a succession of glacial and inter-glacial epochs might continue so long as the sun was repeatedly disturbed.

8 S. S. Visher: The Geography of South Dakota; S. D. Geol. Surv., 1918. 


\section{CHAPTER VIII}

\section{SOME PROBLEMS OF GLACIAL PERIODS}

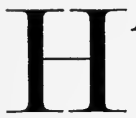

AVING outlined in general terms the coming of the ice sheets and their disappearance, we are now ready to discuss certain problems of compelling climatic interest. The discussion will be grouped under five heads: (I) the localization of glaciation; (II) the sudden coming of glaciation; (III) peculiar variations in the height of the snow line and of glaciation; (IV) lakes and other evidences of humidity in unglaciated regions during the glacial epochs; (V) glaciation at sea level and in low latitudes in the Permian and Proterozoic eras. The discussion of perhaps the most difficult of all climatic problems of glaciation, that of the succession of cold glacial and mild inter-glacial epochs, has been postponed to the next to the final chapter of this book. It cannot be properly considered until we take up the history of solar disturbances.

I. The first problem, the localization of the ice sheets, arises from the fact that in both the Pleistocene and the Permian periods glaciation was remarkably limited. In neither period were all parts of high latitudes glaciated; yet in both cases glaciation occurred in large regions in lower latitudes. Many explanations of this localization have been offered, but most are entirely inadequate. Even hypotheses with something of proven worth, such as those of variations in volcanic dust and in atmospheric 
carbon dioxide, fail to account for localization. The cyclonic form of the solar hypothesis, however, seems to afford a satisfactory explanation.

The distribution of the ice in the last glacial period is well known, and is shown in Fig. 6. Four-fifths of the ice-covered area, which was eight million square miles, more or less, was near the borders of the North Atlantic in eastern North America and northwestern Europe. The ice spread out from two great centers in North America, the Labradorean east of Hudson Bay, and the Keewatin west of the bay. There were also many glaciers in the western mountains, especially in Canada, while subordinate centers occurred in Newfoundland, the Adirondacks, and the White Mountains. The main ice sheet at its maximum extension reached as far south as latitude $39^{\circ}$ in Kansas and Kentucky, and $37^{\circ}$ in Illinois. Huge boulders were transferred more than one thousand miles from their source in Canada. The northward extension was somewhat less. Indeed, the northern margin of the continent was apparently relatively little glaciated and much of Alaska unglaciated. Why should northern Kentucky be glaciated when northern Alaska was not?

In Europe the chief center from which the continental glacier moved was the Scandinavian highlands. It pushed across the depression now occupied by the Baltic to southern Russia and across the North Sea depression to England and Belgium. The Alps formed a center of considerable importance, and there were minor centers in Scotland, Ireland, the Pyrenees, Apennines, Caucasus, and Urals. In Asia numerous ranges also contained large glaciers, but practically all the glaciation was of the alpine type and very little of the vast northern lowland was covered with ice.

In the southern hemisphere glaciation at low latitudes 
was less striking than in the northern hemisphere. Most of the increase in the areas of ice was confined to mountains which today receive heavy precipitation and still contain small glaciers. Indeed, except for relatively slight glaciation in the Australian Alps and in Tasmania, most of the Pleistocene glaciation in the southern hemisphere was merely an extension of existing glaciers, such as those of south Chile, New Zealand, and the Andes. Nevertheless, fairly extensive glaciation existed much nearer the equator than is now the case.

In considering the localization of Pleistocene glaciation, three main factors must be taken into account, namely, temperature, topography, and precipitation. The absence of glaciation in large parts of the Arctic regions of North America and of Asia makes it certain that low temperature was not the controlling factor. Aside from Antarctica, the coldest place in the world is northeastern Siberia. There for seven months the average temperature is below $0^{\circ} \mathrm{C}$., while the mean for the whole year is below $-10^{\circ} \mathrm{C}$. If the temperature during a glacial period averaged $6^{\circ} \mathrm{C}$. lower than now, as is commonly supposed, this part of Siberia would have had a temperature below freezing for at least nine months out of the twelve even if there were no snowfield to keep the summers cold. Yet even under such conditions no glaciation occurred, although in other places, such as parts of Canada and northwestern Europe, intense glaciation occurred where the mean temperature is much higher.

The topography of the lands apparently had much more influence upon the localization of glaciation than did temperature. Its effect, however, was always to cause glaciation exactly where it would be expected and not in unexpected places as actually occurred. For example, in North America the western side of the Canadian Rockies 
suffered intense glaciation, for there precipitation was heavy because the westerly winds from the Pacific are forced to give up their moisture as they rise. In the same way the western side of the Sierra Nevadas was much more heavily glaciated than the eastern side. In similar fashion the windward slopes of the Alps, the Caucasus, the Himalayas, and many other mountain ranges suffered extensive glaciation. Low temperature does not seem to have been the cause of this glaciation, for in that case it is hard to see why both sides of the various ranges did not show an equal percentage of increase in the size of their icefields.

From what has been said as to temperature and topography, it is evident that variations in precipitation have had much more to do with glaciation than have variations in temperature. In the Arctic lowlands and on the leeward side of mountains, the slight development of glaciation appears to have been due to scarcity of precipitation. On the windward side of mountains, on the other hand, a notable increase in precipitation seems to have led to abundant glaciation. Such an increase in precipitation must be dependent on increased evaporation and this could arise either from relatively high temperature or strong winds. Since the temperature in the glacial period was lower than now, we seem forced to attribute the increased precipitation to a strengthening of the winds. If the westerly winds from the Pacific should increase in strength and waft more moisture to the western side of the Canadian Rockies, or if similar winds increased the snowfall on the upper slopes of the Alps or the Tian-Shan Mountains, the glaciers would extend lower than now without any change in temperature.

Although the incompetence of low temperature to cause glaciation, and the relative unimportance of the moun- 
tains in northeastern Canada and northwestern Europe throw most glacial hypotheses out of court, they are in harmony with the cyclonic hypothesis. The answer of that hypothesis to the problem of the localization of ice sheets seems to be found in certain maps of storminess and rainfall in relation to solar activity. In Fig. 2 a marked belt of increased storminess at times of many sunspots is seen in southern Canada. A comparison of this with a series of maps given in Earth and Sun shows that the stormy belt tends to migrate northward in harmony with an increase in the activity of the sun's atmosphere. If the sun were sufficiently active the belt of maximum storminess would apparently pass through the Keewatin and Labradorean centers of glaciation instead of well to the south of them, as at present. It would presumably cross another center in Greenland, and then would traverse the fourth of the great centers of Pleistocene glaciation in Scandinavia. It would not succeed in traversing northern Asia, however, any more than it does now, because of the great high-pressure area which develops there in winter. When the ice sheets expanded from the main centers of glaciation, the belt of storms would be pushed southward and outward. Thus it might give rise to minor centers of glaciers such as the Patrician between Hudson Bay and Lake Superior, or the centers in Ireland, Cornwall, Wales, and the northern Ural Mountains. As the main ice sheets advanced, however, the minor centers would be overridden and the entire mass of ice would be merged into one vast expanse in the Atlantic portion of each of the two continents.

In this connection it may be well to consider briefly the most recent hypothesis as to the growth and hence the localization of glaciation. In 1911 and more fully in 1915, 
Hobbs, ${ }^{1}$ advanced the anti-cyclonic hypothesis of the origin of ice sheets. This hypothesis has the great merit of focusing attention upon the fact that ice sheets are pronounced anti-cyclonic regions of high pressure. This is proved by the strong outblowing winds which prevail along their margins. Such winds must, of course, be balanced by inward-moving winds at high levels. Abundant observations prove that such is the case. For example, balloons sent up by Barkow near the margin of the Antarctic ice sheet reveal the occurrence of inblowing winds, although they rarely occur below a height of 9000 meters. The abundant data gathered by Guervain on the coast of Greenland indicate that outblowing winds prevail up to a height of about 4000 meters. At that height inblowing winds commence and increase in frequency until at an altitude of over 5000 meters they become more common than outblowing winds. It should be noted, however, that in both Antarctica and Greenland, although the winds at an elevation of less than a thousand meters generally blow outward, there are frequent and decided departures from this rule, so that "variable winds" are quite commonly mentioned in the reports of expeditions and balloon soundings.

The undoubted anti-cyclonic conditions which Hobbs thus calls to the attention of scientists seem to him to necessitate a peculiar mechanism in order to produce the snow which feeds the glaciers. He assumes that the winds which blow toward the centers of the ice sheets at high levels carry the necessary moisture by which the glaciers grow. When the air descends in the centers of the highs, it is supposed to be chilled on reaching the sur-

1 W. H. Hobbs: Characteristics of Existing Glaciers, 1911. The Rôle of the Glacial Anticyclones in the Air Circulation of the Globe; Proc. Am. Phil. Soc., Vol. 54, 1915, pp. 185-225. 
face of the ice, and hence to give up its moisture in the form of minute crystals. This conclusion is doubtful for several reasons. In the first place, Hobbs does not seem to appreciate the importance of the variable winds which he quotes Arctic and Antarctic explorers as describing quite frequently on the edges of the ice sheets. They are one of many signs that cyclonic storms are fairly frequent on the borders of the ice though not in its interior. Thus there is a distinct and sufficient form of precipitation actually at work near the margin of the ice, or exactly where the thickness of the ice sheet would lead us to expect.

Another consideration which throws grave doubt on the anti-cyclonic hypothesis of ice sheets is the small amount of moisture possible in the highs because of their low temperature. Suppose, for the sake of argument, that the temperature in the middle of an ice sheet averages $20^{\circ} \mathrm{F}$. This is probably much higher than the actual fact and therefore unduly favorable to the anti-cyclonic hypothesis. Suppose also that the decrease in temperature from the earth's surface upward proceeds at the rate of $1^{\circ} \mathrm{F}$. for each 300 feet, which is 50 per cent less than the actual rate for air with only a slight amount of moisture, such as is found in cold regions. Then at a height of 10,000 feet, where the inblowing winds begin to be felt, the temperature would be $-20^{\circ} \mathrm{F}$. At that temperature the air is able to hold approximately 0.166 grain of moisture per cubic foot when fully saturated. This is an exceedingly small amount of moisture and even if it were all precipitated could scarcely build a glacier. However, it apparently would not be precipitated because when such air descends in the center of the anti-cyclone it is warmed adiabatically, that is, by compression. On reaching the surface it would have a temperature of $20^{\circ}$ 
and would be able to hold 0.898 grain of water vapor per cubic foot; in other words, it would have a relative humidity of about 18 per cent. Under no reasonable assumption does the upper air at the center of an ice sheet appear to reach the surface with a relative humidity of more than 20 or 25 per cent. Such air cannot give up moisture. On the contrary, it absorbs it and tends to diminish rather than increase the thickness of the sheet of ice and snow. But after the surplus heat gained by descent has been lost by radiation, conduction, and evaporation, the air may become super-saturated with the moisture picked up while warm. Hobbs reports that explorers in Antarctica and Greenland have frequently observed condensation on their clothing. If such moisture is not derived directly from the men's own bodies, it is apparently picked up from the ice sheet by the descending air, and not added to the ice sheet by air from aloft.

The relation of all this to the localization of ice sheets is this. If Hobbs' anti-cyclonic hypothesis of glacial growth is correct, it would appear that ice sheets should grow up where the temperature is lowest and the highpressure areas most persistent; for instance, in northern Siberia. It would also appear that so far as the topography permitted, the ice sheets ought to move out uniformly in all directions; hence the ice sheet ought to be as prominent to the north of the Keewatin and Labradorean centers as to the south, which is by no means the case. Again, in mountainous regions, such as the glacial areas of Alaska and Chile, the glaciation ought not to be confined to the windward slope of the mountains so closely as is actually the fact. In each of these cases the glaciated region was large enough so that there was probably a true anti-cyclonic area comparable with that now prevailing over southern Greenland. In both places 
the correlation between glaciation and mountain ranges seems much too close to support the anti-cyclonic hypothesis, for the inblowing winds which on that hypothesis bring the moisture are shown by observation to occur at heights far greater than that of all but the loftiest ranges.

II. The sudden coming of glaciation is another problem which has been a stumbling-block in the way of every glacial hypothesis. In his Climates of Geologic Times, Schuchert states that the fossils give almost no warning of an approaching catastrophe. If glaciation were solely due to uplift, or other terrestrial changes aside from vulcanism, Schuchert holds that it would have come slowly and the stages preceding glaciation would have affected life sufficiently to be recorded in the rocks. He considers that the suddenness of the coming of glaciation is one of the strongest arguments against the carbon dioxide hypothesis of glaciation.

According to the cyclonic hypothesis, however, the suddenness of the oncoming of glaciation is merely what would be expected on the basis of what happens today. Changes in the sun occur suddenly. The sunspot cycle is only eleven or twelve years long, and even this short period of activity is inaugurated more suddenly than it declines. Again the climatic record derived from the growth of trees, as given in Figs. 4 and 5, also shows that marked changes in climate are initiated more rapidly than they disappear. In this connection, however, it must be remembered that solar activity may arise in various ways, as will appear more fully later. Under certain conditions storminess may increase and decrease slowly.

III. The height of the snow line and of glaciation furnishes another means of testing glacial hypotheses. It is well established that in times of glaciation the snow line 
was depressed everywhere, but least near the equator. For example, according to Penck, permanent snow extended 4000 feet lower than now in the Alps, whereas it stood only 1500 feet below the present level near the equator in Venezuela. This unequal depression is not readily accounted for by any hypothesis depending solely upon the lowering of temperature. By the carbon dioxide and the volcanic dust hypotheses, the temperature presumably was lowered amost equally in all latitudes, but a little more at the equator than elsewhere. If glaciation were due to a temporary lessening of the radiation received from the sun, such as is demanded by the thermal solar hypothesis, and by the longer periods of Croll's hypothesis, the lowering would be distinctly greatest at the equator. Thus, according to all these hypotheses, the snow line should have been depressed most at the equator, instead of least.

The cyclonic hypothesis explains the lesser depression of the snow line at the equator as due to a diminution of precipitation. The effectiveness of precipitation in this respect is illustrated by the present great difference in the height of the snow line on the humid and dry sides of mountains. On the wet eastern side of the Andes near the equator, the snow line lies at 16,000 feet; on the dry western side, at 18,500 feet. Again, although the humid side of the Himalayas lies toward the south, the snow line has a level of 15,000 feet, while farther north, on the dry side, it is 16,700 feet. $^{2}$ The fact that the snow line is lower near the margin of the Alps than toward the center points in the same direction. The bearing of all this on the glacial period may be judged by looking again at Fig. 3 in Chapter $V$. This shows that at times of sunspot activity and hence of augmented storminess, the precipi-

2 R. D. Salisbury: Physiography, 1919. 
tation diminishes near the heat equator, that is, where the average temperature for the whole year is highest. At present the great size of the northern continents and their consequent high temperature in summer, cause the heat equator to lie north of the "real" equator, except where Australia draws it to the southward. ${ }^{3}$ When large parts of the northern continents were covered with ice, however, the heat equator and the true equator were probably much closer than now, for the continents could not become so hot. If so, the diminution in equatorial precipitation, which accompanies increased storminess throughout the world as a whole, would take place more nearly along the true equator than appears in Fig. 3. Hence so far as precipitation alone is concerned, we should actually expect that the snow line near the equator would rise a little during glacial periods. Another factor, however, must be considered. Köppen's data, it will be remembered, show that at times of solar activity the earth's temperature falls more at the equator than in higher latitudes. If this effect were magnified it would lower the snow line. The actual position of the snow line at the equator during glacial periods thus appears to be the combined effect of diminished precipitation, which would raise the line, and of lower temperature, which would bring it down.

Before leaving this subject it may be well to recall that the relative lessening of precipitation in equatorial latitudes during the glacial epochs was probably caused by the diversion of moisture from the trade-wind belt. This diversion was presumably due to the great number of tropical cyclones and to the fact that the cyclonic storms of middle latitudes also drew much moisture from the trade-wind belt in summer when the northern position of

3 Griffith Taylor: Australian Meteorology, 1920, p. 283. 
the sun drew that belt near the storm track which was forced to remain south of the ice sheet. Such diversion of moisture out of the trade-wind belt must diminish the amount of water vapor that is carried by the trades to equatorial regions; hence it would lessen precipitation in the belt of so-called equatorial calms, which lies along the heat equator rather than along the geographical equator.

Another phase of the vertical distribution of glaciation has been the subject of considerable discussion. In the Alps and in many other mountains the glaciation of the Pleistocene period appears to have had its upper limit no higher than today. This has been variously interpreted. It seems, however, to be adequately explained as due to decreased precipitation at high altitudes during the cold periods. This is in spite of the fact that precipitation in general increased with increased storminess. The low temperature of glacial times presumably induced condensation at lower altitudes than now, and most of the precipitation occurred upon the lower slopes of the mountains, contributing to the lower glaciers, while little of it fell upon the highest glaciers. Above a moderate altitude in all lofty mountains the decrease in the amount of precipitation is rapid. In most cases the decrease begins at a height of less than 3000 feet above the base of the main slope, provided the slope is steep. The colder the air, the lower the altitude at which this occurs. For example, it is much lower in winter than in summer. Indeed, the higher altitudes in the Alps are sunny in winter even where there are abundant clouds lower down.

IV. The presence of extensive lakes and other evidences of a pluvial climate during glacial periods in non-glaciated regions which are normally dry is another of the facts which most glacial hypotheses fail to explain satis- 
factorily. Beyond the ice sheets many regions appear to have enjoyed an unusually heavy precipitation during the glacial epochs. The evidence of this is abundant, including numerous abandoned strand lines of salt lakes and an abundance of coarse material in deltas and flood plains. J. D. Whitney, ${ }^{4}$ in an interesting but neglected volume, was one of the first to marshal the evidence of this sort. More recently Free ${ }^{5}$ has amplified this. According to him in the Great Basin region of the United States sixty-two basins either contain unmistakable evidence of lakes, or belong to one of the three great lake groups named below. Two of these, the Lake Lahontan and the Lake Bonneville groups, comprise twenty-nine present basins, while the third, the Owens-Searles chain, contained at least five large lakes, the lowest being in Death Valley. In western and central Asia a far greater series of salt lakes is found and most of these are surrounded by strands at high levels. Many of these are described in Explorations in Turkestan, The Pulse of Asia, and Palestine and Its Transformation. There has been a good deal of debate as to whether these lakes actually date from the glacial period, as is claimed by C. E. P. Brooks, for example, or from some other period. The evidence, however, seems to be convincing that the lakes expanded when the ice also expanded.

According to the older glacial hypotheses the lower temperature which is postulated as the cause of glaciation would almost certainly mean less evaporation over the oceans and hence less precipitation during glacial periods. To counteract this the only way in which the

4 J. D. Whitney: Climatic Changes of the Later Geological Times, 1882.

5 E. E. Free: U. S. Dept. of Agriculture, Bull. 54, 1914. Mr. Free has prepared a summary of this Bulletin which appears in The Solar Hypothesis, Bull. Geol. Soc. of Am., Vol. 25, pp. 559-562. 
level of the lakes could be raised would be because the lower temperature would cause less evaporation from their surfaces. It seems quite impossible, however, that the lowering of temperature, which is commonly taken to have been not more than $10^{\circ} \mathrm{C}$, could counteract the lessened precipitation and also cause an enormous expansion of most of the lakes. For example, ancient Lake Bonneville was more than ten times as large as its modern remnant, Great Salt Lake, and its average depth more than forty times as great. ${ }^{\circ}$ Many small lakes in the Old World expanded still more. ${ }^{7}$ For example, in eastern Persia many basins which now contain no lake whatever are floored with vast deposits of lacustrine salt and are surrounded by old lake bluffs and beaches. In northern Africa similar conditions prevail. ${ }^{8}$ Other, but less obvious, evidence of more abundant rainfall in regions that are now dry is found in thick strata of gravel, sand, and fine silt in the alluvial deposits of flood plains and deltas. ${ }^{9}$

The cyclonic hypothesis supposes that increased storminess accounts for pluvial climates in regions that are now dry just as it accounts for glaciation in the regions of the ice sheets. Figs. 2 and 3, it will be remembered, illustrate what happens when the sun is active. Solar activity is accompanied by an increase in storminess in the southwestern United States in exactly the region where elevated strands of diminished salt lakes are most numerous. In Fig. 3, the same condition is seen in

6 G. K. Gilbert: Lake Bonneville; Monograph 1, U. S. Geol. Surv.

7 C. E. P. Brooks: Quart. Jour. Royal Meteorol. Soc., 1914, pp. 63-66.

8 H. J. L. Beadnell: An Egyptian Oasis, London, 1909.

Ellsworth Huntington: The Libyan Oasis of Kharga; Bull. Am. Geog. Soc., Vol. 42, Sept., 1910, pp. 641-661.

$9 \mathrm{~S}$. S. Visher: The Bajada of the Tueson Bolson of Southern Arizona; Seience, N. S., Mar. 23, 1913.

Ellsworth Huntington: The Basins of Eastern Persia and Seistan, in Explorations in Turkestan. 
the region of salt lakes in the Old World. Judging by these maps, which illustrate what has happened since careful meteorological records were kept, an increase in solar activity is accompanied by increased rainfall in large parts of what are now semi-arid and desert regions. Such precipitation would at once cause the level of the lakes to rise. Later, when ice sheets had developed in Europe and America, the high-pressure areas thus caused might force the main storm belt so far south that it would lie over these same arid regions. The increase in tropical hurricanes at times of abundant sunspots may also have a bearing on the climate of regions that are now arid. During the glacial period some of the hurricanes probably swept far over the lands. The numerous tropical cyclones of Australia, for example, are the chief source of precipitation for that continent. ${ }^{10}$ Some of the stronger cyclones locally yield more rain in a day or two than other sources yield in a year.

V. The occurrence of widespread glaciation near the tropics during the Permian, as shown in Fig. 7, has given rise to much discussion. The recent discovery of glaciation in latitudes as low as $30^{\circ}$ in the Proterozoic is correspondingly significant. In all cases the occurrence of glaciation in low and middle latitudes is probably due to the same general causes. Doubtless the position and altitude of the mountains had something to do with the matter. Yet taken by itself this seems insufficient. Today the loftiest range in the world, the Himalayas, is almost unglaciated, although its southern slope may seem at first thought to be almost ideally located in this respect. Some parts rise over 20,000 feet and certain lower slopes receive 400 inches of rain per year. The small size of the Himalayan glaciers in spite of these favorable conditions

10 Griffith Taylor: Australian Meteorology, 1920, p. 189. 


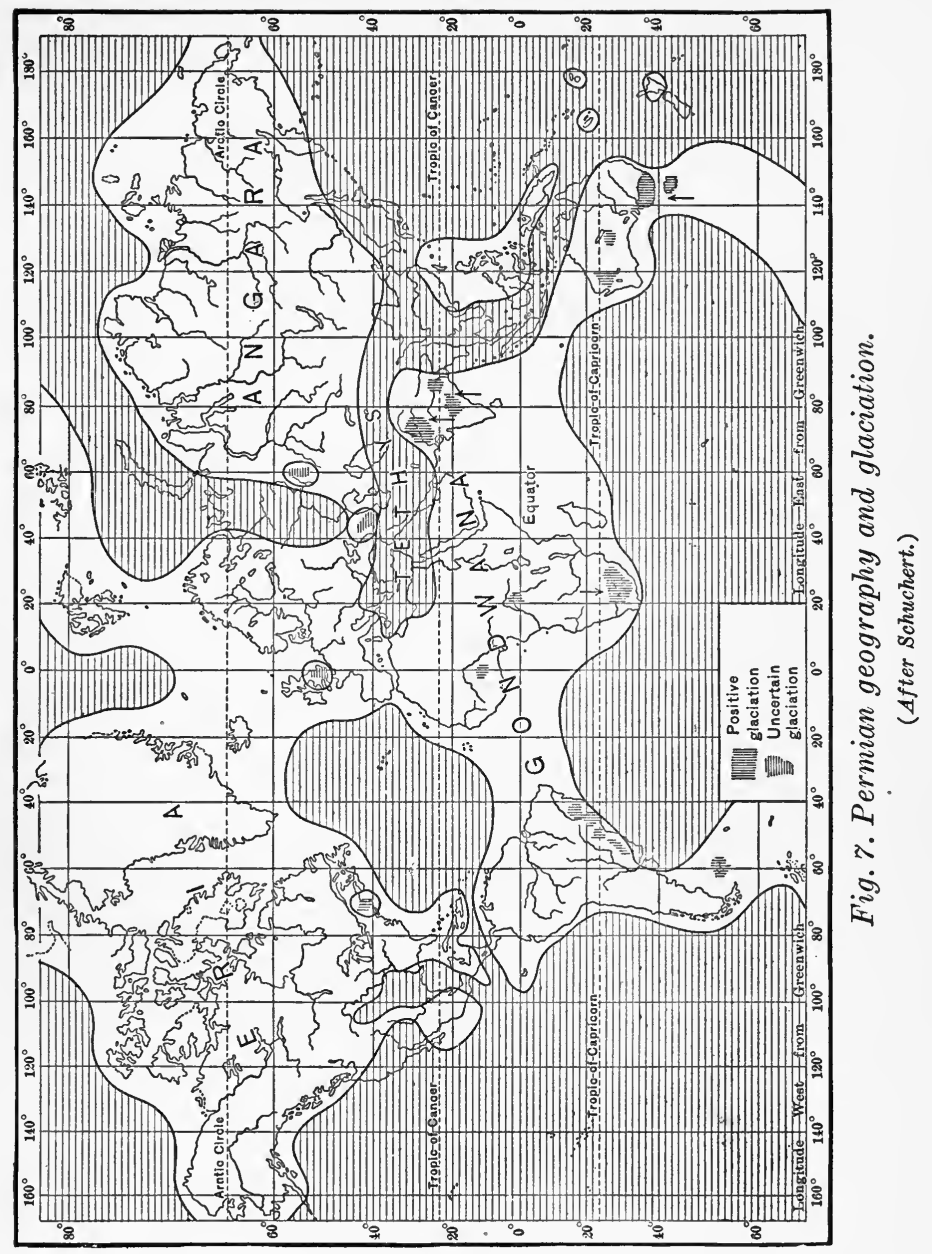


is apparently due largely to the seasonal character of the monsoon winds. The strong outblowing monsoons of winter cause about half the year to be very dry with clear skies and dry winds from the interior of Asia. In all low latitudes the sun rides high in the heavens at midday, even in winter, and thus melts snow fairly effectively in clear weather. This is highly unfavorable to glaciation. The inblowing southern monsoons bring all their moisture in midsummer at just the time when it is least effective in producing snow. Conditions similar to those now prevailing in the Himalayas must accompany any great uplift of the lands which produces high mountains and large continents in subtropical and middle latitudes. Hence, uplift alone cannot account for extensive glaciation in subtropical latitudes during the Permian and Proterozoic.

The assumption of a great general lowering of temperature is also not adequate to explain glaciation in subtropical latitudes. In the first place this would require a lowering of many degrees,-far more than in the Pleistocene glacial period. The marine fossils of the Permian, however, do not indicate any such condition. In the second place, if the lands were widespread as they appear to have been in the Permian, a general lowering of temperature would diminish rather than increase the present slight efficiency of the monsoons in producing glaciation. Monsoons depend upon the difference between the temperatures of land and water. If the general temperature were lowered, the reduction would be much less pronounced on the oceans than on the lands, for water tends to preserve a uniform temperature, not only because of its mobility, but because of the large amount of heat given out when freezing takes place, or consumed in evaporation. Hence the general lowering of temperature 
would make the contrast between continents and oceans less than at present in summer, for the land temperature would be brought toward that of the ocean. This would diminish the strength of the inblowing summer monsoons and thus cut off part of the supply of moisture. Evidence that this actually happened in the cold fourteenth century has already been given in Chapter VI. On the other hand, in winter the lands would be much colder than now and the oceans only a little colder, so that the dry outblowing monsoons of the cold season would increase in strength and would also last longer than at present. In addition to all this, the mere fact of low temperature would mean a general reduction in the amount of water vapor in the air. Thus, from almost every point of view a mere lowering of temperature seems to be ruled out as a cause of Permian glaciation. Moreover, if the Permian or Proterozoic glacial periods were so cold that the lands above latitude $30^{\circ}$ were snowcovered most of the time, the normal surface winds in subtropical latitudes would be largely equatorward, just as the winter monsoons now are. Hence little or no moisture would be available to feed the snowfields which give rise to the glaciers.

It has been assumed by Marsden Manson and others that increased general cloudiness would account for the subtropical glaciation of the Permian and Proterozoic. Granting for the moment that there could be universal persistent cloudiness, this would not prevent or counteract the outblowing anti-cyclonic winds so characteristic of great snowfields. Therefore, under the hypothesis of general cloudiness there would be no supply of moisture to cause glaciation in low latitudes. Indeed, persistent cloudiness in all higher latitudes would apparently deprive the Himalayas of most of their present moisture, 
for the interior of Asia would not become hot in summer and no inblowing monsoons would develop. In fact, winds of all kinds would seemingly be scarce, for they arise almost wholly from contrasts of temperature and hence of atmospheric pressure. The only way to get winds and hence precipitation would be to invoke some other agency, such as cyclonic storms, but that would be a departure from the supposition that glaciation arose from cloudiness.

Let us now inquire how the cyclonic hypothesis accounts for glaciation in low latitudes. We will first consider the terrestrial conditions in the early Permian, the last period of glaciation in such latitudes. Geologists are almost universally agreed that the lands were exceptionally extensive and also high, especially in low latitudes. One evidence of this is the presence of abundant conglomerates composed of great boulders. It is also probable that the carbon dioxide in the air during the early Permian had been reduced to a minimum by the extraordinary amount of coal formed during the preceding period. This would tend to produce low temperature and thus make the conditions favorable for glaciation as soon as an accentuation of solar activity caused unusual storminess. If the storminess became extreme when terrestrial conditions were thus universally favorable to glaciation, it would presumably produce glaciation in low latitudes. Numerous and intense tropical cyclones would carry a vast amount of moisture out of the tropics, just as now happens when the sun is active, but on a far larger scale. The moisture would be precipitated on the equatorward slopes of the subtropical mountain ranges. At high elevations this precipitation would be in the form of snow even in summer. Tropical cyclones, however, as is shown in Earth and Sun, occur in the autumn and 
winter as well as in summer. For example, in the Bay of Bengal the number recorded in October is fifty, the largest for any month; while in November it is thirtyfour, and December fourteen as compared with an average of forty-two for the months of July to September. From January to March, when sunspot numbers averaged more than forty, the number of tropical hurricanes was 143 per cent greater than when the sunspot numbers averaged below forty. During the months from April to June, which also would be times of considerable snowy precipitation, tropical hurricanes averaged 58 per cent more numerous with sunspot numbers above forty than with numbers below forty, while from July to September the difference amounted to 23 per cent. Even at this season some snow falls on the higher slopes, while the increased cloudiness due to numerous storms also tends to preserve the snow. Thus a great increase in the frequency of sunspots is accompanied by increased intensity of tropical hurricanes, especially in the cooler autumn and spring months, and results not only in a greater accumulation of snow but in a decrease in the melting of the snow because of more abundant clouds. At such times as the Permian, the general low temperature due to rapid convection and to the scarcity of carbon dioxide presumably joined with the extension of the lands in producing great high-pressure areas over the lands in middle latitudes during the winters, and thus caused the more northern, or mid-latitude type of cyclonic storms to be shifted to the equatorward side of the continents at that season. This would cause an increase of precipitation in winter as well as during the months when tropical hurricanes abound. Many other circumstances would coöperate to produce a similar result. For example, the general low temperature would cause the sea to be covered with 
ice in lower latitudes than now, and would help to create high-pressure areas in middle latitudes, thus driving the storms far south. If the sea water were fresher than now, as it probably was to a notable extent in the Proterozoic and perhaps to some slight extent in the Permian, the higher freezing point would also further the extension of the ice and help to keep the storms away from high latitudes. If to this there is added a distribution of land and sea such that the volume of the warm ocean currents flowing from low to high latitudes was diminished, as appears to have been the case, there seems to be no difficulty in explaining the subtropical location of the main glaciation in both the Permian and the Proterozoic. An increase of storminess seems to be the key to the whole situation.

One other possibility may be mentioned, although little stress should be laid on it. In Earth and Sun it has been shown that the main storm track in both the northern and southern hemispheres is not concentric with the geographical poles. Both tracks are roughly concentric with the corresponding magnetic poles, a fact which may be important in connection with the hypothesis of an electrical effect of the sun upon terrestrial storminess. The magnetic poles are known to wander considerably. Such wandering gives rise to variations in the direction of the magnetic needle from year to year. In 1815 the compass in England pointed $2412^{\circ}$ W. of N. and in 1906 $17^{\circ} 45^{\prime} \mathrm{W}$. Such a variation seems to mean a change of many miles in the location of the north magnetic pole. Certain changes in the daily march of electromagnetic phenomena over the oceans have led Bauer and his associates to suggest that the magnetic poles may even be subject to a slight daily movement in response to the changes in the relative positions of the earth and sun. 
Thus there seems to be a possibility that a pronounced change in the location of the magnetic pole in Permian times, for example, may have had some connection with a shifting in the location of the belt of storms. It must be clearly understood that there is as yet no evidence of any such change, and the matter is introduced merely to call attention to a possible line of investigation.

Any hypothesis of Permian and Proterozoic glaciation must explain not only the glaciation of low latitudes but the lack of glaciation and the accumulation of red desert beds in high latitudes. The facts already presented seem to explain this. Glaciation could not occur extensively in high latitudes partly because during most of the year the air was too cold to hold much moisture, but still more because the winds for the most part must have blown outward from the cold northern areas and the cyclonic storm belt was pushed out of high latitudes. Because of these conditions precipitation was apparently limited to a relatively small number of storms during the summer. Hence great desert areas must have prevailed at high latitudes. Great aridity now prevails north of the Himalayas and related ranges, and red beds are accumulating in the centers of the great deserts, such as those of the Tarim Basin and the Transcaspian. The redness is not due to the original character of the rock, but to intense oxidation, as appears from the fact that along the edges of the desert and wherever occasional floods carry sediment far out into the midst of the sand, the material has the ordinary brownish shades. As soon as one goes out into the places where the sand has been exposed to the air for a long time, however, it becomes pink, and then red. Such conditions may have given rise to the high degree of oxidation in the famous Permian red beds. If the air of the early Permian contained an unusual percentage of 
oxygen because of the release of that gas by the great plant beds which formed coal in the preceding era, as Chamberlin has thought probable, the tendency to produce red beds would be still further increased.

It must not be supposed, however, that these conditions would absolutely limit glaciation to subtropical latitudes. The presence of early Permian glaciation in North America at Boston and in Alaska and in the Falkland Islands of the South Atlantic Ocean proves that at least locally there was sufficient moisture to form glaciers near the coast in relatively high latitudes. The possibility of this would depend entirely upon the form of the lands and the consequent course of ocean currents. Even in those high latitudes cyclonic storms would occur unless they were kept out by conditions of pressure such as have been described above.

The marine faunas of Permian age in high latitudes have been interpreted as indicating mild oceanic temperatures. This is a point which requires further investigation. Warm oceans during times of slight solar activity are a necessary consequence of the cyclonic hypothesis, as will appear later. The present cold oceans seem to be the expectable result of the Pleistocene glaciation and of the present relatively disturbed condition of the sun. If a sudden disturbance threw the solar atmosphere into violent commotion within a few thousand years during Permian times, glaciation might occur as described above, while the oceans were still warm. In fact their warmth would increase evaporation while the violent cyclonic storms and high winds would cause heavy rain and keep the air cool by constantly raising it to high levels where it would rapidly radiate its heat into space.

Nevertheless it is not yet possible to determine how warm the oceans were at the actual time of the Permian 
glaciation. Some faunas formerly reported as Permian are now known to be considerably older. Moreover, others of undoubted Permian age are probably not strictly contemporaneous with the glaciation. So far back in the geological record it is very doubtful whether we can date fossils within the limits of say 100,000 years. Yet a difference of 100,000 years would be more than enough to allow the fossils to have lived either before or after the glaciation, or in an inter-glacial epoch. One such epoch is known to have occurred and nine others are suggested by the inter-stratification of glacial till and marine sediments in eastern Australia. The warm currents which would flow poleward in inter-glacial epochs must have favored a prompt reintroduction of marine faunas driven out during times of glaciation. Taken all and all, the Permian glaciation seems to be accounted for by the cyclonic hypothesis quite as well as does the Pleistocene. In both these cases, as well as in the various pulsations of historic times, it seems to be necessary merely to magnify what is happening today in order to reproduce the conditions which prevailed in the past. If the conditions which now prevail at times of sunspot minima were magnified, they would give the mild conditions of inter-glacial epochs and similar periods. If the conditions which now prevail at times of sunspot maxima are magnified a little they seem to produce periods of climatic stress such as those of the fourteenth century. If they are magnified still more the result is apparently glacial epochs like those of the Pleistocene, and if they are magnified to a still greater extent, the result is Permian or Proterozoic glaciation. Other factors must indeed be favorable, for climatic changes are highly complex and are unquestionably due to a combination of circumstances. The point which is chiefly emphasized in this book is that among 
those several circumstances, changes in cyclonic storms due apparently to activity of the sun's atmosphere must always be reckoned. 


\section{CHAPTER IX}

\section{THE ORIGIN OF LOESS}

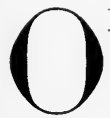

$\mathrm{NE}$ of the most remarkable formations associated with glacial deposits consists of vast sheets of the fine-grained, yellowish, wind-blown material called loess. Somewhat peculiar climatic conditions evidently prevailed when it was formed. At present similar deposits are being laid down only near the leeward margin of great deserts. The famous loess deposits of China in the lee of the Desert of Gobi are examples. During the Pleistocene period, however, loess accumulated in a broad zone along the margin of the ice sheet at its maximum extent. In the Old World it extended from France across Germany and through the Black Earth region of Russia into Siberia. In the New World a still larger area is loess-covered. In the Mississippi Valley, tens of thousands of square miles are mantled by a layer exceeding twenty feet in thickness and in many places approaching a hundred feet. Neither the North American nor the European deposits are associated with a desert. Indeed, loess is lacking in the western and drier parts of the great plains and is best developed in the well-watered states of Iowa, Illinois, and Missouri. Part of the loess overlies the non-glacial materials of the great central plain, but the northern portions overlie the drift deposits of the first three glaciations. A few traces of loess are associated with the Kansan and Illinoian, the second and third glaciations, but most of the Ameri- 
can loess appears to have been formed at approximately the time of the Iowan or fourth glaciation, while only a little overlies the drift sheets of the Wisconsin age. The loess is thickest near the margin of the Iowan till sheet and thins progressively both north and south. The thinning southward is abrupt along the stream divides, but very gradual along the larger valleys. Indeed, loess is abundant along the bluffs of the Mississippi, especially the east bluff, almost to the Gulf of Mexico. ${ }^{1}$

It is now generally agreed that all typical loess is wind blown. There is still much question, however, as to its time of origin, and thus indirectly as to its climatic implications. Several American and European students have thought that the loess dates from inter-glacial times. On the other hand, Penck has concluded that the loess was formed shortly before the commencement of the glacial epochs; while many American geologists hold that the loess accumulated while the ice sheets were at approximately their maximum size. W. J. McGee, Chamberlin and Salisbury, Keyes, and others lean toward this view. In this chapter the hypothesis is advanced that it was formed at the one other possible time, namely, immediately following the retreat of the ice.

These four hypotheses as to the time of origin of loess imply the following differences in its climatic relations. If loess was formed during typical inter-glacial epochs, or toward the close of such epochs, profound general aridity must seemingly have prevailed in order to kill off the vegetation and thus enable the wind to pick up sufficient dust. If the loess was formed during times of extreme glaciation when the glaciers were supplying large quantities of fine material to outflowing streams, less aridity would be required, but there must have been

1 Chamberlin and Salisbury: Geology, 1906, Vol. III, pp. 405-412. 
sharp contrasts between wet seasons in summer when the snow was melting and dry seasons in winter when the storms were forced far south by the glacial high pressure. Alternate floods and droughts would thus affect broad areas along the streams. Hence arises the hypothesis that the wind obtained the loess from the flood plains of streams at times of maximum glaciation. If the loess was formed during the rapid retreat of the ice, alternate summer floods and winter droughts would still prevail, but much material could also be obtained by the winds not only from flood plains, but also from the deposits exposed by the melting of the ice and not yet covered by vegetation.

The evidence for and against the several hypotheses may be stated briefly. In support of the hypothesis of the inter-glacial origin of loess, Shimek and others state that the glacial drift which lies beneath the loess commonly gives evidence that some time elapsed between the disappearance of the ice and the deposition of the loess. For example, abundant shells of land snails in the loess are not of the sort now found in colder regions, but resemble those found in the drier regions. It is probable that if they represented a glacial epoch they would be depauperated by the cold as are the snails of far northern regions. The gravel pavement discussed below seems to be strong evidence of erosion between the retreat of the ice and the deposition of the loess.

Turning to the second hypothesis, namely, that the loess accumulated near the close of the inter-glacial epoch rather than in the midst of it, we may follow Penck. The mammalian fossils seem to him to prove that the loess was formed while boreal animals occupied the region, for they include remains of the hairy mammoth, woolly rhinoceros, and reindeer. On the other hand, the typical 
inter-glacial beds not far away yield remains of species characteristic of milder climates, such as the elephant, the smaller rhinoceros, and the deer. In connection with these facts it should be noted that occasional remains of tundra vegetation and of trees are found beneath the loess, while in the loess itself certain steppe animals, such as the common gopher or spermaphyl, are found. Penck interprets this as indicating a progressive desiccation culminating just before the oncoming of the next ice sheet.

The evidence advanced in favor of the hypothesis that the loess was formed when glaciation was near its maximum includes the fact that if the loess does not represent the outwash from the Iowan ice, there is little else that does, and presumably there must have been outwash. Also the distribution of loess along the margins of streams suggests that much of the material came from the flood plains of overloaded streams flowing from the melting ice.

Although there are some points in favor of the hypothesis that the loess originated (1) in strictly interglacial times, (2) at the end of inter-glacial epochs, and (3) at times of full glaciation, each hypothesis is much weakened by evidence that supports the others. The evidence of boreal animals seems to disprove the hypothesis that the loess was formed in the middle of a mild interglacial epoch. On the other hand, Penck's hypothesis as to loess at the end of inter-glacial times fails to account for certain characteristics of the lowest part of the loess deposits and of the underlying topography. Instead of normal valleys and consequent prompt drainage such as ought to have developed before the end of a long interglacial epoch, the surface on which the loess lies shows many undrained depressions. Some of these can be seen 
in exposed banks, while many more are inferred from the presence of shells of pond snails here and there in the overlying loess. The pond snails presumably lived in shallow pools occupying depressions in the uneven surface left by the ice. Another reason for questioning whether the loess was formed at the end of an interglacial epoch is that this hypothesis does not provide a reasonable origin for the material which composes the loess. Near the Alps where the loess deposits are small and where glaciers probably persisted in the inter-glacial epochs and thus supplied flood plain material in large quantities, this does not appear important. In the broad upper Mississippi Basin, however, and also in the Black Earth region of Russia there seems to be no way to get the large body of material composing the loess except by assuming the existence of great deserts to windward. But there seems to be little or no evidence of such deserts where they could be effective. The mineralogical character of the loess of Iowan age proves that the material came from granitic rocks, such as formed a large part of the drift. The nearest extensive outcrops of granite are in the southwestern part of the United States, nearly a thousand miles from Iowa and Illinois. But the loess is thickest near the ice margin and thins toward the southwest and in other directions, whereas if its source were the southwestern desert, its maximum thickness would probably be near the margin of the desert.

The evidence cited above seems inconsistent not only with the hypothesis that the loess was formed at the end of an inter-glacial epoch, but also with the idea that it originated at times of maximum glaciation either from river-borne sediments or from any other source. A further and more convincing reason for this last conclusion is the probability and almost the certainty that 
when the ice advanced, its front lay close to areas where the vegetation was not much thinner than that which today prevails under similar climatic conditions. If the average temperature of glacial maxima was only $6^{\circ} \mathrm{C}$. lower than that of today, the conditions just beyond the ice front when it was in the loess region from southern Illinois to Minnesota would have been like those now prevailing in Canada from New Brunswick to Winnipeg. The vegetation there is quite different from the grassy, semi-arid vegetation of which evidence is found in the loess. The roots and stalks of such grassy vegetation are generally agreed to have helped produce the columnar structure which enables the loess to stand with almost vertical surfaces.

We are now ready to consider the probability that loess accumulated mainly during the retreat of the ice. Such a retreat exposed a zone of drift to the outflowing glacial winds. Most glacial hypotheses, such as that of uplift, or depleted carbon dioxide, call for a gradual retreat of the ice scarcely faster than the vegetation could advance into the abandoned area. Under the solar-cyclonic hypothesis, on the other hand, the climatic changes may have been sudden and hence the retreat of the ice may have been much more rapid than the advance of vegetation. Now wind-blown materials are derived from places where vegetation is scanty. Scanty vegetation on good soil, it is true, is usually due to aridity, but may also result because the time since the soil was exposed to the air has not been long enough for the soil to be sufficiently weathered to support vegetation. Even when weathering has had full opportunity, as when sand bars, mud flats, and flood plains are exposed, vegetation takes root only slowly. Moreover, storms and violent winds may prevent the spread of vegetation, as is seen on sandy beaches even 
in distinctly humid regions like New Jersey and Denmark. Thus it appears that unless the retreat of the ice were as slow as the advance of vegetation, a barren area of more or less width must have bordered the retreating ice and formed an ideal source of loess.

Several other lines of evidence seemingly support the conclusion that the loess was formed during the retreat of the ice. For example, Shimek, who has made almost a lifelong study of the Iowan loess, emphasizes the fact that there is often an accumulation of stones and pebbles at its base. This suggests that the underlying till was eroded before the loess was deposited upon it. The first reaction of most students is to assume that of course this was due to running water. That is possible in many cases, but by no means in all. So widespread a sheet of gravel could not be deposited by streams without destroying the irregular basins and hollows of which we have seen evidence where the loess lies on glacial deposits. On the other hand, the wind is competent to produce a similar gravel pavement without disturbing the old topography. "Desert pavements" are a notable feature in most deserts. On the edges of an ice sheet, as Hobbs has made us realize, the commonest winds are outward. They often attain a velocity of eighty miles an hour in Antarctica and Greenland. Such winds, however, usually decline rapidly in velocity only a few score miles from the ice. Thus their effect would be to produce rapid erosion of the freshly bared surface near the retreating ice. The pebbles would be left behind as a pavement, while sand and then loess would be deposited farther from the ice where the winds were weaker and where vegetation was beginning to take root. Such a decrease in wind velocity may explain the occasional vertical gradation from gravel through sand to coarse loess and then to 
normal fine loess. As the ice sheet retreated the wind in any given place would gradually become less violent. As the ice continued to retreat the area where loess was deposited would follow at a distance, and thus each part of the gravel pavement would in turn be covered with the loess.

The hypothesis that loess is deposited while the ice is retreating is in accord with many other lines of evidence. For example, it accords with the boreal character of the mammal remains as described above. Again, the advance of vegetation into the barren zone along the front of the ice would be delayed by the strong outblowing winds. The common pioneer plants depend largely on the wind for the distribution of their seeds, but the glacial winds would carry them away from the ice rather than toward it. The glacial winds discourage the advance of vegetation in another way, for they are drying winds, as are almost all winds blowing from a colder to a warmer region. The fact that remains of trees sometimes occur at the bottom of the loess probably means that the deposition of loess extended into the forests which almost certainly persisted not far from the ice. This seems more likely than that a period of severe aridity before the advance of the ice killed the trees and made a steppe or desert. Penck's chief argument in favor of the formation of loess before the advance of the ice rather than after, is that since loess is lacking upon the youngest drift sheet in Europe it must have been formed before rather than after the last or Würm advance of the ice. This breaks down on two counts. First, on the corresponding (Wisconsin) drift sheet in America, loess is present,-in small quantities to be sure, but unmistakably present. Second, there is no reason to assume that conditions were identical at each advance and retreat of the ice. Indeed, the 
fact that in Europe, as in the United States, nearly all the loess was formed at one time, and only a little is associated with the other ice advances, points clearly against Penck's fundamental assumption that the accumulation of loess was due to the approach of a cold climate.

Having seen that the loess was probably formed during the retreat of the ice, we are now ready to inquire what conditions the cyclonic hypothesis would postulate in the loess areas during the various stages of a glacial eycle. Fig. 2, in Chapter IV, gives the best idea of what would apparentlyhappen in NorthAmerica,andeventsin Europe would presumably be similar. During the nine maximum years on which Fig. 2 is based the sunspot numbers averaged seventy, while during the nine minimum years they averaged less than five. It seems fair to suppose that the maximum years represent the average conditions which prevailed in the past at times when the sun was in a median stage between the full activity which led to glaciation and the mild activity of the minimum years which appear to represent inter-glacial conditions. This would mean that when a glacial period was approaching, but before an ice sheet had accumulated to any great extent, a crescent-shaped strip from Montana through Illinois to Maine would suffer a diminution in storminess ranging up to 60 per cent as compared with inter-glacial conditions. This is in strong contrast with an increase in storminess amounting to 75 or even 100 per cent both in the boreal storm belt in Canada and in the subtropical belt in the Southwest. Such a decrease in storminess in the central United States would apparently be most noticeable in summer, as is shown in Earth and Sun. Hence it would have a maximum effect in producing aridity. This would favor the formation of loess, but it is doubtful whether the aridity would become extreme 
enough to explain such vast deposits as are found throughout large parts of the Mississippi Basin. That would demand that hundreds of thousands of square miles should become almost absolute desert, and it is not probable that any such thing occurred. Nevertheless, according to the cyclonic hypothesis the period immediately before the advent of the ice would be relatively dry in the central United States, and to that extent favorable to the work of the wind.

As the climatic conditions became more severe and the ice sheet expanded, the dryness and lack of storms would apparently diminish. The reason, as has been explained, would be the gradual pushing of the storms southward by the high-pressure area which would develop over the ice sheet. Thus at the height of a glacial epoch there would apparently be great storminess in the area where the loess is found, especially in summer. Hence the cyclonic hypothesis does not accord with the idea of great deposition of loess at the time of maximum glaciation.

Finally we come to the time when the ice was retreating. We have already seen that not only the river flood plains, but also vast areas of fresh glacial deposits would be exposed to the winds, and would remain without vegetation for a long time. At that very time the retreat of the ice sheet would tend to permit the storms to follow paths determined by the degree of solar activity, in place of the far southerly paths to which the high atmospheric pressure over the expanded ice sheet had previously forced them. In other words, the conditions shown in Fig. 2 would tend to reappear when the sun's activity was diminishing and the ice sheet was retreating, just as they had appeared when the sun was becoming more active and the ice sheet was advancing. This time, however, the semi-arid conditions arising from the scarcity 
of storms would prevail in a region of glacial deposits and widely spreading river deposits, few or none of which would be covered with vegetation. The conditions would be almost ideal for eolian erosion and for the transportation of loess by the wind to areas a little more remote from the ice where grassy vegetation had made a start.

The cyclonic hypothesis also seems to offer a satisfactory explanation of variations in the amount of loess associated with the several glacial epochs. It attributes these to differences in the rate of disappearance of the ice, which in turn varied with the rate of decline of solar activity and storminess. This is supposed to be the reason why the Iowan loess deposits are much more extensive than those of the other epochs, for the Iowan ice sheet presumably accomplished part of its retreat much more suddenly than the other ice sheets. ${ }^{2}$ The more sudden the retreat, the greater the barren area where the winds could gather fine bits of dust. Temporary readvances may also have been so distributed and of such intensity that they frequently accentuated the condition shown in Fig. 2 , thus making the central United States dry soon after the exposure of great amounts of glacial débris. The closeness with which the cyclonic hypothesis accords with the facts as to the loess is one of the pleasant surprises of the hypothesis. The first draft of Fig. 2 and the first outlines of the hypothesis were framed without thought of the loess. Yet so far as can now be seen, both agree closely with the conditions of loess formation.

2 It may have retreated soon after reaching its maximum. If so, the general lack of thick terminal moraines would be explained. See page 122 . 


\section{CHAPTER X}

\section{CAUSES OF MILD GEOLOGICAL CLIMATES}

T $\mathrm{N}$ discussions of climate, as of most subjects, a peculiar psychological phenomenon is observable. Everyone sees the necessity of explaining conditions different from those that now exist, but few realize that present conditions may be abnormal, and that they need explanation just as much as do others. Because of this tendency glaciation has been discussed with the greatest fullness, while there has been much neglect not only of the periods when the climate of the earth resembled that of the present, but also of the vastly longer periods when it was even milder than now.

How important the periods of mild climate have been in geological times may be judged from the relative length of glacial compared with inter-glacial epochs, and still more from the far greater relative length of the mild parts of periods and eras when compared with the severe parts. Recent estimates by R. T. Chamberlin ${ }^{1}$ indicate that according to the consensus of opinion among geologists the average inter-glacial epoch during the Pleistocene was about five times as long as the average glacial epoch, while the whole of a given glacial epoch averaged five times as long as the period when the ice was at a maximum. Climatic periods far milder, longer, and more monotonous than any inter-glacial epoch appear repeat-

1 Rollin T. Chamberlin: Personal Communication. 
edly during the course of geological history. Our task in this chapter is to explain them.

Knowlton ${ }^{2}$ has done geology a great service by collecting the evidence as to the mild type of climate which has again and again prevailed in the past. He lays special stress on botanical evidence since that pertains to the variable atmosphere of the lands, and hence furnishes a better guide than does the evidence of animals that lived in the relatively unchanging water of the oceans. The nature of the evidence has already been indicated in various parts of this book. It includes palms, tree ferns, and a host of other plants which once grew in regions which are now much too cold to support them. With this must be placed the abundant reef-building corals and other warmth-loving marine creatures in latitudes now much too cold for them. Of a piece with this are the conditions of inter-glacial epochs in Europe, for example, when elephants and hippopotamuses, as well as many species of plants from low latitudes, were abundant. These conditions indicate not only that the climate was warmer than now, but that the contrast from season to season was much less. Indeed, Knowlton goes so far as to say that "relative uniformity, mildness, and comparative equability of climate, accompanied by high humidity, have prevailed over the greater part of the earth, extending to, or into, polar circles, during the greater part of geologic time-since, at least, the Middle Paleozoic. This is the regular, the ordinary, the normal condition." . . . "By many it is thought that one of the strongest arguments against a gradually cooling globe and a humid, non-zonally disposed climate in the ages before the Pleistocene is the discovery of evidences of glacial action

2 F. H. Knowlton: Evolution of Geologic Climates; Bull. Geol. Soc. Am., Vol. 30, 1919, pp. 499-566. 
practically throughout the entire geologic column. Hardly less than a dozen of these are now known, ranging in age from Huronian to Eocene. It seems to be a very general assumption by those who hold this view that these evidences of glacial activities are to be classed as ice ages, largely comparable in effect and extent to the Pleistocene refrigeration, but as a matter of fact only three are apparently of a magnitude to warrant such designation. These are the Huronian glaciation, that of the 'Permo-Carboniferous,' and that of the Pleistocene. The others, so far as available data go, appear to be explainable as more or less local manifestations that had no widespread effect on, for instance, ocean temperatures, distribution of life, et cetera. They might well have been of the type of ordinary mountain glaciers, due entirely to local elevation and precipitation." . . . "If the sun had been the principal source of heat in pre-Pleistocene time, terrestrial temperatures would of necessity have been disposed in zones, whereas the whole trend of this paper has been the presentation of proof that these temperatures were distinctly non-zonal. Therefore it seems to follow that the sun-at least the present smallangle sun-could not have been the sole or even the principal source of heat that warmed the early oceans."

Knowlton is so strongly impressed by the widespread fossil floras that usually occur in the middle parts of the geological periods, that as Schuchert ${ }^{3}$ puts it, he neglects the evidence of other kinds. In the middle of the periods and eras the expansion of the warm oceans over the continents was greatest, while the lands were small and hence had more or less insular climates of the oceanic type. At such times, the marine fauna agrees with the

3 Chas. Schuchert: Review of Knowlton's Evolution of Geological Climates, in Am. Jour. Sci., 1921. 
flora in indicating a mild climate. Large colony-forming foraminifera, stony corals, shelled cephalopods, gastropods and thick-shelled bivalves, generally the cemented forms, were common in the Far North and even in the Arctic. This occurred in the Silurian, Devonian, Pennsylvanian, and Jurassic periods, yet at other times, such as the Cretaceous and Eocene, such forms were very greatly reduced in variety in the northern regions or else wholly absent. These things, as Schuchert ${ }^{3}$ says, can only mean that Knowlton is right when he states that "climatic zoning such as we have had since the beginning of the Pleistocene did not obtain in the geologic ages prior to the Pleistocene." It does not mean, however, that there was a "non-zonal arrangement" and that the temperature of the oceans was everywhere the same and "without widespread effect on the distribution of life."

Students of paleontology hold that as far back as we can go in the study of plants, there are evidences of seasons and of relatively cool climates in high latitudes. The cycads, for instance, are one of the types most often used as evidence of a warm climate. Yet Wieland, ${ }^{4}$ who has made a lifelong study of these plants, says that many of them "might well grow in temperate to cool climates. Until far more is learned about them they should at least be held as valueless as indices of tropic climates." The inference is "that either they or their close relatives had the capacity to live in every clime. There is also a suspicion that study of the associated ferns may compel revision of the long-accepted view of the universality of tropic climates throughout the Mesozoic." Nathorst is quoted by Wieland as saying, "I think . . . that during the time when the Gingkophytes and Cycadophytes domi-

4 G. R. Wieland: Distribution and Relationships of the Cycadeoids; Am. Jour. Bot., Vol. 7, 1920, pp. 125-145. 
nated, many of them must have adapted themselves for living in cold climates also. Of this I have not the least doubt."

Another important line of evidence which Knowlton and others have cited as a proof of the non-zonal arrangement of climate in the past, is the vast red beds which are found in the Proterozoic, late Silurian, Devonian, Permian, and Triassic, and in some Tertiary formations. These are believed to resemble laterite, a red and highly oxidized soil which is found in great abundance in equatorial regions. Knowlton does not attempt to show that the red beds present equatorial characteristics in other respects, but bases his conclusion on the statement that "red beds are not being formed at the present time in any desert region." This is certainly an error. As has already been said, in both the Transcaspian and Takla Makan deserts, the color of the sand regularly changes from brown on the borders to pale red far out in the desert. Kuzzil Kum, or Red Sand, is the native name. The sands in the center of the desert apparently were originally washed down from the same mountains as those on the borders, and time has turned them red. Since the same condition is reported from the Arabian Desert, it seems that redness is characteristic of some of the world's greatest deserts. Moreover, beds of salt and gypsum are regularly found in red beds, and they can scarcely originate except in deserts, or in shallow almost landlocked bays on the coasts of deserts, as appears to have happened in the Silurian where marine fossils are found interbedded with gypsum.

Again, Knowlton says that red beds cannot indicate deserts because the plants found in them are not "pinched or depauperate, nor do they indicate xerophytic adaptations. Moreover, very considerable deposits 
of coal are found in red beds in many parts of the world, which implies the presence of swamps but little above sea-level."

Students of desert botany are likely to doubt the force of these considerations. As MacDougal ${ }^{5}$ has shown, the variety of plants in deserts is greater than in moist regions. Not only do xerophytic desert species prevail, but halophytes are present in the salty areas, and hygrophytes in the wet swampy areas, while ordinary mesophytes prevail along the water courses and are washed down from the mountains. The ordinary plants, not the xerophytes, are the ones that are chiefly preserved since they occur in most abundance near streams where deposition is taking place. So far as swamps are concerned, few are of larger size than those of Seistan in Persia, Lop Nor in Chinese Turkestan, and certain others in the midst of the Asiatic deserts. Streams flowing from the mountains into deserts are almost sure to form large swamps, such as those along the Tarim River in central Asia. Lake Chad in Africa is another example. In it, too, reeds are very numerous.

Putting together the evidence on both sides in this disputed question, it appears that throughout most of geological time there is some evidence of a zonal arrangement of climate. The evidence takes the form of traces of cool climates, of seasons, and of deserts. Nevertheless, there is also strong evidence that these conditions were in general less intense than at present and that times of relatively warm, moist climate without great seasonal extremes have prevailed very widely during periods much longer than those when a zonal arrangement as

\footnotetext{
5 D. T. MacDougal: Botanical Features of North American Deserts; Carnegie Instit. of Wash., No. 99, 1908.
} 
marked as that of today prevailed. As Schuchert ${ }^{6}$ puts it: "Today the variation on land between the tropics and the poles is roughly between $110^{\circ}$ and $-60^{\circ} \mathrm{F}$., in the oceans between $85^{\circ}$ and $31^{\circ} \mathrm{F}$. In the geologic past the temperature of the oceans for the greater parts of the periods probably was most often between $85^{\circ}$ and $55^{\circ} \mathrm{F}$., while on land it may have varied between $90^{\circ}$ and $0^{\circ} \mathrm{F}$. At rare intervals the extremes were undoubtedly as great as they are today. The conclusion is therefore that at all times the earth had temperature zones, varying between the present-day intensity and times which were almost without such belts, and at these latter times the greater part of the earth had an almost uniformly mild climate, without winters."

It is these mild climates which we must now attempt to explain. This leads us to inquire what would happen to the climate of the earth as a whole if the conditions which now prevail at times of few sunspots were to become intensified. That they could become greatly intensified seems highly probable, for there is good reason to think that aside from the sunspot cycle the sun's atmosphere is in a disturbed condition. The prominences which sometimes shoot out hundreds of thousands of miles seem to be good evidence of this. Suppose that the sun's atmosphere should become very quiet. This would apparently mean that cyclonic storms would be much less numerous and less severe than during the present times of sunspot minima. The storms would also apparently follow paths in middle latitudes somewhat as they do now when sunspots are fewest. The first effect of such a condition, if we can judge from what happens at present, would be a rise in the general temperature of the earth, because less heat would be carried aloft by storms.

${ }^{6}$ Loc. cit. 
Today, as is shown in Earth and Sun, a difference of perhaps 10 per cent in the average storminess during periods of sunspot maxima and minima is correlated with a difference of $3^{\circ} \mathrm{C}$. in the temperature at the earth's surface. This includes not only an actual lowering of $0.6^{\circ} \mathrm{C}$. at times of sunspot maxima, but the overcoming of the effect of increased insolation at such times, an effect which Abbot calculates as about $2.5^{\circ} \mathrm{C}$. If the storminess were to be reduced to one-half or one-quarter its present amount at sunspot minima, not only would the loss of heat by upward convection in storms be diminished, but the area covered by clouds would diminish so that the sun would have more chance to warm the lower air. Hence the average rise of temperature might amount to as much at $5^{\circ}$ or $10^{\circ} \mathrm{C}$.

Another effect of the decrease in storminess would be to make the so-called westerly winds, which are chiefly southwesterly in the northern hemisphere and northwesterly in the southern hemisphere, more strong and steady than at present. They would not continually suffer interruption by cyclonic winds from other directions, as is now the case, and would have a regularity like that of the trades. This conclusion is strongly reënforced in a paper by Clayton ${ }^{7}$ which came to hand after this chapter had been completed. From his studies of the solar constant and the temperature of the earth which are described in Earth and Sun, he reaches the following conclusion: "The results of these researches have led me to believe: 1 . That if there were no variation in solar radiation the atmospheric motions would establish a stable system with exchanges of air between equator and pole and between ocean and land, in which the only varia-

7 H. H. Clayton: Variation in Solar Radiation and the Weather; Smiths. Misc. Coll., Vol. 71, No. 3, Washington, 1920. 
tions would be daily and annual changes set in operation by the relative motions of the earth and sun. 2 . The existing abnormal changes, which we call weather, have their origins chiefly, if not entirely, in the variations of solar radiation."

If cyclonic storms and "weather" were largely eliminated and if the planetary system of winds with its steady trades and southwesterlies became everywhere dominant, the regularity and volume of the polewardflowing currents, such as the Gulf Stream and the Atlantic Drift in one ocean, and the Japanese Current in another, would be greatly increased. How important this is may be judged from the work of Helland-Hansen and Nansen. ${ }^{8}$ These authors find that with the passage of each cyclonic storm there is a change in the temperature of the surface water of the Atlantic Ocean. Winds at right angles to the course of the Drift drive the water first in one direction and then in the other but do not advance it in its course. Winds with an easterly component, on the other hand, not only check the Drift but reverse it, driving the warm water back toward the southwest and. allowing cold water to well up in its stead. The driving force in the Atlantic Drift is merely the excess of the winds with a westerly component over those with an easterly component.

Suppose that the numbers in Fig. 8 represent the strength of the winds in a certain part of the North Atlantic or North Pacific, that is, the total number of miles moved by the air per year. In quadrant $\mathrm{A}$ of the left-hand part all the winds move from a more or less southwesterly direction and produce a total movement

8 B. Helland-Hansen and F. Nansen: Temperature Variations in the North Atlantic Ocean and in the Atmosphere; Misc. Coll., Smiths. Inst., Vol. 70, No. 4, Washington, 1920. 
CAUSES OF MILD GEOLOGICAL CLIMATES 175
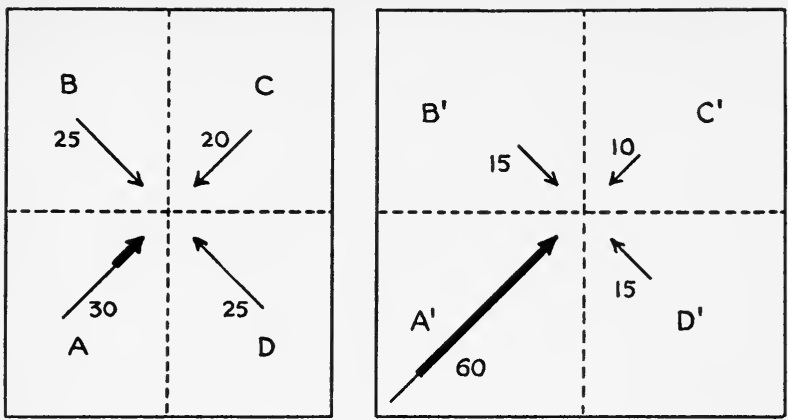

Fig. 8. Effect of diminution of storms on movement of water.

of the air amounting to thirty units per year. Those coming from points between north and west move twentyfive units; those between north and east, twenty units; and those between east and south, twenty-five units. Since the movement of the winds in quadrants $B$ and $\mathrm{D}$ is the same, these winds have no effect in producing currents. They merely move the water back and forth, and thus give it time to lose whatever heat it has brought from more southerly latitudes. On the other hand, since the easterly winds in quadrant $\mathrm{C}$ do not wholly check the currents caused by the westerly winds of quadrant $A$, the effective force of the westerly winds amounts to ten, or the difference between a force of thirty in quadrant $A$ and of twenty in quadrant $\mathrm{C}$. Hence the water is moved forward toward the northeast, as shown by the thick part of arrow A.

Now suppose that cyclonic storms should be greatly reduced in number so that in the zone of prevailing westerlies they were scarcely more numerous than tropi- 
cal hurricanes now are in the trade-wind belt. Then the more or less southwesterly winds in quadrant $A^{\prime}$ in the right-hand part of Fig. 8 would not only become more frequent but would be stronger than at present. The total movement from that quarter might rise to sixty units, as indicated in the figure. In quadrants $\mathrm{B}^{\prime}$ and $\mathrm{D}^{\prime}$ the movement would fall to fifteen and in quadrant $\mathrm{C}^{\prime}$ to ten. $\mathrm{B}^{\prime}$ and $\mathrm{D}^{\prime}$ would balance one another as before. The movement in $\mathrm{A}^{\prime}$, however, would exceed that in $\mathrm{C}^{\prime}$ by fifty instead of ten. In other words, the current-making force would become five times as great as now. The actual effect would be increased still more, for the winds from the southwest would be stronger as well as steadier if there were no storms. A strong wind which causes whitecaps has much more power to drive the water forward than a weaker wind which does not cause whitecaps. In a wave without a whitecap the water returns to practically the original point after completing a circle beneath the surface. In a wave with a whitecap, however, the cap moves forward. Any increase in velocity beyond the rate at which whitecaps are formed has a great influence upon the amount of water which is blown forward. Several times as much water is drifted forward by a persistent wind of twenty miles an hour as by a ten-mile wind. ${ }^{\circ}$

In this connection a suggestion which is elaborated in Chapter XIII may be mentioned. At present the salinity of the oceans checks the general deep-sea circulation and thereby increases the contrasts from zone to zone. In the past, however, the ocean must have been fresher than now. Hence the circulation was presumably less impeded, and the transfer of heat from low latitudes to high was facilitated.

9 The climatic significance of ocean currents is well discussed in Croll's Climate and Time, 1875, and his Climate and Cosmogony, 1889. 
Consider now the magnitude of the probable effect of a diminution in storms. Today off the coast of Norway in latitude $65^{\circ} \mathrm{N}$. and longitude $10^{\circ} \mathrm{E}$., the mean temperature in January is $2^{\circ} \mathrm{C}$. and in July $12^{\circ} \mathrm{C}$. This represents a plus anomaly of about $22^{\circ}$ in January and $2^{\circ}$ in July; that is, the Norwegian coast is warmer than the normal for its latitude by these amounts. Suppose that in some past time the present distribution of lands and seas prevailed, but Norway was a lowland where extensive deposits could accumulate in great flood plains. Suppose, also, that the sun's atmosphere was so inactive that few cyclonic storms occurred, steady winds from the westsouthwest prevailed, and strong, uninterrupted ocean currents brought from the Caribbean Sea and Gulf of Mexico much greater supplies of warm water than at present. The Norwegian winters would then be warmer than now not only because of the general increase in temperature which the earth regularly experiences at sunspot minima, but because the currents would accentuate this condition. In summer similar conditions would prevail except that the warming effect of the winds and currents would presumably be less than in winter, but this might be more than balanced by the increased heat of the sun during the long summer days, for storms and clouds would be rare.

If such conditions raised the winter temperature only $8^{\circ} \mathrm{C}$. and the summer temperature $4^{\circ} \mathrm{C}$., the climate would be as warm as that of the northern island of New Zealand (latitude $35^{\circ}-43^{\circ} \mathrm{S}$.). The flora of that part of New Zealand is subtropical and includes not only pines and beeches, but palms and tree ferns. A climate scarcely warmer than that of New Zealand would foster a flora like that which existed in far northern latitudes during some of the milder geological periods. If, however, the 
general temperature of the earth's surface were raised $5^{\circ}$ because of the scarcity of storms, if the currents were strong enough so that they increased the present anomaly by 50 per cent, and if more persistent sunshine in summer raised the temperature at that season about $4^{\circ} \mathrm{C}$, the January temperature would be $18^{\circ} \mathrm{C}$. and the July temperature $22^{\circ} \mathrm{C}$. These figures perhaps make summer and winter more nearly alike than was ever really the case in such latitudes. Nevertheless, they show that a diminution of storms and a consequent strengthening and steadying of the southwesterlies might easily raise the temperature of the Norwegian coast so high that corals could flourish within the Arctic Circle.

Another factor would coöperate in producing mild temperatures in high latitudes during the winter, namely, the fogs which would presumably accumulate. It is well known that when saturated air from a warm ocean is blown over the lands in winter, as happens so often in the British Islands and around the North Sea, fog is formed. The effect of such a fog is indeed to shut out the sun's radiation, but in high latitudes during the winter when the sun is low, this is of little importance. Another effect is to retain the heat of the earth itself. When a constant supply of warm water is being brought from low latitudes this blanketing of the heat by the fog becomes of great importance. In the past, whenever cyclonic storms were weak and westerly winds were correspondingly strong, winter fogs in high latitudes must have been much more widespread and persistent than now.

The bearing of fogs on vegetation is another interesting point. If a region in high latitudes is constantly protected by fog in winter, it can support types of vegetation characteristic of fairly low latitudes, for plants are oftener killed by dry cold than by moist cold. Indeed, 
excessive evaporation from the plant induced by dry cold when the evaporated water cannot be rapidly replaced by the movement of sap is a chief reason why large plants are winterkilled. The growing of transplanted palms on the coast of southwestern Ireland, in spite of its location in latitude $50^{\circ} \mathrm{N}$., is possible only because of the great fogginess in winter due to the marine climate. The fogs prevent the escape of heat and ward off killing frosts. The tree ferns in latitude $46^{\circ} \mathrm{S}$. in New Zealand, already referred to, are often similarly protected in winter. Therefore, the relative frequency of fogs in high latitudes when storms were at a minimum would apparently tend not merely to produce mild winters but to promote tropical vegetation.

The strong steady trades and southwesterlies which would prevail at times of slight solar activity, according to our hypothesis, would have a pronounced effect on the water of the deep seas as well as upon that of the surface. In the first place, the deep-sea circulation would be hastened. For convenience let us speak of the northern hemisphere. In the past, whenever the southwesterly winds were steadier than now, as was probably the case when cyclonic storms were relatively rare, more surface water than at present was presumably driven from low latitudes and carried to high latitudes. This, of course, means that a greater volume of water had to flow back toward the equator in the lower parts of the ocean, or else as a cool surface current. The steady southwesterly winds, however, would interfere with south-flowing surface currents, thus compelling the polar waters to find their way equatorward beneath the surface. In low latitudes the polar waters would rise and their tendency would be to lower the temperature. Hence steadier westerlies would make for lessened latitudinal contrasts in climate not 
only by driving more warm water poleward but by causing more polar water to reach low latitudes.

At this point a second important consideration must be faced. Not only would the deep-sea circulation be hastened, but the ocean depths might be warmed. The deep parts of the ocean are today cold because they receive their water from high latitudes where it sinks because of low temperature. Suppose, however, that a diminution in storminess combined with other conditions should permit corals to grow in latitude $70^{\circ} \mathrm{N}$. The ocean temperature would then have to average scarcely lower than $20^{\circ} \mathrm{C}$. and even in the coldest month the water could scarcely fall below about $15^{\circ} \mathrm{C}$. Under such conditions, if the polar ocean were freely connected with the rest of the oceans, no part of it would probably have a temperature much below $10^{\circ} \mathrm{C}$., for there would be no such thing as ice caps and snowfields to reflect the scanty sunlight and radiate into space what little heat there was. On the contrary, during the winter an almost constant state of dense fogginess would prevail. So great would be the blanketing effect of this that a minimum monthly temperature of $10^{\circ} \mathrm{C}$. for the coldest part of the ocean may perhaps be too low for a time when corals thrived in latitude $70^{\circ}$.

The temperature of the ocean depths cannot permanently remain lower than that of the coldest parts of the surface. Temporarily this might indeed happen when a solar change first reduced the storminess and strengthened the westerlies and the surface currents. Gradually, however, the persistent deep-sea circulation would bring up the colder water in low latitudes and carry downward the water of medium temperature at the coldest part of the surface. Thus in time the whole body of the ocean would become warm. The heat which at present is carried away from the earth's surface in storms would slowly 
accumulate in the oceans. As the process went on, all parts of the ocean's surface would become warmer, for equatorial latitudes would be less and less cooled by cold water from below, while the water blown from low latitudes to high would be correspondingly warmer. The warming of the ocean would come to an end only with the attainment of a state of equilibrium in which the loss of heat by radiation and evaporation from the ocean's surface equaled the loss which under other circumstances would arise from the rise of warm air in cyclonic storms. When once the oceans were warmed, they would form an extremely strong conservative force tending to preserve an equable climate in all latitudes and at all seasons. According to the solar cyclonic hypothesis such conditions ought to have prevailed throughout most of geological time. Only after a strong and prolonged solar disturbance with its consequent storminess would conditions like those of today be expected.

In this connection another possibility may be mentioned. It is commonly assumed that the earth's axis is held steadily in one direction by the fact that the rotating earth is a great gyroscope. Having been tilted to a certain position, perhaps by some extraneous force, the axis is supposed to maintain that position until some other force intervenes. Cordeiro, ${ }^{10}$ however, maintains that this is true only of an absolutely rigid gyroscope. He believes that it is mathematically demonstrable that if an elastic gyroscope be gradually tilted by some extraneous force, and if that force then ceases to act, the gyroscope as a whole will oscillate back and forth. The earth appears to be slightly elastic. Cordeiro therefore applies his formulæ to it, on the following assumptions: (1) That the original position of the axis was nearly vertical to the

10 F. J. B. Cordeiro: The Gyroscope, 1913. 
plane of the ecliptic in which the earth revolves around the sun; (2) that at certain times the inclination has been even greater than now ; and (3) that the position of the axis with reference to the earth has not changed to any great extent, that is, the earth's poles have remained essentially stationary with reference to the earth, although the whole earth has been gyroscopically tilted back and forth repeatedly.

With a vertical axis the daylight and darkness in all parts of the earth would be of equal duration, being always twelve hours. There would be no seasons, and the climate would approach the average condition now experienced at the two equinoxes. On the whole the climate of high latitudes would give the impression of being milder than now, for there would be less opportunity for the accumulation of snow and ice with their strong cooling effect. On the other hand, if the axis were tilted more than now, the winter nights would be longer and the winters more severe than at present, and there would be a tendency toward glaciation. Thus Cordeiro accounts for alternating mild and glacial epochs. The entire swing from the vertical position to the maximum inclination and back to the vertical may last millions of years depending on the earth's degree of elasticity. The swing beyond the vertical position in the other direction would be equally prolonged. Since the axis is now supposed to be much nearer its maximum than its minimum degree of tilting, the duration of epochs having a climate more severe than that of the present would be relatively short, while the mild epochs would be long.

Cordeiro's hypothesis has been almost completely ignored. One reason is that his treatment of geological facts, and especially his method of riding rough-shod over widely accepted conclusions, has not commended his 
work to geologists. Therefore they have not deemed it worth while to urge mathematicians to test the assumptions and methods by which he reached his results. It is perhaps unfair to test Cordeiro by geology, for he lays no claim to being a geologist. In mathematics he labors under the disadvantage of having worked outside the usual professional channels, so that his work does not seem to have been subjected to sufficiently critical analysis.

Without expressing any opinion as to the value of Cordeiro's results we feel that the subject of the earth's gyroscopic motion and of a possible secular change in the direction of the axis deserves investigation for two chief reasons. In the first place, evidences of seasonal changes and of seasonal uniformity seem to occur more or less alternately in the geological record. Second, the remarkable discoveries of Garner and Allard ${ }^{11}$ show that the duration of daylight has a pronounced effect upon the reproduction of plants. We have referred repeatedly to the tree ferns, corals, and other forms of life which now live in relatively low latitudes and which cannot endure strong seasonal contrasts, but which once lived far to the north. On the other hand, Sayles, ${ }^{12}$ for example, finds that microscopical examination of the banding of ancient shales and slates indicates distinct seasonal banding like that of recent Pleistocene clays or of the Squantum slate formed during or near the Permian glacial period. Such seasonal banding is found in rocks of various ages: (a) Huronian, in cobalt shales previously reported by Coleman; (b) late Proterozoic or early Cam-

$11 \mathrm{~W}$. W. Garner and H. A. Allard: Flowering and Fruition of Plants as Controlled by Length of Day; Yearbook Dept. Agri., 1920, pp. 377-400. 12 Report of Committee on Sedimentation, National Research Council, April, 1922. 
brian, in Hiwassee slate; (c) lower Cambrian, in Georgian slates of Vermont; (d) lower Ordovician, in Georgia (Rockmart slate), Tennessee (Athens shale), Vermont (slates), and Quebec (Beekmantown formation); and (e) Permian in Massachusetts (Squantum slate). How far the periods during which such evidence of seasons was recorded really alternated with mild periods, when tropical species lived in high latitudes and the contrast of seasons was almost or wholly lacking, we have as yet no means of knowing. If periods characterized by marked seasonal changes should be found to have alternated with those when the seasons were of little importance, the fact would be of great geological significance.

The discoveries of Garner and Allard as to the effect of light on reproduction began with a peculiar tobacco plant which appeared in some experiments at Washington. The plant grew to unusual size, and seemed to promise a valuable new variety. It formed no seeds, however, before the approach of cold weather. It was therefore removed to a greenhouse where it flowered and produced seed. In succeeding years the flowering was likewise delayed till early winter, but finally it was discovered that if small plants were started in the greenhouse in the early fall they flowered at the same time as the large ones. Experiments soon demonstrated that the time of flowering depends largely upon the length of the daily period when the plants are exposed to light. The same is true of many other plants, and there is great variety in the conditions which lead to flowering. Some plants, such as witch hazel, appear to be stimulated to bloom by very short days, while others, such as evening primrose, appear to require relatively long days. So sensitive are plants in this respect that Garner and Allard, by changing the length of the period of light, have 
caused a flowerbud in its early stages not only to stop developing but to return once more to a vegetative shoot.

Common iris, which flowers in May and June, will not blossom under ordinary conditions when grown in the greenhouse in winter, even under the same temperature conditions that prevail in early summer. Again, one variety of soy beans will regularly begin to flower in June of each year, a second variety in July, and a third in August, when all are planted on the same date. There are no temperature differences during the summer months which could explain these differences in time of flowering; and, since "internal causes" alone cannot be accepted as furnishing a satisfactory explanation, some external factor other than temperature must be responsible.

The ordinary varieties of cosmos regularly flower in the fall in northern latitudes if they are planted in the spring or summer. If grown in a warm greenhouse during the winter months the plants also flower readily, so that the cooler weather of fall is not a necessary condition. If successive plantings of cosmos are made in the greenhouse during the late winter and early spring months, maintaining a uniform temperature throughout, the plantings made after a certain date will fail to blossom promptly, but, on the contrary, will continue to grow till the following fall, thus flowering at the usual season for this species. This curious reversal of behavior with advance of the season cannot be attributed to change in temperature. Some other factor is responsible for the failure of cosmos to blossom during the summer months. In this respect the behavior of cosmos is just the opposite of that observed in iris.

Certain varieties of soy beans change their behavior in a peculiar manner with advance of the summer season. The variety known as Biloxi, for example, when planted early in the spring in the latitude of Washington, D. C., continues to grow throughout the summer, flowering in September. The plants maintain growth without flowering for fifteen to eighteen weeks, attaining a height of five feet or more. As the dates of successive plantings are moved forward through the months of June and July, how- 
ever, there is a marked tendency for the plants to eut short the period of growth which precedes flowering. This means, of course, that there is a tendency to flower at approximately the same time of year regardless of the date of planting. As a necessary consequence, the size of the plants at the time of flowering is reduced in proportion to the delay in planting.

The bearing of this on geological problems lies in a query which it raises as to the ability of a genus or family of plants to adapt itself to days of very different length from those to which it is wonted. Could tree ferns, ginkgos, cycads, and other plants whose usual range of location never subjects them to daylight for more than perhaps fourteen hours or less than ten, thrive and reproduce themselves if subjected to periods of daylight ranging all the way from nothing up to about twentyfour hours? No answer to this is yet possible, but the question raises most interesting opportunities of investigation. If Cordeiro is right as to the earth's elastic gyroscopic motion, there may have been certain periods when a vertical or almost vertical axis permitted the days to be of almost equal length at all seasons in all latitudes. If such an absence of seasons occurred when the lands were low, when the oceans were extensive and widely open toward the poles, and when storms were relatively inactive, the result might be great mildness of climate such as appears sometimes to have prevailed in the middle of geological eras. Suppose on the other hand that the axis should be tilted more than now, and that the lands should be widely emergent and the storm belt highly active in low latitudes, perhaps because of the activity of the sun. The conditions might be favorable for glaciation at latitudes as low as those where the PermoCarboniferous ice sheets appear to have centered. The possibilities thus suggested by Cordeiro's hypothesis are 
so interesting that the gyroscopic motion of the earth ought to be investigated more thoroughly. Even if no such gyroscopic motion takes place, however, the other causes of mild climate discussed in this chapter may be enough to explain all the observed phenomena.

Many important biological consequences might be drawn from this study of mild geological climates, but this book is not the place for them. In the first chapter we saw that one of the most remarkable features of the climate of the earth is its wonderful uniformity through hundreds of millions of years. As we come down through the vista of years the mild geological periods appear to represent a return as nearly as possible to this standard condition of uniformity. Certain changes of the earth itself, as we shall see in the next chapter, may in the long run tend slightly to change the exact conditions of this climatic standard, as we might perhaps call it. Yet they act so slowly that their effect during hundreds of millions of years is still open to question. At most they seem merely to have produced a slight increase in diversity from season to season and from zone to zone. The normal climate appears still to be of a milder type than that which happens to prevail at present. Some solar condition, whose possible nature will be discussed later, seems even now to cause the number of cyclonic storms to be greater than normal. Hence the earth's climate still shows something of the great diversity of seasons and of zones which is so marked a characteristic of glacial epochs. 


\section{TERRESTRIAI CAUSES OF CLIMATIC CHANGES}

T 1 Hajor portion of this book has been concerned with the explanation of the more abrupt and extreme changes of climate. This chapter and the next consider two other sorts of climatic changes, the slight secular progression during the hundreds of millions of years of recorded earth history, and especially the long slow geologic oscillations of millions or tens of millions of years. It is generally agreed among geologists that the progressive change has tended toward greater extremes of climate; that is, greater seasonal contrasts, and greater contrasts from place to place and from zone to zone. ${ }^{1}$ The slow cyclic changes have been those that favored widespread glaciation at one extreme near the ends of geologic periods and eras, and mild temperatures even in subpolar regions at the other extreme during the medial portions of the periods.

As has been pointed out in an earlier chapter, it has often been assumed that all climatic changes are due to terrestrial causes. We have seen, however, that there is strong evidence that solar variations play a large part in modifying the earth's climate. We have also seen that no known terrestrial agency appears to be able to produce the abrupt changes noted in recent years, the longer

1 Chas. Schuchert: The Earth's Changing Surface and Climate during Geologic Time; in Lull: The Evolution of the Earth and Its Inhabitants, 1918, p. 55. 
cycles of historical times, or geological changes of the shorter type, such as glaciation. Nevertheless, terrestrial changes doubtless have assisted in producing both the progressive change and the slow cyclic changes recorded in the rocks, and it is the purpose of this chapter and the two that follow to consider what terrestrial changes have taken place and the probable effect of such changes.

The terrestrial changes that have a climatic significance are numerous. Some, such as variations in the amount of volcanic dust in the higher air, have been considered in an earlier chapter. Others are too imperfectly known to warrant discussion, and in addition there are presumably others which are entirely unknown. Doubtless some of these little known or unknown changes have been of importance in modifying climate. For example, the climatic influence of vegetation, animals, and man may be appreciable. Here, however, we shall confine ourselves to purely physical causes, which will be treated in the following order: First, those concerned with the solid parts of the earth, namely: (I) amount of land; (II) distribution of land; (III) height of land; (IV) lava flows; and (V) internal heat. Second, those which arise from the salinity of oceans, and third, those depending on the composition and amount of atmosphere.

The terrestrial change which appears indirectly to have caused the greatest change in climate is the contraction of the earth. The problem of contraction is highly complex and is as yet only imperfectly understood. Since only its results and not its processes influence climate, the following section as far as page 196 is not necessary to the general reader. It is inserted in order to explain why we assume that there have been oscillations between certain types of distribution of the lands.

The extent of the earth's contraction may be judged 
from the shrinkage indicated by the shortening of the rock formations in folded mountains such as the Alps, Juras, Appalachians, and Caucasus. Geologists are continually discovering new evidence of thrust faults of great magnitude where masses of rock are thrust bodily over other rocks, sometimes for many miles. Therefore, the estimates of the amount of shrinkage based on the measurements of folds and faults need constant revision upward. Nevertheless, they have already reached a considerable figure. For example, in 1919, Professor A. Heim estimated the shortening of the meridian passing through the modern Alps and the ancient Hercynian and Caledonian mountains as fully a thousand miles in Europe, and over five hundred miles for the rest of this meridian. ${ }^{2}$ This is a radial shortening of about 250 miles. Possibly the shrinkage has been even greater than this. Chamber$\operatorname{lin}^{3}$ has compared the density of the earth, moon, Mars, and Venus with one another, and found it probable that the radial shrinkage of the earth may be as much as 570 miles. This result is not so different from Heim's as appears at first sight, for Heim made no allowance for unrecognized thrust faults and for the contraction incident to metamorphism. Moreover, Heim did not include shrinkage during the first half of geological time before the above-mentioned mountain systems were upheaved.

According to a well-established law of physics, contraction of a rotating body results in more rapid rotation and greater centrifugal force. These conditions must increase the earth's equatorial bulge and thereby cause changes in the distribution of land and water. Opposed to the rearrangement of the land due to increased rota-

2 Quoted by J. Cornet: Cours de Géologie, 1920, p. 330.

3 T. C. Chamberlin: The Order of Magnitude of the Shrinkage of the Earth; Jour. Geol., Vol. 28, 1920, pp. 1-17, 126-157. 
tion caused by contraction, there has presumably been another rearrangement due to tidal retardation of the earth's rotation and a consequent lessening of the equatorial bulge. G. H. Darwin long ago deduced a relatively large retardation due to lunar tides. A few years ago W. D. MacMillan, on other assumptions, deduced only a negligible retardation. Still more recently Taylor ${ }^{4}$ has studied the tides of the Irish Sea, and his work has led Jeffreys $^{5}$ and Brown ${ }^{6}$ to conclude that there has been considerable retardation, perhaps enough, according to Brown, to equal the acceleration due to the earth's contraction. From a prolonged and exhaustive study of the motions of the moon Brown concludes that tidal friction or some other cause is now lengthening the day at the rate of one second per thousand years, or an hour in almost four million years if the present rate continues. He makes it clear that the retardation due to tides would not correspond in point of time with the acceleration due to contraction. The retardation would occur slowly, and would take place chiefly during the long quiet periods of geologic history, while the acceleration would occur rapidly at times of diastrophic deformation. As a consequence, the equatorial bulge would alternately be reduced at a slow rate, and then somewhat suddenly augmented.

The less rigid any part of the earth is, the more quickly it responds to the forces which lead to bulging or which tend to lessen the bulge. Since water is more fluid than land, the contraction of the earth and the tidal retardation presumably tend alternately to increase and decrease the amount of water near the equator more than the

4 G. I. Taylor: Philosophical Transactions, A. 220, 1919, pp. 1-33; Monthly Notices Royal Astron. Soc., Jan., 1920, Vol. 80, p. 308.

5 J. Jeffreys: Monthly Notices Royal Astron. Soc., Jan., 1920, Vol. 80, p. 309.

6 E. W. Brown: personal communication. 
amount of land. Thus, throughout geological history we should look for cyclic changes in the relative area of the lands within the tropics and similar changes of opposite phase in higher latitudes. The extent of the change would depend upon (a) the amount of alteration in the speed of rotation, and (b) the extent of low land in low latitudes and of shallow sea in high latitudes. According to Slichter's tables, if the earth should rotate in twentythree hours instead of twenty-four, the great Amazon lowland would be submerged by the inflow of oceanic water, while wide areas in Hudson Bay, the North Sea, and other northern regions, would become land because the ocean water would flow away from them. ${ }^{\text {? }}$

Following the prompt equatorward movement of water which would occur as the speed of rotation increased, there must also be a gradual movement or creepage of the solid rocks toward the equator, that is, a bulging of the ocean floor and of the lands in low latitudes, with a consequent emergence of the lands there and a relative rise of sea level in higher latitudes. Tidal retardation would have a similar effect. Suess ${ }^{8}$ has described widespread elevated strand lines in the tropics which he interprets as indicating a relatively sudden change in sea level, though he does not suggest a cause of the change. However, in speaking of recent geological times, Suess reports that a movement more recent than the old strands "was an accumulation of water toward the equator, a diminution toward the poles, and (it appears) as though this last movement were only one of the many oscillations which succeed each other with the same tendency, i.e., with a positive excess at the equator, a nega-

7 C. S. Slichter: The Rotational Period of a Heterogeneous Spheroid; in Contributions to the Fundamental Problems of Geology, by T. C. Chamberlin, et al., Carnegie Inst. of Wash., No. 107, 1909.

8 E. Suess: The Face of the Earth, Vol. II, p. 553, 1901. 
tive excess at the poles." (Vol. II, p. 551.) This creepage of the rocks equatorward seemingly might favor the growth of mountains in tropical and subtropical regions, because it is highly improbable that the increase in the bulge would go on in all longitudes with perfect uniformity. Where it went on most rapidly mountains would arise. That such irregularity of movement has actually occurred is suggested not only by the fact that many Cenozoic and older mountain ranges extend east and west, but by the further fact that these include some of our greatest ranges, many of which are in fairly low latitudes. The Himalayas, the Javanese ranges, and the halfsubmerged Caribbean chains are examples. Such mountains suggest a thrust in a north and south direction which is just what would happen if the solid mass of the earth were creeping first equatorward and then poleward.

A fact which is in accord with the idea of a periodic increase in the oceans in low latitudes because of renewed bulging at the equator is the exposure in moderately high latitudes of the greatest extent of ancient rocks. This seems to mean that in low latitudes the frequent deepening of the oceans has caused the old rocks to be largely covered by sediments, while the old lands in higher latitudes have been left more fully exposed to erosion.

Another suggestion of such periodic equatorward movements of the ocean water is found in the reported contrast between the relative stability with which the northern part of North America has remained slightly above sea level except at times of widespread submergence, while the southern parts have suffered repeated submergence alternating with great emergence. ${ }^{9}$ Furthermore, although

9 Chas. Schuchert: The Earth's Changing Surface and Climate; in Lull: The Evolution of the Earth and Its Inhabitants, 1918, p. 78. 
the northern part of North America has been generally exposed to erosion since the Proterozoic, it has supplied much less sediment than have the more southern land areas. ${ }^{10}$ This apparently means that much of Canada has stood relatively low, while repeated and profound uplift alternating with depression has occurred in subtropical latitudes, apparently in adjustment to changes in the earth's speed of rotation. The uplifts generally followed the times of submergence due to equatorward movement of the water, though the buckling of the crust which accompanies shrinkage doubtless caused some of the submergence. The evidence that northern North America stood relatively low throughout much of geological time depends not only on the fact that little sediment came to the south from the north, but also on the fact that at times of especially widespread epicontinental seas, the submergence was initiated at the north. ${ }^{11}$ This is especially true for Ordovician, Silurian, Devonian, and Jurassic times in North America. General submergence of this kind is supposed to be due chiefly to the overflowing of the ocean when its level is slowly raised by the deposition of sediment derived from the erosion of what once were continental highlands but later are peneplains. The fact that such submergence began in high latitudes, however, seems to need a further explanation. The bulging of the rock sphere at the equator and the consequent displacement of some of the water in low latitudes would furnish such an explanation, as would also a decrease in the speed of rotation induced by tidal retardation, if that retardation were great enough and rapid enough to be geologically effective.

$10 \mathrm{~J}$. Barrell: Rhythms and the Measurement of Geologic Time; Bull. Geol. Soc. Am., Vol. 28, 1917, p. 838.

11 Chas. Sehuchert: loc. cit., p. 78. 
The climatic effects of the earth's contraction, which we shall shortly discuss, are greatly complicated by the fact that contraction has taken place irregularly. Such irregularity has occurred in spite of the fact that the processes which cause contraction have probably gone on quite steadily throughout geological history. These processes include the chemical reorganization of the minerals of the crust, a process which is illustrated by the metamorphism of sedimentary rocks into crystalline forms. The escape of gases through volcanic action or otherwise has been another important process.

Although the processes which cause contraction probably go on steadily, their effect, as Chamberlin ${ }^{12}$ and others have pointed out, is probably delayed by inertia. Thus the settling of the crust or its movement on a large scale is delayed. Perhaps the delay continues until the stresses become so great that of themselves they overcome the inertia, or possibly some outside agency, whose nature we shall consider later, reënforces the stresses and gives the slight impulse which is enough to release them and allow the earth's crust to settle into a new state of equilibrium. When contraction proceeds actively, the ocean segments, being largest and heaviest, are likely to settle most, resulting in a deepening of the oceans and an emergence of the lands. Following each considerable contraction there would be an increase in the speed of rotation. The repeated contractions with consequent growth of the equatorial bulge would alternate with long quiet periods during which tidal retardation would again decrease the speed of rotation and hence lessen the bulge. The result would be repeated changes of distribution of land and water, with consequent changes in climate.

12 T. C. Chamberlin: Diastrophism, the Ultimate Basis of Correlation; Jour. Geol., Vol. 16, 1909; Chas. Schuchert: loc. cit. 
I. We shall now consider the climatic effect of the repeated changes in the relative amounts of land and water which appear to have resulted from the earth's contraction and from changes in its speed of rotation. During many geologic epochs a larger portion of the earth was covered with water than at present. For example, during at least twelve out of about twenty epochs, North America has suffered extensive inundations, ${ }^{13}$ and in general the extensive submergence of Europe, the other area well known geologically, has coincided with that of North America. At other times, the ocean has been less extensive than now, as for example during the recent glacial period, and probably during several of the glacial periods of earlier date. Each of the numerous changes in the relative extent of the lands must have resulted in a modification of climate. ${ }^{14}$ This modification would occur chiefly because water becomes warm far more slowly than land, and cools off far more slowly.

An increase in the lands would cause changes in several climatic conditions. (a) The range of temperature between day and night and between summer and winter would increase, for lands become warmer by day and in summer than do oceans, and cooler at night and in winter. The higher summer temperature when the lands are widespread is due chiefly to the fact that the land, if not snow-covered, absorbs more of the sun's radiant energy than does the ocean, for its reflecting power is low. The lower winter temperature when lands are widespread occurs not only because they cool off rapidly but

13 Pirsson-Schuchert: Textbook of Geology, 1915, Vol. II, p. 982; Chas. Schuchert: Paleogeography of North America; Bull. Geol. Soc. Am., Vol. 20, pp. 427-606; reference on p. 499.

14 The general subject of the climatic significance of continentality is discussed by C. E. P. Brooks: Continentality and Temperature; Quart. Jour. Royal Meteorol. Soc., April, 1917, and Oct., 1918. 
because the reduced oceans cannot give them so much heat. Moreover, the larger the land, the more generally do the winds blow outward from it in winter and thus prevent the ocean heat from being carried inland. So long as the ocean is not frozen in high latitudes, it is generally the chief source of heat in winter, for the nights are several months long near the poles, and even when the sun does shine its angle is so low that reflection from the snow is very great. Furthermore, although on the average there is more reflection from water than from land, the opposite is true in high latitudes in winter when the land is snow-covered while the ocean is relatively dark and is roughened by the waves. Another factor in causing large lands to have extremely low temperature in winter is the fact that in proportion to their size they are less protected by fog and cloud than are smaller areas. The belt of cloud and fog which is usually formed when the wind blows from the ocean to the relatively cold land is restricted to the coastal zone. Thus the larger the land, the smaller the fraction in which loss of heat by radiation is reduced by clouds and fogs. Hence an increase in the land area is accompanied by an increase in the contrasts in temperature between land and water.

(b) The contrasts in temperature thus produced must cause similar contrasts in atmospheric pressure, and hence stronger barometric gradients. (c) The strong gradients would mean strong winds, flowing from land to sea or from sea to land. (d) Local convection would also be strengthened in harmony with the expansion of the lands, for the more rapid heating of land than of water favors active convection.

(e) As the extent of the ocean diminished, there would normally be a decrease in the amount of water vapor for 
three reasons: (1) Evaporation from the ocean is the great source of water vapor. Other conditions being equal, the smaller the ocean becomes, the less the evaporation. (2) The amount of water vapor in the air diminishes as convection increases, since upward convection is a chief method by which condensation and precipitation are produced, and water vapor removed from the atmosphere. (3) Nocturnal cooling sufficient to produce dew and frost is very much more common upon land than upon the ocean. The formation of dew and frost diminishes the amount of water vapor at least temporarily. (f) Any diminution in water vapor produced in these ways, or otherwise, is significant because water vapor is the most essential part of the atmosphere so far as regulation of temperature is concerned. It tends to keep the days from becoming hot or the nights cold. Therefore any decrease in water vapor would increase the diurnal and seasonal range of temperature, making the climate more extreme and severe. Thus a periodic increase in the area of the continents would clearly make for periodic increased climatic contrasts, with great extremes, a type of climatic change which has recurred again and again. Indeed, each great glaciation accompanied or followed extensive emergence of the lands. ${ }^{15}$

Whether or not there has been a progressive increase from era to era in the area of the lands is uncertain. Good anthorities disagree widely. There is no doubt, however, that at present the lands are more extensive than at most times in the past, though smaller, perhaps, than at certain periods. The wide expanse of lands helps explain the prominence of seasons at present as compared with the past.

15 Chas. Schuchert: Climates of Geologic Time; in The Climatic Factor; Carnegie Institution, 1914, p. 286. 
II. The contraction of the earth, as we have seen, has produced great changes in the distribution as well as in the extent of land and water. Large parts of the present continents have been covered repeatedly by the sea, and extensive areas now covered with water have been land. In recent geological times, that is, during the Pliocene and Pleistocene, much of the present continental shelf, the zone less than 600 feet below sea level, was land. If the whole shelf had been exposed, the lands would have been greater than at present by an area larger than North America. When the lands were most elevated, or a little earlier, North America was probably connected with Asia and almost with Europe. Asia in turn was apparently connected with the larger East Indian islands. In much earlier times land occupied regions where now the ocean is fairly deep. Groups of islands, such as the East Indies and Malaysia and perhaps the West Indies, were united into widespreading land masses. Figs. 7 and 9, illustrating the paleography of the Permian and the Cretaceous periods, respectively, indicate a land distribution radically different from that of today.

So far as appears from the scattered facts of geological history, the changes in the distribution of land seem to have been marked by the following characteristics : (1) Accompanying the differentiation of continental and oceanic segments of the earth's crust, the oceans have become somewhat deeper, and their basins perhaps larger, while the continents, on the average, have been more elevated and less subject to submergence. Hence there have been less radical departures from the present distribution during the relatively recent Cenozoic era than in the ancient Paleozoic because the submergence of continental areas has become less general and less frequent. For example, the last extensive epeiric or interior 
sea in North America was in the Cretaceous, at least ten million years ago, and according to Barrell perhaps fifty million, while in Europe, according to de Lapparent, ${ }^{16}$ a smaller share of the present continent has been submerged since the Cretaceous than before. Indeed, as in North America, the submergence has decreased on the average since the Paleozoic era. (2) The changes in distribution of land which have taken place during earth history have been cyclic. Repeatedly, at the close of each of the score or so of geologic periods, the continents emerged more or less, while at the close of the groups of periods known as eras, the lands were especially large and emergent. After each emergence, a gradual encroachment of the sea took place, and toward the close of several of the earlier periods, the sea appears to have covered a large fraction of the present land areas. (3) On the whole, the amount of land in the middle and high latitudes of the northern hemisphere appears to have increased during geologic time. Such an increase does not require a growth of the continents, however, in the broader sense of the term, but merely that a smaller fraction of the continent and its shelf should be submerged. (4) In tropical latitudes, on the other hand, the extent of the lands seems to have decreased, apparently by the growth of the ocean basins. South America and Africa are thought by many students to have been connected, and Africa was united with India via Madagascar, as is suggested in Fig. 9. The most radical cyclic as well as the most radical progressive changes in land distribution also seem to have taken place in tropical regions. ${ }^{17}$

Although there is much evidence of periodic increase

16 A. de Lapparent: Traité de Géologie, 1906.

17 Chas. Sehuchert: Historical Geology, 1915, p. 464. 


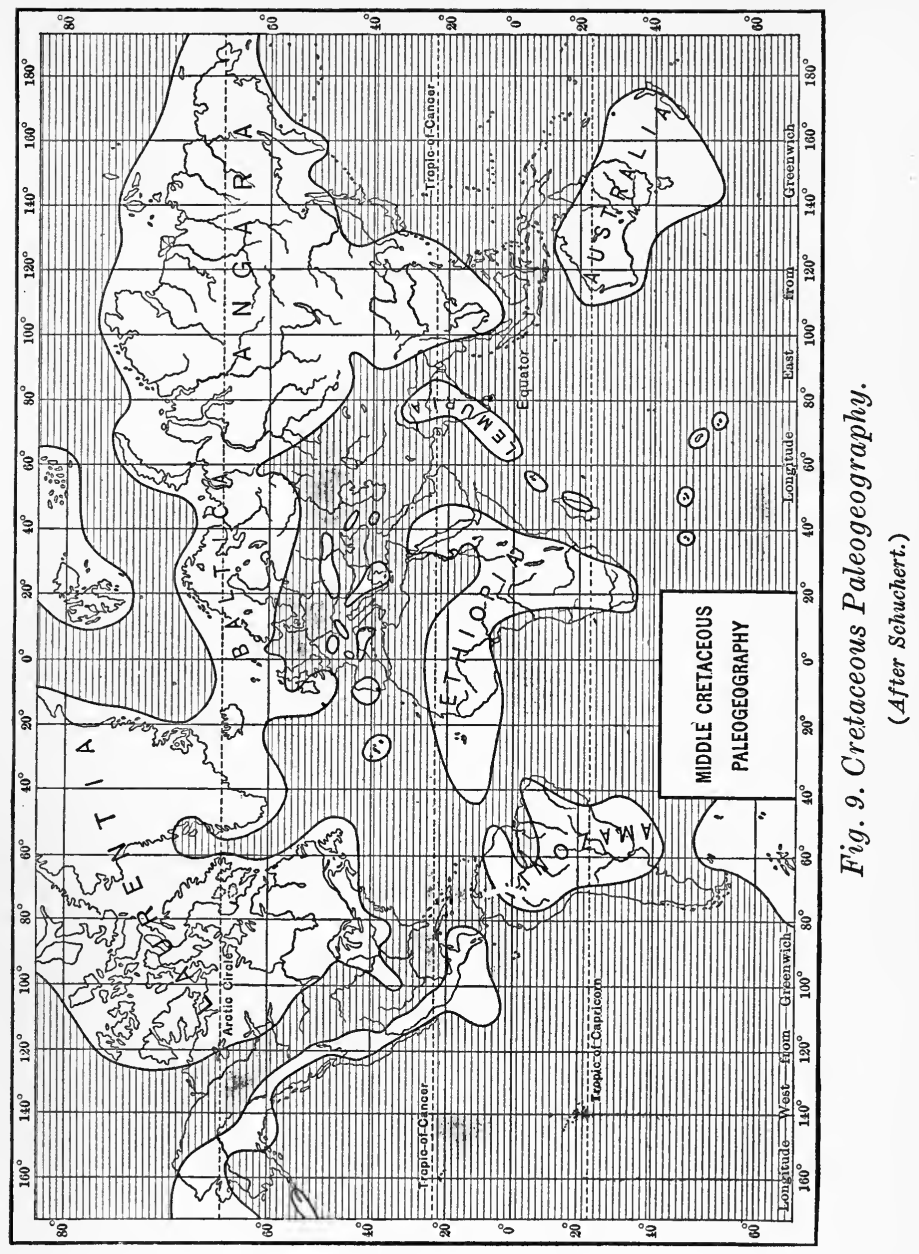


of the sea in equatorial latitudes and of land in high latitudes, it has remained for the zoölogist Metcalf to present a very pretty bit of evidence that at certain times submergence along the equator coincided with emergence in high latitudes, and vice versa. Certain fresh .water frogs which carry the same internal parasite are confined to two widely separated areas in tropical and south temperate America and in Australia. The extreme improbability that both the frogs and the parasites could have originated independently in two unconnected areas and could have developed by convergent evolution so that they are almost identical in the two continents makes it almost certain that there must have been a land connection between South America and Australia, presumably by way of Antarctica. The facts as to the parasites seem also to prove that while the land connection existed there was a sea across South America in equatorial latitudes. The parasite infests not only the frogs but the American toads known as Bufo. Now Bufo originated north of the equator in America and differs from the frogs which originated in southern South America in not being found in Australia. This raises the question of how the frogs could go to Australia via Antarctica carrying the parasite with them, while the toads could not go. Metcalf's answer is that the toads were cut off from the southern part of South America by an equatorial sea until after the Antarctic connection between the Old World and the New was severed.

As Patagonia let go of Antarctica by subsidence of the intervening land area, there was a probable concomitant rise of land through what is now middle South America and the northern and southern portions of this continent came together. ${ }^{18}$

18 M. M. Metealf: Upon an important method of studying problems of relationship and of geographical distribution; Proceedings National Academy of Sciences, Vol. 6, July, 1920, pp. 432-433. 
These various changes in the earth's crust have given rise to certain specific types of distribution of the lands, which will now be considered. We shall inquire what climatic conditions would arise from changes in (a) the continuity of the lands from north to south, (b) the amount of land in tropical latitudes, and (c) the amount of land in middle and high latitudes.

(a) At present the westward drift of warm waters, set in motion by the trade winds, is interrupted by land masses and turned poleward, producing the important Gulf Stream Drift and Japan Current in the northern hemisphere, and corresponding, though less important, currents in the southern hemisphere. During the past, quite different sets of ocean currents doubtless have existed in response to a different distribution of land. Repeatedly, in the mid-Cretaceous (Fig. 9) and several other periods, the present American barrier to the westward-moving tropical current was broken in Central America. Even if the supposed continent of "Gondwana Land" extended from Africa to South America in equatorial latitudes, strong currents must still have flowed westward along its northern shore under the impulse of the peculiarly strong trade winds which the equatorial land would create. Nevertheless at such times relatively little warm tropical water presumably entered the North Atlantic, for it escaped into the Pacific. At several other times, such as the late Ordovician and mid-Devonian, when the isthmian barrier existed, it probably turned an important current northward into what is now the Mississippi Basin instead of into the Atlantic. There it traversed an epeiric, or mid-continental sea open to both north and south. Hence its effectiveness in warming Arctic regions must have been quite different from that of the present Gulf Stream. 
(b) We will next consider the influences of changes in the amount of equatorial and tropical land. As such lands are much hotter than the corresponding seas, the intensity and width of the equatorial belt of low pressure must be great when they are extensive. Hence the trade winds must have been stronger than now whenever tropical lands were more extensive than at present. This is because the trades are produced by the convection due to excessive heat along the heat equator. There the air expands upward and flows poleward at high altitudes. The trade wind consists of air moving toward the heat equator to take the place of the air which there rises. When the lands in low latitudes were wide the trade winds must also have dominated a wide belt. The greater width of the trade-wind belt today over Africa than over the Atlantic illustrates the matter. The belt must have been still wider when Gondwana Land was large, as it is believed to have been during the Paleozoic era and the early Mesozoic.

An increase in the width of the equatorial belt of low pressure under the influence of broad tropical lands would be accompanied not only by stronger and more widespread trade winds, but by a corresponding strengthening of the subtropical belts of high pressure. The chief reason would be the greater expansion of the air in the equatorial low pressure belt and the consequent more abundant outflow of air at high altitudes in the form of anti-trades or winds returning poleward above the trades. Such winds would pile up the air in the region of the highpressure belt. Moreover, since the meridians converge as one proceeds away from the equator, the air of the poleward-moving anti-trades tends to be crowded as it reaches higher latitudes, thus increasing the pressure. Unless there were a corresponding increase in tropical 
cyclones, one of the most prominent results of the strengthened trades and the intensified subtropical highpressure belt at times of broad lands in low latitudes would be great deserts. It will be recalled that the tradewind lowlands and the extra-tropical belt of highs are the great desert belts at present. The trade-wind lowlands are desert because air moving into warmer latitudes takes up water except where it is cooled by rising on mountain-sides. The belt of highs is arid because there, too, air is being warmed, but in this case by descending from aloft.

Again, if the atmospheric pressure in the subtropical belt should be intensified, the winds flowing poleward from this belt would necessarily become stronger. These would begin as southwesterlies in the northern hemisphere and northwesterlies in the southern. In the preceding chapter we have seen that such winds, especially when cyclonic storms are few and mild, are a powerful agent in transferring subtropical heat poleward. If the strength of the westerlies were increased because of broad lands in low latitudes, their efficacy in transferring heat would be correspondingly augmented. It is thus evident that any change in the extent of tropical lands during the geologic past must have had important climatic consequences in changing the velocity of the atmospheric circulation and in altering the transfer of heat from low latitudes to high. When the equatorial and tropical lands were broad the winds and currents must have been strong, much heat must have been carried away from low latitudes, and the contrast between low and high latitudes must have been relatively slight. As we have already remarked, leading paleogeographers believe that changes in the extent of the lands have been especially marked in low latitudes, and that on the aver- 
age there has been a decrease in the extent of land within the tropics. Gondwana Land is the greatest illustration of this. In the same way, on the numerous paleogeographic maps of North America, most paleogeographers have shown fairly extensive lands south of the latitude of the United States during most of the geologic epochs. ${ }^{19}$

(c) There is evidence that during geologic history the area of the lands in middle and high latitudes, as well as in low latitudes, has changed radically. An increase in such lands would cause the winters to grow colder. This would be partly because of the loss of heat by radiation into the cold dry air over the continents in winter, and partly because of increased reflection from snow and frost, which gather much more widely upon the land than upon the ocean. Furthermore, in winter when the continents are relatively cold, there is a strong tendency for winds to blow out from the continent toward the ocean. The larger the land the stronger this tendency. In Asia it gives rise to strong winter monsoons. The effect of such winds is illustrated by the way in which the westerlies prevent the Gulf Stream from warming the eastern United States in winter. The Gulf Stream warms northwestern Europe much more than the United States because, in Europe, the prevailing winds are onshore.

Another effect of an increase in the area of the lands in middle and high latitudes would be to interpose barriers to oceanic circulation and thus lower the temperature of polar regions. This would not mean glaciation in high latitudes, however, even when the lands were widespread as in the Mesozoic and early Tertiary. Students of glaciology are more and more thoroughly convinced

19 Chas. Schuchert: Paleogeography of North America; Bull. Geol. Soc. Am., Vol. 20, 1910; and Willis, Salisbury, and others: Outlines of Geologic History, 1910. 
that glaciation depends on the availability of moisture even more than upon low temperature.

In conclusion it may be noted that each of the several climatic influences of increased land area in the high latitudes would tend to increase the contrasts between land and sea, between winter and summer, and between low latitudes and high. In other words, so far as the effect upon high latitudes themselves is concerned, an expansion of the lands there would tend in the same direction as a diminution in low latitudes. In so far as the general trend of geological evolution has been toward more land in high latitudes and less in low, it would help to produce a progressive increase in climatic diversity such as is faintly indicated in the rock strata. On the other hand, the oscillations in the distribution of the lands, of which geology affords so much evidence, must certainly have played an important part in producing the periodic changes of climate which the earth has undergone.

III. Throughout geological history there is abundant evidence that the process of contraction has led to marked differences not only in the distribution and area of the lands, but in their height. On the whole the lands have presumably increased in height since the Proterozoic, somewhat in proportion to the increased differentiation of continents and oceans..$^{20}$ If there has been such an increase, the contrast between the climate of ocean and land must have been accentuated, for highlands have a greater diurnal and seasonal range of temperature than do lowlands. The ocean has very little range of either sort. The large range at high altitudes is due chiefly to the small quantity of water vapor, for this declines

20 Chas. Schuchert: The Earth's Changing Surface and Climate; in Lull: The Evolution of the Earth and Its Inhabitants, 1918, p. 50. 
steadily with increased altitude. A diminution in the density of the other constituents of the air also decreases the blanketing effect of the atmosphere. In conformity with the great seasonal range in temperature at times when the lands stand high, the direction of the wind would be altered. When the lands are notably warmer than the oceans, the winds commonly flow from land to sea, and when the continents are much colder than the oceans, the direction is reversed. The monsoons of Asia are examples. Strong seasonal winds disturb the normal planetary circulation of the trade winds in low latitudes and of the westerlies in middle latitudes. They also interfere with the ocean currents set in motion by the planetary winds. The net result is to hinder the transfer of heat from low latitudes to high, and thus to increase the contrasts between the zones. Local as well as zonal contrasts are also intensified. The higher the land, the greater, relatively speaking, are the cloudiness and precipitation on seaward slopes, and the drier the interior. Indeed, most highlands are arid. Henry's ${ }^{21}$ recent study of the vertical distribution of rainfall on mountain-sides indicates that a decrease sets in at about 3500 feet in the tropics and only a little higher in mid-latitudes.

In addition to the main effects upon atmospheric circulation and precipitation, each of the many upheavals of the lands must have been accompanied by many minor conditions which tended toward diversity. For example, the streams were rejuvenated, and instead of meandering perhaps over vast flood plains they intrenched their channels and in many cases dug deep gorges. The water table was lowered, soil was removed from considerable areas, the bare rock was exposed, and the type of domi-

21 A. J. Henry: The Decrease of Precipitation with Altitude; Monthly Weather Review, Vol. 47, 1919, pp. 33-41. 
nant vegetation altered in many places. An almost barren ridge may represent all that remains of what was once a vast forested flood plain. Thus, increased elevation of the land produces contrasted conditions of slope, vegetation, availability of ground water, exposure to wind and so forth, and these unite in diversifying climate. Where mountains are formed, strong contrasts are sure to occur. The windward slopes may be very rainy, while neighboring leeward slopes are parched by a dry foehn wind. At the same time the tops may be snow-covered. Increased local contrasts in climatic conditions are known to influence the intensity of cyclonic storms, ${ }^{22}$ and these affect the climatic conditions of all middle and high latitudes, if not of the entire earth. The paths followed by cyclonic storms are also altered by increased contrast between land and water. When the continents are notably colder than the neighboring oceans, high atmospheric pressure develops on the lands and interferes with the passage of lows, which are therefore either deflected around the continent or forced to move slowly.

The distribution of lofty mountains has an even more striking climatic effect than the general uplift of a region. In Proterozoic times there was a great range in the Lake Superior region; in the late Devonian the Acadian mountains of New England and the Maritime Provinces of Canada possibly attained a height equal to the present Rockies. Subsequently, in the late Paleozoic a significant range stood where the Ouachitas now are. Accompanying the uplift of each of these ranges, and all others, the climate of the surrounding area, especially to leeward, must have been altered greatly. Many extensive salt de-

22 Chas. F. Brooks: Monthly Weather Review, Vol. 46, 1918, p. 511; and also A. J. Henry and others: Weather Forecasting in the United States, 1913. 
posits found now in fairly humid regions, for example, the Pennsylvanian and Permian deposits of Kansas and Oklahoma, were probably laid down in times of local aridity due to the cutting off of moisture-bearing winds by the mountains of Llanoria in Louisiana and Texas. Hence such deposits do not necessarily indicate periods of widespread and profound aridity.

When the causes of ancient glaciation were first considered by geologists, about the middle of the nineteenth century, it was usually assumed that the glaciated areas had been elevated to great heights, and thus rendered cold enough to permit the accumulation of glaciers. The many glaciers occurring in the Alps of central Europe where glaciology arose doubtless suggested this explanation. However, it is now known that most of the ancient glaciation was not of the alpine type, and there is adequate proof that the glacial periods cannot be explained as due directly and solely to uplift. Nevertheless, upheavals of the lands are among the most important factors in controlling climate, and variations in the height of the lands have doubtless assisted in producing climate oscillations, especially those of long duration. Moreover, the progressive increase in the height of the lands has presumably played a part in fostering local and zonal diversity in contrast with the relative uniformity of earlier geological times.

IV. The contraction of the earth has been accompanied by volcanic activity as well as by changes in the extent, distribution, and altitude of the lands. The probable part played by volcanic dust as a contributory factor in producing short sudden climatic variations has already been discussed. There is, however, another though probably less important respect in which volcanic activity may have had at least a slight climatic significance. The oldest 
known rocks, those of the Archean era, contain so much igneous matter that many students have assumed that they show that the entire earth was once liquid. It is now considered that they merely indicate igneous activity of great magnitude. In the later part of Proterozoic time, during the second quarter of the earth's history according to Schuchert's estimate, there were again vast outflowings of lava. In the Lake Superior district, for example, a thickness of more than a mile accumulated over a large area, and lavas are common in many areas where rocks of this age are known. The next quarter of the earth's history elapsed without any correspondingly great outflows so far as is known, though several lesser ones occurred. Toward the end of the last quarter, and hence quite recently from the geological standpoint, another period of outflows, perhaps as noteworthy as that of the Proterozoic, occurred in the Cretaceous and Tertiary.

The climatic effects of such extensive lava flows would be essentially as follows: In the first place so long as the lavas were hot they would set up a local system of convection with inflowing winds. This would interfere at least a little with the general winds of the area. Again, where the lava flowed out into water, or where rain fell upon hot lava, there would be rapid evaporation which would increase the rainfall. Then after the lava had cooled, it would still influence climate a trifle in so far as its color was notably darker or lighter than that of the average surface. Dark surfaces absorb solar heat and become relatively warm when the sun shines upon them. Dark objects likewise radiate heat more rapidly than light-colored objects. Hence they cool more rapidly at night, and in the winter. As most lavas are relatively dark they increase the average diurnal range of tempera- 
ture. Hence even after they are cool they increase the climatic diversity of the land.

The amount of heat given to the atmosphere by an extensive lava flow, though large according to human standards, is small compared with the amount received from the sun by a like area, except during the first few weeks or months before the lava has formed a thick crust. Furthermore, probably only a small fraction of any large series of flows occurred in a given century or millennium. Moreover, even the largest lava flows covered an area of only a few hundredths of one per cent of the earth's surface. Nevertheless, the conditions which modify climate are so complicated that it would be rash to state that this amount of additional heat has been of no climatic significance. Like the proverbial "straw that broke the camel's back," the changes it would surely produce in local convection, atmospheric pressure, and the direction of the wind may have helped to shift the paths of storms and to produce other complications which were of appreciable climatic significance.

V. The last point which we shall consider in connection with the effect of the earth's interior upon climate is internal heat. The heat given off by lavas is merely a small part of that which is emitted by the earth as a whole. In the earliest part of geological history enough heat may have escaped from the interior of the earth to exert a profound influence on the climate. Knowlton, ${ }^{23}$ as we have seen, has recently built up an elaborate theory on this assumption. At present, however, accurate measurements show that the escape of heat is so slight that it has no appreciable influence except in a few volcanic

23 F. H. Knowlton: Evolution of Geologic Climates; Bull. Geol. Soc. Am., Vol. 30, Dec., 1919, pp. 499-566. 
areas. It is estimated to raise the average temperature of the earth's surface less than $0.1^{\circ} \mathrm{C} .^{24}$

In order to contribute enough heat to raise the surface temperature $1^{\circ} \mathrm{C}$, the temperature gradient from the interior of the earth to the surface would need to be ten times as great as now, for the rate of conduction varies directly with the gradient. If the gradient were ten times as great as now, the rocks at a depth of two and one-half miles would be so hot as to be almost liquid according to Barrell's ${ }^{25}$ estimates. The thick strata of unmetamorphosed Paleozoic rocks indicate that such high temperatures have not prevailed at such slight depths since the Proterozoic. Furthermore, the fact that the climate was cold enough to permit glaciation early in the Proterozoic era and at from one to three other times before the opening of the Paleozoic suggests that the rate of escape of heat was not rapid even in the first half of the earth's recorded history. Yet even if the general escape of heat has never been large since the beginning of the betterknown part of geological history, it was presumably greater in early times than at present.

If there actually has been an appreciable decrease in the amount of heat given out by the earth's interior, its effects would agree with the observed conditions of the geological record. It would help to explain the relative mildness of zonal, seasonal, and local contrasts of climate in early geological times, but it would not help to explain the long oscillations from era to era which appear to have been of much greater importance. Those oscillations, so far as we can yet judge, may have been due in part to solar changes, but in large measure they seem to be

24 Talbert, quoted by I. Bowman: Forest Physiography, 1911, p. 63.

25 J. Barrell: Rhythms and the Measurement of Geologic Time; Bull. Geol. Soc. Am., Vol. 28, 1917, pp. 745-904. 
explained by variations in the extent, distribution, and altitude of the lands. Such variations appear to be the inevitable result of the earth's contraction. 


\title{
CHAPTER XII
}

\section{POST-GLACIAL CRUSTAL MOVEMENTS AND CLIMATIC CHANGES}

\begin{abstract}
A $\mathrm{N}$ interesting practical application of some of the preceding generalizations is found in an attempt by C. E. P. Brooks ${ }^{1}$ to interpret post-glacial climatic changes almost entirely in terms of crustal movement. We believe that he carries the matter much too far, but his discussion is worthy of rather full recapitulation, not only for its theoretical value but because it gives a good summary of post-glacial changes. His climatic table for northwest Europe as reprinted from the annual report of the Smithsonian Institution for 1917, p. 366, is as follows:
\end{abstract}

\section{Phase Climate Date}

1. The Last Great Glaciation.

Arctic climate.

$30,000-18,000$ B. C.

2. The Retreat of the Glaciers.

Severe continental climate.

$18,000-6000$ B. C.

$\begin{array}{lll}\text { 3. The Continental Phase. } & \text { Continental elimate. } & 6000-4000 \text { B. C. } \\ \text { 4. The Maritime Phase. } & \text { Warm and moist. } & 4000-3000 \text { B. C. }\end{array}$

5. The Later Forest Phase.

6. The Peat-Bog Phase.

Warm and dry. 3000-1800 B. C.

Cooler and moister. 1800 B. C.-300 A. D.

7. The Recent Phase.

Becoming drier. 300 A. D.-

Brooks bases his chronology largely on De Geer's measurements of the annual layers of clay in lake

1 C. E. P. Brooks: The Evolution of Climate in Northwest Europe. Quart. Jour. Royal Meteorol. Soc., Vol. 47, 1921, pp. 173-194. 
bottoms but makes much use of other evidence. According to Brooks the last glacial epoch lasted roughly from 30,000 to 18,000 B. C., but this includes a slight amelioration of climate followed by a readvance of the ice, known as the Buhl stage. During the time of maximum glaciation the British Isles stood twenty or thirty feet higher than now and Scandinavia was "considerably" more elevated. The author believes that this caused a fall of $1^{\circ} \mathrm{C}$. in the temperature of the British Isles and of $2^{\circ} \mathrm{C}$. in Scandinavia. By an ingenious though not wholly convincing method of calculation he concludes that this lowering of temperature, aided by an increase in the area of the lands, sufficed to start an ice sheet in Scandinavia. The relatively small area of ice cooled the air and gave rise to an area of high barometric pressure. This in turn is supposed to have caused further expansion of the ice and to have led to full-fledged glaciation.

About 18,000 B. C. the retreat of the ice began in good earnest. Even though no evidence has yet been found, Brooks believes there must have been a change in the distribution of land and sea to account for the diminution of the ice. The ensuing millenniums formed the Magdalenian period in human history, the last stage of the Paleolithic, when man lived in caves and reindeer were abundant in central Europe. ${ }^{2}$ At first the ice retreated very slowly and there were periods when for scores of years the ice edge remained stationary or even readvanced. About 10,000 B. C. the edge of the ice lay along the southern coast of Sweden. During the next 2000 years it withdrew more rapidly to about $59^{\circ} \mathrm{N}$. Then came the Fennoscandian pause, or Gschnitz stage, when for about

2 H. F. Osborn: Men of the Old Stone Age, N. Y., 1915; J. M. Tyler: The New Stone Age in Northwestern Europe, N. Y., 1920. 
200 years the ice edge remained in one position, forming a great moraine. Brooks suggests that this pause about 8000 B. C. was due to the closing of the connection between the Atlantic Ocean and the Baltic Sea and the synchronous opening of a connection between the Baltic and the White Seas, whereby cold Arctic waters replaced the warmer Atlantic waters. He notes, however, that about 7500 B. C. the obliquity of the ecliptic was probably nearly $1^{\circ}$ greater than at present. This he calculates to have caused the climate of Germany and Sweden to be $1^{\circ} \mathrm{F}$. colder than at present in winter and $1^{\circ} \mathrm{F}$. warmer in summer.

The next climatic stage was marked by a rise of temperature till about 6000 B. C. During this period the ice at first retreated, presumably because the climate was ameliorating, although no cause of such amelioration is assigned. At length the ice lay far enough north to allow a connection between the Baltic and the Atlantic by way of Lakes Wener and Wetter in southern Sweden. This is supposed to have warmed the Baltic Sea and to have caused the climate to become distinctly milder. Next the land rose once more so that the Baltic was separated from the Atlantic and was converted into the Ancylus lake of fresh water. The southwest Baltic region then stood 400 feet higher than now. The result was the Daun stage, about 5000 B. C., when the ice halted or perhaps readvanced a little, its front being then near Ragunda in about latitude $63^{\circ}$. Why such an elevation did not cause renewed glaciation instead of merely the slight Daun pause, Brooks does not explain, although his calculations as to the effect of a slight elevation of the land during the main period of glaciation from 30,000 to 18,000 B. C. would seem to demand a marked readvance. 
After 5000 B. C. there ensued a period when the climate, although still distinctly continental, was relatively mild. The winters, to be sure, were still cold but the summers were increasingly warm. In Sweden, for example, the types of vegetation indicate that the summer temperature was $7^{\circ} \mathrm{F}$. higher than now. Storms, Brooks assumes, were comparatively rare except on the outer fringe of Great Britain. There they were sufficiently abundant so that in the Northwest they gave rise to the first Peat-Bog period, during which swamps replaced forests of birch and pine. Southern and eastern England, however, probably had a dry continental climate. Even in northwest Norway storms were rare as is indicated by remains of forests on islands now barren because of the strong winds and fierce storms. Farther east most parts of central and northern Europe were relatively dry. This was the early Neolithic period when man advanced from the use of unpolished to polished stone implements.

Not far from 4000 B. C. the period of continental climate was replaced by a comparatively moist maritime climate. Brooks believes that this was because submergence opened the mouth of the Baltic and caused the fresh Ancylus lake to give place to the so-called Litorina sea. The temperature in Sweden averaged about $3^{\circ} \mathrm{F}$. higher than at present and in southwestern Norway $2^{\circ}$. More important than this was the small annual range of temperature due to the fact that the summers were cool while the winters were mild. Because of the presence of a large expanse of water in the Baltic region, storms, as our author states, then crossed Great Britain and followed the Baltic depression, carrying the moisture far inland. In spite of the additional moisture thus available the snow line in southern Norway was higher than now.

At this point Brooks turns to other parts of the world. 
He states that not far from 4000 B. C., a submergence of the lands, rarely amounting to more than twenty-five feet, took place not only in the Baltic region but in Ireland, Iceland, Spitzbergen, and other parts of the Arctic Ocean, as well as in the White Sea, Greenland, and the eastern part of North America. Evidences of a mild climate are found in all those places. Similar evidence of a mild warm climate is found in East Africa, East Australia, Tierra del Fuego, and Antarctica. The dates are not established with certainty but they at least fall in the period immediately preceding the present epoch. In explanation of these conditions Brooks assumes a universal change of sea level. He suggests with some hesitation that this may have been due to one of Pettersson's periods of maximum "tide-generating force." According to Pettersson the varying positions of the moon, earth, and sun cause the tides to vary in cycles of about 9,90 , and 1800 years, though the length of the periods is not constant. When tides are high there is great movement of ocean waters and hence a great mixture of the water at different latitudes. This is supposed to cause an amelioration of climate. The periods of maximum and minimum tide-generating force are as follows:

Maxima 3500 B. C.

Minima 2100 B. C. 350 B. C. A. D. 1434

Brooks thinks that the big trees in California and the Norse sagas and Germanic myths indicate a rough agreement of climatic phenomena with Pettersson's last three dates, while the mild climate of 4000 B. C. may really belong to $3500 \mathrm{~B}$. C. He gives no evidence confirming Pettersson's view at the other three dates.

To return to Brooks' sketch of the relation of climatic pulsations to the altitude of the lands, by 3000 B. C., that 
is, toward the close of the Neolithic period, further elevation is supposed to have taken place over the central latitudes of western Europe. Southern Britain, which had remained constantly above its present level ever since 30,000 B. C., was perhaps ninety feet higher than now. Ireland was somewhat enlarged by elevation, the Straits of Dover were almost closed, and parts of the present North Sea were land. To these conditions Brooks ascribes the prevalence of a dry continental climate. The storms shifted northward once more, the winds were mild, as seems to be proved by remains of trees in exposed places; and forests replaced fields of peat and heath in Britain and Germany. The summers were perhaps warmer than now but the winters were severe. The relatively dry climate prevailed as far west as Ireland. For example, in Drumkelin Bog in Donegal County a corded oak road and a two-story log cabin appear to belong to this time. Fourteen feet of bog lie below the floor and twenty-six above. This period, perhaps 3000-2000 B. C., was the legendary heroic age of Ireland when "the vigour of the Irish reached a level not since attained." This, as Brooks points out, may have been a result of the relatively dry climate, for today the extreme moisture of Ireland seems to be a distinct handicap. In Scandinavia, civilization, or at least the stage of relative progress, was also high at this time.

By 1600 B. C. the land had assumed nearly its present level in the British Isles and the southern Baltic region, while northern Scandinavia still stood lower than now. The climate of Britain and Germany was so humid that there was an extensive formation of peat even on high ground not before covered. This moist stage seems to have lasted almost to the time of Christ, and may have been the reason why the Romans described Britain as 
peculiarly wet and damp. At this point Brooks again departs from northwest Europe to a wider field:

It is possible that we have to attribute this damp period in Northwest Europe to some more general cause, for Ellsworth Huntington's curves of tree-growth in California and climate in Western Asia both show moister conditions from about 1000 B. C. to A. D. 200 , and the same author believes that the Mediterranean lands had a heavier rainfall about 500 B. C. to A. D. 200. It seems that the phase was marked by a general increase of the storminess of the temperate regions of the northern hemisphere at least, with a maximum between Ireland and North Germany, indicating probably that the Baltic again became the favourite track of depressions from the Atlantic.

Brooks ends his paper with a brief résumé of glacial changes in North America, but as the means of dating events are unreliable the degree of synchronism with Europe is not clear. He sums up his conclusions as follows :

On the whole it appears that though there is a general similarity in the climatic history of the two sides of the North Atlantic, the changes are not really contemporaneous, and such relationship as appears is due mainly to the natural similarity in the geographical history of two regions both recovering from an Ice Age, and only very partially to world-wide pulsations of climate. Additional evidence on this head will be available when Baron de Geer publishes the results of his recent investigations of the seasonal glacial clays of North America, especially if, as he hopes, he is able to correlate the banding of these clays with the growth-rings of the big trees.

When we turn to the northwest of North America, this is brought out very markedly. For in Yukon and Alaska the Ice Age was a very mild affair compared with its severity in eastern America and Scandinavia. As the land had not a heavy ice-load to recover from, there were no complicated geographical 
changes. Also, there were no fluctuations of climate, but simply a gradual passage to present conditions. The latter circumstance especially seems to show that the emphasis laid on geographical rather than astronomical factors of great climatic changes is not misplaced.

Brooks' painstaking discussion of post-glacial climatic changes is of great value because of the large body of material which he has so carefully wrought together. His strong belief in the importance of changes in the level of the lands deserves serious consideration. It is difficult, however, to accept his final conclusion that such changes are the main factors in recent climatic changes. It is almost impossible, for example, to believe that movements of the land could produce almost the same series of climatic changes in Europe, Central Asia, the western and eastern parts of North America, and the southern hemisphere. Yet such changes appear to have occurred during and since the glacial period. Again there is no evidence whatever that movements of the land have anything to do with the historic cycles of climate or with the cycles of weather in our own day, which seem to be the same as glacial cycles on a small scale. Also, as Dr. Simpson points out in discussing Brooks' paper, there appears "no solution along these lines of the problem connected with rich vegetation in both polar circles and the ice-age which produced the ice-sheet at sea-level in Northern India." Nevertheless, we may well believe that Brooks is right in holding that changes in the relative level and relative area of land and sea have had important local effects. While they are only one of the factors involved in climatic changes, they are certainly one that must constantly be kept in mind. 


\section{CHAPTER XIII}

\section{THE CHANGING COMPOSITION OF OCEANS AND ATMOSPHERE}

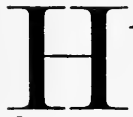

AVING discussed the climatic effect of movements of the earth's crust during the course of geological time, we are now ready to consider the corresponding effects due to changes in the movable envelopes-the oceans and the atmosphere. Variations in the composition of sea water and of air, and in the amount of air must almost certainly have occurred, and must have produced at least slight climatic consequences. It should be pointed out at once that such variations appear to be far less important climatically than do movements of the earth's crust and changes in the activity of the sun. Moreover, in most cases, they are not reversible as are the crustal and solar phenomena. Hence, while most of them appear to have been unimportant so far as climatic oscillations and fluctuations are concerned, they seemingly have aided in producing the slight secular progression to which we have so often referred.

There is general agreement among geologists that the ocean has become increasingly saline throughout the ages. Indeed, calculations of the rate of accumulation of salt have been a favorite method of arriving at estimates of the age of the ocean, and hence of the earliest marine sediments. So far as known, however, no geologist or climatologist has discussed the probable climatic effects 
of increased salinity. Yet it seems clear that an increase in salinity must have a slight effect upon climate.

Salinity affects climate in four ways: (1) It appreciably influences the rate of evaporation; (2) it alters the freezing point; (3) it produces certain indirect effects through changes in the absorption of carbon dioxide; and (4) it has an effect on oceanic circulation.

(1) According to the experiments of Mazelle and Okada, as reported by Krümmel, ${ }^{1}$ evaporation from ordinary sea water is from 9 to 30 per cent less rapid than from fresh water under similar conditions. The variation from 9 to 30 per cent found in the experiments depends, perhaps, upon the wind velocity. When salt water is stagnant, rapid evaporation tends to result in the development of a film of salt on the top of the water, especially where it is sheltered from the wind. Such a film necessarily reduces evaporation. Hence the relatively low salinity of the oceans in the past probably had a tendency to increase the amount of water vapor in the air. Even a little water vapor augments slightly the blanketing effect of the air and to that extent diminishes the diurnal and seasonal range of temperature and the contrast from zone to zone.

(2) Increased salinity means a lower freezing temperature of the oceans and hence would have an effect during cold periods such as the present and the Pleistocene ice age. It would not, however, be of importance during the long warm periods which form most of geologic time. A salinity of about 3.5 per cent at present lowers the freezing point of the ocean roughly $2^{\circ} \mathrm{C}$. below that of fresh water. If the ocean were fresh and our winters as cold as now, all the harbors of New England and the Middle Atlantic States would be icebound. The

1 Encyclopædia Britannica, 11th edition: article "Ocean." 
Baltic Sea would also be frozen each winter, and even the eastern harbors of the British Isles would be frequently locked in ice. At high latitudes the area of permanently frozen oceans would be much enlarged. The effect of such a condition upon marine life in high latitudes would be like that of a change to a warmer climate. It would protect the life on the continental shelf from the severe battering of winter storms. It would also lessen the severity of the winter temperature in the water for when water freezes it gives up much latent heat,-eighty calories per cubic centimeter. Part of this raises the temperature of the underlying water.

The expansion of the ice near northern shores would influence the life of the lands quite differently from that of the oceans. It would act like an addition of land to the continents and would, therefore, increase the atmospheric contrasts from zone to zone and from continental interior to ocean. In summer the ice upon the sea would tend to keep the coastal lands cool, very much as happens now near the Arctic Ocean, where the ice floes have a great effect through their reflection of light and their absorption of heat in melting. In winter the virtual enlargement of the continents by the addition of an ice fringe would decrease the snowfall upon the lands. Still more important would be the effect in intensifying the anticyclonic conditions which normally prevail in winter not only over continents but over ice-covered oceans. Hence the outblowing cold winds would be strengthened. ${ }^{2}$ The net effect of all these conditions would apparently be a diminution of snowfall in high latitudes upon the lands even though the summer snowfall upon the ocean and the

2 C. E. P. Brooks: The Meteorological Conditions of an Ice Sheet and Their Bearing on the Desiceation of the Globe; Quart. Jour. Royal Meteorol. Soc., Vol. 40, 1914, pp. 53-70. 
coasts may have increased. This condition may have been one reason why widespread glaciation does not appear to have prevailed in high latitudes during the Proterozoic and Permian glaciations, even though it occurred farther south. If the ocean during those early glacial epochs were ice-covered down to middle latitudes, a lack of extensive glaciation in high latitudes would be no more surprising than is the lack of Pleistocene glaciation in the northern parts of Alaska and Asia. Great ice sheets are impossible without a large supply of moisture.

(3) Among the indirect effects of salinity one of the chief appears to be that the low salinity of the water in the past and the greater ease with which it froze presumably allowed the temperature of the entire ocean to be slightly higher than now. This is because ice serves as a blanket and hinders the radiation of heat from the underlying water. The temperature of the ocean has a climatic significance not only directly, but indirectly through its influence on the amount of carbon dioxide held by the oceans. A change of even $1^{\circ} \mathrm{C}$. from the present mean temperature of $2^{\circ} \mathrm{C}$. would alter the ability of the entire ocean to absorb carbon dioxide by about 4 per cent. This, according to $\mathrm{F}$. W. Clarke, ${ }^{3}$ is because the oceans contain from eighteen to twenty-seven times as much carbon dioxide as the air when only the free carbon dioxide is considered, and about seventy times as much according to Johnson and Williamson ${ }^{4}$ when the partially combined carbon dioxide is also considered. Moreover, the capacity of water for carbon dioxide varies sharply with the temperature. ${ }^{5}$ Hence a rise in temperature of only $1^{\circ} \mathrm{C}$. would theoretically cause the oceans to give up from 30

\footnotetext{
3 Data of Geochemistry, Fourth Ed., 1920; Bull. No. 695, U. S. Geol. Survey.

4 Quoted by Schuchert in The Evolution of the Earth.

5 Smithsonian Physical Tables, Sixth Revision, 1914, p. 142.
} 
to 280 times as much carbon dioxide as the air now holds. This, however, is on the unfounded assumption that the oceans are completely saturated. The important point is merely that a slight change in ocean temperature would cause a disproportionately large change in the amount of carbon dioxide in the air with all that this implies in respect to blanketing the earth, and thus altering temperature.

(4) Another and perhaps the most important effect of salinity upon climate depends upon the rapidity of the deep-sea circulation. The circulation is induced by differences of temperature, but its speed is affected at least slightly by salinity. The vertical circulation is now dominated by cold water from subpolar latitudes. Except in closed seas like the Mediterranean the lower portions of the ocean are near the freezing point. This is because cold water sinks in high latitudes by reason of its superior density, and then "creeps" to low latitudes. There it finally rises and replaces either the water driven poleward by the winds, or that which has evaporated from the surface. ${ }^{\circ}$

During past ages, when the sea water was less salty, the circulation was presumably more rapid than now. This was because, in tropical regions, the rise of cold

6 Chamberlin, in a very suggestive article "On a possible reversal of oceanic circulation"' (Jour. of Geol., Vol. 14, pp. 363-373, 1906), discusses the probable climatic consequences of a reversal in the direction of deepsea circulation. It is not wholly beyond the bounds of possibility that in the course of ages the increasing drainage of salt from the lands not only by nature but by man's activities in agriculture and drainage, may ultimately cause such a reversal by increasing the ocean's salinity until the more saline tropical portion is heavier than the cooler but fresher subpolar waters. If that should happen, Greenland, Antaretica, and the northern shores of America and Asia would be warmed by the tropical heat which had been transferred poleward beneath the surface of the ocean, without loss en route. Subpolar regions, under such a condition of reversed deep-sea circulation, might have a mild climate. Indeed, they might be among the world's most favorable regions climatically. 
water is hindered by the sinking of warm surface water which is relatively dense because evaporation has removed part of the water and caused an accumulation of salt. According to Krümmel and Mill, ${ }^{7}$ the surface salinity of the subtropical belt of the North Atlantic commonly exceeds 3.7 per cent and sometimes reaches 3.77 per cent, whereas the underlying waters have a salinity of less than 3.5 per cent and locally as little as 3.44 per cent. The other oceans are slightly less saline than the North Atlantic at all depths, but the vertical salinity gradients along the tropics are similar. According to the Smithsonian Physical Tables, the difference in salinity between the surface water and that lying below is equivalent to a difference of .003 in density, where the density of fresh water is taken as 1.000. Since the decrease in density produced by warming water from the temperature of its greatest density $\left(4^{\circ} \mathrm{C}\right.$. $)$ to the highest temperatures which ever prevail in the ocean $\left(30^{\circ} \mathrm{C}\right.$. or $86^{\circ} \mathrm{F}$.) is only .004 , the more saline surface waters of the dry tropics are at most times almost as dense as the less saline but colder waters beneath the surface, which have come from higher latitudes. During days of especially great evaporation, however, the most saline portions of the surface waters in the dry tropics are denser than the underlying waters and therefore sink, and produce a temporary local stagnation in the general circulation. Such a sinking of the warm surface waters is reported by Krümmel, who detected it by means of the rise in temperature which it produces at considerable depths. If such a hindrance to the circulation did not exist, the velocity of the deep-sea movements would be greater.

If in earlier times a more rapid circulation occurred, low latitudes must have been cooled more than now by

7 Encyclopædia Britannica: article "Ocean." 
the rise of cold waters. At the same time higher latitudes were presumably warmed by a greater flow of warm water from tropical regions because less of the surface heat sank in low latitudes. Such conditions would tend to lessen the climatic contrast between the different latitudes. Hence, in so far as the rate of deep-sea circulation depends upon salinity, the slowly increasing amount of salt in the oceans must have tended to increase the contrasts between low and high latitudes. Thus for several reasons, the increase of salinity during geologic history seems to deserve a place among the minor agencies which help to explain the apparent tendency toward a secular progression of climate in the direction of greater contrasts between tropical and subpolar latitudes.

Changes in the composition and amount of the atmosphere have presumably had a climatic importance greater than that of changes in the salinity of the oceans. The atmospheric changes may have been either progressive or cyclic, or both. In early times, according to the nebular hypothesis, the atmosphere was much more dense than now and contained a larger percentage of certain constituents, notably carbon dioxide and water. The planetesimal hypothesis, on the other hand, postulates an increase in the density of the atmosphere, for according to this hypothesis the density of the atmosphere depends upon the power of the earth to hold gases, and this power increases as the earth grows bigger with the infall of material from without. ${ }^{8}$

Whichever hypothesis may be correct, it seems probable that when life first appeared on the land the atmosphere resembled that of today in certain fundamental respects. It contained the elements essential to life, and

8 Chamberlin and Salisbury: Geology, Vol. II, pp. 1-132, 1906; and T. C. Chamberlin: The Origin of the Earth, 1916. 
its blanketing effect was such as to maintain temperatures not greatly different from those of the present. The evidence of this depends largely upon the narrow limits of temperature within which the activities of modern life are possible, and upon the cumulative evidence that ancient life was essentially similar to the types now living. The resemblance between some of the oldest forms and those of today is striking. For example, according to Professor Schuchert:" "Many of the living genera of forest trees had their origin in the Cretaceous, and the giant sequoias of California go back to the Triassic, while Ginkgo is known in the Permian. Some of the fresh-water molluses certainly were living in the early periods of the Mesozoic, and the lung-fish of today (Ceratodus) is known as far back as the Triassic and is not very unlike other lung-fishes of the Devonian. The higher vertebrates and insects, on the other hand, are very sensitive to their environment, and therefore do not extend back generically beyond the Cenozoic, and only in a few instances even as far as the Oligocene. Of marine invertebrates the story is very different, for it is well known that the horseshoe crab (Limulus) lived in the Upper Jurassic, and Nautilus in the Triassic, with forms in the Devonian not far removed from this genus. Still longer-ranging genera occur among the brachiopods, for living Lingula and Crania have specific representatives as far back as the early Ordovician. Among living foraminifers, Lagena, Globigerina, and Nodosaria are known in the later Cambrian or early Ordovician. In the Middle Cambrian near Field, British Columbia, Walcott has found a most varied array of invertebrates among which are crustaceans not far removed from living forms. Zoölogists who see these wonderful fossils are at once

9 Personal communication. 
struck with their modernity and the little change that has taken place in certain stocks since that far remote time. Back of the Paleozoic, little can be said of life from the generic standpoint, since so few fossils have been recovered, but what is at hand suggests that the marine environment was similar to that of today."

At present, as we have repeatedly seen, little growth takes place either among animals or plants at temperatures below $0^{\circ} \mathrm{C}$. or above $40^{\circ} \mathrm{C}$., and for most species the limiting temperatures are about $10^{\circ}$ and $30^{\circ}$. The maintenance of so narrow a scale of temperature is a function of the atmosphere, as well as of the sun. Without an atmosphere, the temperature by day would mount fatally wherever the sun rides high in the sky. By night it would fall everywhere to a temperature approaching absolute zero, that is $-273^{\circ} \mathrm{C}$. Some such temperature prevails a few miles above the earth's surface, beyond the effective atmosphere. Indeed, even if the atmosphere were almost as it is now, but only lacked one of the minor constituents, a constituent which is often actually ignored in statements of the composition of the air, life would be impossible. Tyndall concludes that if water vapor were entirely removed from the atmosphere for a single day and night, all life-except that which is dormant in the form of seeds, eggs, or spores-would be exterminated. Part would be killed by the high temperature developed by day when the sun was high, and part, by the cold night.

The testimony of ancient glaciation as to the slight difference in the climate and therefore in the atmosphere of early and late geological times is almost as clear as that of life. Just as life proves that the earth can never have been extremely cold during hundreds of millions of years, so glaciation in moderately low latitudes near 
the dawn of earth history and at several later times, proves that the earth was not particularly hot even in those early days. The gentle progressive change of climate which is recorded in the rocks appears to have been only in slight measure a change in the mean temperature of the earth as a whole, and almost entirely a change in the distribution of temperature from place to place and season to season. Hence it seems probable that neither the earth's own emission of heat, nor the supply of solar heat, nor the power of the atmosphere to retain heat can have been much greater a few hundred million years ago than now. It is indeed possible that these three factors may have varied in such a way that any variation in one has been offset by variations of the others in the opposite direction. This, however, is so highly improbable that it seems advisable to assume that all three have remained relatively constant. This conclusion together with a realization of the climatic significance of carbon dioxide has forced most of the adherents of the nebular hypothesis to abandon their assumption that carbon dioxide, the heaviest gas in the air, was very abundant until taken out by coal-forming plants or combined with the calcium oxide of igneous rocks to form the limestone secreted by animals. In the same way the presence of sun cracks in sedimentary rocks of all ages suggests that the air cannot have contained vast quantities of water vapor such as have been assumed by Knowlton and others in order to account for the former lack of sharp climatic contrast between the zones. Such a large amount of water vapor would almost certainly be accompanied by wellnigh universal and continual cloudiness so that there would be little chance for the pools on the earth's watersoaked surface to dry up. Furthermore, there is only one way in which such cloudiness could be maintained and 
that is by keeping the air at an almost constant temperature night and day. This would require that the chief source of warmth be the interior of the earth, a condition which the Proterozoic, Permian, and other widespread glaciations seem to disprove.

Thus there appears to be strong evidence against the radical changes in the atmosphere which are sometimes postulated. Yet some changes must have taken place, and even minor changes would be accompanied by some sort of climatic effect. The changes would take the form of either an increase or a decrease in the atmosphere as a whole, or in its constituent elements. The chief means by which the atmosphere has increased appear to be as follows: (a) By contributions from the interior of the earth via volcanoes and springs and by the weathering of igneous rocks with the consequent release of their enclosed gases $;^{10}$ (b) by the escape of some of the abundant gases which the ocean holds in solution; (c) by the arrival on the earth of gases from space, either enclosed in meteors or as free-flying molecules; (d) by the release of gases from organic compounds by oxidation, or by exhalation from animals and plants. On the other hand, one or another of the constituents of the atmosphere has presumably decreased (a) by being locked up in newly formed rocks or organic compounds; (b) by being dissolved in the ocean; (c) by the escape of molecules into space; and (d) by the condensation of water vapor.

The combined effect of the various means of increase and decrease depends partly on the amount of each constituent received from the earth's interior or from space, and partly on the fact that the agencies which tend to deplete the atmosphere are highly selective in their 1908 .

10 R. T. Chamberlin: Gases in Rocks, Carnegie Inst. of Wash., No. 106, 
action. Our knowledge of how large a quantity of new gases the air has received is very scanty, but judging by present conditions the general tendency is toward a slow increase chiefly because of meteorites, volcanic action, and the work of deep-seated springs. As to decrease, the case is clearer. This is because the chemically active gases, oxygen, $\mathrm{CO}_{2}$, and water vapor, tend to be locked up in the rocks, while the chemically inert gases, nitrogen and argon, show almost no such tendency. Though oxygen is by far the most abundant element in the earth's crust, making up more than 50 per cent of the total, it forms only about one-fifth of the air. Nitrogen, on the other hand, is very rare in the rocks, but makes up nearly four-fifths of the air. It would, therefore, seem probable that throughout the earth's history, there has been a progressive increase in the amount of atmospheric nitrogen, and presumably a somewhat corresponding increase in the mass of the air. On the other hand, it is not clear what changes have occurred in the amount of atmospheric oxygen. It may have increased somewhat or perhaps even notably. Nevertheless, because of the greater increase in nitrogen, it may form no greater percentage of the air now than in the distant past.

As to the absolute amounts of oxygen, Barrell ${ }^{11}$ thought that atmospheric oxygen began to be present only after plants had appeared. It will be recalled that plants absorb carbon dioxide and separate the carbon from the oxygen, using the carbon in their tissues and setting free the oxygen. As evidence of a paucity of oxygen in the air in early Proterozoic times, Barrell cites the fact that the sedimentary rocks of that remote

$11 \mathrm{~J}$. Barrell: The Origin of the Earth, in Evolution of the Earth and Its Inhabitants, 1918, p. 44, and more fully in an unpublished manuscript. 
time commonly are somewhat greyish or greenish-grey wackes, or other types, indicating incomplete oxidation. He admits, however, that the stupendous thicknesses of red sandstones, quartzite, and hematitic iron ores of the later Proterozoic prove that by that date there was an abundance of atmospheric oxygen. If so, the change from paucity to abundance must have occurred before fossils were numerous enough to give much clue to climate. However, Barrell's evidence as to a former paucity of atmospheric oxygen is not altogether convincing. In the first place, it does not seem justifiable to assume that there could be no oxygen until plants appeared to break down the carbon dioxide, for some oxygen is contributed by volcanoes, ${ }^{12}$ and lightning decomposes water into its elements. Part of the hydrogen thus set free escapes into space, for the earth's gravitative force does not appear great enough to hold this lightest of gases, but the oxygen remains. Thus electrolysis of water results in the accumulation of oxygen. In the second place, there is no proof that the ancient greywackes are not deoxidized sediments. Light colored rock formations do not necessarily indicate a paucity of atmospheric oxygen, for such rocks are abundant even in recent times. For example, the Tertiary formations are characteristically light colored, a result, however, of deoxidation. Finally, the fact that sedimentary rocks, irrespective of their age, contain an average of about 1.5 per cent more oxygen than do igneous rocks, ${ }^{13}$ suggests that oxygen was present in the air in quantity even when the earliest shales and sandstones were formed, for atmospheric oxygen seems to be the probable source of the extra oxygen they

12 F. W. Clarke: Data of Geochemistry, Fourth Ed., 1920, Bull. No. 695, U. S. Geol. Survey, p. 256.

13 F. W. Clarke: loc. cit., pp. 27-34 et al. 
contain. The formation of these particular sedimentary rocks by weathering of igneous rocks involves only a little carbon dioxide and water. Although it seems probable that oxygen was present in the atmosphere even at the beginning of the geological record, it may have been far less abundant then than now. It may have been removed from the atmosphere by animals or by the oxidation of the rocks almost as rapidly as it was added by volcanoes, plants, and other agencies.

After this chapter was in type, St. John ${ }^{13}$ announced his interesting discovery that oxygen is apparently lacking in the atmosphere of Venus. He considers that this proves that Venus has no life. Furthermore he concludes that so active an element as oxygen cannot be abundant in the atmosphere of a planet unless plants continually supply large quantities by breaking down carbon dioxide.

But even if the earth has experienced a notable increase in atmospheric oxygen since the appearance of life, this does not necessarily involve important climatic changes except those due to increased atmospheric density. This is because oxygen has very little effect upon the passage of light or heat, being transparent to all but a few wave lengths. Those absorbed are chiefly in the ultra violet.

The distinct possibility that oxygen has increased in amount, makes it the more likely that there has been an increase in the total atmosphere, for the oxygen would supplement the increase in the relatively inert nitrogen and argon, which has presumably taken place. The climatic effects of an increase in the atmosphere include, in the first place, an increased scattering of light as it approaches the earth. Nitrogen, argon, and oxygen all

13a Chas. E. St. John: Science Service Press Reports from the Mt. Wilson Observatory, May, 1922. 
scatter the short waves of light and thus interfere with their reaching the earth. Abbot and Fowle, ${ }^{14}$ who have carefully studied the matter, believe that at present the scattering is quantitatively important in lessening insolation. Hence our supposed general increase in the volume of the air during part of geological times would tend to reduce the amount of solar energy reaching the earth's surface. On the other hand, nitrogen and argon do not appear to absorb the long wave lengths known as heat, and oxygen absorbs so little as to be almost a nonabsorber. Therefore the reduced penetration of the air by solar radiation due to the scattering of light would apparently not be neutralized by any direct increase in the blanketing effect of the atmosphere, and the temperature near the earth's surface would be slightly lowered by a thicker atmosphere. This would diminish the amount of water vapor which would be held in the air, and thereby lower the temperature a trifle more.

In the second place, the higher atmospheric pressure which would result from the addition of gases to the air would cause a lessening of the rate of evaporation, for that rate declines as pressure increases. Decreased evaporation would presumably still further diminish the vapor content of the atmosphere. This would mean a greater daily and seasonal range of temperature, as is very obvious when we compare clear weather with cloudy. Cloudy nights are relatively warm while clear nights are cool, because water vapor is an almost perfect absorber of radiant heat, and there is enough of it in the air on moist nights to interfere greatly with the escape of the heat accumulated during the day. Therefore, if atmos-

14 Abbot and Fowle: Annals Astrophysical Observatory; Smiths. Inst., Vol. II, 1908, p. 163.

F. E. Fowle: Atmospheric Seattering of Light; Misc. Coll. Smiths. Inst., Vol. 69, 1918. 
pheric moisture were formerly much more abundant than now, the temperature must have been much more uniform. The tendency toward climatic severity as time went on would be still further increased by the cooling which would result from the increased wind velocity discussed below; for cooling by convection increases with the velocity of the wind, as does cooling by conduction.

Any persistent lowering of the general temperature of the air would affect not only its ability to hold water vapor, but would produce a lessening in the amount of atmospheric carbon dioxide, for the colder the ocean becomes the more carbon dioxide it can hold in solution. When the oceanic temperature falls, part of the atmospheric carbon dioxide is dissolved in the ocean. This minor constituent of the air is important because although it forms only 0.003 per cent of the earth's atmosphere, Abbot and Fowle' ${ }^{15}$ calculations indicate that it absorbs over 10 per cent of the heat radiated outward from the earth. Hence variations in the amount of carbon dioxide may have caused an appreciable variation in temperature and thus in other climatic conditions. Humphreys, as we have seen, has calculated that a doubling of the carbon dioxide in the air would directly raise the earth's temperature to the extent of $1.3^{\circ} \mathrm{C}$., and a halving would lower it a like amount. The indirect results of such an increase or decrease might be greater than the direct results, for the change in temperature due to variations in carbon dioxide would alter the capacity of the air to hold moisture.

Two conditions would especially help in this respect; first, changes in nocturnal cooling, and second, changes in local convection. The presence of carbon dioxide diminishes nocturnal cooling because it absorbs the heat radi-

15 Abbot and Fowle: loc. cit., p. 172. 
ated by the earth, and re-radiates part of it back again. Hence with increased carbon dioxide and with the consequent warmer nights there would be less nocturnal condensation of water vapor to form dew and frost. Local convection is influenced by carbon dioxide because this gas lessens the temperature gradient. In general, the less the gradient, that is, the less the contrast between the temperature at the surface and higher up, the less convection takes place. This is illustrated by the seasonal variation in convection. In summer, when the gradient is steepest, convection reaches its maximum. It will be recalled that when air rises it is cooled by expansion, and if it ascends far the moisture is soon condensed and precipitated. Indeed, local convection is considered by C. P. Day to be the chief agency which keeps the lower air from being continually saturated with moisture. The presence of carbon dioxide lessens convection because it increases the absorption of heat in the zone above the level in which water vapor is abundant, thus warming these higher layers. The lower air may not be warmed correspondingly by an increase in carbon dioxide if Abbot and Fowle are right in stating that near the earth's surface there is enough water vapor to absorb practically all the wave lengths which carbon dioxide is capable of absorbing. Hence carbon dioxide is chiefly effective at heights to which the low temperature prevents water vapor from ascending. Carbon dioxide is also effective in cold winters and in high latitudes when even the lower air is too cold to contain much water vapor. Moreover, carbon dioxide, by altering the amount of atmospheric water vapor, exerts an indirect as well as a direct effect upon temperature.

Other effects of the increase in air pressure which we are here assuming during at least the early part of geo- 
logical times are corresponding changes in barometric contrasts, in the strength of winds, and in the mass of air carried by the winds along the earth's surface. The increase in the mass of the air would reënforce the greater velocity of the winds in their action as eroding and transporting agencies. Because of the greater weight of the air, the winds would be capable of picking up more dust and of carrying it farther and higher; while the increased atmospheric friction would keep it aloft a longer time. The significance of dust at high levels and its relation to solar radiation have already been discussed in connection with volcanoes. It will be recalled that on the average it lowers the surface temperature. At lower levels, since dust absorbs heat quickly and gives it out quickly, its presence raises the temperature of the air by day and lowers it by night. Hence an increase in dustiness tends toward greater extremes.

From all these considerations it appears that if the atmosphere has actually evolved according to the supposition which is here tentatively entertained, the general tendency of the resultant climatic changes must have been partly toward long geological oscillations and partly toward a general though very slight increase in climatic severity and in the contrasts between the zones. This seems to agree with the geological record, although the fact that we are living in an age of relative climatic severity may lead us astray.

The significant fact about the whole matter is that the three great types of terrestrial agencies, namely, those of the earth's interior, those of the oceans, and those of the air, all seem to have suffered changes which lead to slow variations of climate. Many reversals have doubtless taken place, and the geologic oscillations thus induced are presumably of much greater importance than 
the progressive change, yet so far as we can tell the purely terrestrial changes throughout the hundreds of millions of years of geological time have tended toward complexity and toward increased contrasts from continent to ocean, from latitude to latitude, from season to season, and from day to night.

Throughout geological history the slow and almost imperceptible differentiation of the earth's surface has been one of the most noteworthy of all changes. It has been opposed by the extraordinary conservatism of the universe which causes the average temperature today to be so like that of hundreds of millions of years ago that many types of life are almost identical. Nevertheless, the differentiation has gone on. Often, to be sure, it has presumably been completely masked by the disturbances of the solar atmosphere which appear to have been the cause of the sharper, shorter climatic pulsations. But regardless of cosmic conservatism and of solar impulses toward change, the slow differentiation of the earth's surface has apparently given to the world of today much of the geographical complexity which is so stimulating a factor in organic evolution. Such complexity-such diversity from place to place-appears to be largely accounted for by purely terrestrial causes. It may be regarded as the great terrestrial contribution to the climatic environment which guides the development of life. 


\section{CHAPTER XIV}

\section{THE EFFEC'T OF O'THER BODIES ON THE SUN}

I

F solar activity is really an important factor in causing climatic changes, it behooves us to subject the sun to the same kind of inquiry to which we have subjected the earth. We have inquired into the nature of the changes through which the earth's crust, the oceans, and the atmosphere have influenced the climate of geological times. It has not been necessary, however, to study the origin of the earth, nor to trace its earlier stages. Our study of the geological record begins only when the earth had attained practically its present mass, essentially its present shape, and a climate so similar to that of today that life as we know it was possible. In other words, the earth had passed the stages of infancy, childhood, youth, and early maturity, and had reached full maturity. As it still seems to be indefinitely far from old age, we infer that during geological times its relative changes have been no greater than those which a man experiences between the ages of perhaps twenty-five and forty.

Similar reasoning applies with equal or greater force to the sun. Because of its vast size it presumably passes through its stages of development much more slowly than the earth. In the first chapter of this book we saw that the earth's relative uniformity of climate for hundreds of millions of years seems to imply a similar uniformity in solar activity. This accords with a recent tendency among 
astronomers who are more and more recognizing that the stars and the solar system possess an extraordinary degree of conservatism. Changes that once were supposed to take place in thousands of years are now thought to have required millions. Hence in this chapter we shall assume that throughout geological times the condition of the sun has been almost as at present. It may have been somewhat larger, or different in other ways, but it was essentially a hot, gaseous body such as we see today and it gave out essentially the same amount of energy. This assumption will affect the general validity of what follows only if it departs widely from the truth. With this assumption, then, let us inquire into the degree to which the sun's atmosphere has probably been disturbed throughout geological times.

In Earth and Sun, as already explained, a detailed study has led to the conclusion that cyclonic storms are influenced by the electrical action of the sun. Such action appears to be most intense in sunspots, but apparently pertains also to other disturbed areas in the sun's atmosphere. A study of sunspots suggests that their true periodicity is almost if not exactly identical with that of the orbital revolution of Jupiter, 11.8 years. Other investigations show numerous remarkable coincidences between sunspots and the orbital revolution of the other planets, including especially Saturn and Mercury. This seems to indicate that there is some truth in the hypothesis that sunspots and other related disturbances of the solar atmosphere owe their periodicity to the varying effects of the planets as they approach and recede from the sun in their eccentric orbits and as they combine or oppose their effects according to their relative positions. This does not mean that the energy of the solar disturbances is supposed to come from the planets, but merely 
that their variations act like the turning of a switch to determine when and how violently the internal forces of the sun shall throw the solar atmosphere into commotion. This hypothesis is by no means new, for in one form or another it has been advocated by Wolfer, Birkeland, E. W. Brown, Schuster, Aretowski, and others.

The agency through which the planets influence the solar atmosphere is not yet clear. The suggested agencies are the direct pull of gravitation, the tidal effect of the planets, and an electro-magnetic effect. In Earth and Sun the conclusion is reached that the first two are out of the question, a conclusion in which E. W. Brown acquiesces. Unless some unknown cause is appealed to, this leaves an electro-magnetic hypothesis as the only one which has a reasonable foundation. Schuster inclines to this view. The conclusions set forth in Earth and Sun as to the electrical nature of the sun's influence on the earth point somewhat in the same direction. Hence in this chapter we shall inquire what would happen to the sun, and hence to the earth, on their journey through space, if the solar atmosphere is actually subject to disturbance by the electrical or other effects of other heavenly bodies. It need hardly be pointed out that we are here venturing into highly speculative ground, and that the verity or falsity of the conclusions reached in this chapter has nothing to do with the validity of the reasoning in previous chapters. Those chapters are based on the assumption that terrestrial causes of climatic changes are supplemented by solar disturbances which produce their effect partly through variations in temperature but also through variations in the intensity and paths of cyclonic storms. The present chapter seeks to shed some light on the possible causes and sequence of solar disturbances.

Let us begin by scanning the available evidence as to 
solar disturbances previous to the time when accurate sunspot records are available. Two rather slender bits of evidence point to cycles of solar activity lasting hundreds of years. One of these has already been discussed in Chapter VI, where the climatic stress of the fourteenth century was described. At that time sunspots are known to have been unusually numerous, and there were great climatic extremes. Lakes overflowed in Central Asia; storms, droughts, floods, and cold winters were unusually severe in Europe; the Caspian Sea rose with great rapidity; the trees of California grew with a vigor unknown for centuries; the most terrible of recorded famines occurred in England and India; the Eskimos were probably driven south by increasing snowiness in Greenland; and the Mayas of Yucatan appear to have made their last weak attempt at a revival of civilization under the stimulus of greater storminess and less constant rainfall.

The second bit of evidence is found in recent exhaustive studies of periodicities by Turner ${ }^{1}$ and other astronomers. They have sought every possible natural occurrence for which a numerical record is available for a long period. The most valuable records appear to be those of tree growth, Nile floods, Chinese earthquakes, and sunspots. Turner reaches the conclusion that all four types of phenomena show the same periodicity, namely, cycles with an average length of about 260 to 280 years. He suggests that if this is true, the cycles in tree growth and in floods, both of which are climatic, are probably due to a non-terrestrial cause. The fact that the sunspots

1 H. H. Turner: On a Long Period in Chinese Earthquake Records; Mon. Not. Royal Astron. Soc., Vol. 79, 1919, pp. 531-539; Vol. 80, 1920, pp. 617 619; Long Period Terms in the Growth of Trees; idem, pp. 793-808. 


\section{CLIMATIC CHANGES}

show similar cycles suggests that the sun's variations are the cause.

These two bits of evidence are far too slight to form the foundation of any theory as to changes in solar activity in the geological past. Nevertheless it may be helpful to set forth certain possibilities as a stimulus to further research. For example, it has been suggested that meteoric bodies may have fallen into the sun and caused it suddenly to flare up, as it were. This is not impossible, although it does not appear to have taken place since men became advanced enough to make careful observations. Moreover, the meteorites which now fall on the earth are extremely small, the average size being computed as no larger than a grain of wheat. The largest ever found on the earth's surface, at Bacubirito in Mexico, weighs only about fifty tons, while within the rocks the evidences of meteorites are extremely scanty and insignificant. If meteorites had fallen into the sun often enough and of sufficient size to cause glacial fluctuations and historic pulsations of climate, it seems highly probable that the earth would show much more evidence of having been similarly disturbed. And even if the sun should be bombarded by large meteors the result would probably not be sudden cold periods, which are the most notable phenomena of the earth's climatic history, but sudden warm periods followed by slow cooling. Nevertheless, the disturbance of the sun by collision with meteoric matter can by no means be excluded as a possible cause of climatic variations.

Allied to the preceding hypothesis is Shapley's ${ }^{2}$ nebular hypothesis. At frequent intervals, averaging about

2 Harlow Shapley: Note on a Possible Factor in Geologic Climates; Jour. Geol., Vol. 29, No. 4, May, 1921; Novæ and Variable Stars, Pub. Astron. Soc. Pac., No. 194, Aug., 1921. 
once a year during the last thirty years, astronomers have discovered what are known as novæ. These are stars which were previously faint or even invisible, but which flash suddenly into brilliancy. Often their light-giving power rises seven or eight magnitudes-a thousand-fold. In addition to the spectacular novæ there are numerous irregular variables whose brilliancy changes in every ratio from a few per cent up to several magnitudes. Most of them are located in the vicinity of nebulæ, as is also the case with novæ. This, as well as other facts, makes it probable that all these stars are "friction variables," as Shapley calls them. Apparently as they pass through the nebulæ they come in contact with its highly diffuse matter and thereby become bright much as the earth would become bright if its atmosphere were filled with millions of almost infinitesimally small meteorites. A star may also lose brilliancy if nebulous matter intervenes between it and the observer. If our sun has been subjected to any of these changes some sort of climatic effect must have been produced.

In a personal communication Shapley amplifies the nebular climatic hypothesis as follows:

Within 700 light years of the sun in many directions (Taurus, Cygnus, Ophiuchus, Scorpio) are great diffuse clouds of nebulosity, some bright, most of them dark. The probability that stars moving in the general region of such clouds will encounter this material is very high, for the clouds fill enormous volumes of space,-e.g., probably more than a hundred thousand cubic light years in the Orion region, and are presumably composed of rarefied gases or of dust particles. Probably throughout all our part of space such nebulosity exists (it is all around us, we are sure), but only in certain regions is it dense enough to affect conspicuously the stars involved in it. If a star moving at high velocity should collide with a dense part of such a nebulous 
cloud, we should probably have a typical nova. If the relative velocity of nebulous material and star were low or moderate, or if the material were rare, we should not expect a conspicuous effect on the star's light.

In the nebulous region of Orion, which is probably of unusually high density, there are about 100 known stars, varying between $20 \%$ and $80 \%$ of their total light-all of them irregularly-some slowly, some suddenly. Apparently they are "friction variables." Some of the variables suddenly lose $40 \%$ of their light as if blanketed by nebulous matter. In the Trifid Nebula there are variables like those of Orion, in Messier 8 also, and probably many of the 100 or so around the Rho Ophiuchi region belong to this kind.

I believe that our sun could not have been a typical nova, at least not since the Archeozoic, that is for perhaps a billion years. I believe we have in geological climates final proof of this, because an increase in the amount of solar radiation by 1000 times as in the typical nova, would certainly punctuate emphatically the life cycle on the earth, even if the cause of the nova would not at the same time eliminate the smaller planets. But the sun may have been one of these miniature novæ or friction variables; and I believe it very probable that its wanderings through this part of space could not long leave its mean temperature unaffected to the amount of a few per cent.

One reason we have not had this proposal insisted upon before is that the data back of it are mostly new-the Orion variables have been only recently discovered and studied, the distribution and content of the dark nebulæ are hardly as yet generally known.

This interesting hypothesis cannot be hastily dismissed. If the sun should pass through a nebula it seems inevitable that there would be at least slight climatic effects and perhaps catastrophic effects through the action of the gaseous matter not only on the sun but on the earth's own atmosphere. As an explanation of the 
general climatic conditions of the past, however, Shapley points out that the hypothesis has the objection of being vague, and that nebulosity should not be regarded as more than "a possible factor." One of the chief difficulties seems to be the enormously wide distribution of as yet undiscovered nebulous matter which must be assumed if any large share of the earth's repeated climatic changes is to be ascribed to such matter. If such matter is actually abundant in space, it is hard to see how any but the nearest stars would be visible. Another objection is that there is no known nebulosity near at hand with which to connect the climatic vicissitudes of the last glacial period. Moreover, the known nebulæ are so much less numerous than stars that the chances that the sun will encounter one of them are extremely slight. This, however, is not an objection, for Shapley points out that during geological times the sun can never have varied as much as do the novæ, or even as most of the friction variables. Thus the hypothesis stands as one that is worth investigating, but that cannot be finally rejected or accepted until it is made more definite and until more information is available.

Another suggested cause of solar variations is the relatively sudden contraction of the sun such as that which sometimes occurs on the earth when continents are uplifted and mountains upheaved. It seems improbable that this could have occurred in a gaseous body like the sun. Lacking, as it does, any solid crust which resists a change of form, the sun probably shrinks steadily. Hence any climatic effects thus produced must be extremely gradual and must tend steadily in one direction for millions of years.

Still another suggestion is that the tidal action of the stars and other bodies which may chance to approach 
the sun's path may cause disturbances of the solar atmosphere. The vast kaleidoscope of space is never quiet. The sun, the stars, and all the other heavenly bodies are moving, often with enormous speed. Hence the effect of gravitation upon the sun must vary constantly and irregularly, as befits the geological requirements. In the case of the planets, however, the tidal effect does not seem competent to produce the movements of the solar atmosphere which appear to be concerned in the inception of sunspots. Moreover, there is only the most remote probability that a star and the sun will approach near enough to one another to produce a pronounced gravitational disturbance in the solar atmosphere. For instance, if it be assumed that changes in Jupiter's tidal effect on the sun are the main factor in regulating the present difference between sunspot maxima and sunspot minima, the chances that a star or some non-luminous body of similar mass will approach near enough to stimulate solar activity and thereby bring on glaciation are only one in twelve billion years, as will be explained below. This seems to make a gravitational hypothesis impossible.

Another possible cause of solar disturbances is that the stars in their flight through space may exert an electrical influence which upsets the equilibrium of the solar atmosphere. At first thought this seems even more impossible than a gravitational effect. Electrostatic effects, however, differ greatly from those of tides. They vary as the diameter of a body instead of as its mass; their differentials also vary inversely as the square of the distance instead of as the cube. Electrostatic effects also increase as the fourth power of the temperature or at least would do so if they followed the law of black bodies; they are stimulated by the approach of one body 
to another; and they are cumulative, for if ions arrive from space they must accumulate until the body to which they have come begins to discharge them. Hence, on the basis of assumptions such as those used in the preceding paragraph, the chances of an electrical disturbance of the solar atmosphere sufficient to cause glaciation on the earth may be as high as one in twenty or thirty million years. This seems to put an electrical hypothesis within the bounds of possibility. Further than that we cannot now go. There may be other hypotheses which fit the facts much better, but none seems yet to have been suggested.

In the rest of this chapter the tidal and electrical hypotheses of stellar action on the sun will be taken up in detail. The tidal hypothesis is considered because in discussions of the effect of the planets it has hitherto held almost the entire field. The electrical hypothesis will be considered because it appears to be the best yet suggested, although it still seems doubtful whether electrical effects can be of appreciable importance over such vast distances as are inevitably involved. The discussion of both hypotheses will necessarily be somewhat technical, and will appeal to the astronomer more than to the layman. It does not form a necessary part of this book, for it has no bearing on our main thesis of the effect of the sun on the earth. It is given here because ultimately the question of changes in solar activity during geological times must be faced.

In the astronomical portion of the following discussion we shall follow Jeans ${ }^{3}$ in his admirable attempt at a mathematical analysis of the motions of the universe. Jeans divides the heavenly bodies into five main types: (1) Spiral nebulæ, which are thought by some astrono-

3 J. H. Jeans: Problems of Cosmogony and Stellar Dynamies, Cambridge, 1919. 
mers to be systems like our own in the making, and by others to be independent universes lying at vast distances beyond the limits of our Galactic universe, as it is called from the Galaxy or Milky Way. (2) Nebulæ of a smaller type, called planetary. These lie within the Galactic portion of the universe and seem to be early stages of what may some day be stars or solar systems. (3) Binary or multiple stars, which are extraordinarily numerous. In some parts of the heavens they form 50 or even 60 per cent of the stars and in the galaxy as a whole they seem to form "fully one third." (4) Star clusters. These consist of about a hundred groups of stars in each of which the stars move together in the same direction with approximately the same velocity. These, like the spiral nebulæ, are thought by some astronomers to lie outside the limits of the galaxy, but this is far from certain. (5) The solar system. According to Jeans this seems to be unique. It does not fit into the general mathematical theory by which he explains spiral nebulæ, planetary nebulæ, binary stars, and star clusters. It seems to demand a special explanation, such as is furnished by tidal disruption due to the passage of the sun close to another star.

The part of Jeans' work which specially concerns us is his study of the probability that some other star will approach the sun closely enough to have an appreciable gravitative or electrical effect, and thus cause disturbances in the solar atmosphere. Of course both the star and the sun are moving, but to avoid circumlocution we shall speak of such mutual approaches simply as approaches of the sun. For our present purpose the most fundamental fact may be summed up in a quotation from Jeans in which he says that most stars "show evidence of having experienced considerable disturbance by other systems; there is no reason why our solar system should 
be expected to have escaped the common fate." Jeans gives a careful calculation from which it is possible to derive some idea of the probability of any given degree of approach of the sun and some other star. Of course all such calculations must be based on certain assumptions. The assumptions made by Jeans are such as to make the probability of close approaches as great as possible. For example, he allows only 560 million years for the entire evolution of the sun, whereas some astronomers and geologists would put the figure ten or more times as high. Nevertheless, Jeans' assumptions at least show the order of magnitude which we may expect on the basis of reasonable astronomical conclusions.

According to the planetary hypothesis of sunspots, the difference in the effect of Jupiter when it is nearest and farthest from the sun is the main factor in starting the sunspot cycle and hence the corresponding terrestrial cycle. The climatic difference between sunspot maxima and minima, as measured by temperature, apparently amounts to at least a twentieth and perhaps a tenth of the difference between the climate of the last glacial epoch and the present. We may suppose, then, that a body which introduced a gravitative or electrical factor twenty times as great as the difference in Jupiter's effect at its maximum and minimum distances from the sun would cause a glacial epoch if the effect lasted long enough. Of course the other planets combine their effects with that of Jupiter, but for the sake of simplicity we will leave the others out of account. The difference between Jupiter's maximum and minimum tidal effect on the sun amounts to 29 per cent of the planet's average effect. The corresponding difference, according to the electrical hypothesis, is about 19 per cent, for electrostatic action varies as the square of the distance instead of as the cube. 
Let us assume that a body exerting four times Jupiter's present tidal effect and placed at the average distance of Jupiter from the sun would disturb the sun's atmosphere twenty times as much as the present difference between sunspot maxima and minima, and thus, perhaps, cause a glacial period on the earth.

On the basis of this assumption our first problem is to estimate the frequency with which a star, visible or dark, is likely to approach near enough to the sun to produce a tidal effect four times that of Jupiter. The number of visible stars is known or at least well estimated. As to dark stars, which have grown cool, Arrhenius believed that they are a hundred times as numerous as bright stars; few astronomers believe that there are less than three or four times as many. Dr. Shapley of the Harvard Observatory states that a new investigation of the matter suggests that eight or ten is probably a maximum figure. Let us assume that nine is correct. The average visible star, so far as measured, has a mass about twice that of the sun, or about 2100 times that of Jupiter. The distances of the stars have been measured in hundreds of cases and thus we can estimate how many stars, both visible and invisible, are on an average contained in a given volume of space. On this basis Jeans estimates that there is only one chance in thirty billion years that a visible star will approach within 2.8 times the distance of Neptune from the sun, that is, within about eight billion miles. If we include the invisible stars the chances become one in three billion years. In order to produce four times the tidal effect of Jupiter, however, the average star would have to approach within about four billion miles of the sun, and the chances of that are only one in twelve billion years. The disturbing star 
would be only 40 per cent farther from the sun than Neptune, and would almost pass within the solar system.

Even though Jeans holds that the frequency of the mutual approach of the sun and a star was probably much greater in the distant past than at present, the figures just given lend little support to the tidal hypothesis. In fact, they apparently throw it out of court. It will be remembered that Jeans has made assumptions which give as high a frequency of stellar encounters as is consistent with the astronomical facts. We have assumed nine dark stars for every bright one, which may be a liberal estimate. Also, although we have assumed that a disturbance of the sun's atmosphere sufficient to cause a glacial period would arise from a tidal effect only twenty times as great as the difference in Jupiter's effect when nearest the sun and farthest away, in our computations this has actually been reduced to thirteen. With all these favorable assumptions the chances of a stellar approach of the sort here described are now only one in twelve billion years. Yet within a hundred million years, according to many estimates of geological time, and almost certainly within a billion, there have been at least half a dozen glaciations.

Our use of Jeans' data interposes another and equally insuperable difficulty to any tidal hypothesis. Four billion miles is a very short distance in the eyes of an astronomer. At that distance a star twice the size of the sun would attract the outer planets more strongly than the sun itself, and might capture them. If a star should come within four billion miles of the sun, its effect in distorting the orbits of all the planets would be great. If this had happened often enough to cause all the glaciations known to geologists, the planetary orbits would be strongly elliptical instead of almost circular. The con- 
siderations here advanced militate so strongly against the tidal hypothesis of solar disturbances that it seems scarcely worth while to consider it further.

Let us turn now to the electrical hypothesis. Here the conditions are fundamentally different from those of the tidal hypothesis. In the first place the electrostatic effect of a body has nothing to do with its mass, but depends on the area of its surface; that is, it varies as the square of the radius. Second, the emission of electrons varies exponentially. If hot glowing stars follow the same law as black bodies at lower temperatures, the emission of electrons, like the emission of other kinds of energy, varies as the fourth power of the absolute temperature. In other words, suppose there are two black bodies, otherwise alike, but one with a temperature of $27^{\circ} \mathrm{C}$. or $300^{\circ}$ on the absolute scale, and the other with $600^{\circ}$ on the absolute scale. The temperature of one is twice as high as that of the other, but the electrostatic effect will be sixteen times as great. ${ }^{4}$ Third, the number of electrons

4 This fact is so important and at the same time so surprising to the layman, that a quotation from The Electron Theory of Matter by $\mathrm{O}$. W. Richardson, 1914, pp. 326 and 334 is here added.

"It is a very familiar fact that when material bodies are heated they emit electromagnetic radiations, in the form of thermal, luminous, and actinic rays, in appreciable quantities. Such an effect is a natural consequence of the electron and kinetic theories of matter. On the kinetic theory, temperature is a measure of the violence of the motion of the ultimate particles; and we have seen that on the electron theory, electromagnetic radiation is a consequence of their acceleration. The ealculation of this emission from the standpoint of the electron theory alone is a very complex problem which takes us deeply into the structure of matter and which has probably not yet been satisfactorily resolved. Fortunately, we can find out a great deal about these phenomena by the application of general principles like the conservation of energy and the second law of thermodynamics without considering special assumptions about the ultimate constitution of matter. It is to be borne in mind that the emission under consideration occurs at all temperatures although it is more marked the higher the temperature. . . The energy per unit volume, in vacuo, of the radiation in equilibrium in an enclosure at the absolute temperature, $\mathrm{T}$, is equal to a universal constant, A, multiplied by the fourth power of the 
that reach a given body varies inversely as the square of the distance, instead of as the cube which is the case with tide-making forces.

In order to use these three principles in calculating the effect of the stars we must know the diameters, distances, temperature, and number of the stars. The distances and number may safely be taken as given by Jeans in the calculations already cited. As to the diameters, the measurements of the stars thus far made indicate that the average mass is about twice that of the sun. The average density, as deduced by Shapley from the movements of double stars, is about one-eighth the solar density. This would give an average diameter about two and a half times that of the sun. For the dark stars, we shall assume for convenience that they are ten times as numerous as the bright ones. We shall also assume that their diameter is half that of the sun, for being cool they must be relatively dense, and that their temperature is the same as that which we shall assume for Jupiter.

As to Jupiter we shall continue our former assumption that a body with four times the effectiveness of that planet, which here means with twice as great a radius, would disturb the sun enough to cause glaciation. It would produce about twenty times the electrostatic effect

absolute temperature. Since the intensity of the radiation is equal to the energy per unit volume multiplied by the velocity of light, it follows that the former must also be proportional to the fourth power of the absolute temperature. Moreover, if $\mathbf{E}$ is the total emission from unit area of a perfectly black body, we see from p. 330 that $E=A^{\prime \prime} T^{4}$, where $A^{\prime}$ is a new universal constant. This result is usually known as Stefan's Law. It was suggested by Stefan in the inaceurate form that the total radiant energy of emission from bodies varies as the fourth power of the absolute temperature, as a generalization from the results of experiments. The credit for showing that it is a consequence of the existence of radiation pressure combined with the principles of thermodynamies is due to Bartoli and Boltzmann."'

5 Quoted by Moulton in his Introduction to Astronomy. 
which now appears to be associated with the difference in Jupiter's effect at maximum and minimum. The temperature of Jupiter must also be taken into account. The planet is supposed to be hot because its density is low, being only about 1.25 that of water. Nevertheless, it is probably not luminous, for as Moulton ${ }^{6}$ puts it, shadows upon it are black and its moons show no sign of illumination except from the sun. Hence a temperature of about $600^{\circ} \mathrm{C}$., or approximately $900^{\circ}$ on the absolute scale, seems to be the highest that can reasonably be assigned to the cold outer layer whence electrons are emitted. As to the temperature of the sun, we shall adopt the common estimate of about $6300^{\circ} \mathrm{C}$. on the absolute scale. The other stars will be taken as averaging the same, although of course they vary greatly.

When Jeans' method of calculating the probability of a mutual approach of the sun and a star is applied to the assumptions given above, the results are as shown in Table 5. On that basis the dark stars seem to be of negligible importance so far as the electrical hypothesis is concerned. Even though they may be ten times as numerous as the bright ones there appears to be only one chance in 130 billion years that one of them will approach the sun closely enough to cause the assumed disturbance of the solar atmosphere. On the other hand, if all the visible stars were the size of the sun, and as hot as that body, their electrical effect would be fourfold that of our assumed dark star because of their size, and 2401 times as great because of their temperature, or approximately 10,000 times as great. Under such conditions the theoretical chance of an approach that would cause glaciation is one in 130 million years. If the average visible star is somewhat cooler than the sun and has a

6 Introduction to Astronomy. 
radius about two and one-half times as great, as appears to be the fact, the chances rise to one in thirty-eight million years. A slight and wholly reasonable change in our assumptions would reduce this last figure to only five or ten million. For instance, the earth's mean temperature during the glacial period has been assumed as $10^{\circ} \mathrm{C}$. lower than now, but the difference may have been only $6^{\circ}$. Again, the temperature of the outer atmosphere of Jupiter where the electrons are shot out may be only $500^{\circ}$ or $700^{\circ}$ absolute, instead of $900^{\circ}$. Or the diameter of the average star may be five or ten times that of the sun, instead of only two and one-half times as great. All this, however, may for the present be disregarded. The essential point is that even when the assumptions err on the side of conservatism, the results are of an order of magnitude which puts the electrical hypothesis within the bounds of possibility, whereas similar assumptions put the tidal hypothesis, with its single approach in twelve billion years, far beyond those limits.

The figures for Betelgeuse in Table 5 are interesting. At a meeting of the American Association for the Advancement of Science in December, 1920, Michelson reported that by measurements of the interference of light coming from the two sides of that bright star in Orion, the observers at Mount Wilson had confirmed the recent estimates of three other authorities that the star's diameter is about 218 million miles, or 250 times that of the sun. If other stars so much surpass the estimates of only a decade or two ago, the average diameter of all the visible stars must be many times that of the sun. The low figure for Betelgeuse in section $D$ of the table means that if all the stars were as large as Betelgeuse, several might often be near enough to cause profound disturbances of the solar atmosphere. Nevertheless, because of the low 
TABLE 5

THEORETICAL PROBABILITY OF STELLAR APPROACHES

\begin{tabular}{|c|c|c|c|c|}
\hline & $\begin{array}{c}1 \\
\text { Dark Star8 }\end{array}$ & $\begin{array}{c}2 \\
\text { Sun }\end{array}$ & $\begin{array}{c}3 \\
\text { Average } \\
\text { Star }\end{array}$ & $\begin{array}{c}4 \\
\text { Betelgeuse }\end{array}$ \\
\hline $\begin{array}{l}\text { A. Approximate } \\
\text { radius in miles }\end{array}$ & 430,000 & 860,000 & $2,150,000$ & $218,000,000$ \\
\hline $\begin{array}{l}\text { B. Assumed tem- } \\
\text { perature above } \\
\text { absolute zero.. }\end{array}$ & $900^{\circ} \mathrm{C}$ & $6300^{\circ} \mathrm{C}$. & $5400^{\circ} \mathrm{C}$. & $3150^{\circ} \mathrm{C}$. \\
\hline $\begin{array}{l}\text { C. Approximate } \\
\text { theoretical dis- } \\
\text { tance at which } \\
\text { s t a r w o u l d } \\
\text { cause solar dis- } \\
\text { turbance great } \\
\text { enough to cause } \\
\text { glaciation (bil- } \\
\text { lions }{ }^{7} \text { of miles). }\end{array}$ & 1.2 & 120 & 220 & 3200 \\
\hline $\begin{array}{l}\text { D. Average in- } \\
\text { terval between } \\
\text { approa ehes } \\
\text { close enough to } \\
\text { cause glacia- } \\
\text { tion if all stars } \\
\text { were of given } \\
\text { type. Years.. }\end{array}$ & $130,000,000,000^{8}$ & $130,000,000$ & $|38,000,000|$ & 700,000 \\
\hline
\end{tabular}

temperature of the giant red stars of the Betelgeuse type, the distance at which one of them would produce a given electrical effect is only about five times the distance at which our assumed average star would produce the same effect. This, to be sure, is on the assumption that the

7 The term billions, here and elsewhere, is used in the American sense, 109.

8 The assumed number of stars here is ten times as great as in the other parts of this line. 
EFFECT OF OTHER BODIES ON THE SUN 261

radiation of energy from incandescent bodies varies according to temperature in the same ratio as the radiation from black bodies. Even if this assumption departs somewhat from the truth, it still seems almost certain that the lower temperature of the red compared with the high temperature of the white stars must to a considerable degree reduce the difference in electrical effect which would otherwise arise from their size.

Thus far in our attempt to estimate the distance at which a star might disturb the sun enough to cause glaciation on the earth, we have considered only the star's size and temperature. No account has been taken of the degree to which its atmosphere is disturbed. Yet in the case of the sun this seems to be one of the most important factors. The magnetic field of sunspots is sometimes 50 or 100 times as strong as that of the sun in general. The strength of the magnetic field appears to depend on the strength of the electrical currents in the solar atmosphere. But the intensity of the sunspots and, by inference, of the electrical currents, may depend on the electrical action of Jupiter and the other planets. If we apply a similar line of reasoning to the stars, we are at once led to question whether the electrical activity of double stars may not be enormously greater than that of isolated stars like the sun.

If this line of reasoning is correct, the atmosphere of every double star must be in a state of commotion vastly greater than that of the sun's atmosphere even when it is most disturbed. For example, suppose the sun were accompanied by a companion of equal size at a distance of one million miles, which would make it much like many known double stars. Suppose also that in accordance with the general laws of physics the electrical effect of the two suns upon one another is proportional to the fourth 
power of the temperature, the square of the radius, and the inverse square of the distance. Then the effect of each sun upon the other would be sixty billion $\left(6 \times 10^{10}\right)$ times as great as the present electrical effect of Jupiter upon the sun. Just what this would mean as to the net effect of a pair of such suns upon the electrical potential of other bodies at a distance we can only conjecture. The outstanding fact is that the electrical conditions of a double star must be radically different and vastly more intense than those of a single star like the sun.

This conclusion carries weighty consequences. At present twenty or more stars are known to be located within about 100 trillion miles of the sun (five parsecs, as the astronomers say), or 16.5 light years. According to the assumptions employed in Table 5 an average single star would influence the sun enough to cause glaciation if it came within approximately 200 billion miles. If the star were double, however, it might have an electrical capacity enormously greater than that of the sun. Then it would be able to cause glaciation at a correspondingly great distance. Today Alpha Centauri, the nearest known star, is about twenty-five trillion miles, or 4.3 light years from the sun, and Sirius, the brightest star in the heavens, is about fifty trillion miles away, or 8.5 light years. If these stars were single and had a diameter three times that of the sun, and if they were of the same temperature as has been assumed for Betelgeuse, which is about fifty times as far away as Alpha Centauri, the relative effects of the three stars upon the sun would be, approximately, Betelgeuse 700, Alpha Centauri 250, Sirius 1. But Alpha Centauri is triple and Sirius double, and both are much hotter than Betelgeuse. Hence Alpha Centauri and even Sirius may be far more effective than Betelgeuse.

The two main components of Alpha Centauri are sepa- 
rated by an average distance of about $2,200,000,000$ miles, or somewhat less than that of Neptune from the sun. A third and far fainter star, one of the faintest yet measured, revolves around them at a great distance. In mass and brightness the two main components are about like the sun, and we will assume that the same is true of their radius. Then, according to the assumptions made above, their effect in disturbing one another electrically would be about 10,000 times the total effect of Jupiter upon the sun, or 2500 times the effect that we have assumed to be necessary to produce a glacial period. We have already seen in Table 5 that, according to our assumptions, a single star like the sun would have to approach within 120 billion miles of the solar system, or within 2 per cent of a light year, in order to cause glaciation. By a similar process of reasoning it appears that if the mutual electrical excitation of the two main parts of Alpha Centauri, regardless of the third part, is proportional to the apparent excitation of the sun by Jupiter, Alpha Centauri would be 5000 times as effective as the sun. In other words, if it came within $8,500,000,000,000$ miles of the sun, or 1.4 light years, it would so change the electrical conditions as to produce a glacial epoch. In that case Alpha Centauri is now so near that it introduces a disturbing effect equal to about one-sixth of the effect needed to cause glaciation on the earth. Sirius and perhaps others of the nearer and brighter or larger stars may also create appreciable disturbances in the electrical condition of the sun's atmosphere, and may have done so to a much greater degree in the past, or be destined to do so in the future. Thus an electrical hypothesis of solar disturbances seems to indicate that the position of the sun in respect to other stars may be a factor of great importance in determining the earth's climate. 


\section{CHAPTER XV}

\section{THE SUN'S JOURNEY THROUGH SPACE}

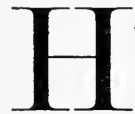

AVING gained some idea of the nature of the electrical hypothesis of solar disturbances and of the possible effect of other bodies upon the sun's atmosphere, let us now compare the astronomical data with those of geology. Let us take up five chief points for which the geologist demands an explanation, and which any hypothesis must meet if it is to be permanently accepted. These are (1) the irregular intervals at which glacial periods occur ; $(2)$ the division of glacial periods into epochs separated sometimes by hundreds of thousands of years; (3) the length of glacial periods and epochs; (4) the occurrence of glacial stages and historic pulsations in the form of small climatic waves superposed upon the larger waves of glacial epochs; (5) the occurrence of climatic conditions much milder than those of today, not only in the middle portion of the great geological eras, but even in some of the recent interglacial epochs.

1. The irregular duration of the interval from one glacial epoch to another corresponds with the irregular distribution of the stars. If glaciation is indirectly due to stellar influences, the epochs might fall close together, or might be far apart. If the average interval were ten million years, one interval might be thirty million or more and the next only one or two hundred thousand. 
According to Schuchert, the known periods of glacial or semi-glacial climate have been approximately as follows:

\section{LIST OF GLACIAL PERIODS}

1. Archeozoic.

( $1 / 4$ of geological time or perhaps much more)

No known glacial periods.

2. Proterozoic.

( $1 / 4$ of geological time)

a. Oldest known glacial period near base of Proterozoic in Canada. Evidence widely distributed.

b. Indian glacial period; time unknown.

c. African glacial period; time unknown.

d. Glaciation near end of Proterozoic in Australia, Norway, and China.

3. Paleozoic.

( $1 / 4$ of geological time)

a. Late Ordovician( ( ). Local in Aretic Norway.

b. Silurian. Local in Alaska.

e. Early Devonian. Local in South Africa.

d. Early Permian. World-wide and very severe.

4. Mesozoic and Cenozoic.

( $1 / 4$ of geological time)

a-b. None definitely determined during Mesozoic, although there appears to have been periods of cooling (a) in the late Triassic, and (b) in the late Cretacic, with at least local glaciation in early Eocene.

c. Severe glacial period during Pleistocene.

This table suggests an interesting inquiry. During the last few decades there has been great interest in ancient glaciation and geologists have carefully examined rocks of all ages for signs of glacial deposits. In spite of the large parts of the earth which are covered with deposits belonging to the Mesozoic and Cenozoic, which form the 
last quarter of geological time, the only signs of actual glaciation are those of the great Pleistocene period and a few local occurrences at the end of the Mesozoic or beginning of the Cenozoic. Late in the Triassic and early in the Jurassic, the climate appears to have been rigorous, although no tillites have been found to demonstrate glaciation. In the preceding quarter, that is, the Paleozoic, the Permian glaciation was more severe than that of the Pleistocene, and the Devonian than that of the Eocene, while the Ordovician evidences of low temperature are stronger than those at the end of the Triassic. In view of the fact that rocks of Paleozoic age cover much smaller areas than do those of later age, the three Paleozoic glaciations seem to indicate a relative frequency of glaciation. Going back to the Proterozoic, it is astonishing to find that evidence of two highly developed glacial periods, and possibly four, has been discovered. Since the Indian and the African glaciations of Proterozoic times are as yet undated, we cannot be sure that they are not of the same date as the others. Nevertheless, even two is a surprising number, for not only are most Proterozoic rocks so metamorphosed that possible evidences of glacial origin are destroyed, but rocks of that age occupy far smaller areas than either those of Paleozoic or, still more, Mesozoic and Cenozoic age. Thus the record of the last three-quarters of geological time suggests that if rocks of all ages were as abundant and as easily studied as those of the later periods, the frequency of glacial periods would be found to increase as one goes backward toward the beginnings of the earth's history. This is interesting, for Jeans holds that the chances that the stars would approach one another were probably greater in the past than at present. This conclusion is based on the assumption that our universe 
is like the spiral nebulæ in which the orbits of the various members are nearly circular during the younger stages. Jeans considers it certain that in such cases the orbits will gradually become larger and more elliptical because of the attraction of one body for another. Thus as time goes on the stars will be more widely distributed and the chances of approach will diminish. If this is correct, the agreement between astronomical theory and geological conclusions suggests that the two are at least not in opposition.

The first quarter of geological time as well as the last three must be considered in this connection. During the Archeozoic, no evidence of glaciation has yet been discovered. This suggests that the geological facts disprove the astronomical theory. But our knowledge of early geological times is extremely limited, so limited that lack of evidence of glaciation in the Archeozoic may have no significance. Archeozoic rocks have been studied minutely over a very small percentage of the earth's land surface. Moreover, they are highly metamorphosed so that, even if glacial tills existed, it would be hard to recognize them. Third, according to both the nebular and the planetesimal hypotheses, it seems possible that during the earliest stages of geological history the earth's interior was somewhat warmer than now, and the surface may have been warmed more than at present by conduction, by lava flows, and by the fall of meteorites. If the earth during the Archeozoic period emitted enough heat to raise its surface temperature a few degrees, the heat would not prevent the development of low forms of life but might effectively prevent all glaciation. This does not mean that it would prevent changes of climate, but merely changes so extreme that their record would be preserved by means of ice. It will be most interesting 
to see whether future investigations in geology and astronomy indicate either a semi-uniform distribution of glacial periods throughout the past, or a more or less regular decrease in frequency from early times down to the present.

2. The Pleistocene glacial period was divided into at least four epochs, while in the Permian at least one inter-glacial epoch seems certain, and in some places the alternation between glacial and non-glacial beds suggests no less than nine. In the other glaciations the evidence is not yet clear. The question of periodicity is so important that it overthrows most glacial hypotheses. Indeed, had their authors known the facts as established in recent years, most of the hypotheses would never have been advanced. The carbon dioxide hypothesis is the only one which was framed with geologically rapid climatic alternations in mind. It certainly explains the facts of periodicity better than does any of its predecessors, but even so it does not account for the intimate way in which variations of all degrees from those of the weather up to glacial epochs seem to grade into one another.

According to our stellar hypothesis, occasional groups of glacial epochs would be expected to occur close together and to form long glacial periods. This is because many of the stars belong to groups or clusters in which the stars move in parallel paths. A good example is the cluster in the Hyades, where Boss has studied thirty-nine stars with special care. ${ }^{1}$ The stars are grouped about a center about 130 light years from the sun. The stars themselves are scattered over an area about thirty light years in diameter. They average about the same distance apart as do those near the sun, but toward the

1 Lewis Boss: Convergent of a Moving Cluster in Taurus; Astronom. Jour., Vol. 26, No. 4, 1908, pp. 31-36. 
center of the group they are somewhat closer together. The whole thirty-nine sweep forward in essentially parallel paths. Boss estimates that 800,000 years ago the cluster was only half as far from the sun as at present, but probably that was as near as it has been during recent geological times. All of the thirty-nine stars of this cluster, as Moulton ${ }^{2}$ puts it, "are much greater in lightgiving power than the sun. The luminosities of even the five smallest are from five to ten times that of the sun, while the largest are one hundred times greater in lightgiving power than our own luminary. Their masses are probably much greater than that of the sun." If the sun were to pass through such a cluster, first one star and then another might come so near as to cause a profound disturbance in the sun's atmosphere.

3. Another important point upon which a glacial hypothesis may come to grief is the length of the periods or rather of the epochs which compose the periods. During the last or Pleistocene glacial period the evidence in America and Europe indicates that the inter-glacial epochs varied in length and that the later ones were shorter than the earlier. Chamberlin and Salisbury, from a comparison of various authorities, estimate that the intervals from one glacial epoch to another form a declining series, which may be roughly expressed as follows: 16-8-4-2-1, where unity is the interval from the climax of the late Wisconsin, or last glacial epoch, to the present. Most authorities estimate the culmination of the late Wisconsin glaciation as twenty or thirty thousand years ago. Penck estimates the length of the last interglacial period as 60,000 years and the preceding one as $240,000 .^{3}$ R. T. Chamberlin, as already stated, finds that

2 F. R. Moulton: in Introduction to Astronomy, 1916.

3 A. Penck: Die Alpen im Eiszeitalter, Leipzig, 1909. 
the consensus of opinion is that inter-glacial epochs have averaged five times as long as glacial epochs. The actual duration of the various glaciations probably did not vary in so great a ratio as did the intervals from one glaciation to another. The main point, however, is the irregularity of the various periods.

The relation of the stellar electrical hypothesis to the length of glacial epochs may be estimated from column $\mathrm{C}$, in Table 5. There we see that the distances at which a star might possibly disturb the sun enough to cause glaciation range all the way from 120 billion miles in the case of a small star like the sun, to 3200 billion in the case of Betelgeuse, while for double stars the figure may rise a hundred times higher. From this we can calculate how long it would take a star to pass from a point where its influence would first amount to a quarter of the assumed maximum to a similar point on the other side of the sun. In making these calculations we will assume that the relative rate at which the star and the sun approach each other is about twenty-two miles per second, or 700 million miles per year, which is the average rate of motion of all the known stars. According to the distances in Table 5 this gives a range from about 500 years up to about 10,000 , which might rise to a million in the case of double stars. Of course the time might be relatively short if the sun and a rapidly moving star were approaching one another almost directly, or extremely long if the sun and the star were moving in almost the same direction and at somewhat similar rates, -a condition more common than the other. Here, as in so many other cases, the essential point is that the figures which we thus obtain seem to be of the right order of magnitude.

4. Post-glacial climatic stages are so well known that in Europe they have definite names. Their sequence has 
already been discussed in Chapter XII. Fossils found in the peat bogs of Denmark and Scandinavia, for example, prove that since the final disappearance of the continental ice cap at the close of the Wisconsin there has been at least one period when the climate of Europe was distinctly milder than now. Directly overlying the sheets of glacial drift laid down by the ice there is a flora corresponding to that of the present tundras. Next come remains of a forest vegetation dominated by birches and poplars, showing that the climate was growing a little warmer. Third, there follow evidences of a still more favorable climate in the form of a forest dominated by pines; fourth, one where oak predominates; and fifth, a flora similar to that of the Black Forest of Germany, indicating that in Scandinavia the temperature was then decidedly higher than today. This fifth flora has retreated southward once more, having been driven back to its present latitude by a slight recurrence of a cool stormy climate. In central Asia evidence of post-glacial stages is found not only in five distinct moraines but in a corresponding series of elevated strands surrounding salt lakes and of river terraces in non-glaciated arid regions. ${ }^{5}$

In historic as well as prehistoric times, as we have already seen, there have been climatic fluctuations. For instance, the twelfth or thirteenth century B. C. appears to have been almost as mild as now, as does the seventh century B. C. On the other hand about 1000 B. C., at the time of Christ, and in the fourteenth century there were times of relative severity. Thus it appears that both on

4 R. D. Salisbury: Physical Geography of the Pleistocene, in Outlines of Geologic History, by Willis and Salisbury, 1910, pp. 273-274.

5 Davis, Pumpelly, and Huntington: Explorations in Turkestan, Carnegie Inst. of Wash., No. 26, 1905.

In North America the stages have been the subject of intensive studies on the part of Taylor, Leverett, Goldthwait, and many others. 
a large and on a small scale pulsations of climate are the rule. Any hypothesis of climatic changes must satisfy the periods of these pulsations. These conditions furnish a problem which makes difficulty for almost all hypotheses of climatic change. According to the present hypothesis, earth movements such as are discussed in Chapter XII may coöperate with two astronomical factors. One is the constant change in the positions of the stars, a change which we have already called kaleidoscopic, and the other is the fact that a large proportion of the stars are double or multiple. When one star in a group approaches the sun closely enough to cause a great solar disturbance, numerous others may approach or recede and have a minor effect. Thus, whenever the sun is near groups of stars we should expect that the earth would show many minor climatic pulsations and stages which might or might not be connected with glaciation. The historic pulsations shown in the curve of tree growth in California, Fig. 4, are the sort of changes that would be expected if movements of the stars have an effect on the solar atmosphere.

Not only are fully a third of all the visible stars double, as we have already seen, but at least a tenth of these are known to be triple or multiple. In many of the double stars the two bodies are close together and revolve so rapidly that whatever periodicity they might create in the sun's atmosphere would be very short. In the triplets, however, the third star is ordinarily at least ten times as far from the other two as they are from each other, and its period of rotation sometimes runs into hundreds or thousands of years. An actual multiple star in the constellation Polaris will serve as an example. The main star is believed by Jeans to consist of two parts which are almost in contact and whirl around each other with 
extraordinary speed in four days. If this is true they must keep each other's atmospheres in a state of intense commotion. Much farther away a third star revolves around this pair in twelve years. At a much greater distance a fourth star revolves around the common center of gravity of itself and the other three in a period which may be 20,000 years. Still more complicated cases probably exist. Suppose such a system were to traverse a path where it would exert a perceptible influence on the sun for thirty or forty thousand years. The varying movements of its members would produce an intricate series of cycles which might show all sorts of major and minor variations in length and intensity. Thus the varied and irregular stages of glaciation and the pulsations of historic times might be accounted for on the hypothesis of the proximity of the sun to a multiple star, as well as on that of the less pronounced approach and recession of a number of stars. In addition to all this, an almost infinitely complex series of climatic changes of long and short duration might arise if the sun passed through a nebula.

5. We have seen in Chapter VIII that the contrast between the somewhat severe climate of the present and the generally mild climate of the past is one of the great geological problems. The glacial period is not a thing of the distant past. Geologists generally recognize that it is still with us. Greenland and Antarctica are both shrouded in ice sheets in latitudes where fossil floras prove that at other periods the climate was as mild as in England or even New Zealand. The present glaciated regions, be it noted, are on the polar borders of the world's two most stormy oceanic areas, just where ice would be expected to last longest according to the solar cyclonic hypothesis. In contrast with the semi-glacial 
conditions of the present, the last inter-glacial epoch was so mild that not only men but elephants and hippopotamuses flourished in central Europe, while at earlier times in the middle of long eras, such as the Paleozoic and Mesozoic, corals, cycads, and tree ferns flourished within the Arctic circle.

If the electro-stellar hypothesis of solar disturbances proves well founded, it may explain these peculiarities. Periods of mild climate would represent a return of the sun and the earth to their normal conditions of quiet. At such times the atmosphere of the sun is assumed to be little disturbed by sunspots, faculæ, prominences, and other allied evidences of movements; and the rice-grain structure is perhaps the most prominent of the solar markings. The earth at such times is supposed to be correspondingly free from cyclonic storms. Its winds are then largely of the purely planetary type, such as trade winds and westerlies. Its rainfall also is largely planetary rather than cyclonic. It falls in places such as the heat equator where the air rises under the influence of heat, or on the windward slopes of mountains, or in regions where warm winds blow from the ocean over cold lands.

According to the electro-stellar hypothesis, the conditions which prevailed during hundreds of millions of years of mild climate mean merely that the solar system was then in parts of the heavens where stars-especially double stars-were rare or small, and electrical disturbances correspondingly weak. Today, on the other hand, the sun is fairly near a number of stars, many of which are large doubles. Hence it is supposed to be disturbed, although not so much as at the height of the last glacial epoch.

After the preceding parts of this book had been 
written, the assistance of Dr. Schlesinger made it possible to test the electro-stellar hypothesis by comparing actual astronomical dates with the dates of climatic or solar phenomena. In order to make this possible, Dr. Schlesinger and his assistants have prepared Table 6, giving the position, magnitude, and motions of the thirtyeight nearest stars, and especially the date at which each was nearest the sun. In column 10 where the dates are given, a minus sign indicates the past and a plus sign the future. Dr. Shapley has kindly added column 12, giving the absolute magnitudes of the stars, that of the sun being 4.8, and column 13, showing their luminosity or absolute radiation, that of the sun being unity. Finally, column 14 shows the effective radiation received by the sun from each star when the star is at a minimum distance. Unity in this case is the effect of a star like the sun at a distance of one light year.

It is well known that radiation of all kinds, including light, heat, and electrical emissions, varies in direct proportion to the exposed surface, that is, as the square of the radius of a sphere, and inversely as the square of the distance. From black bodies, as we have seen, the total radiation varies as the fourth power of the absolute temperature. It is not certain that either light or electrical emissions from incandescent bodies vary in quite this same proportion, nor is it yet certain whether luminous and electrical emissions vary exactly together. Nevertheless they are closely related. Since the light coming from each star is accurately measured, while no information is available as to electrical emissions, we have followed Dr. Shapley's suggestion and used the luminosity of the stars as the best available measure of total radiation. This is presumably an approximate measure of electrical activity, provided some allowance 
TABLE

\section{THIRTY-EIGHT S'TARS HAVING}

(1)

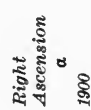

Groombr. $34 \ldots \ldots \ldots$

${ }^{*} \eta$ Cassiop. . . . . . . . .

${ }^{*}{ }_{\kappa}$ Tueanæ...$\ldots \ldots$.

$\tau$ Ceti .............

$\delta_{2}$ Eridani............

${ }^{*} \epsilon$ Eridani ............

${ }^{*} 40(0)^{2}$ Eridani ........

Cordoba Z. 243 .......

Weisse $592 \ldots \ldots \ldots \ldots$.
(2)

(3)

(4)

(5)

(6)

\section{$0^{\mathrm{h}} 12^{\mathrm{m}} .7$}

$43 \quad .0$

43.9

112.4

39 .

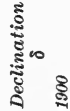

$+43^{\circ} 27^{\prime}$

$+5717$

$+455$

$-6924$

$-1628$

$\begin{array}{lllll}3 & 15 & .9 & -43 & 27\end{array}$

$28.2-948$

$\begin{array}{lllll}4 & 10 & .7 & -7 & 49\end{array}$

$\begin{array}{llllll}5 & 7 & .7 & -44 & 59\end{array}$

$\begin{array}{lll}26 & .4 & -342\end{array}$

\section{हूँ}

$8.1 \mathrm{Ma}$

3.6 F8

12.3 F0

5.0 F8

$3.6 \mathrm{~K} 0$

4.3 G5

$3.8 \mathrm{~K} 0$

4.5 G5

$9.2 \mathrm{~K} 2$

$8.8 \mathrm{~K} 2$
ई. हैं

$2^{\prime \prime} .89+3$

$1.24+10$

$3.01 \quad \ldots .$.

$.39+12$

$1.92-16$

$3.16+87$

$.97+16$

$4.08-42$

$8.75+242$

$2.22 \quad \ldots .$.

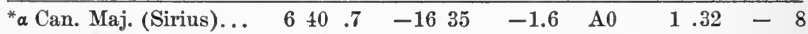

${ }^{*} a$ Can. Min. (Procyon). $734.1+529 \quad 0.5$ F5 $1.24-4$

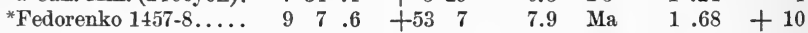

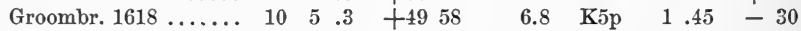

\begin{tabular}{lrrrrrr} 
Weisse $234 \ldots \ldots \ldots$ & $14.2 \quad+20$ & 22 & 9.0 & $\ldots$ & .49 & $\ldots$ \\
\hline
\end{tabular}

\begin{tabular}{lllllllll}
\hline Lalande $21185 . \ldots \ldots \ldots$ & 57.9 & +36 & 38 & 7.6 & $\mathrm{Mb}$ & 4.78 & -87
\end{tabular}

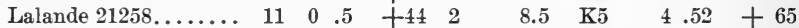

$\begin{array}{llllllll}12 & .0 & -57 & 2 & 12.0 & \ldots & 2.69 & \ldots\end{array}$

Lalande $25372 \ldots \ldots . \quad 1340.7 \quad+1526 \quad 8.5 \quad$ K5 $\quad 2.30 \quad \ldots \ldots$

${ }^{*} a$ Centauri .......... $1432.8 \quad-6025 \quad 0.2 \quad \mathrm{G} \quad 3.68+22$

${ }^{*} \xi$ Bootes ............ $1446.8 \quad+1931 \quad 4.6$ K5p $.17+4$

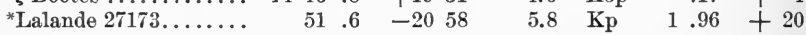

Weisse $1259 \ldots \ldots \ldots .61641 .4 \quad+3341 \quad 8.4 \quad \ldots . \quad .37 \quad \ldots \ldots$

$\begin{array}{lllllllllll}\text { Lacaille } & 7194 \ldots \ldots \ldots & 17 & 11 & .5 & -46 & 32 & 5.7 & \mathrm{~K} & .97 & \ldots \ldots\end{array}$

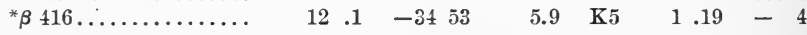

\begin{tabular}{llllllll}
\hline Argel $-0.17415-6 \ldots$ & 37.0 & +68 & 26 & 9.1 & $\mathrm{~K}$ & 1.33 & $\ldots \ldots$
\end{tabular}

Barnard's star ...... $52.9+425 \quad 9.7 \mathrm{Mb} \quad 10.30-80$

*70p Ophiuchi ....... $180.4+231 \quad 4.3$ K $1.13 \ldots \ldots$

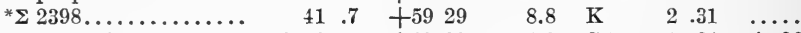

$\sigma$ Draconis $\ldots \ldots \ldots \ldots .1932 .5 \quad+6929 \quad 4.8$ G5 $1.84+26$

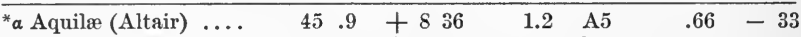

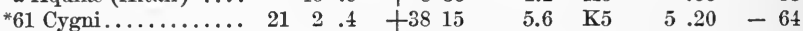

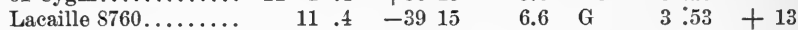

$\epsilon$ Indi............. $55.7 \quad-57 \quad 12 \quad 4.8$ K5 $\quad 4.70 \quad-39$

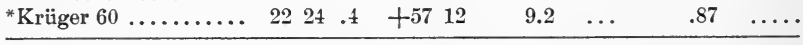

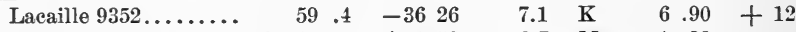

$\begin{array}{lrrrrlllll}\text { Lalande } 46650 \ldots \ldots & 23 & 44.0 & +152 & 8.7 & \text { Ma } & 1.39 & \ldots . . \\ \text { C. G. A. } 32416 \ldots \ldots & 59.5 & -3751 & 8.2 & \text { G } & 6.05 & +26\end{array}$

* Double star. 
6

\section{LARGEST KNOWN PARALLAXES}

\begin{tabular}{|c|c|c|c|c|c|c|c|}
\hline (7) & $(8)$ & (9) & (10) & (11) & (12) & (13) & (14) \\
\hline 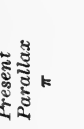 & 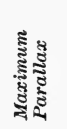 & 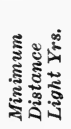 & 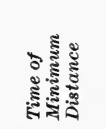 & 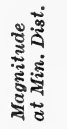 & 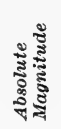 & 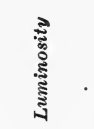 & 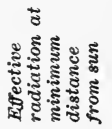 \\
\hline$" .28$ & " .28 & 11.6 & -4000 & 8.1 & 10.3 & 0.0063 & 0.000051 \\
\hline .18 & .19 & 17.1 & -47000 & 3.5 & 4.9 & 0.91 & 0.003110 \\
\hline .24 & $\ldots$ & $\ldots$ & $\ldots \ldots \ldots$ & $\ldots$ & 14.2 & 0.00017 & $\ldots \ldots \ldots$ \\
\hline .16 & .23 & 14.2 & -264000 & 4.2 & 6.0 & 0.33 & 0.001610 \\
\hline .32 & .37 & 8.8 & +46000 & 3.3 & 6.1 & 0.30 & 0.003840 \\
\hline .16 & .22 & 14.8 & -33000 & 3.6 & 5.3 & 0.63 & 0.002960 \\
\hline .31 & .46 & 7.1 & -106000 & 3.0 & 6.3 & 0.25 & 0.004970 \\
\hline .21 & .23 & 14.2 & +19000 & 4.3 & 6.1 & 0.30 & 0.001470 \\
\hline $.32 r$ & .68 & 4.8 & -10000 & 7.6 & 11.7 & 0.0017 & 0.000074 \\
\hline .17 & $\ldots$ & $\cdots$ & ........ & $\ldots$ & 9.9 & 0.009 & ........ \\
\hline .37 & .41 & 8.0 & +65000 & -1.8 & 1.2 & 27.50 & 0.429000 \\
\hline .31 & .32 & 10.2 & +34000 & 0.5 & 3.0 & 5.25 & 0.051300 \\
\hline .16 & .16 & 20.4 & -24000 & 7.9 & 8.9 & 0.023 & 0.000055 \\
\hline .18 & .23 & 14.2 & +69000 & 6.3 & 8.1 & 0.048 & 0.000238 \\
\hline .19 & $\ldots$ & $\ldots$ & ........ & $\ldots$ & 10.4 & 0.0057 & ......... \\
\hline .41 & .76 & 4.3 & +20000 & 6.2 & 10.7 & 0.0044 & 0.000238 \\
\hline .19 & .22 & 14.8 & -20000 & 8.2 & 9.9 & 0.009 & 0.000041 \\
\hline .34 & $\ldots$ & $\ldots$ & ........ & $\ldots$ & 14.7 & 0.00011 & ........ \\
\hline .19 & $\ldots$ & $\ldots$ & $\ldots \ldots \ldots$ & $\ldots$ & 9.9 & 0.009 & $\ldots \ldots \ldots$ \\
\hline $.76^{\circ}$ & 1.03 & 3.2 & -28000 & -0.5 & 4.6 & 1.20 & 0.117500 \\
\hline .17 & .22 & 14.8 & -598000 & 4.0 & 5.8 & 0.40 & 0.001815 \\
\hline .18 & .19 & 17.1 & -36000 & 5.6 & 7.1 & 0.12 & 0.000412 \\
\hline .18 & $\ldots$ & $\ldots$ & $\ldots \ldots \ldots$ & $\ldots$ & 9.7 & 0.011 & $\ldots \ldots \ldots$ \\
\hline .19 & $\ldots$ & .... & $\ldots \ldots \ldots$ & $\cdots$ & 7.1 & 0.12 & $\ldots \ldots \ldots$ \\
\hline .17 & .17 & 19.2 & +21000 & 5.7 & 7.1 & 0.12 & 0.000329 \\
\hline .22 & $\ldots$ & $\ldots$ & $\ldots \ldots \ldots$ & $\cdots$ & 10.8 & 0.004 & \\
\hline .53 & .70 & 4.7 & +10000 & 9.1 & 13.3 & 0.0025 & 0.000114 \\
\hline .19 & $\ldots$ & ... & $\ldots \ldots \ldots$ & $\ldots$ & 5.7 & 0.44 & $\ldots \ldots \ldots$ \\
\hline .29 & $\ldots$. & $\ldots$ & $\ldots \ldots$ & $\ldots$ & 11.1 & 0.0030 & $\ldots \ldots \ldots$ \\
\hline .20 & .23 & 14.2 & -49000 & 4.5 & 6.3 & 0.25 & 0.001238 \\
\hline .21 & .51 & 6.4 & +117000 & -0.7 & 2.8 & 6.30 & 0.153600 \\
\hline .30 & .38 & 8.6 & +19000 & 5.1 & 8.0 & 0.053 & 0.000715 \\
\hline .25 & .26 & 12.6 & -11000 & 6.6 & 8.6 & 0.030 & 0.000189 \\
\hline .28 & .31 & 10.5 & +17000 & 4.6 & 7.0 & 0.13 & 0.001230 \\
\hline .26 & $\ldots$ & $\ldots$ & $\ldots \ldots \ldots$ & $\ldots$ & 11.3 & 0.0025 & ........ \\
\hline .29 & .29 & 11.2 & -3000 & 7.1 & 9.4 & 0.014 & 0.000111 \\
\hline .17 & $\cdots$ & $\because \cdots$ & $\ldots \ldots \ldots$ & $\cdots$ & 9.9 & 0.009 & $\ldots . \cdots$ \\
\hline .22 & .22 & 14.8 & $-\quad 7000$ & 8.2 & 9.9 & 0.009 & 0.000041 \\
\hline
\end{tabular}


be made for disturbances by outside bodies such as companion stars. Hence the inclusion of column 14.

On the basis of column 14 and of the movements and distances of the stars as given in the other columns Fig. 10 has been prepared. This gives an estimate of the approximate electrical energy received by the sun from the nearest stars for 70,000 years before and after the present. It is based on the twenty-six stars for which complete data are available in Table 6. The inclusion of the other twelve would not alter the form of the curve, for even the largest of them would not change any part by more than about half of 1 per cent, if as much. Nor would the curve be visibly altered by the omission of all except four of the twenty-six stars actually used. The four that are important, and their relative luminosity when nearest the sun, are Sirius 429,000, Altair 153,000, Alpha Centauri 117,500, and Procyon 51,300. The figure for the next star is only 4970, while for this star combined with the other twenty-one that are unimportant it is only 24,850 .

Figure 10 is not carried more than 70,000 years into the past or into the future because the stars near the sun at more remote times are not included among the thirty-eight having the largest known parallaxes. That is, they have either moved away or are not yet near enough to be included. Indeed, as Dr. Schlesinger strongly emphasizes, there may be swiftly moving, bright or gigantic stars which are now quite far away, but whose inclusion would alter Fig. 10 even within the limits of the 140,000 years there shown. It is almost certain, however, that the most that these would do would be to raise, but not obliterate, the minima on either side of the main maximum.

In preparing Fig. 10 it has been necessary to make 


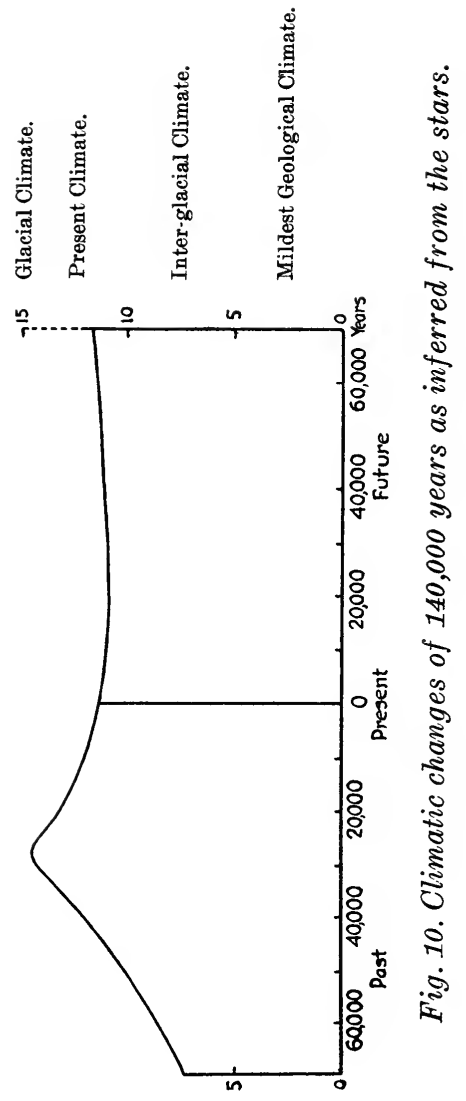


allowance for double stars. Passing by the twenty-two unimportant stars, it appears that the companion of Sirius is eight or ten magnitudes smaller than that star, while the companions of Procyon and Altair are five or more magnitudes smaller than their bright comrades. This means that the luminosity of the faint components is at most only 1 per cent of that of their bright companions and in the case of Sirius not a hundredth of 1 per cent. Hence their inclusion would have no visible effect on Fig. 10. In Alpha Centauri, on the other hand, the two components are of almost the same magnitude. For this reason the effective radiation of that star as given in column 14 is doubled in Fig. 10, while for another reason it is raised still more. The other reason is that if our inferences as to the electrical effect of the sun on the earth and of the planets on the sun are correct, double stars, as we have seen, must be much more effective electrically than single stars. By the same reasoning two bright stars close together must excite one another much more than a bright star and a very faint one, even if the distances in both cases are the same. So, too, other things being equal, a triple star must be more excited electrically than a double star. Hence in preparing Fig. 10 all double stars receive double weight and each part of Alpha Centauri receives an additional 50 per cent because both parts are bright and because they have a third companion to help in exciting them.

According to the electro-stellar hypothesis, Alpha Centauri is more important climatically than any other star in the heavens not only because it is triple and bright, but because it is the nearest of all stars, and moves fairly rapidly. Sirius and Procyon move slowly in respect to the sun, only about eleven and eight kilometers per second respectively, and their distances at minimum are 
fairly large, that is, 8 and 10.2 light years. Hence their effect on the sun changes slowly. Altair moves faster, about twenty-six kilometers per second, and its minimum distance is 6.4 light years, so that its effect changes fairly rapidly. Alpha Centauri moves about twenty-four kilometers per second, and its minimum distance is only 3.2 light years. Hence its effect changes very rapidly, the change in its apparent luminosity as seen from the sun amounting at maximum to about 30 per cent in 10,000 years against 14 per cent for Altair, 4 for Sirius, and 2 for Procyon. The vast majority of the stars change so much more slowly than even Procyon that their effect is almost uniform. All the stars at a distance of more than perhaps twenty or thirty light years may be regarded as sending to the sun a practically unchanging amount of radiation. It is the bright stars within this limit which are important, and their importance increases with their proximity, their speed of motion, and the brightness and number of their companions. Hence Alpha Centauri causes the main maximum in Fig. 10, while Sirius, Altair, and Procyon combine to cause a general rise of the curve from the past to the future.

Let us now interpret Fig. 10 geologically. The low position of the curve fifty to seventy thousand years ago suggests a mild inter-glacial climate distinctly less severe than that of the present. Geologists say that such was the case. The curve suggests a glacial epoch culminating about 28,000 years ago. The best authorities put the climax of the last glacial epoch between twenty-five and thirty thousand years ago. The curve shows an amelioration of climate since that time, although it suggests that there is still considerable severity. The retreat of the ice from North America and Europe, and its persistence in Greenland and Antarctica agree with this. And the curve 
indicates that the change of climate is still persisting, a conclusion in harmony with the evidence as to historic changes.

If Alpha Centauri is really so important, the effect of its variations, provided it has any, ought perhaps to be evident in the sun. The activity of the star's atmosphere presumably varies, for the orbits of the two components have an eccentricity of 0.51 . Hence during their period of revolution, 81.2 years, the distance between them ranges from $1,100,000,000$ to $3,300,000,000$ miles. They were at a minimum distance in 1388, 1459, 1550, 1631, 1713, 1794, 1875, and will be again in 1956. In Fig. 11, showing sunspot variations, it is noticeable that the years 1794 and 1875 come just at the ends of periods of unusual solar activity, as indicated by the heavy horizontal line. A similar period of great activity seems to have begun about 1914. If its duration equals the average of its two predecessors, it will end about 1950. Back in the fourteenth century a period of excessive solar activity, which has already been described, culminated from 1370 to 1385 , or just before the two parts of Alpha Centauri were at a minimum distance. Thus in three and perhaps four cases the sun has been unusually active during a time when the two parts of the star were most rapidly approaching each other and when their atmospheres were presumably most disturbed and their electrical emanations strongest.

The fact that Alpha Centauri, the star which would be expected most strongly to influence the sun, and hence the earth, was nearest the sun at the climax of the last glacial epoch, and that today the solar atmosphere is most active when the star is presumably most disturbed may be of no significance. It is given for what it is worth. Its importance lies not in the fact that it proves any- 


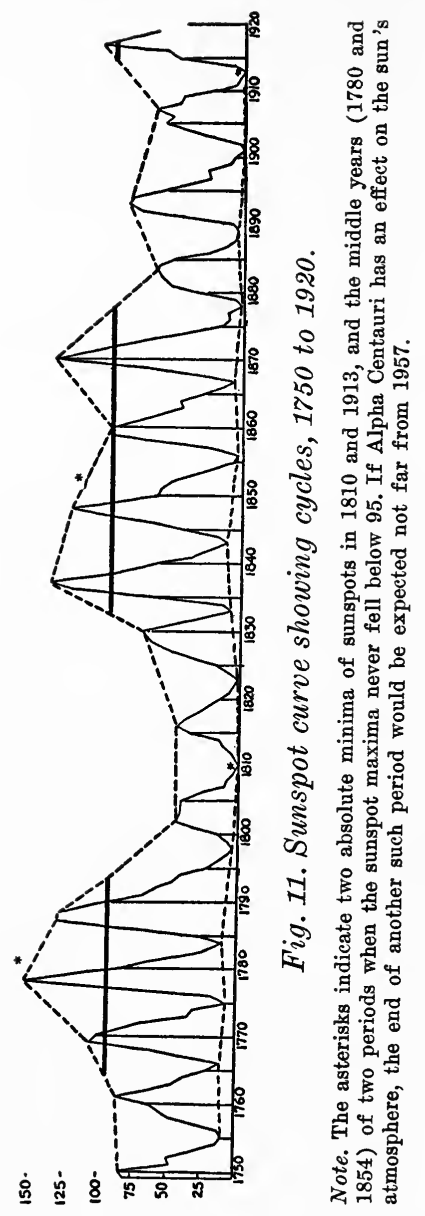


thing, but that no contradiction is found when we test the electro-stellar hypothesis by facts which were not thought of when the hypothesis was framed. A vast amount of astronomical work is still needed before the matter can be brought to any definite conclusion. In case the hypothesis stands firm, it may be possible to use the stars as a help in determining the exact chronology of the later part of geological times. If the hypothesis is disproved, it will merely leave the question of solar variations where it is today. It will not influence the main conclusions of this book as to the causes and nature of climatic changes. Its value lies in the fact that it calls attention to new lines of research. 


\section{CHAPTER XVI}

\section{THE EARTH'S CRUST AND THE SUN}

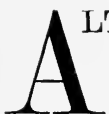

LTHOUGH the problems of this book may lead far afield, they ultimately bring us back to the earth and to the present. Several times in the preceding pages there has been mention of the fact that periods of extreme climatic fluctuations are closely associated with great movements of the earth's crust whereby mountains are uplifted and continents upheaved. In attempting to explain this association the general tendency has been to look largely at the past instead of the present. Hence it has been almost impossible to choose among three possibilities, all beset with difficulties. First, the movements of the crust may have caused the climatic fluctuations; second, climatic changes may cause crustal movements; and third, variations in solar activity or in some other outside agency may give rise to both types of terrestrial phenomena.

The idea that movements of the earth's crust are the main cause of geological changes of climate is becoming increasingly untenable as the complexity and rapidity of climatic changes become more clear, especially during post-glacial times. It implies that the earth's surface moves up and down with a speed and facility which appear to be out of the question. If volcanic activity be invoked the problem becomes no clearer. Even if volcanic dust should fill the air frequently and completely, neither its presence nor absence would produce such peculiar fea- 
tures as the localization of glaciers, the distribution of loess, and the mild climate of most parts of geological time. Nevertheless, because of the great difficulties presented by the other two possibilities many geologists still hold that directly or indirectly the greater climatic changes have been mainly due to movements of the earth's crust and to the reaction of the crustal movements on the atmosphere.

The possibility that climatic changes are in themselves a cause of movements of the earth's crust seems so improbable that no one appears to have investigated it with any seriousness. Nevertheless, it is worth while to raise the question whether climatic extremes may coöperate with other agencies in setting the time when the earth's crust shall be deformed.

As to the third possibility, it is perfectly logical to ascribe both climatic changes and crustal deformation to some outside agency, solar or otherwise, but hitherto there has been so little evidence on this point that such an ascription has merely begged the question. If heavenly bodies should approach the earth closely enough so that their gravitational stresses caused crustal deformation, all life would presumably be destroyed. As to the sun, there has hitherto been no conclusive evidence that it is related to crustal movements, although various writers have made suggestions along this line. In this chapter we shall carry these suggestions further and shall see that they are at least worthy of study.

As a preliminary to this study it may be well to note that the coincidence between movements of the earth's crust and climatic changes is not so absolute as is sometimes supposed. For example, the profound crustal changes at the end of the Mesozoic were not accompanied by widespread glaciation so far as is yet known, although 
the temperature appears to have been lowered. Nor was the violent volcanic and diastrophic activity in the Miocene associated with extreme climates. Indeed, there appears to have been little contrast from zone to zone, for figs, bread fruit trees, tree ferns, and other plants of low latitudes grew in Greenland. Nevertheless, both at the end of the Mesozoic and in the Miocene the climate may possibly have been severe for a time, although the record is lost. On the other hand, Kirk's recent discovery of glacial till in Alaska between beds carrying an undoubted Middle Silurian fauna indicates glaciation at a time when there was little movement of the crust so far as yet appears. ${ }^{1}$ Thus we conclude that while climatic changes and crustal movements usually occur together, they may occur separately.

According to the solar-cyclonic hypothesis such a condition is to be expected. If the sun were especially active when the terrestrial conditions prohibited glaciation, changes of climate would still occur, but they would be milder than under other circumstances, and would leave little record in the rocks. Or there might be glaciation in high latitudes, such as that of southern Alaska in the Middle Silurian, and none elsewhere. On the other hand, when the sun was so inactive that no great storminess occurred, the upheaval of continents and the building of mountains might go on without the formation of ice sheets, as apparently happened at the end of the Mesozoic. The lack of absolute coincidence between glaciation and periods of widespread emergence of the lands is evident even today, for there is no reason to suppose that the lands are notably lower or less extensive now than they were during the Pleistocene glaciation. In fact, there is much evidence that many areas have risen

1 E. Kirk: Paleozoic Glaciation in Alaska; Am. Jour. Sci., 1918, p. 511. 
since that time. Yet glaciation is now far less extensive than in the Pleistocene. Any attempt to explain this difference on the basis of terrestrial changes is extremely difficult, for the shape and altitude of continents and mountains have not changed much in twenty or thirty thousand years. Yet the present moderately mild epoch, like the puzzling inter-glacial epochs of earlier times, is easily explicable on the assumption that the sun's atmosphere may sometimes vary in harmony with crustal activity, but does not necessarily do so at all times.

Turning now to the main problem of how climatic changes may be connected with movements of the earth's crust, let us follow our usual method and examine what is happening today. Let us first inquire whether earthquakes, which are one of the chief evidences that crustal movements are actually taking place in our own times, show any connection with sunspots. In order to test this, we have compared Milne's Catalogue of Destructive Earthquakes from 1800 to 1899, with Wolf's sunspot numbers for the same period month by month. The earthquake catalogue, as its compiler describes it, "is an attempt to give a list of earthquakes which have announced changes of geological importance in the earth's crust; movements which have probably resulted in the creation or the extension of a line of fault, the vibrations accompanying which could, with proper instruments, have been recorded over a continent or the whole surface of our world. Small earthquakes have been excluded, while the number of large earthquakes both for ancient and modern times has been extended. As an illustration of exclusion, I may mention that between 1800 and 1808, which are years taken at random, I find in Mallet's catalogue 407 entries. Only thirty-seven of these, which were accompanied by structural damage, have been retained. 
Other catalogues such as those of Perry and Fuchs have been treated similarly.",

If the earthquakes in such a carefully selected list bear a distinct relation to sunspots, it is at least possible and perhaps probable that a similar relation may exist between solar activity and geological changes in the earth's crust. The result of the comparison of earthquakes and sunspots is shown in Table 7. The first column gives the sunspot numbers; the second, the number of months that had the respective spot numbers during the century from 1800 to 1899 . Column $\mathrm{C}$ shows the total number of earthquakes during the months having any particular degree of spottedness; while $\mathrm{D}$, which is the significant column, gives the average number of destructive earthquakes per month under each of the six conditions of solar spotted-

\section{TABLE 7}

DESTRUCTIVE EARTHQUAKES FROM 1800 TO 1899 COMPARED WITH SUNSPOTS

\begin{tabular}{|c|c|c|c|c|c|}
\hline A & $B$ & $C$ & $D$ & $E$ & $F$ \\
\hline $\begin{array}{l}\text { Sunspot } \\
\text { numbers }\end{array}$ & $\begin{array}{c}\text { Number } \\
\text { of months } \\
\text { per Wolf's } \\
\text { Table }\end{array}$ & $\begin{array}{c}\text { Number } \\
\text { of earth- } \\
\text { quakes }\end{array}$ & $\begin{array}{l}\text { Average } \\
\text { number } \\
\text { of earth- } \\
\text { quakes per } \\
\text { month }\end{array}$ & $\begin{array}{l}\text { Number } \\
\text { of earth- } \\
\text { quakes in } \\
\text { succeeding } \\
\text { month }\end{array}$ & $\begin{array}{l}\text { Average } \\
\text { number } \\
\text { of earth- } \\
\text { quakes in } \\
\text { succeeding } \\
\text { month }\end{array}$ \\
\hline $0-15$ & 344 & 522 & 1.52 & 512 & 1.49 \\
\hline 15. 30 & 194 & 306 & 1.58 & 310 & 1.60 \\
\hline $30-50$ & 237 & 433 & 1.83 & 439 & 1.85 \\
\hline 50- 70 & 195 & 402 & 2.06 & 390 & 2.00 \\
\hline $70-100$ & 135 & 286 & 2.12 & 310 & 2.30 \\
\hline ver 100 & 95 & 218 & 2.30 & 175 & 1.84 \\
\hline
\end{tabular}

2 J. Milne: Catalogue of Destructive Earthquakes; Rep. Brit. Asso. Adv. Sei., 1911. 
ness. The regularity of column $\mathrm{D}$ is so great as to make it almost certain that we are here dealing with a real relationship. Column F, which shows the average number of earthquakes in the month succeeding any given condition of the sun, is still more regular except for the last entry.

The chance that six numbers taken at random will arrange themselves in any given order is one in 720 . In other words, there is one chance in 720 that the regularity of column $\mathrm{D}$ is accidental. But column $\mathrm{F}$ is as regular as column $\mathrm{D}$ except for the last entry. If columns $\mathrm{D}$ and $\mathrm{E}$ were independent there would be one chance in about 500,000 that the six numbers in both columns would fall in the same order, and one chance in 14,400 that five numbers in each would fall in the same order. But the two columns are somewhat related, for although the after-shocks of a great earthquake are never included in Milne's table, a world-shaking earthquake in one region during a given month probably creates conditions that favor similar earthquakes elsewhere during the next month. Hence the probability that we are dealing with a purely accidental arrangement in Table 7 is less than one in 14,400 and greater than one in 500,000 . It may be one in 20,000 or 100,000 . In any event it is so slight that there is high probability that directly or indirectly sunspots and earthquakes are somehow connected.

In ascertaining the relation between sunspots and earthquakes it would be well if we could employ the strict method of correlation coefficients. This, however, is impossible for the entire century, for the record is by no means homogeneous. The earlier decades are represented by only about one-fourth as many earthquakes as the later ones, a condition which is presumably due to lack of information. This makes no difference with the method 
employed in Table 7, since years with many and few sunspots are distributed almost equally throughout the entire nineteenth century, but it renders the method of correlation coefficients inapplicable. During the period from 1850 onward the record is much more nearly homogeneous, though not completely so. Even in these later decades, however, allowance must be made for the fact that there are more earthquakes in winter than in summer, the average number per month for the fifty years being as follows:

$\begin{array}{llll}\text { Jan. } 2.8 & \text { May } 2.4 & \text { Sept. } 2.5 \\ \text { Feb. } 2.4 & \text { June } 2.3 & \text { Oct. } 2.6 \\ \text { Mar. } 2.5 & \text { July } 2.4 & \text { Nov. } 2.7 \\ \text { Apr. } 2.4 & \text { Aug. } 2.4 & \text { Dec. } 2.8\end{array}$

The correlation coefficient between the departures from these monthly averages and the corresponding departures from the monthly averages of the sunspots for the same period, 1850-1899, are as follows :

Sunspots and earthquakes of same month: +0.042 , or 1.5 times the probable error.

Sunspots of a given month and earthquakes of that month and the next: +0.084 , or 3.1 times the probable error.

Sunspots of three consecutive months and earthquakes of three consecutive months allowing a lag of one month, i.e., sunspots of January, February, and March compared with earthquakes of February, March, and April; sunspots of February, March, and April with earthquakes of March, April, and May, etc.; +0.112 , or 4.1 times the probable error.

These coefficients are all small, but the number of individual cases, 600 months, is so large that the probable error is greatly reduced, being only \pm 0.027 or \pm 0.028 . Moreover, the nature of our data is such that even if 
there is a strong connection between solar changes and earth movements, we should not expect a large correlation coefficient. In the first place, as already mentioned, the earthquake data are not strictly homogeneous. Second, an average of about two and one-half strong earthquakes per month is at best only a most imperfect indication of the actual movement of the earth's crust. Third, the sunspots are only a partial and imperfect measure of the activity of the sun's atmosphere. Fourth, the relation between solar activity and earthquakes is almost certainly indirect. In view of all these conditions, the regularity of Table 7 and the fact that the most important correlation coefficient rises to more than four times the probable error makes it almost certain that the solar and terrestrial phenomena are really connected.

We are now confronted by the perplexing question of how this connection can take place. Thus far only three possibilities present themselves, and each is open to objections. The chief agencies concerned in these three possibilities are heat, electricity, and atmospheric pressure. Heat may be dismissed very briefly. We have seen that the earth's surface becomes relatively cool when the sun is active. Theoretically even the slightest change in the temperature of the earth's surface must influence the thermal gradient far into the interior and hence cause a change of volume which might cause movements of the crust. Practically the heat of the surface ceases to be of appreciable importance at a depth of perhaps twenty feet, and even at that depth it does not act quickly enough to cause the relatively prompt response which seems to be characteristic of earthquakes in respect to the sun.

The second possibility is based on the relationship between solar and terrestrial electricity. When the sun is active the earth's atmospheric electrical potential is 
subject to slight variations. It is well known that when two opposing points of an ionized solution are oppositely charged electrically, a current passes through the liquid and sets up electrolysis whereby there is a segregation of materials, and a consequent change in the volume of the parts near the respective electrical poles. The same process takes place, although less freely, in a hot mass such as forms the interior of the earth. The question arises whether internal electrical currents may not pass between the two oppositely charged poles of the earth, or even between the great continental masses and the regions of heavier rock which underlie the oceans. Could this lead to electrolysis, hence to differentiation in volume, and thus to movements of the earth's crust? Could the results vary in harmony with the sun? Bowie ${ }^{3}$ has shown that numerous measurements of the strength and direction of the earth's gravitative pull are explicable only on the assumption that the upheaval of a continent or a mountain range is due in part not merely to pressure, or even to flowage of the rocks beneath the crust, but also to an actual change in volume whereby the rocks beneath the continent attain relatively great volume and those under the oceans a small volume in proportion to their weight. The query arises whether this change of volume may be related to electrical currents at some depth below the earth's surface.

The objections to this hypothesis are numerous. First, there is little evidence of electrolytic differentiation in the rocks. Second, the outer part of the earth's crust is a very poor conductor so that it is doubtful whether even a high degree of electrification of the surface would have much effect on the interior. Third, electrolysis due to any

$3 \mathrm{Wm}$. Bowie: Lecture before the Geological Club of Yale University. See Am. Jour. Sci., 1921. 
such mild causes as we have here postulated must be an extremely slow process, too slow, presumably, to have any appreciable result within a month or two. Other objections join with these three in making it seem improbable that the sun's electrical activity has any direct effect upon movements of the earth's crust.

The third, or meteorological hypothesis, which makes barometric pressure the main intermediary between solar activity and earthquakes, seems at first sight almost as improbable as the thermal and electrical hypotheses. Nevertheless, it has a certain degree of observational support of a kind which is wholly lacking in the other two cases. Among the extensive writings on the periodicity of earthquakes one main fact stands out with great distinctness: earthquakes vary in number according to the season. This fact has already been shown incidentally in the table of earthquake frequency by months. If allowance is made for the fact that February is a short month, there is a regular decrease in the frequency of severe earthquakes from December and January to June. Since most of Milne's earthquakes occurred in the northern hemisphere, this means that severe earthquakes occur in winter about 20 per cent oftener than in summer.

The most thorough investigation of this subject seems to have been that of Davisson. ${ }^{4}$ His results have been worked over and amplified by Knott, ${ }^{5}$ who has tested them by Schuster's exact mathematical methods. His results are given in Table $8 .^{6}$ Here the northern hemisphere

4 Chas. Davisson: On the Annual and Semi-annual Seismic Periods; Roy. Soc. of London, Philosophical Transactions, Vol. 184, 1893, $1107 \mathrm{ff}$.

5 C. G. Knott: The Physies of Earthquake Phenomena, Oxford, 1908.

- In Table 8 the first column indicates the region; the second, the dates; and the third, the number of shocks. The fourth column gives the month in which the annual maximum occurs when the crude figures are smoothed by the use of overlapping six-monthly means. In other words, the average for each successive six months has been placed in the middle of the period. 
TABLE 8

SEASONAL MARCH OF EARTHQUAKES

AFTER DAVISSON AND KNOTT

\begin{tabular}{|c|c|c|c|c|c|c|}
\hline$A$ & $B$ & $C$ & $D$ & $E$ & $\boldsymbol{F}$ & $G$ \\
\hline Region & 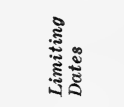 & 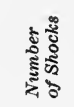 & 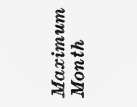 & 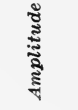 & 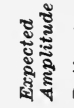 & 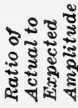 \\
\hline Northern Hemisphere & $223-1850$ & 5879 & Dec. & 0.110 & 0.023 & 4.8 \\
\hline Northern Hemisphere & $1865-1884$ & 8133 & Dec. & 0.290 & 0.020 & 14.5 \\
\hline Europe & $1865-1884$ & 5499 & Dec. & 0.350 & 0.024 & 14.6 \\
\hline Europe & $306-1843$ & 1961 & Dec. & 0.220 & 0.040 & 5.5 \\
\hline Southeast Europe & $1859-1887$ & 3470 & Dec. & 0.210 & 0.030 & 7.0 \\
\hline Vesuvius District & $1865-1883$ & 513 & Dec. & 0.250 & 0.078 & 3.2 \\
\hline \multicolumn{7}{|l|}{ Italy: } \\
\hline Old Tromometre & $1872-1887$ & 61732 & Dec. & 0.490 & 0.007 & 70.0 \\
\hline Old Tromometre & $1876-1887$ & 38546 & Dec. & 0.460 & 0.009 & 49.5 \\
\hline Normal Tromometre & $1876-1887$ & 38546 & Dec. & 0.490 & 0.009 & 52.8 \\
\hline Balkan, ete. & $1865-1884$ & 624 & Dec. & 0.270 & 0.071 & 3.8 \\
\hline Hungary, etc. & $1865-1884$ & 384 & Dec. & 0.310 & 0.090 & 3.4 \\
\hline Italy & $1865-1883$ & 2350 & Dec. (Sept.) & 0.140 & 0.037 & 3.8 \\
\hline Grecian Archip. & $1859-1881$ & 3578 & Dec.-Jan. & 0.164 & 0.030 & 5.5 \\
\hline Austria & $1865-1884$ & 461 & Jan. & 0.370 & 0.083 & 4.4 \\
\hline Switzerland, etc. & $1865-1883$ & 524 & Jan. & 0.560 & 0.077 & 7.3 \\
\hline Asia & $1865-1884$ & 458 & Feb. & 0.330 & 0.083 & 4.0 \\
\hline North America & $1865-1884$ & 552 & Nov. & 0.350 & 0.075 & 4.7 \\
\hline California & $1850-1886$ & 949 & Oct. & 0.300 & 0.058 & 5.2 \\
\hline Japan & $1878-1881$ & 246 & Dec. & 0.460 & 0.113 & 4.1 \\
\hline Japan & $1872-1880$ & 367 & Dec.-Jan. & 0.256 & 0.093 & 2.8 \\
\hline Japan & $1876-1891$ & 1104 & Feb. & 0.190 & 0.053 & 3.6 \\
\hline Japan & $1885-1889$ & 2997 & Oet. & 0.080 & 0.032 & 2.5 \\
\hline Zante & $1825-1863$ & 1326 & Aug. & 0.100 & 0.049 & 2.0 \\
\hline Italy, North of Naples & $1865-1883$ & 1513 & Sept. (Nov.) & 0.210 & 0.046 & 4.6 \\
\hline East Indies & $1873-1881$ & 515 & $\begin{array}{l}\text { Aug., Oct., } \\
\text { or Dec. ? }\end{array}$ & 0.0719 & 0.078 & 0.9 \\
\hline Malay Archip. & $1865-1884$ & 598 & May & 0.190 & 0.072 & 2.6 \\
\hline New Zealand & $1869-1879$ & 585 & Aug.-Sept. & 0.203 & 0.073 & 2.8 \\
\hline Chile & $1873-1881$ & 212 & July & 0.480 & 0.122 & 3.9 \\
\hline Southern Hemisphere & $1865-1884$ & 751 & July & 0.370 & 0.065 & 5.7 \\
\hline New Zealand & $1868-1890$ & 641 & Mareh, May & 0.050 & 0.070 & 0.7 \\
\hline Chile & $1865-1883 ?$ & 316 & July, Dec. & 0.270 & 0.100 & 2.7 \\
\hline Peru, Bolivia & $1865-1884$ & 350 & July & 0.480 & 0.095 & 5.1 \\
\hline
\end{tabular}


is placed first; then come the East Indies and the Malay Archipelago lying close to the equator; and finally the southern hemisphere. In the northern hemisphere practically all the maxima come in the winter, for the month of December appears in fifteen cases out of the twentyfive in column D, while January, February, or November appears in six others. It is also noticeable that in sixteen cases out of twenty-five the ratio of the actual to the expected amplitude in column $G$ is four or more, so that a real relationship is indicated, while the ratio falls below three only in Japan and Zante. The equatorial data, unlike those of the northern hemisphere, are indefinite, for in the East Indies no month shows a marked maximum and the expected amplitude exceeds the actual amplitude. Even in the Malay Archipelago, which shows a maximum in May, the ratio of actual to expected amplitude is only 2.6. Turning to the southern hemisphere, the winter months of that hemisphere are as strongly marked by a maximum as are the winter months of the northern

Thus the average of January to June, inclusive, is placed between March and April, that for February to July between April and May, and so on. This method eliminates the minor fluctuations and also all periodicities having a duration of less than a year. If there were no annual periodicity the smoothing would result in practically the same figure for each month. The column marked "Amplitude" gives the range from the highest month to the lowest divided by the number of earthquakes and then corrected according to Schuster's method which is well known to mathematicians, but which is so confusing to the layman that it will not be described. Next, in the column marked "Expected Amplitude," we have the amplitude that would be expected if a series of numbers corresponding to the earthquake numbers and having a similar range were arranged in accidental order throughout the year. This also is calculated by Schuster's method in which the expected amplitude is equal to the square root of "pi" divided by the number of shocks. When the actual amplitude is four or more times the expected amplitude, the probability that there is a real periodicity in the observed phenomena becomes so great that we may regard it as practically certain. If there is no periodicity the two are equal. The last column gives the number of times by which the actual exceeds the expected amplitude, and thus is a measure of the probability that earthquakes vary systematically in a period of a year. 
hemisphere. July or August appears in five out of six cases. Here the ratio between the actual and expected amplitudes is not so great as in the northern hemisphere. Nevertheless, it is practically four in Chile, and exceeds five in Peru and Bolivia, and in the data for the entire southern hemisphere.

The whole relationship between earthquakes and the seasons in the northern and southern hemispheres is summed up in Fig. 12 taken from Knott. The northern hemisphere shows a regular diminution in earthquake frequency from December until June, and an increase the rest of the year. In the southern hemisphere the course of events is the same so far as summer and winter are concerned, for August with its maximum comes in winter, while February with its minimum comes in summer. In the southern hemisphere the winter month of greatest seismic activity has over 100 per cent.more earthquakes than the summer month of least activity. In the northern hemisphere this difference is about 80 per cent, but this smaller figure occurs partly because the northern data include certain interesting and significant regions like Japan and China where the usual conditions are reversed. ${ }^{7}$ If equatorial regions were included in Fig. 12, they would give an almost straight line.

The connection between earthquakes and the seasons is so strong that almost no students of seismology question it, although they do not agree as to its cause. A meteorological hypothesis seems to be the only logical explanation. ${ }^{8}$ Wherever sufficient data are available, earthquakes

7 N. F. Drake: Destructive Earthquakes in China; Bull. Seism. Soc. Am., Vol. 2, 1912, pp. 40-91, 124-133.

8 The only other explanation that seems to have any standing is the psychological hypothesis of Montessus de Ballore as given in Les Tremblements de Terre. He attributes the apparent seasonal variation in earthquakes to the fact that in winter people are within doors, and hence notice 
appear to be most numerous when climatic conditions cause the earth's surface to be most heavily loaded or to change its load most rapidly. The main factor in the loading is apparently atmospheric pressure. This acts in two ways. First, when the continents become cold in winter the pressure increases. On an average the air at sea level presses upon the earth's surface at the rate of 14.7 pounds per square inch, or over a ton per square foot, and only a little short of thirty million tons per square mile. An average difference of one inch between the atmospheric pressure of summer and winter over ten million square miles of the continent of Asia, for example, means that the continent's load in winter is about ten million million tons heavier than in summer. Second, the changes in atmospheric pressure due to the passage of storms are relatively sharp and sudden. Hence they are probably more effective than the variations in the load from season to season. This is suggested by the rapidity with which the terrestrial response seems to follow the supposed solar cause of earthquakes. It is also suggested by the fact that violent storms are frequently followed by violent earthquakes. "Earthquake weather," as Dr. Schlesinger suggests, is a common phrase in the typhoon region of Japan, China, and the East Indies. During tropical hurricanes a change of pressure amounting to half an inch in two hours is common. On Septem-

movements of the earth much more than in summer when they are out of doors. There is a similar difference between people's habits in high latitudes and low. Undoubtedly this does have a marked effect upon the degree to which minor earthquake shocks are noticed. Nevertheless, de Ballore's contention, as well as any other psychological explanation, is completely upset by two facts: First, instrumental records show the same seasonal distribution as do records based on direct observation, and instruments certainly are not influenced by the seasons. Second, in some places, notably China, as Drake has shown, the summer rather than the winter is very decidedly the time when earthquakes are most frequent. 
THE EARTH'S CRUST AND THE SUN

ber 22, 1885, at False Point Lighthouse on the Bay of Bengal, the barometer fell about an inch in six hours, then nearly an inch and a half in not much over two hours, and finally rose fully two inches inside of two hours. A drop of two inches in barometric pressure means that a load of about two million tons is removed
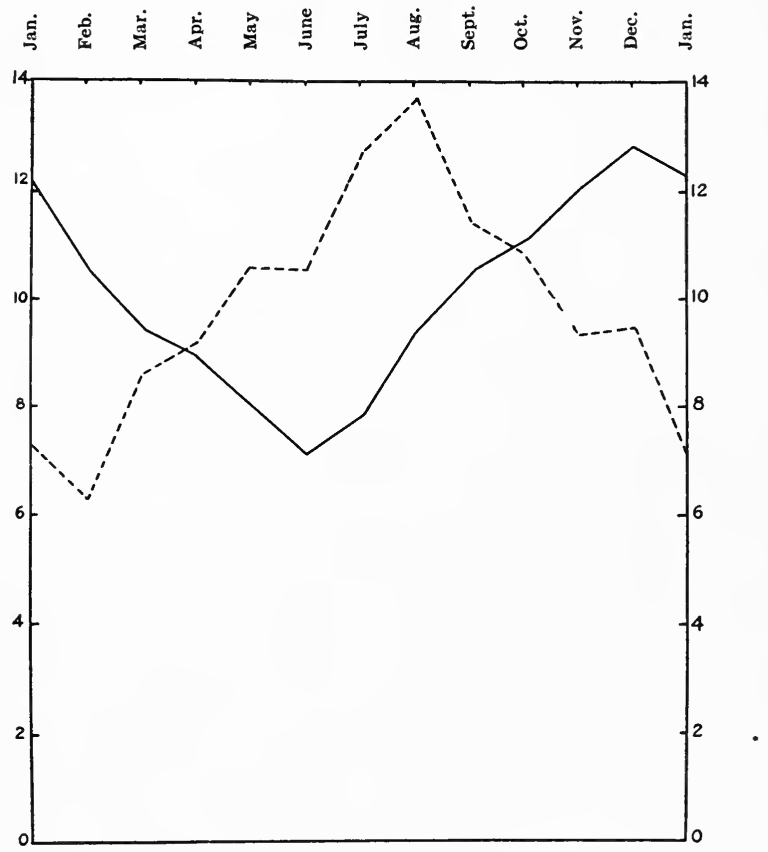

Fig. 12. Seasonal distribution of earthquakes.

(After Davisson and Knott.)

— Northern Hemisphere. ..... Southern Hemisphere. 
from each square mile of land; the corresponding rise of pressure means the addition of a similar load. Such a storm, and to a less degree every other storm, strikes a blow upon the earth's surface, first by removing millions of tons of pressure and then by putting them on again. ${ }^{9}$ Such storms, as we have seen, are much more frequent and severe when sunspots are numerous than at other times. Moreover, as Veeder ${ }^{10}$ long ago showed, one of the most noteworthy evidences of a connection between sunspots and the weather is a sudden increase of pressure in certain widely separated high pressure areas. In most parts of the world winter is not only the season of highest pressure and of most frequent changes of Veeder's type, but also of severest storms. Hence a meteorological hypothesis would lead to the expectation that earthquakes would occur more frequently in winter than in summer. On the Chinese coast, however, and also on the oceanic side of Japan, as well as in some more tropical regions, the chief storms come in summer in the form of typhoons. These are the places where earthquakes also are most abundant in summer. Thus, wherever we turn, storms and the related barometric changes seem to be most frequent and severe at the very times when earthquakes are also most frequent.

Other meteorological factors, such as rain, snow, winds, and currents, probably have some effect on earth-

9 A comparison of tropical hurricanes with earthquakes is interesting. Taking all the hurricanes recorded in August, September, and October, from 1880 to 1899 , and the corresponding earthquakes in Milne's catalogue, the correlation coefficient between hurricanes and earthquakes is +0.236 , with a probable error of \pm 0.082 , the month being used as the unit. This is not a large correlation, yet when it is remembered that the hurricanes represent only a small part of the atmospheric disturbances in any given month, it suggests that with fuller data the correlation might be large.

10 Ellsworth Huntington: The Geographic Work of Dr. M. A. Veeder; Geog. Rev., Vol. 3, March and April, 1917, Nos. 3 and 4. 
quakes through their ability to load the earth's crust. The coming of vegetation may also help. These agencies, however, appear to be of small importance compared with the storms. In high latitudes and in regions of abundant storminess most of these factors generally combine with barometric pressure to produce frequent changes in the load of the earth's crust, especially in winter. In low latitudes, on the other hand, there are few severe storms, and relatively little contrast in pressure and vegetation from season to season; there is no snow; and the amount of ground water changes little. With this goes the twofold fact that there is no marked seasonal distribution of earthquakes, and that except in certain local volcanic areas, earthquakes appear to be rare. In proportion to the areas concerned, for example, there is little evidence of earthquakes in equatorial Africa and South America.

The question of the reality of the connection between meteorological conditions and crustal movements is so important that every possible test should be applied. At the suggestion of Professor Schlesinger we have looked up a very ingenious line of inquiry. During the last decades of the nineteenth century, a long series of extremely accurate observations of latitude disclosed a fact which had previously been suspected but not demonstrated, namely, that the earth wabbles a little about its axis. The axis itself always points in the same direction, and since the earth slides irregularly around it the latitude of all parts of the earth keeps changing. Chandler has shown that the wabbling thus induced consists of two parts. The first is a movement in a circle with a radius of about fifteen feet which is described in approximately 430 days. This so-called Eulerian movement is a normal gyroscopic motion like the slow gyration of a 
spinning top. This depends on purely astronomical causes, and no terrestrial cause can stop it or eliminate it. The period appears to be constant, but there are certain puzzling irregularities. The usual amplitude of this movement, as Schlesinger ${ }^{11}$ puts it, "is about 0 ".27, but twice in recent years it has jumped to $0^{\prime \prime} .40$. Such a change could be accounted for by supposing that the earth had received a severe blow or a series of milder blows tending in the same direction." These blows, which were originally suggested by Helmert are most interesting in view of our suggestion as to the blows struck by storms.

The second movement of the pole has a period of a year, and is roughly an ellipse whose longest radius is fourteen feet and the shortest, four feet; or, to put it technically, there is an annual term with a maximum amplitude of about $0^{\prime \prime} .20$. This, however, varies irregularly. The result is that the pole seems to wander over the earth's surface in the spiral fashion illustrated in Fig. 13. It was early suggested that this peculiar wandering of the pole in an annual period must be due to meteorological causes. Jeffreys ${ }^{12}$ has investigated the matter exhaustively. He assumes certain reasonable values for the weight of air added or subtracted from different parts of the earth's surface according to the seasons. He also considers the effect of precipitation, vegetation, and polar ice, and of variations of temperature and atmospheric pressure in their relation to movements of the ocean. Then he proceeds to compare all

11 Frank Schlesinger: Variations of Latitude; Their Bearing upon Our Knowledge of the Interior of the Earth; Proc. Am. Phil. Soc., Vol. 54, 1915, pp. 351-358. Also Smithsonian Report for 1916, pp. 248-254.

12 Harold Jeffreys: Causes Contributory to the Annual Variations of Latitude; Monthly Notices, Royal Astronomical Soc., Vol. 76, 1916, pp. 499-525. 
these with the actual wandering of the pole from 1907 to 1913. While it is as yet too early to say that any special movement of the pole was due to the specific meteorological conditions of any particular year, Jeffreys' work makes it clear that meteorological causes, especially atmospheric pressure, are sufficient to cause the observed irregular wanderings. Slight wanderings may arise from various other sources such as movements of the rocks when geological faults occur or the rush of a great wave due to a submarine earthquake. So far as

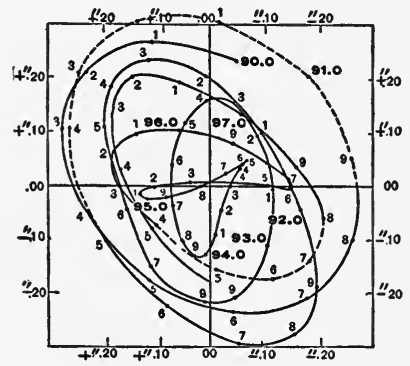

Fig. 13. Wandering of the pole from 1890 to 1898.

(After Moulton.)

known, however, all these other agencies cause insignificant displacements compared with those arising from movements of the air. This fact coupled with the mathematical certainty that meteorological phenomena must produce some wandering of the pole, has caused most astronomers to accept Jeffreys' conclusion. If we follow their example we are led to conclude that changes in atmospheric pressure and in the other meteorological conditions strike blows which sometimes shift the earth 
several feet from its normal position in respect to the axis.

If the foregoing reasoning is correct, the great and especially the sudden departures from the smooth gyroscopic circle described by the pole in the Eulerian motion would be expected to occur at about the same time as unusual earthquake activity. This brings us to an interesting inquiry carried out by Milne $^{13}$ and amplified by Knott. ${ }^{14}$ Taking Albrecht's representation of the irregular spiral-like motion of the pole, as given in Fig. 13 , they show that there is a preponderance of severe earthquakes at times when the direction of motion of the earth in reference to its axis departs from the smooth Eulerian curve. A summary of their results is given in Table 9. The table indicates that during the period from 1892 to 1905 there were nine different times when the curve of Fig. 13 changed its direction or was deflected by less than $10^{\circ}$ during a tenth of a year. In other words, during those periods it did not curve as much as it ought according to the Eulerian movement. At such times there were 179 world-shaking earthquakes, or an average of about 19.9 per tenth of a year. According to the other lines of Table 9, in thirty-two cases the deflection during a tenth of a year was between $10^{\circ}$ and $25^{\circ}$, while in fiftysix cases it was from $25^{\circ}$ to $40^{\circ}$. During these periods the curve remained close to the Eulerian path and the world-shaking earthquakes averaged only 8.2 and 12.9. Then, when the deflection was high, that is, when meteorological conditions threw the earth far out of its Eulerian course, the earthquakes were again numerous, the number rising to 23.4 when the deflection amounted to more than $55^{\circ}$.

13 John Milne: British Association Reports for 1903 and 1906.

14 C. G. Knott: The Physies of Earthquake Phenomena, Oxford, 1908. 
TABLE 9

DEFLECTION OF PATH OF POLE COMPARED WITH EARTHQUAKES

$\begin{array}{cccc}\text { Deflection } & \begin{array}{c}\text { No. of } \\ \text { Deflections }\end{array} & \begin{array}{c}\text { No. of } \\ \text { Earthquakes }\end{array} & \begin{array}{c}\text { Average No. } \\ \text { of Earthquakes }\end{array} \\ 0-10^{\circ} & 9 & 179 & 19.9 \\ 10-25^{\circ} & 32 & 263 & 8.2 \\ 25-40^{\circ} & 56 & 722 & 12.9 \\ 40-55^{\circ} & 19 & 366 & 19.3 \\ {\text { over } 55^{\circ}}^{\circ} & 7 & 164 & 23.4\end{array}$

In order to test this conclusion in another way we have followed a suggestion of Professor Schlesinger. Under his advice the Eulerian motion has been eliminated and a new series of earthquake records has been compared with the remaining motions of the poles which presumably arise largely from meteorological causes. For this purpose use has been made of the very full records of earthquakes published under the auspices of the International Seismological Commission for the years 1903 to 1908 , the only years for which they are available. These include every known shock of every description which was either recorded by seismographs or by direct observation in any part of the world. Each shock is given the same weight, no matter what its violence or how closely it follows another. The angle of deflection has been measured as Milne measured it, but since the Eulerian motion is eliminated, our zero is approximately the normal condition which would prevail if there were no meteorological complications. Dividing the deflections into six equal groups according to the size of the angle, we get the result shown in Table 10. 
TABLE 10

EARTHQUAKES IN 1903-1908 COMPARED

WITH DEPARTURES OF THE PROJECTED CURVE OF THE EARTH'S

AXIS FROM THE EULERIAN POSITION

Average angle of deflection (10 periods of $1 / 10$ year each)

$-10.5^{\circ}$

$11.5^{\circ}$

$25.8^{\circ}$

$40.2^{\circ}$

$54.7^{\circ}$

$90.3^{\circ}$
Average daily number of earthquakes

8.31

8,35

8.23

8.14

8.86

11.81

Here where some twenty thousand earthquakes are employed the result agrees closely with that of Milne for a different series of years and for a much smaller number of earthquakes. So long as the path of the pole departs less than about $45^{\circ}$ from the smooth gyroscopic Eulerian path, the number of earthquakes is almost constant, about eight and a quarter per day. When the angle becomes large, however, the number increases by nearly 50 per cent. Thus the work of Milne, Knott, and Jeffreys is confirmed by a new investigation. Apparently earthquakes and crustal movements are somehow related to sudden changes in the load imposed on the earth's crust by meteorological conditions.

This conclusion is quite as surprising to the authors as to the reader-perhaps more so. At the beginning of this investigation we had no faith whatever in any im- 
portant relation between climate and earthquakes. At its end we are inclined to believe that the relation is close and important.

It must not be supposed, however, that meteorological conditions are the cause of earthquakes and of movements of the earth's crust. Even though the load that the climatic agencies can impose upon the earth's crust runs into millions of tons per square mile, it is a trifle compared with what the crust is able to support. There is, however, a great difference between the cause and the occasion of a phenomenon. Suppose that a thick sheet of glass is placed under an increasing strain. If the strain is applied slowly enough, even so rigid a material as glass will ultimately bend rather than break. But suppose that while the tension is high the glass is tapped. A gentle tap may be followed by a tiny crack. A series of little taps may be the signal for small cracks to spread in every direction. A few slightly harder taps may cause the whole sheet to break suddenly into many pieces. Yet even the hardest tap may be the merest trifle compared with the strong force which is keeping the glass in a state of strain and which would ultimately bend it if given time.

The earth as a whole appears to stand between steel and glass in rigidity. It is a matter of common observation that rocks stand high in this respect and in the consequent difficulty with which they can be bent without breaking. Because of the earth's contraction the crust endures a constant strain, which must gradually become enormous. This strain is increased by the fact that sediment is transferred from the lands to the borders of the sea and there forms areas of thick accumulation. From this has arisen the doctrine of isostasy, or of the equalization of crustal pressure. An important illustration of 
this is the oceanward and equatorial creep which has been described in Chapter XI. There we saw that when the lands have once been raised to high levels or when a shortening of the earth's axis by contraction has increased the oceanic bulge at the equator, or when the reverse has happened because of tidal retardation, the outer part of the earth appears to creep slowly back toward a position of perfect isostatic adjustment. If the sun had no influence upon the earth, either direct or indirect, isostasy and other terrestrial processes might flex the earth's crust so gradually that changes in the form and height of the lands would always take place slowly, even from the geological point of view. Thus erosion would usually be able to remove the rocks as rapidly as they were domed above the general level. If this happened, mountains would be rare or unknown, and hence climatic contrasts would be far less marked than is actually the case on our earth where crustal movements have repeatedly been rapid enough to produce mountains.

Nature's methods rarely allow so gradual an adjustment to the forces of isostasy. While the crust is under a strain, not only because of contraction, but because of changes in its load through the transference of sediments and the slow increase or decrease in the bulge at the equator, the atmosphere more or less persistently carries on the tapping process. The violence of that process varies greatly, and the variations depend largely on the severity of the climatic contrasts. If the main outlines of the cyclonic hypothesis are reliable, one of the first effects of a disturbance of the sun's atmosphere is increased storminess upon the earth. This is accompanied by increased intensity in almost every meteorological process. The most important effect, however, so far as the earth's crust is concerned would apparently be the rapid and 
intense changes of atmospheric pressure which would arise from the swift passage of one severe storm after another. Each storm would be a little tap on the tensely strained crust. Any single tap might be of little consequence, even though it involved a change of a billion tons in the pressure on an area no larger than the state of Rhode Island. Yet a rapid and irregular succession of such taps might possibly cause the crust to crack, and finally to collapse in response to stresses arising from the shrinkage of the earth.

Another and perhaps more important effect of variations in storminess and especially in the location of the stormy areas would be an acceleration of erosion in some places and a retardation elsewhere. A great increase in rainfall may almost denude the slopes of soil, while a diminution to the point where much of the vegetation dies off has a similar effect. If such changes should take place rapidly, great thicknesses of sediment might be concentrated in certain areas in a short time, thus disturbing the isostatic adjustment of the earth's crust. This might set up a state of strain which would ultimately have to be relieved, thus perhaps initiating profound crustal movements. Changes in the load of the earth's crust due to erosion and the deposition of sediment, no matter how rapid they may be from the geological standpoint, are slow compared with those due to changes in barometric pressure. A drop of an inch in barometric pressure is equivalent to the removal of about five inches of solid rock. Even under the most favorable circumstances, the removal of an average depth of five inches of rock or its equivalent in soil over millions of square miles would probably take several hundred years, while the removal of a similar load of air might occur in half a day or even a few hours. Thus the erosion and depo- 
sition due to climatic variations presumably play their part in crustal deformation chiefly by producing crustal stresses, while the storms, as it were, strike sharp, sudden blows.

Suppose now that a prolonged period of world-wide mild climate, such as is described in Chapter X, should permit an enormous accumulation of stresses due to contraction and tidal retardation. Suppose that then a sudden change of climate should produce a rapid shifting of the deep soil that had accumulated on the lands, with a corresponding localization and increase in strains. Suppose also that frequent and severe storms play their part, whether great or small, by producing an intensive tapping of the crust. In such a case the ultimate collapse would be correspondingly great, as would be evident in the succeeding geological epoch. The sea floor might sink lower, the continents might be elevated, and mountain ranges might be shoved up along lines of special weakness. This is the story of the geological period as known to historical geology. The force that causes such movements would be the pull of gravity upon the crust surrounding the earth's shrinking interior. Nevertheless climatic changes might occasionally set the date when the gravitative pull would finally overcome inertia, and thus usher in the crustal movements that close old geologic periods and inaugurate new ones. This, however, could occur only if the crust were under sufficient strain. As Lawson" says in his discussion of the "elastic rebound theory," the sudden shifts of the crust which seem to be the underlying cause of earthquakes "can occur only after the accumulation of strain to a limit and . . . this accumulation involves a slow creep of the region affected.

15 A. C. Lawson: The Mobility of the Coast Ranges of California; Univ. of Calif. Pub., Geology, Vol. 12, No. 7, pp. 431-473. 
In the long periods between great earthquakes the energy necessary for such shocks is being stored up in the rocks as elastic compression."

If a period of intense storminess should occur when the earth as a whole was in such a state of strain, the sudden release of the strains might lead to terrestrial changes which would alter the climate still further, making it more extreme, and perhaps permitting the storminess due to the solar disturbances to bring about glaciation. At the same time if volcanic activity. should increase it would add its quota to the tendency toward glaciation. Nevertheless, it might easily happen that a very considerable amount of crustal movement would take place without causing a continental ice sheet or even a marked alpine ice sheet. Or again, if the strains in the earth's crust had already been largely released through other agencies before the stormy period began, the climate might become severe enough to cause glaciation in high latitudes without leading to any very marked movements of the earth's crust, as apparently happened in the Mid-Silurian period.

\section{CONCLUSION}

Here we must bring this study of the earth's evolution to a close. Its fundamental principle has been that the present, if rightly understood, affords a full key to the past. With this as a guide we have touched on many hypotheses, some essential and some unessential to the general line of thought. The first main hypothesis is that the earth's present climatic variations are correlated with changes in the solar atmosphere. This is the keynote of the whole book. It is so well established, however, 
that it ranks as a theory rather than as an hypothesis. Next comes the hypothesis that variations in the solar atmosphere influence the earth's climate chiefly by causing variations not only in temperature but also in atmospheric pressure and thus in storminess, wind, and rainfall. This, too, is one of the essential foundations on which the rest of the book is built, but though this cyclonic hypothesis is still a matter of discussion, it seems to be based on strong evidence. These two hypotheses might lead us astray were they not balanced by another. This other is that many climatic conditions are due to purely terrestrial causes, such as the form and altitude of the lands, the degree to which the continents are united, the movement of ocean currents, the activity of volcanoes, and the composition of the atmosphere and the ocean. Only by combining the solar and the terrestrial can the truth be perceived. Finally, the last main hypothesis of this book holds that if the climatic conditions which now prevail at times of solar activity were magnified sufficiently and if they occurred in conjunction with certain important terrestrial conditions of which there is good evidence, they would produce most of the notable phenomena of glacial periods. For example, they would explain such puzzling conditions as the localization and periodicity of glaciation, the formation of loess, and the occurrence of glaciation in low latitudes during Permian and Proterozoic times. The converse of this is that if the conditions which now prevail at times when the sun is relatively inactive should be intensified, that is, if the sun's atmosphere should become calmer than now, and if the proper terrestrial conditions of topographic form and atmospheric composition should prevail, there would arise the mild climatic conditions which appear to have prevailed during the greater part of geological 
time. In short, there seems thus far to be no phase of the climate of the past which is not in harmony with an hypothesis which combines into a single unit the three main hypotheses of this book, solar, cyclonic, and terrestrial.

Outside the main line of thought lie several other hypotheses. Several of these, as well as some of the main hypotheses, are discussed chiefly in Earth and Sun, but as they are given a practical application in this book they deserve a place in this final summary. Each of these secondary hypotheses is in its way important. Yet any or all may prove untrue without altering our main conclusions. This point cannot be too strongly emphasized, for there is always danger that differences of opinion as to minor hypotheses and even as to details may divert attention from the main point. Among the non-essential hypotheses is the idea that the sun's atmosphere influences that of the earth electrically as well as thermally. This idea is still so new that it has only just entered the stage of active discussion, and naturally the weight of opinion is against it. Although not necessary to the main purpose of this book, it plays a minor rôle in the chapter dealing with the relation of the sun to other astronomical bodies. It also has a vital bearing on the further advance of the science of meteorology and the art of weather forecasting. Another secondary hypothesis holds that sunspots are set in motion by the planets. Whether the effect is gravitational or more probably electrical, or perhaps of some other sort, does not concern us at present, although the weight of evidence seems to point toward electronic emissions. This question, like that of the relative parts played by heat and electricity in terrestrial climatic changes, can be set aside for the moment. What does concern us is a third hypothesis, namely, that 
if the planets really determine the periodicity of sunspots, even though not supplying the energy, the sun in its flight through space must have been repeatedly and more strongly influenced in the same way by many other heavenly bodies. In that case, climatic changes like those of the present, but sometimes greatly magnified, have presumably arisen because of the constantly changing position of the solar system in respect to other parts of the universe. Finally, the fourth of our secondary hypotheses postulates that at present the date of movements of the earth's crust is often determined by the fact that storms and other meteorological conditions keep changing the load upon first one part of the earth's surface and then upon another. Thus stresses that have accumulated in the earth's isostatic shell during the preceding months are released. In somewhat the same way epochs of extreme storminess and rapid erosion in the past may possibly have set the date for great movements of the earth's crust. This hypothesis, like the other three in our secondary or non-essential group, is still so new that only the first steps have been taken in testing it. Yet it seems to deserve careful study.

In testing all the hypotheses here discussed, primary and secondary alike, the first necessity is a far greater amount of quantitative work. In this book there has been a constant attempt to subject every hypothesis to the test of statistical facts of observation. Nevertheless, we have been breaking so much new ground that in many cases exact facts are not yet available, while in others they can be properly investigated only by specialists in physics, astronomy, or mathematics. In most cases the next great step is to ascertain whether the forces here called upon are actually great enough to produce the observed results. Even though they act only as a means 
of releasing the far greater forces due to the contraction of the earth and the sun, they need to be rigidly tested as to their ability to play even this minor rôle. Still another line of study that cries aloud for research is a fuller comparison between earthquakes on the one hand and meteorological conditions and the wandering of the poles on the other. Finally, an extremely interesting and hopeful quest is the determination of the positions and movements of additional stars and other celestial bodies, the faint and invisible as well as the bright, in order to ascertain the probable magnitude of their influence upon the sun and thus upon the earth at various times in the past and in the future. Perhaps we are even now approaching some star that will some day give rise to a period of climatic stress like that of the fourteenth century, or possibly to a glacial epoch. Or perhaps the variations in others of the nearer stars as well as Alpha Centauri may show a close relation to changes in the sun.

Throughout this volume we have endeavored to discover new truth concerning the physical environment that has molded the evolution of all life. We have seen how delicate is the balance among the forces of nature, even though they be of the most stupendous magnitude. We have seen that a disturbance of this balance in one of the heavenly bodies may lead to profound changes in another far away. Yet during the billion years, more or less, of which we have knowledge, there appears never to have been a complete cataclysm involving the destruction of all life. One star after another, if our hypothesis is correct, has approached the solar system closely enough to set the atmosphere of the sun in such commotion that great changes of climate have occurred upon the earth. Yet never has the solar system passed so close to any other body or changed in any other way suffi- 
ciently to blot out all living things. The effect of climatic changes has always been to alter the environment and therefore to destroy part of the life of a given time, but with this there has invariably gone a stimulus to other organic types. New adaptations have occurred, new lines of evolutionary progress have been initiated, and the net result has been greater organic diversity and richness. Temporarily a great change of climate may seem to retard evolution, but only for a moment as the geologist counts time. Then it becomes evident that the march of progress has actually been more rapid than usual. Thus the main periods of climatic stress are the most conspicuous milestones upon the upward path toward more varied adaptation. The end of each such period of stress has found the life of the world nearer to the high mentality which reaches out to the utmost limits of space, of time, and of thought in the search for some explanation of the meaning of the universe. Each approach of the sun to other bodies, if such be the cause of the major climatic changes, has brought the organic world one step nearer to the solution of the greatest of all problems,--the problem of whether there is a psychic goal beyond the mental goal toward which we are moving with ever accelerating speed. Throughout the vast eons of geological time the adjustment of force to force, of one body of matter to another, and of the physical environment to the organic response has been so delicate, and has tended so steadily toward the one main line of mental progress that there seems to be a purpose in it all. If the cosmic uniformity of climate continues to prevail and if the uniformity is varied by changes as stimulating as those of the past, the imagination can scarcely picture the wonders of the future. In the course of millions or even billions of years the development of mind, and perhaps of soul, many excel 
THE EARTH'S CRUST AND THE SUN 317 that of today as far as the highest known type of mentality excels the primitive plasma from which all life appears to have arisen. 



\section{INDEX}

\section{* Indicates illustrations.}

Abbot, C. G., cited, 45, 52, 237, 238, 239.

Aboskun, 104.

Africa, earthquakes, 301; East, see East Africa; lakes, 143; North, see North Africa.

African glaciation, 266.

Air, see Atmosphere.

Alaska, glacial till in, 287; Ice Age in, 221.

Albrecht, cited, 304.

Alexander, march of, $88 \mathrm{f}$.

Allard, H. A., eited, 183, 184.

Alpha Centauri, companion of, 280; distance from sun, 262; luminosity, 278; speed of, 281 ; variations, 282.

Alps, loess in, 159; precipitation in, 141; snow level in, 139.

Altair, companion of, 280 ; luminosity, 278; speed of, 281.

Amazon forest, temperature, 17.

Ancylus lake, 217.

Andes, snow line, 139.

Animals, climate and, 1.

Antaretica, mild climate, 219; thickness of ice in, 125; winds, 135, 161.

Anti-cyclonic hypothesis, $135 \mathrm{ff}$.

Appalachians, effect on ice sheet, 121.

Arabia, civilization in, 67.

Aral, Sea of, 108.

Archean rocks, 211.

Archeozoic, 3 f.; climate of, 267.

Arctic Ocean, submergence, 219.

Arctowski, H., cited, 29, 46, 244.

Argon, increase of, 236.
Arizona, rainfall, 89, 108; trees measured in, 73.

Arrhenius, S., cited, 36, 254.

Arsis, of pulsation, 24.

Asbjörn Selsbane, corn of, 101.

Asia, atmospheric pressure, 298; central, changes of climate, * 75 ; central, post-glacial climate, 271; climate, 66; glaciation in, 131; storminess in, 60 ; western, climate in, $84 \mathrm{f}$.

Atlantic Ocean, storminess, 57.

A tmosphere, changes, 19 f., 229; composition of, 223.241; effect on temperature, 231.

Atmospheric circulation, glaciation and, 42.

Atmospheric electricity, solar relations of, 56 .

Atmospheric pressure, earthquakes and, 298; evaporation and, 237; increase in, 239 ; redistribution of, 49 ; variation, 53.

Australia, East, mild climate, 219; precipitation, 144.

Axis, earth's, 48; wabbling of, 301.

Bacon, Sir Francis, cited, 27.

Bacubirito, meteor at, 246.

Baltic Sea, as lake, 217; freezing of, 100 ; ice, 26 ; storm-floods, 99 ; submergence, 219.

Bardsson, Ivar, 106.

Barkow, eited, 135.

Barometric pressure, solar relations of, 56.

Barrell, J., cited, 3, 200, 213, 234.

Bartoli, A. G., cited, 257. 
Bauer, L. A., cited, 150.

Beaches, under water, 97.

Beadnell, H. J. L., cited, 143.

Beluchistan, rainfall, 89.

Bengal, Bay of, eyclones in, 149.

Bengal, famine in, $104 \mathrm{f}$.

Berlin, rainfall and temperature, 93.

Betelgeuse, $259 \mathrm{f}$.; distance from sun, 262.

Bible, climatic evidence in, $91 \mathrm{f}$; palms in, 92.

Binary stars, 252.

Birkeland, K., cited, 244.

Black Earth region, loess in, 159.

Boca, Cal., correlation coefficients, $83,85$.

Boltzmann, L., cited, 257.

Bonneville, Lake, 142, 143.

Borkum, storm-flood in, 99.

Boss, L. cited, 268, 269.

Botanical evidence of mild climates, $167 \mathrm{ff}$.

Boulders, on Irish coast, 119.

Bowie, W., eited, 293.

Bowman, I., eited, 213.

Britain, forests, 220 ; level of land, 220.

British Isles, height of land, 111; temperature, 216.

Brooks, C. E. P., cited, 115, 143, 196, $215,225$.

Brooks, C. F., cited, 209.

Brown, E. W., eited, 191, 244.

Brückner, E., cited, 27.

Brückner periods, $27 \mathrm{f}$.

Bufo, habitat of, 202.

Buhl stage, 216.

Bull, Dr., eited, 100, 101.

Butler, H. C., cited, 66,67 ff., 70 , 76.

California, changes of climate, ${ }^{*} 75$; correlations of rainfall, 86 ; measurements of sequoias in, $73,74 \mathrm{ff}$.; rainfall, 108.

Cambrian period, $4 \mathrm{f}$.

Canada, storminess, 53 f., 57 ; storm tracks in, 113.

Cape Farewell, shore ice at, 105.
Carbon dioxide, erosion and, $119 \mathrm{f}$; from volcanoes, 23; hypothesis, 139 ; importance of, $9,11 \mathrm{f}$; in Permian, 148; in atmosphere, 20, 96,238 ; in ocean, 226 ; nebular hypothesis and, 232; theory of glaciation, $36 \mathrm{ff}$.

Caribbean mountains, origin of, 193.

Carnegie Institution of Washington, 74.

Caspian Sea, climatic stress, 104; rainfall, $107 \mathrm{f}$.; rise and fall, 27; ruins in, 71 .

Cenozoic, climate, 266 ; fossils, 21.

Central America, Maya ruins, 95.

Chad, Lake, swamps of, 171.

Chamberlin, R. T., eited, 166, 233, 269.

Chamberlin, T. C., cited, $19,36,38$, $39,42 \mathrm{f}$., $48,122,125,152,156$, $190,195,227,269$.

Chandler, S. C., eited, 301 .

Chinese earthquakes, periodicity of, 245.

Chinese, sunspot observations, $108 \mathrm{f}$.

Chinese Turkestan, desiccation in, 66.

Chronology, glacial, 215.

Clarke, F. W., cited, 226, 235.

Clayton, H. H., eited, $173 \mathrm{f}$.

Climate, effect of contraction, $189 \mathrm{ff}$; effect of salinity, 224 ; in history, 64-97; uniformity, 1-15 ; variability, 16-32.

Climates, mild, causes of, 166-187; mild, periods of, 274 .

Climatic changes, and erustal movements, 285 ff.; hypotheses of, 3350 ; mountain-building and, ${ }^{*} 25$; post-glacial crustal movements and, 215-222; terrestrial causes of, 188-214.

Climatic sequence, $16 \mathrm{f}$.

Climatic stages, post-glacial, 270.

Climatic stress, in fourteenth century, 98-109.

Climatic uniformity, hypothesis of, $65,71 \mathrm{f}$.

Climatic zoning, 169. 
Cloudiness, glaciation and, 114, 147. Clouds, as protection, 197.

Colfax, Cal., correlation coefficients, 83.

Cologne, flood at, 99.

Compass, variations, 150.

Continental climate, variations, 103.

Continents, effect on climate, $111 \mathrm{f}$.

Contraction, effect on climate, $189 \mathrm{ff}$., 199, 207; effect on lands, 207; heat of sun and, $13 \mathrm{f}$.; irregular, 195 ; of the earth, 18; of the sun, 249 ; stresses caused by, 310 .

Convection, carbon dioxide and, 239.

Corals, in high latitudes, $21,39,167$, 178.

Cordeiro, F. J. B., eited, 181, 183, 186.

Correlation coefficients, earthquakes and sunspots, 291; Jerusalem rainfall and sequoia growth, $83 \mathrm{ff}$; rainfall and tree growth, $79 \mathrm{ff}$.

Cosmos, effect of light, 185.

Cressey, G. B., cited, 80.

Cretaceous, lava, 211; mountain ranges, 44 ; paleogeography, * 201; submergence of North America, 200.

Croll, J., cited, 34 ff., 176.

Croll's hypothesis, snow line, 139.

Crust, climate and movements of, $63,287,310$; movements of, 43 ; strains in, 22.

Currents and planetary winds, 174.

Cycads, 169.

Cyclonic hypothesis, 97 ; loess and, 163; Permian glaciation and, 148; snow line, 139.

Cyclonic storms, in glacial epochs, $140 \mathrm{f}$.; solar electricity and, 243 (see Storms, Storminess).

Cyclonic vacillations, $30 \mathrm{f}$.; nature of, $57 \mathrm{ff}$.

Daily vibrations, $28 \mathrm{f}$.

Danube, frozen, 98.

Darwin, G. H., cited, 191.

Daun stage, 217.

Davis, W. M., cited, 271.
Davisson, C., cited, 294, 295, 299.

Day, C. P., cited, 239.

Day, length of, 18, 191.

Dead Sea, palms near, 92 .

Death Valley, 142.

De Ballore, M., cited, 297, 298.

Deep-sea circulation, rapidity, 227; salinity and, 176; solar activity and, 179.

De Geer, S., cited, 215, 221.

De Lapparent, A., cited, 200.

Denmark, fossils, 271.

"'Desert pavements,"' 161.

Deserts, abundant flora of, 171 ; and pulsations theory, $88 \mathrm{ff}$.; red beds of, 170.

Devonian, climate, 266; mountains, 209.

Dog, climate and, 1.

Donegal County, Ireland, 220.

Double stars, 272, 280; electrical effect of, 261.

Douglass, A. E., cited, 28, 73, 74 f., 84, 85, 107.

Dragon Town, destruction of, 104, 108.

Drake, N. F., cited, 297, 298.

Droughts, and pulsations theory, $87 \mathrm{f}$; in England, 102; in India, $104 \mathrm{f}$.

Drumkelin Bog, Ireland, log cabin in, 220.

Dust, at high levels, 240.

Earth, crust of and the sun, 285-317; internal heat, 212 ; nature of mild climate, 274; position of axis, 181 ; rigidity of, 307 ; temperature gradient, 213 ; temperature of surface, 8 .

Earthquakes, and seasons, 294, 297 ; and sunspots, $288 \mathrm{f}$.; and tropical hurricanes, 300 ; and wandering of pole, $304 \mathrm{f}$; ; cause of, 307; compared with departures from Eulerian position, 306; seasonal distribution of, 299 ; seasonal march, 295.

“"Earthquake weather," 298. 
East Africa, mild climate, 219.

East Indies, earthquakes of, 296.

Eberswalde, tree growth at, $102 \mathrm{f}$.

Ecliptic, obliquity of, 217.

Electrical currents, in solar atmosphere, 261.

Electrical emissions, variation of, 275.

Electrical hypothesis, 150, $250 \mathrm{f}$., $256 \mathrm{ff}$.

Electrical phenomena, storminess and, 56.

Electricity, and earthquakes, 292; solar, 243.

Electro-magnetic hypothesis, 244.

Electrons, solar, 56; variation of, 256.

Electro-stellar hypothesis, 274.

Elevation, elimatic changes and, 39.

Engedi, palms in, 92.

England, climatic stress, $101 \mathrm{f}$; storminess and rainfall, 107.

Eocene, elimate, 266.

Equinoxes, precession of, 96 .

Erosion, storminess and, 309.

Eskimo, in Greenland, 106.

Eulerian movement, 301, 304.

Euphrates, 67.

Europe, climatic stress, 98 ff., $102 \mathrm{f}$.; climatic table, 215; glaciation in, 131 ; ice sheet, 121 ; inundations of rivers, 99 ; post-glacial climate, 271 ; rainfall, 107 ; submergence, $196,200$.

Evaporation, and glaciation, 112, 114; atmospheric pressure and, 237 ; from plants, 179 ; importance, 129; in trade-wind belt, 117 ; rapidity of, 224.

Evening primrose, effect of light, 184.

Evolution, climate and, 20; geographical complexity and, 241; glaciation and, 33 ; of the earth, 311.

Faculæ, cause of, 61.

False Point Lighthouse, barometric pressure at, 299.
Famine, cause of, 103; in England, $101 \mathrm{f}$.; in India, $104 \mathrm{f}$.; pulsations theory and, $87 \mathrm{f}$.

Faunas, and mild climates, 168 f.; in Permian, $152 \mathrm{f}$.

Fennoscandian pause, 216.

Flowering, light and, 184.

Fog, and glaciation, 116; as protection, 197; temperature and, 178.

Forests, climate and, 66.

Form of the land, $43 \mathrm{ff}$.

Fossil floras, and mild climates, 168; in Antaretica, 273; in Greenland, 273.

Fossils, 169, 230; and loess, 158; Archeozoic, 3 f.; Cenozoic, 21; dating of, 153; glaciation and, 138 ; in peat bogs, 271 ; mild climate, 167; Proterozoic, 4, $6 \mathrm{f}$.

Fourteenth century, elimatic stress in, 98-109.

Fowle, F. E., cited, 45, 237, 238, 239.

Frech, F., cited, 36.

Free, E. E., cited, 142.

Freezing, salinity and, 224.

Fresno, rainfall record, 82.

"Friction variables," 247.

Frisian Islands, storm-flood, 99.

Fritz, H., eited, 109.

Frogs, distribution of, 202.

Fuchs, cited, 289.

Galaxy, 252.

Galveston, Tex., rainfall and temperature, 94.

Garner, W. W., eited, 183, 184.

Gases, in air, 233.

Geographers, and climatic changes, $65 \mathrm{ff}$.

Geological time table, ${ }^{*} 5$.

Geologic oscillations, $18 \mathrm{f}$., $21 \mathrm{ff}$., $188,240$.

Geologists, changes in ideas of, $64 \mathrm{f}$. Germanic myths, 219.

Germany, forests, 220; growth of trees in, 102; storms in, 102.

Gilbert, G. K., cited, 143. 
Glacial epochs, causes of, 268; dates of, 216; intervals between, $264 \mathrm{f}$; length of, $166 \mathrm{f}$.

Glacial fluctuations, $24 \mathrm{ff}$.; nature of, $57 \mathrm{ff}$.

Glacial period, at present, 272; ice in, $57 \mathrm{f}$.; length of, 269 ; list, 265; temperature, 38 .

Glaciation, and loess, $155 \mathrm{f}$; and movement of crust, 287; conditions favorable for, 111; extent of, 124; hypotheses of, $33 \mathrm{ff}$; in southern Canada, 18; localization of, $130 \mathrm{ff}$.; Permian, * 145; solar cyclonic hypothesis of, 110-129; suddenness of, 138; upper limit of, 141.

Goldthwait, J. W., cited, 271.

Gondwana land, 21, 204.

Gravitation, effect on sun, 250; pull of, 244.

Great Basin, in glacial period, 126; salt lakes in, 142.

Great Ice Age, see Pleistocene.

Great Plains, effect on ice sheet, 120.

Greenland, climatic stress, 105 ff.; ice, 26 ; rainfall, 108; storminess, 57; submergence, 219 ; vegetation, 21, 37, 287 ; winds, 135, 161.

Gregory, J. W., cited, 90 ff., 97.

Gschnitz stage, 216.

Guatemala, ruins in, 95.

Guervain, cited, 135.

Gyroscope, earth as, 181.

Hale, G. E., cited, 56, 62.

Hamdulla, cited, 104.

Hann, J., eited, 66.

Hansa Union, operations of, 100.

Harmer, F. W., cited, 115, 119.

Heat, and earthquakes, 292; earth's internal, 18.

Hedin, S., cited, 88.

Heim, A., cited, 190.

Heligoland, flood in, 99.

Helland-Hansen, B., cited, 174.

Helmert, F. R., cited, 302.

Henderson, L. J., cited, 9, 10, 11, 12.
Henry, A. J., cited, 94, 208.

Hercynian Mountains, 45.

High pressure and glaciation, 115, 135.

Himalayas, glaciation, 144; origin of, 193; snow line, 139.

Himley, eited, 104.

Historic pulsations, $24 \mathrm{f}$.; nature of, $57 \mathrm{ff}$.

History, climate of, 64-97; climatic pulsations and, 26.

Hobbs, W. H., cited, 115, 125, 135, 161.

Hot springs, temperature of, 6 .

Humphreys, W. J., cited, 2, $37 \mathrm{f}$., $45,46,50,56,238$.

Hurricanes, in arid regions, 144; sunspots and, 53.

Hyades, cluster in, 268.

Ice, accumulations, $57 \mathrm{f}$; advances of, 122; distribution of, 131; drift, 105.

Ice sheets, disappearance, 128; limits, 120; localization, $130 \mathrm{ff}$; rate of retreat, 165 ; thickness, 125.

Iceland, submergence, 219.

Iowan ice sheet, rapid retreat, 165 .

Iowan loess, 158 .

India, drought, $104 \mathrm{f}$; famine, $104 \mathrm{f}$.; rainfall, 108 .

Indian glaciation, 266.

Inter-glacial epoch, Permian, 153.

Internal heat of earth, 212.

Ireland, Drumkelin Bog, 220; in glacial period, 119; level of land, 220 ; storminess and rainfall, 107 ; submergence, 219.

Irish Sea, tides, 191.

Irrigation ditches, abandoned, 97.

Isostasy, $307 \mathrm{ff}$.

Italy, southern, climate of, $86 \mathrm{f}$.

Japan, earthquakes of, 296.

Javanese mountains, origin of, 193. Jaxartes, 108.

Jeans, J. H., cited, 251, 252, 253, $266,272$. 
Jeffreys, H., cited, 302, 303, 306.

Jeffreys, J., eited, 191.

Jericho, palms in, 92.

Jerusalem, rainfall, 86 ; rainfall and temperature, 94; rainfall in, and sequoia growth, $83 \mathrm{ff}$.

Johnson, cited, 226.

Judea, palms in, 92.

Jupiter, and sunspots, 243 ; effect of, 253 ; periodicity of, $61 \mathrm{f}$; ; temperature of, 258; tidal effect of, 250.

Jurassic, climate, 266; mountain ranges, 44 .

Kansas, variations of seasons, 103.

Kara Koshun marsh, Lop Nor, 104.

Keewatin center, 113; evaporation in, 129.

Keewatin ice sheet, 121.

Kelvin, Lord, cited, $13 \mathrm{f}$.

Keyes, C. R., cited, 156.

Kirk, E., cited, 287.

Knott, C. G., cited, 294, 295, 297, 299, 304, 306.

Knowlton, F. H., cited, 167, 169, $170,212,232$.

Köppen, W., 47, 52, 140.

Krakatoa, glaciation and, 48; volcanic hypothesis and, 45.

Krümmel, O., cited, 224, 228.

Kullmer, C. J., cited, 113, 115, 128; map of storminess, * 54 .

Kungaspegel, sea routes described, 106.

Labor, price in England, 102.

Labradorean center of glaciation, 113.

Lahontan, Lake, 142.

Lake strands, see Strands.

Lake Superior, lava, 211.

Lakes, during glacial periods, $141 \mathrm{f}$; in semi-arid regions, 60 ; of Great Basin, 126; ruins in, 97.

Land, and water, climatic effect of, $196 \mathrm{ff}$; distribution of, 200; form of, $43 \mathrm{ff}$; range of temperature and, 196.
Lavas, climatic effect of, 211.

Lawson, A. C., cited, 310.

Lebanon, cedars of, 83 .

Leiter, H., cited, 71.

Leverett, F., cited, 271.

Life, atmosphere and, $229 \mathrm{f}$.; chemical characteristic of, 12 ; effect of salinity, 225; of glacial period, 127 ; persistence of forms, 230.

Light, effect of atmosphere on, 236; effect on plants, $184 \mathrm{ff}$; ultraviolet, storminess and, 56 ; variation of, 275.

Litorina sea, 218.

Loess, date of, $156 \mathrm{ff}$; origin of, $155,165$.

Lop Nor, rise of, 104; swamps, 171.

Lows, and glacial lobes, 122 ; movements of, 126; see Storms and Cyclones.

Lulan, 104.

Lull, R. S., cited, 5, 188.

MacDougal, D. T., cited, 171.

McGee, W. J., cited, 156.

Macmillan, W. D., eited, 191.

Magdalenian period, 216.

Magnetic fields of sunspots, 56 .

Magnetic poles, relation to storm tracks, 150.

Makran, climate, 89; rainfall, 89.

Malay Archipelago, earthquakes of, 296.

Mallet, R., cited, 288.

Malta, rainfall, 86 .

Manson, M., cited, 147.

Mayas, civilization, 26; ruins, 95.

Mayence, flood at, 99.

Mazelle, E., cited, 224.

Mediterranean, climate of, 72 ; rainfall records, 86; storminess in, 60 .

Mercury, and sunspots, 243.

Mesozoic, climate, 266; crustal changes, 286 ; emergence of lands, 287.

Messier, 8; variables, 248.

Metcalf, M. M., cited, 202.

Meteorological factors and earthquakes, $300 \mathrm{f}$. 
Meteorological hypothesis of erustal movements, 294.

Meteors, and sun's heat, 13, 246.

Michelson, A. A., eited, 259.

Middle Silurian, fauna in Alaska, 287.

Mild climates, see Climates, mild.

Milky Way, 252.

Mill, H. R., eited, 228.

Milne, J., cited, 288, 290, 294, 304, 306.

Miocene, erustal ehanges, 287.

Mississippi Basin, loess in, 159.

Mogul emperor, and famine, 104.

Monsoons, eharacter of, 146; direction of, 208; Indian famines and, 105.

Moulton, F. R., cited, 13, 258, 269.

Mountain building, elimatic ehanges and, ${ }^{*} 25$.

Mountains, folding of, 190 ; rainfall, on, 208.

Multiple stars, 252.

Nansen, F., cited, 122, 174.

Naples, rainfall, 86.

Nathorst, eited, 169.

Nebulæ, 247.

Nebular hypothesis, 232, 267.

Neolithic period, 218.

Nevada, correlations of rainfall, 86 .

New England, height of land, 111.

New Mexico, rainfall, 89.

New Orleans, La., rainfall and temperature, 94 .

New Zealand, elimate, 177; tree ferns, 179.

Newcomb, S., eited, 52.

Nile floods, periodicity in, 245.

Nitrogen, in atmosphere, 19.

Niya, Chinese Turkestan, desiceation at, 66 .

Nocturnal cooling, ehanges in, $238 \mathrm{f}$.

Norlind, A., eited, 100.

Norsemen, route to Greenland, 26.

Norse sagas, 219.

North Africa, elimate of, 71; Roman aqueducts in, 71 .

North America, at maximum glacia- tion, $122 \mathrm{ff}$; emergence of lands, 193; glaciation in, 131; height of land, 111; interior sea in, 200; inundations, 196; loess in, 155; submergence of lands, 19, 21.

North Atlantic Ocean, salinity, 228.

North Sea, elimatic stress, $98 \mathrm{ff}$; floods around, 26, 99; rainfall, 107 ; storminess, 57.

Northern hemisphere, earthquakes of, 294.

Norway, decay, 100; temperature, 177.

Novæ, 247.

Oceanic circulation, carbon dioxide and, $39 \mathrm{ff}$.

Oceanic climate, characteristics, 103.

Oceanic eurrents, diversion, 44; influence of land distribution, 203.

Oceans, age of, 223 ; composition of, 223-241; deepening of, 199; salinity, 19, 223 ; temperature, 6, 152, $180,226$.

Okada, T., cited, 224.

Old Testament, temperature, 92 .

Orbital precessions, 27.

Ordovician, elimate, 266.

Organic evolution, glacial fluetuations and, 26.

Orion, nebulosity near, 247; stars near, 248.

Orontes, 67.

Osborn, H. F., eited, 216.

Owens-Searles, lakes, 142.

Oxus, 108.

Oxygen, in atmosphere, 20, 234; in Permian, 152.

Ozone, cause of, 56.

Paleolithic, 216.

Paleozoic, climate, 266; mountains in, 209.

Palestine, change of climate, $91 \mathrm{f}$.

Palms, climatic change and, $91 \mathrm{f}$.; in Ireland, 179.

Palmyra, ruins of, 66 .

Parallaxes of stars, $276 \mathrm{f}$.

Patrician center, 134. 
Peat-bog period, first, 218.

Penck, A., cited, 139, 156, 157, 158, 269.

Pennsylvanian, life of, 26.

Periodicities, $245 \mathrm{f}$.

Periodicity, of climatic phenomena, $60 \mathrm{f}$.; of glaciation, 268; of sunspots, 243.

Permian, climate, 266; distribution of glaciation, 152; glaciation, 60 , $144, * 145,226$; glaciation and mountains, 45 ; life of, 26 ; red beds, 151; temperature, $146 \mathrm{f}$.

Perry, cited, 289.

Persia, lakes, 143 ; rainfall, 89.

Pettersson, O., cited, 98 ff., 100 f., 103, 106, 219.

Pirsson, L. V., cited, 3, 196.

Planetary hypothesis, 253, 267.

Planetary nebulæ, 252.

Planets, and sunspots, 243; effect of star on, 255; sunspot cycle and, 62 ; temperatures, $8 \mathrm{f}$.

Plants, climate and, $1 \mathrm{f}$.; effect of light, $184 \mathrm{ff}$.

Pleion, defined, 29.

Pleionian migrations, $29 \mathrm{f}$.

Pleistocene, elimate, 266; duration of, 48 ; glaciation, $110 \mathrm{ff}$; ice sheets, * 123 .

Pluvial climate, causes of, 143; during glacial periods, 141 .

Po, frozen, 98.

Polaris, 272.

Polar wandering, hypothesis of, $48 \mathrm{f}$.

Pole and earthquakes, 305.

Post-glacial crustal movements and climatic changes, 215-222.

Poynting, J. H., cited, 8.

Precessional hypothesis, $34 \mathrm{f}$.

Precipitation, and glaciation, 114, 133; during glacial period, 118; snow line and, 139 ; temperature and, 94.

Procyon, companion of, 280 ; luminosity, 278; speed of, 281.

Progressive change, 241.

Progressive desiccation, hypothesis of, $65 \mathrm{ff}$.
Proterozoic, $4 \mathrm{f}$.; fossils, $6 \mathrm{f}$.; glaciation, 18, 144, 226, 266; lava, 211 ; mountains in, 209 ; oceanic salinity, $42 \mathrm{f}$.; oxygen in air, 234; red beds, 151; temperature, $146 \mathrm{f}$. Pulsations, hypothesis of, $65,72 \mathrm{ff}$. Pulsatory climatic changes, 72 ff.

Pulsatory hypothesis, 272.

Pumpelly, R., cited, 271.

Radiation, variation of, 275.

Radioactivity, heat of sun and, $14 \mathrm{f}$.

Rainfall, changes in, $93 \mathrm{f}$.; glaciation and, 50; sunspots and, 53, * 58,59 ; tree growth and, 79 .

Red beds, 151, 170.

Rhine, flood, 99 ; frozen, 98.

Rho Ophiuchi, variables, 248.

"Rice grains," 61.

Richardson, O. W., cited, 256.

Rigidity, of earth, 307 .

Roads, climate and, 66.

Rogers, Thorwald, eited, 101.

Romans, aqueduct of, 71 .

Rome, history of, 87.

Rotation, of earth, $18 \mathrm{f}$.

Ruden, storm-flood, 99.

Rugen, storm-flood, 99.

Ruins, as climatic evidence, 66 ; rainfall and, 60 .

Sacramento, correlation coefficients, $82 \mathrm{f}$., 85 ; rainfall, 86 ; rainfall record, 79.

Sagas, cited, $105 \mathrm{f}$.

St. John, C. E., cited, 236.

Salinity, deep-sea circulation and, 176 ; effect on climate, 224 ; in North Atlantic, 228; ocean temperature and, 226 ; of ocean, 19 , 120.

Salisbury, R. D., cited, 111, 125, 129, 139, 156, 206, 269, 271.

Salt, in ocean, 223.

San Bernardino, correlation of rainfall, 85.

Saturn, and sunspots, 243; sunspot cycle and, 62 . 
Sayles, R. W., eited, 183.

Seandinavia, elimatic stress, $100 \mathrm{f}$; fossils, 271; post-glacial climate, 271 ; rainfall, 107 ; storminess, 57 , 107 ; temperature, 216.

Scandinavian center of glaciation, 113.

Schlesinger, F., cited, 275, 278, 298, 301, 305.

Schuchert, C., eited, 3, 5, 23, * 25, * 123,138 , * $145,168,169,172$, $188,193,196,198,200$, * 201, 206, $211,230,265$.

Schuster, A., cited, 61, 244, 294, 296.

Seulpture, Maya, 96.

Sea level and glaciation, 119.

Seasonal alternations, $28 \mathrm{f}$.

Seasonal banding, $183 \mathrm{f}$.

Seasonal changes, geological, 183.

Seasons, and earthquakes, 294, 295, 297, 299; evidences of, 169.

Secular progression, 17 ff., 188.

Seistan, swamps, 171.

Sequoias, measurements of, $74 \mathrm{ff}$; rainfall record, 79 .

Setchell, W. A., cited, 1.

Shackleton, E., cited, 125.

Shapley, H., eited, 246, 247, 254, $256,275$.

Shimek, E., cited, 157, 161.

Shreveport, La., rainfall and temperature, $93 \mathrm{f}$.

Shrinkage of the earth, 190.

Siberia, and glaciation, 132.

Sierras, rainfall records, 82 .

Simpson, G. C., cited, 222.

Sirius, companion of, 280 ; distance from sun, 262; luminosity, 278; speed of, 281.

Slichter, C. S., eited, 192.

Smith, J. W., eited, 73.

Snowfall, glaciation and, 50, 114.

Snowfield, climatic effects of, 115.

Snow line, height of, 138; in Andes, 139 ; in Himalayas, 139.

Solar activity, cycles of, 245 ; deepsea circulation and, 179 ; ice and, 134.

Solar constant, 114.
Solar-eyelonic hypothesis, 51-63, 287; glaciation and, 110-129.

Solar prominences, cause of, 61 .

Solar system, 252; conservation of, 243 ; proximity to stars, 63.

Solar variations, storms and, 31 .

South America, earthquakes, 301.

South Pole, thickness of ice at, 125.

Southern hemisphere, earthquakes, 296; glaciation in, $131 \mathrm{f}$.

Southern Pacific railroad, rainfall records along, 82.

Soy beans, effect of light, $185 \mathrm{f}$.

Space, sun's journey through, 264284.

Spiral nebulæ, $251 \mathrm{f}$; universe of, 267.

Spitzbergen, submergence, 219.

Springs, elimate and, 66 .

Stars, approach to sun, 253 ; binary, 252 ; clusters, 252, 268; effect on solar atmosphere, 63; dark, 254; parallaxes of, $276 \mathrm{f}$; ; tidal action of, 249 .

Stefan's Law, 257.

Stein, M. A., eited, 78.

Stellar approaches, probability of, 260.

Storm belt in arid regions, 144 .

Storm-floods, in fourteenth century, 99.

Storminess, and erosion, 309; and ice, 134; effect on glaciation, 112; sunspots and, 163; temperature and, 94, 173.

Storms, blows of, 300,302 ; increase, 60 ; movement of, $125 \mathrm{f}$; movement of water and, ${ }^{*} 175$; origin of, $30 \mathrm{f}$; ; sunspots and, 28,53 ; see Cyclones and Lows.

Storm tracks, during glacial period, 117 ; location, 113; relation to magnetic poles, 150 ; shifting of, 119.

Strands, elimate and, 66; in semiarid regions, 60 ; of salt lakes, 142.

Suess, E., cited, 192.

Sun, and the earth's crust, 285-317; approach to star, 253 ; atmosphere 
of, 61,274 ; atmosphere of, and weather, 52; cooling of, 49; contraction of, 249 ; disturbances of 172 ; effect of other bodies on, 242 . 263 ; heat, 13 ; journey through space, 264-284; Knowlton's hypothesis of, 168 .

Suncracks, 232.

Sunspot cycles, $27 \mathrm{f}$.

Sunspots, and earthquakes, 289; causes of, 61 ; magnetic field of, 261 ; maximum of, 109 ; mild elimates and, 172 ; number, $108 \mathrm{f}$.; periodicity, 243; planetary hypothesis of, 253 ; records, 245; storminess and, 163 ; storms and, 300 ; temperature of earth and, $52,173$.

Sunspot variations, 282.

Swamps, as desert phenomena, 171. Sylt, storm-flood, 99.

Syria, civilization in, 67; inseriptions in, 76; Roman aqueducts in, 71.

Syrian Desert, ruins in, 66.

Talbert, eited, 213.

Tarim Basin, red beds, 151.

Tarim Desert, desiceation, 66.

Tarim River, swamps, 171.

Taylor, G., eited, 140, 144, 191, 271.

Temperature, change of in Atlantic, 174 ; changes in, 93 ; climatic change and, 49; critical, 9 ; geological time and, 3 ; glacial period, 38 ; glaciation and, 42, 132, 139; gradient of earth, 213; of ocean, 180 ; in Norway, 177; in Permian, $146 \mathrm{f}$; in Proterozoic, $146 \mathrm{f}$; limits, 6 ff.; precipitation and, 94; range of, 3,8 ; solar activity and, 140 ; storminess and, 94, 112, 173; sunspots and, 28, 173; volcanic eruptions and, 46; zones, 172.

Terrestial causes of climatic changes, 188-214.

Tertiary, lava, 211.

Thames, frozen, 98.

Thermal solar hypothesis, 49 f., 97 .
Thermo-pleion, movements of, 30 .

Thesis, of pulsations, 24 .

Thiryu, storm-flood, 99.

Tian-Shan Mountains, irrigation in, 71.

Tidal action of stars, 249.

Tidal effect, of Jupiter, 253; of planets, 244.

Tidal hypothesis, 251.

Tidal retardation, effect on land and sea, 191; rotation of earth and, $18 \mathrm{f}$.; stress caused by, 310 .

Tides, eycles of, 219 .

Time, geological, see Geological time.

Toads, distribution of, 202.

Tobaceo plant, effect of light, 184 .

Topography, and glaciation, 132.

Transcaspian Basin, red beds, 151.

Tree ferns, in New Zealand, 179.

Tree growth, periodicity in, 245; rainfall and, 79 .

Trees, in California, 219; measurement of, $73 \mathrm{ff}$.

Triassic, climate, 266.

Trifid Nebula, variables, 248.

Trondheim, wheat in, 101.

Trondhenäs, corn in, 101.

Tropical eyclones, in glacial epochs, 140f.; occurrence, 148; solar activity and, 113.

Tropical hurricanes, earthquakes and, 300; sunspots and, 149.

Turfan, temperature, 17.

Turner, H. H., eited, 245.

Tyler, J. M., cited, 216.

Tyndall, J., eited, $36,37$.

Typhoon region, "earthquake weather," 298.

Typhoons, occurrence, 300.

United States, rainfall and temperature in Gulf region, $93 \mathrm{f}$; salt lakes in, 142; southwestern, climate, 66 ; storminess, $53 \mathrm{f}$., 60 .

Variables, 247.

Veeder, M. A., cited, 300 .

Vegetation, theory of pulsations and, 90. 
Venus, atmosphere of, 236.

Vesterbygd, invasion of, 106.

Vicksburg, Miss., rainfall and temperature, $93 \mathrm{f}$.

Volcanic activity, climate and, 210; movement of the earth's crust and, 285; times of uplifting lands and, 23.

Volcanic dust, elimatic changes and, 97.

Volcanic hypothesis, climatic change and, 45 ff.; snow line, 139.

Volcanoes, activity of, 96 .

Volga, 108.

Walcott, C. D., cited, 4, 230.

Wandering of the pole, 302 .

Water, importance, 9.

Water vapor, condensation of, 56 ; effect on life, 231; in atmosphere, 19.

Wave, effect on movement of water, 176.

Weather, changes of, $31 \mathrm{f}$; origin of, 174 ; variations, 52 .

Wells, H. G., cited, 35.
Wendingstadt, storm-flood, 99.

Westerlies, $21 \mathrm{f}$.

Wheat, price in England, 102.

White Sea, submergence, 219.

Whitney, J. D., cited, 142.

Wieland, G. R., cited, 169.

Williamson, E. D., cited, 226.

Willis, B., cited, 206.

Winds, at ice front, 162 ; effect on currents, 174; glaciation and, 133; in Antarctica, 161; in glacial period, 119; in Greenland, 161; planetary system of, 174 ; velocity, 240.

Witch hazel, effect of light, 184 .

Wolf, J. R., cited, 61, 109, 288.

Wolfer, eited, 244.

Wright, W. B., cited, 35, 111, 119.

Writing, among Mayas, 96.

Yucatan, Maya civilization, 26, 107; rainfall, 108; ruins, 95 .

Yukon, Ice Age in, 221.

Zante, earthquakes of, 296.

Zonal crowding, 117. 
PRINTED IN THE UNITED STATES OF AMERICA 
. 

This book is DUE on the last date stamped below.

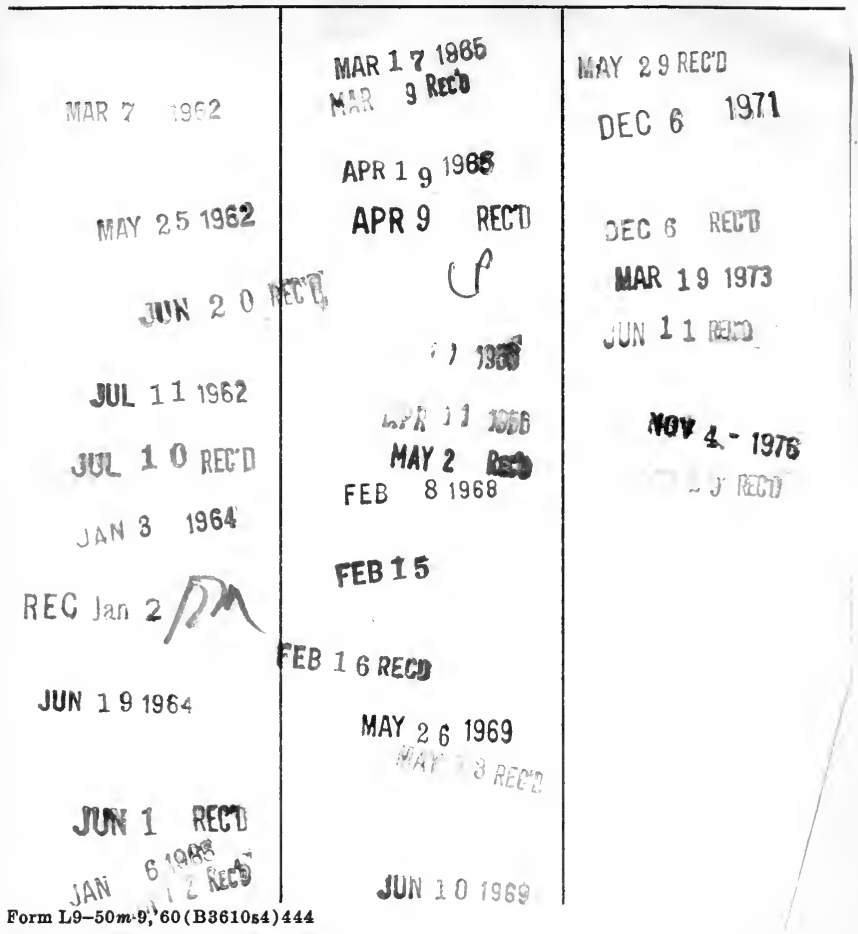




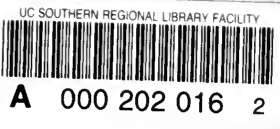

1492

cip. 2

is:

in 
